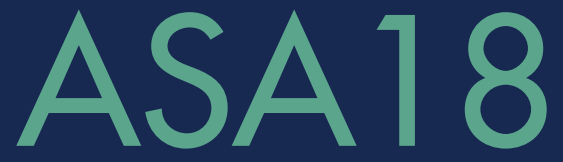

\title{
Sociality, Matter, and the Imagination: Re-Creating Anthropology
}

\author{
OXIVRSITY OF
}

(1) Association of Social Anthropologists 


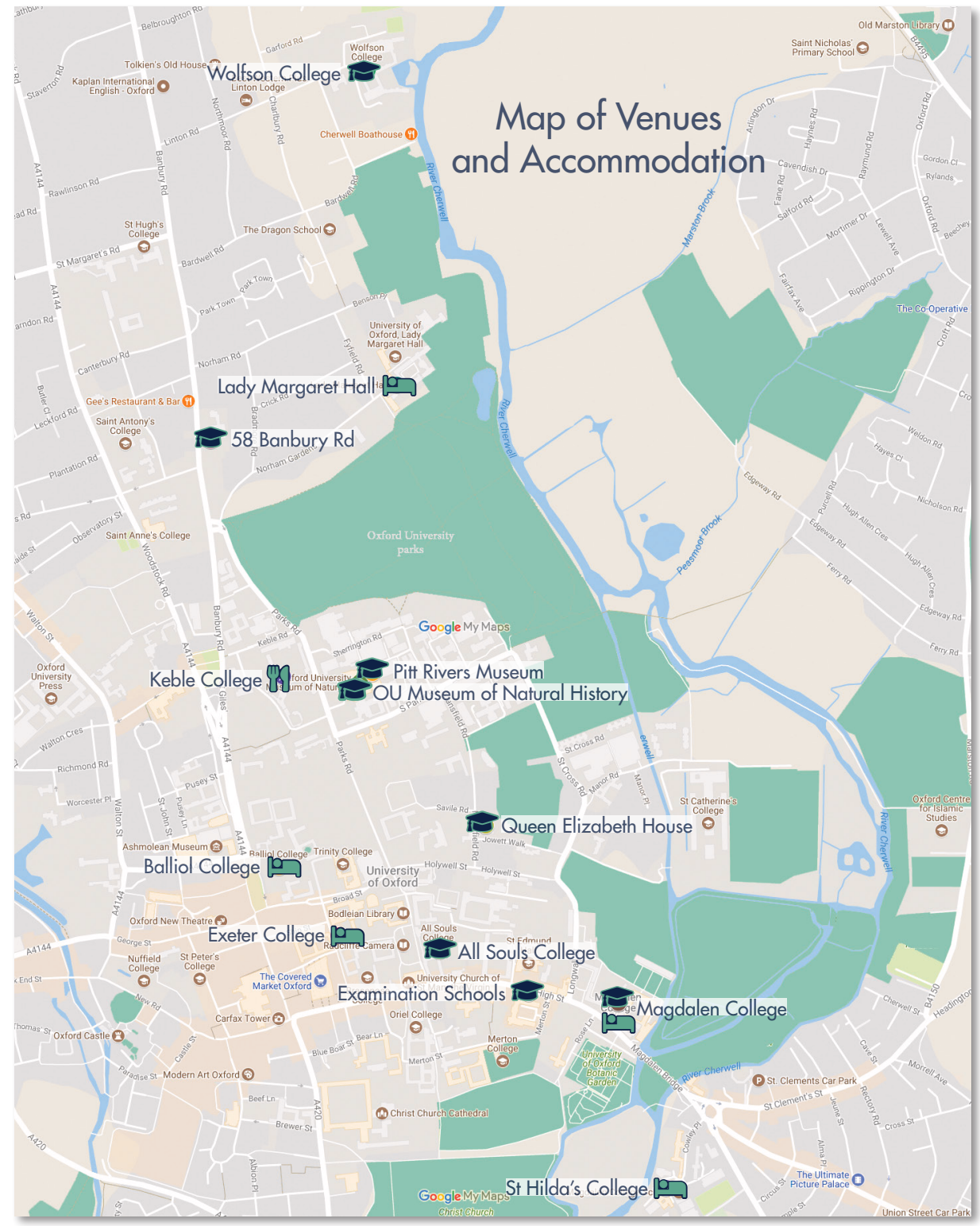

\section{¿ Wifi access at the venue}

Eduroam credentials can be used for accessing Wifi at the University of Oxford. Delegates can also request temporary credentials, for use during the conference, at the Reception desk when checking in. 


\section{ASA 18}

\section{Sociality, Matter, and the Imagination: Re-Creating Anthropology}

Association of Social Anthropologists of the UK and Commonwealth Annual Conference

University of Oxford

18-21 September 2018
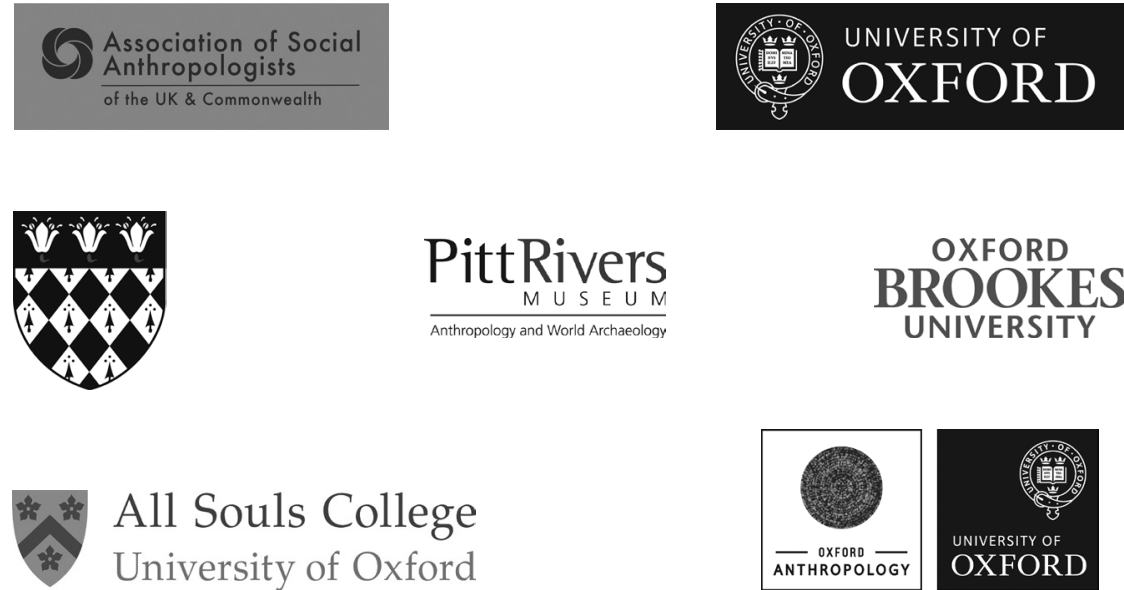
ASA Committee: Chair: Professor Nigel Rapport (chair(at)theasa.org)

Hon. secretary: Dr Cathrine Degnen (secretary(at)theasa.org)

Hon. treasurer: Dr Soumhya Venkatesan (treasurer(at)theasa.org)

ASA Committee members: Ethical guidelines: Dr Jude Robinson (ethics(at)theasa.org)

ASA networks: Dr Julie Scott (networker(at)theasa.org)

ASA series editor: Professor Andrew Irving (publications(at)theasa.org)

Conference officer: Dr Emma Gilberthorpe (E.Gilberthorpe(at)uea.ac.uk)

Media officer: Dr Paul GIlbert (media(at)theasa.org)

Conference convenor: Prof David Gellner (Head of the School of Anthropology and Museum Ethnography at the University of Oxford)

\section{ASA18 Local Organising Committee}

Jason Danely, Senior Lecturer in the Anthropology of Japan, Oxford Brookes University

David Gellner, Professor of Social Anthropology, Head of Department, SAME (Chair)

Chris Gosden, Professor of European Archaeology, Institute of Archaeology, University of Oxford

Elizabeth Hallam, Research Associate, SAME, and Editor of the Journal of the Royal

Anthropological Institute

Clare Harris, Professor of Visual Anthropology, SAME; and Curator for Asian Collections, Pitt

Rivers Museum

Dan Hicks, Professor of Contemporary Archaeology, School of Archaeology, and Curator of

Archaeology, Pitt Rivers Museum

Catherine Hill, Professor of Anthropology, Oxford Brookes University

Jeremy MacClancy, Professor of Anthropology, Oxford Brookes University

Laura Rival, Professor of Anthropology of Development, Oxford Department of International

Development

Ramon Sarró, Associate Professor in the Social Anthropology of Africa, SAME

David Zeitlyn, Professor of Social Anthropology, SAME

Conference administrators: NomadIT: Eli Bugler, James Howard, Rohan Jackson, Saskia Lillepuu, Triinu Mets, Elaine Morley

\section{Acknowledgements for financial and institutional support}

School of Anthropology and Museum Ethnography, University of Oxford

Pitt Rivers Museum

Oxford Brookes University

All Souls College

Magdalen College

Queen Elizabeth House (Oxford Department of International Development)

Wolfson College

The Centre on Migration, Policy and Society (COMPAS)

DFID-Nepal

Other support that deserves a special mention:

We are grateful to: the admin team of the University of Oxford and particularly Kate Atherton for her invaluable assistance; Claire Knowles and her team at the Examination Schools for their patience, flexibility and support; the postgraduate community for volunteering to help at the event. 


\section{Table of contents}

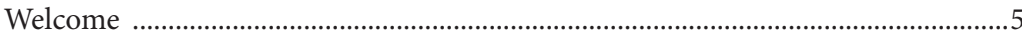

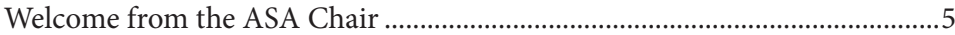

Welcome from the ASA2018 convenor …….................................................6

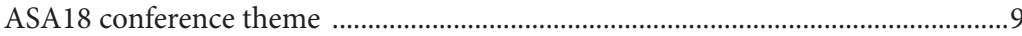

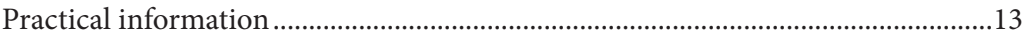

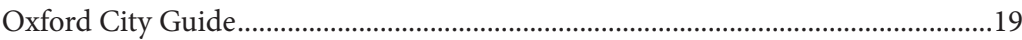

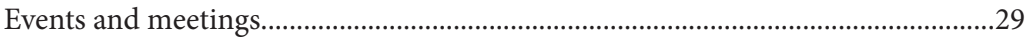

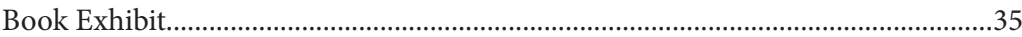

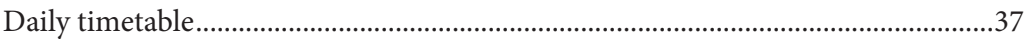

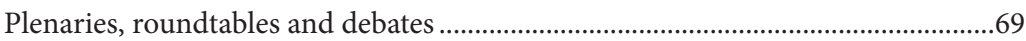

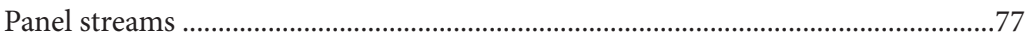

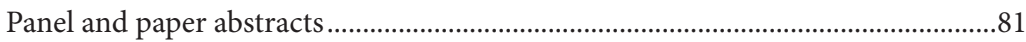

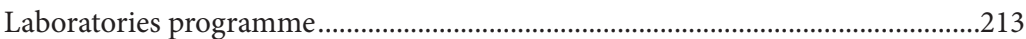

List of participants: convenors, chairs, discussants and presenters ......................219

\section{Cover photo}

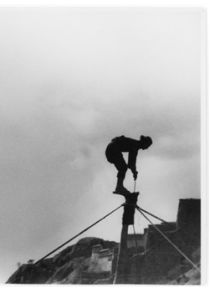

Photographer: Dasang Damdul Tsarong from the collection of Frederick Spencer, Chapman at the Pitt Rivers Museum. Location and Date: Lhasa, Tibet, 1937.

Content: Man performing the 'Sky Dancing Rope Game' or Chakhen Tagshur, 'Sliding down the rope like a bird', as part of the New Year ceremonies at the Potala Palace, Lhasa, Tibet, 13th February 1937.

The images - and more information about them - are presented on The Tibet Album website, an AHRC-funded project directed by staff of the Pitt Rivers Museum that makes 6000 historic photographs of Tibet available to Tibetans and researchers worldwide. http://tibet.prm.ox.ac.uk.

Copyright Pitt Rivers Museum, University of Oxford (1998.131.541) 
Notes 


\section{Welcome from the ASA Chair}

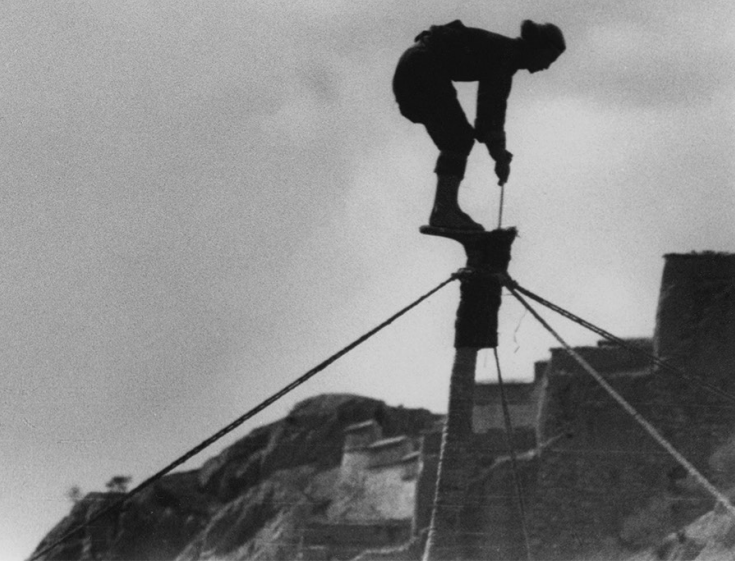

Welcome to the 2018 ASA Conference, Sociality, matter, and the imagination: re-creating Anthropology, jointly hosted by the School of Anthropology and Museum Ethnography of the University of Oxford (including the Pitt Rivers Museum) and the Department of Social Sciences at Oxford Brookes University.

Since 1946, the ASA has represented the interests of professional social anthropologists in the United Kingdom and the Commonwealth. It is an association funded entirely by its membership's subscriptions for the representation of its members' interests on a wide range of fronts, and promoting the discipline in all public arenas. The ASA embodies a vital professional network through which anthropologists can exchange ideas and foster the intellectual debates and developments that maintain the lifeblood of our discipline.

One of the most enjoyable and important aspects of the ASA's rubric is to hold an annual conference on a theme suggested by its members; and to publish conference proceedings in an edited collection that enters an esteemed ASA series (currently published by Bloomsbury) for distribution to the membership. The idea for the present conference has been interdisciplinary: to encourage as wide debate as possible across sociocultural, material, visual, biological, forensic, cognitive, evolutionary, developmental and linguistic anthropologies, and from archaeology and museum studies too. 
The ambition is broad: how to renew and re-create anthropology in the above interdisciplinary and holistic sense when sociality, matter and the imagination are reconsidered from a diversity of perspectives? Since Immanuel Kant first prescribed the word 'anthropology' as a modern discipline that would interrogate and assert the oneness of being human-establish theoretically, methodologically and ethically what it meant (and could and should mean) to be human beings in-the-world-anthropology has been a disciplinary locus of incisive debate on themes that span the social sciences, the humanities and the natural sciences.

I look forward to our significant deliberations over the coming days. Also, on behalf of the ASA Committee, to thank the local organizers for putting in the work to offer such an exciting, diverse and full package of events. From Oxford University: David Gellner, Chris Gosden, Elizabeth Hallam, Clare Harris, Dan Hicks, Laura Rival, Ramon Sarró, David Zeitlyn; and from Oxford Brookes University: Jason Danely, Catherine Hill and Jeremy MacClancy.

Again: welcome!

\section{Welcome from the ASA2018 convenor}

It is my pleasure, as head of Oxford's School of Anthropology and Museum Ethnography (SAME; @oxford_anthro) and chair of the local organizing committee, to welcome you, the participants in this ASA2018 conference, to Oxford and to invite you to explore together new and imaginative ways of considering what anthropology is and should be in the 21st century. We are delighted to be hosting, jointly with the Anthropology at Oxford Brookes, one of the largest ASA gatherings.

Anthropology today is both more popular and more fragmented than ever. Perhaps anthropology's holistic inheritance can inspire an interdisciplinary reconfiguration that encompasses the social, the biological, the evolutionary, the material, and the experiential arenas of human life. The key terms of the ASA2018 conference are:

sociality: as anthropologists - however we label ourselves - we understand that being social is what makes us human;

matter: whether we call ourselves anthropologists or archaeologists, we are all concerned with being in the world, a world of material engagements and limits; 
imagination: uniquely (as far as we know), of all the higher primates, humans live both within society and within their own minds: we can imagine social institutions that allow us to craft and realize new ways of being.

There are over 700 of you here to help us discuss these issues, coming from at least 45 countries. When you are not busy debating the current state of anthropology, Oxford has a lot to offer, and not only the university (see the Oxford City Guide in this book). There are several great museums, including the Pitt Rivers, with which we are proud to have a close connection dating back to the 19th century. Don't miss the special exhibitions there (see page 35) put on to coincide with the conference.

An Anthropology Society was founded in Oxford in 1867 and the subject was taught, as part of the natural sciences, from 1884-5; not coincidentally, that was exactly when the Pitt Rivers Museum was established. Two decades later, in 1905, anthropology was recognized by the university as a separate subject with its own diploma, hence the celebration of Oxford Anthropology's centenary in 2005. Oxford Anthropology today aspires to be both up to date and true to its roots, in cultivating as full a range of, and approaches to, anthropology as any department in the country, including visual, material, and museum anthropology, science and technology studies, medical anthropology, migration studies, cognitive and evolutionary anthropology, primatology, not forgetting classic social and cultural anthropology. When the ASA called for a conference that reached out to all these different kinds of anthropology, including archaeology, this seemed to fit what we were about.

For support that has made this conference possible, we are especially grateful to the Pitt Rivers Museum, All Souls College, Oxford Brookes, and Magdalen College. Thanks too to: the whole team at NomadIT; the 25 or so volunteers who will keep everyone in the right place at the right time; Kate Atherton in SAME who has valiantly fielded enquiries; everyone at Keble College for hosting the dinner and bar; to the Oxford Department of International Development for the use of its seminar rooms; and to the Africa Oxford Initiative (AfOx), DFID-Nepal, and the ASA (to name just those bodies I am aware of), for support enabling participants to be here. Last but certainly not least, I would like to thank the members of the organizing committee for their hard work: chewing over themes and sub-themes, selecting panels, and providing moral support. Looking back at my notes I see that our first meeting of many was nearly two years ago. I hope you think it has all been worth it. 
Notes 


\section{ASA 18 conference theme Sociality, matter, and the imagination: re-creating Anthropology}

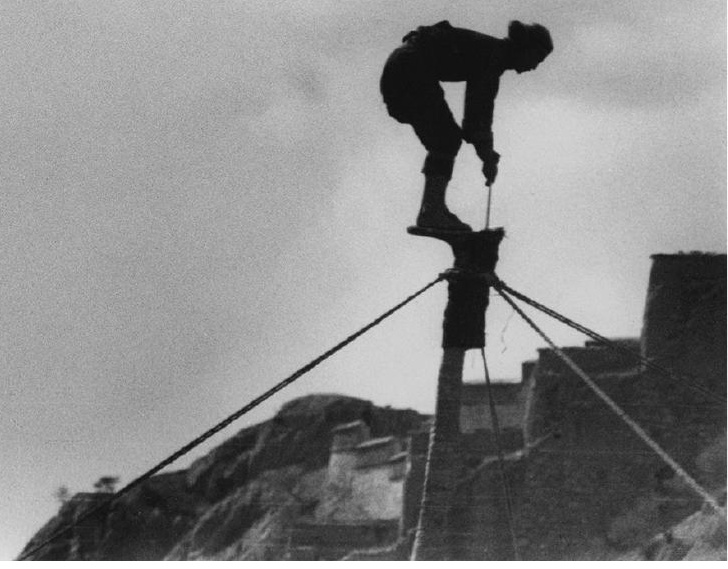

One of the major debates within anthropology broadly defined is the question of how to bridge approaches primarily concerned with the social, and those primarily focused on the material, the physical, or the biological. Much recent anthropology, from a variety of theoretical perspectives, seeks to overcome artificial conceptual divisions, either by proposing new (often hybrid) ontologies or simply by pursuing problems that challenge conventional boundaries. ASA18 aims to address this key question directly. If sociality, matter, and the imagination are reconsidered from multiple perspectives across the discipline, how might we renew and re-create anthropology? What kinds of theoretical, methodological, and ethical concerns are raised by this potential re-creation? Working with a very broad definition of 'the material' - potentially including linguistic, biological, genetic, neurological, environmental, and evolutionary factors-the conference aims to advance debates on sociality and matter, the imagination and creativity, and therefore on what it is to be human in a rapidly changing world. 
Contributions to the conference will be organized according to the following four themes:

\section{Theme 1: Language and Imagination}

Many philosophers argue that the imagination plays a fundamental role in the very conditions of possibility of thinking. Likewise, many anthropological approaches have assumed that without the works of imagination there would be no other forms of cultural work.Imagination underlies politics, ritual, materialities, language, and, of course, art and creativity. Imagination is one of the loci where anthropologies meet, and where serious dialogue must take place. From cognitivist sciences to the anthropology of art, of politics, of religions, of kinship, etc., understanding the capacity of humans (and perhaps non-human primates too) to create potential scenarios is a key part of what we find in the field and a key part of the representations we document in our writings. What are the effects of imagination in life and in anthropology?

Other approaches might consider mind and language in their material manifestations. Social life and the environment work on and are shaped by humans and their languages. Local ideas of how languages and thought relate to the world may challenge academic theorization. Do we need new comparative approaches for the study of radical variation?

\section{Theme 2: Creative Bodies}

The human body has long been recognized as a site where the biological, social, and the material converge. Bodies are creative in the sense that they not only grow and reproduce other bodies, but through performances and gestures, they inscribe, manipulate, and communicate ethnicity and gender, health and sickness, vulnerability and resistance. At the same time, bodies remain sites for the production of inequality and alterity. Proliferating images represent and mediate bodily experiences in diverse ways, and bodies are increasingly mobile, distributed, and virtual. Furthermore, developments in technologies - whether applied to bodies before birth, in life, or after death - are recreating both human physicality and the ways in which it is possible to imagine it. We invite panels to explore questions relating to bodies, their materiality, and their imagined dimensions. How are imaginative processes grounded in embodied action, and how are bodies enmeshed in wider social and ecological relationships? How are shifting relations between the human and the non-human affecting bodies, and indeed redefining the 'human'?

\section{Theme 3: Environmental Imaginations}

Earlier generations of anthropologists tended to focus on human environmental adaptability in a wide range of ecosystems and climates. More recent anthropological research has instead prioritized the spatial possibilities afforded by deterritorialization 
and globalization at many scales. 'Nature', which has always functioned as a repository of social ideas and political values, is being recast through a multiplicity of global environmental change discourses. The landscapes that people inhabit embody forms of agency beyond full human control, and anthropologists are increasingly urged to engage in interdisciplinary work. What people actually mean or desire when they talk about stability and/or transformation has become much more contingent.

Is environmental change limiting the human imagination, or are people using their imagination to adapt to the changing climate? Where weather extremes are already affecting livelihoods and ecological practices, what contests and transformations are they triggering? If place and mobility are mutually constitutive (mobility everywhere depends upon dwelling in specific places), what movements will take place on a rapidly changing earth, and what dwelling projects will succeed in an increasingly uncertain atmosphere? We invite contributions on the roles that ethnographic knowledge and anthropological imagination continue to play in an era bound to involve fraught politicized disputes about ways to live with environmental change.

\section{Theme 4: Transformation and Time}

How do sociality, matter, and the imagination transform over time? Whether addressing short- or long-term processes, anthropologists and archaeologists are confronted with questions relating to the temporal nature of the phenomena they analyse. As social relations form and change over time, how are these shifts registered and expressed in material terms? In what ways do material objects emerge, stabilise, and then disintegrate or re-form? And how does time figure in imaginative processes?

In relation to this theme we welcome panels that explore temporalities and transformations in social life, material formations, and acts of imagining. How is the past reconstructed and the future predicted through material practices? What kinds of institutions promote change or aim to preserve the present? How do the political, ethical, and economic aspects of social, material, and imaginative transformations develop and play out? 
Notes 


\section{Practical information}

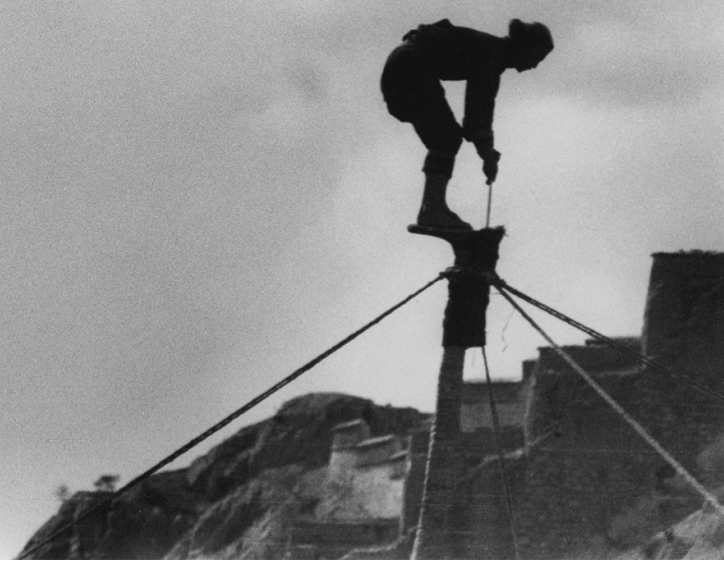

\section{Using this programme}

This chapter explains how to use the printed programme, how to navigate the conference venues and Oxford in general and how to get help in various situations that may occur throughout the conference. The practical info section is followed by a city guide giving suggestions for transport, dining, nightlife and sightseeing.

The general Timetable on the rear cover gives a quick overview of when plenaries, roundtables, receptions, panel sessions etc take place, while the panel grid on the inside rear cover gives a bird's eye view of which panels are happening when and where.

The Events and meetings section, as well as the Plenaries, roundtables, debates chapter (ordered chronologically), gives details of the activities taking place during the conference besides the panel sessions.

The full academic programme, combined with the events, is detailed in the Daily timetable section which shows what is happening and where, at any given moment, in chronological sequence. The Panel and paper abstracts section lists panel and paper abstracts, ordered by panel reference numbers, depending on the thematic stream. 
At the rear of the book there is an alphabetically ordered List of participants to help you identify the panels in which particular colleagues will convene/discuss/present their work. Following this 'index' there are the Publisher advertisements, and you will find the map of conference venues on the inside front cover of the book.

The quickest way of finding out if a colleague you know is present at the conference: check their name from the List of participants which will show you the panels they are involved in. Navigate then to Panel and paper abstracts ordered alphabetically by stream, then numerically within a stream, find the panel reference and you will see the date, start time, number of sessions and location of the panel(s) of interest. You can always ask at the Reception desk if the colleague is already in attendance (arrived to the conference).

The easiest way to get an overview of what is going on at any given time during the conference: the Daily timetable. Find the date and time you need, read the panel titles. If you want to know more (i.e. read paper abstracts), turn to the Panel and paper abstracts.

If you need any help interpreting the information in the conference book, please ask a member of the conference team at the reception desk.

\section{Timing of panels and individual papers}

Panels have been allocated either one, two, or three ninety-minute sessions, depending on the number of accepted papers. There may be up to four papers per session. We are using 16 to 25 panel rooms at a time, so any one panel is up against that number of alternatives. The start times of each panel are shown in the respective abstract section and are also indicated in the Daily timetable.

In order to improve the conference experience for those delegates who like to panel-hop, convenors have been asked to indicate the distribution of papers across the panel sessions and we've marked those session breaks in the printed (but not online) programme. We have asked panel convenors, if at all possible, NOT to subsequently alter the order of the papers, if someone withdraws at the last minute. We ask that you all have the patience to then either have discussion in the 'spare time' or a break, and hence retain papers in the allocated sessions. In most panels, the time allocated per paper will be approximately 15-20 minutes, but this may vary depending on how the convenors have structured their sessions.

\section{ASA18 conference venues}

The conference mostly takes place at the Oxford Examination Schools (81 High St, Oxford OX1 4AS) in the breakout rooms located on the ground floor and the East Schools on the first floor; but some panels will run in Magdalen College (OX1 4AU), All Souls College (OX1 4AL), or in Queen Elizabeth House (Oxford Department of International Development, 3 Mansfield Road, OX1 3TB). 
The reception desk is located near the front entrance of Examination Schools. The opening and closing keynotes, Plenary I and III, the roundtables, the final debate and the AGM will all be held in the spacious South Schools on the first floor, while the North Schools (also first floor) will be used for the Book Exhibit, art exhibitions and catering.

\section{Please note}

Semi-plenaries are split between two venues 15 minutes apart - make sure you plan your time right!

On Wednesday and Thursday, there will be two plenaries taking place at the same time: one will be held in the South School of the Examination Schools, while the other will take place at the Lecture Theatre in the Oxford University Natural History Museum (OUNHM, Parks Rd, OX1 3PW). OUNHM is about a 15-minute walk from Examination Schools, so if you are keen on one of the plenaries taking place there (Transformation and Time on Wednesday and Creative Bodies on Thursday), please ensure that you start off early enough to avoid being late.

\section{Laboratories (labs) and films}

There's a diverse programme of workshops - "labs" - at this conference (as was also the case at ASA16 and ASA/AAS/ASAANZ17), exploring the more experimental modes of doing anthropology. The full programme can be found in a special chapter in this book, but please note that most labs take place at the Pitt Rivers Museum, some at Examinations Schools, and a few at special locations (all are marked on the map on the inside front cover of this book).

The film programme (curated by Prof Marcus Banks) will run at the Lecture Theatre of the Pitt Rivers Museum Tue 13:30-15:00, Wed 16:15-17:45 and Thu 14:15-15:45.

\section{Catering: refreshment breaks, lunches and conference dinner}

Refreshments and lunches (see times in the timetable on the rear cover) can be obtained by delegates on display of their conference badge at one of the refreshment serving areas: North Schools on the first floor and the marquee outside of Examination Schools. All catering will be mindful of allergies and special diets. 
The conference dinner - a three-course sit-down meal with wine - requires a prepurchased ticket $(£ 60)$, booked at the time of registration. The dinner will be held in the magnificent Victorian Gothic Dining Hall of Keble College (OX1 3PG). See the Events \& Meetings section for the menu.

N.B. As the ASA has paid for all dinner tickets before the conference begins, we cannot reimburse unwanted tickets.

\section{Reception desk, ASA18 conference team, NomadIT office}

On arrival at the Reception desk (near the front entrance of Examination Schools) you will have been given this book and your conference badge. If you bought a ticket for the Thursday night conference dinner when you registered, this will be printed on the badge (a cutlery icon).

There is a team of helpful volunteers, familiar with the programme, the venue, and the surrounding area, that you can turn to when in need of assistance. The volunteer team members can be identified by their conference t-shirts. If you cannot see a team member, please ask for help at the Reception desk.

\section{Reception desk \\ \& NomadIT office opening hours \\ Tue $\quad 11: 30-18: 00$ \\ Wed 08:00 -16:15 \\ Thu $08: 00-16: 15$ \\ Fri $\quad 08: 00-16: 15$ \\ All financial arrangements must be dealt with in the conference organisers' (NomadlT) office located in Room 5A on the ground floor of the Examination Schools, near the Reception desk.}




\section{Printing}

If you need to print your conference paper, a boarding pass, or other short text-based documents, this can be done for 20p per page at the NomadIT office in Room 5A at the Examination Schools.

\section{Recycling}

NomadIT re-uses the plastic badge holders and lanyards, so please hand these in at the boxes provided on the reception desk or at the party, or to a member of the conference team when leaving the conference for the final time. This not only saves resources, but helps keep registration costs to a minimum. With similar concern for the environment, we ask delegates to please be careful to use the recycling bins for paper and plastic.

\section{to. Emergency contact details and numbers}

During the conference, emergency messages should be sent to conference(at)theasa.org.

Members of NomadlT can be contacted on UK cell/mobile phones +447482613951 (Triinu Mets)

+447866425805 (Rohan Jackson).

Ambulance, Fire, Police: 999 or 112

NHS Direct (24 hour health helpline): 111

Gas emergency: 0800111999

\section{Wifi access at the venue}

Eduroam credentials can be used for accessing Wifi at the University of Oxford. Delegates can also request temporary credentials, for use during the conference, at the Reception desk when checking in. 
Notes 


\section{Oxford City Guide}

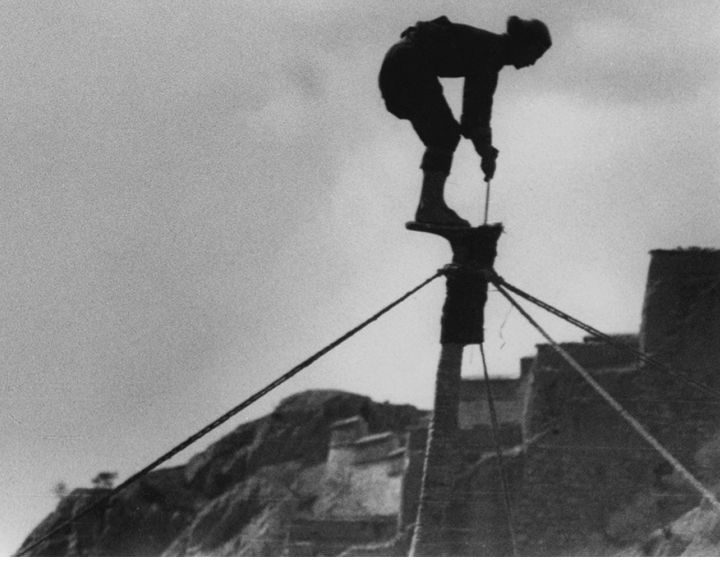

All walking distances indicated are from Carfax Tower in central Oxford and are approximate.

\section{Getting around in Oxford}

Oxford is small and easy to get around, so most destinations in the conference programme are within walking distance.

Cycling is a great way to get around Oxford, as the city is virtually flat. There are several dockless bicycle hire companies operating in Oxford. The Oxford City Council webpage lists the main companies: http://www.oxfordcityguide.com/ee2/index.php?/TouristInfo/ GetAround

\section{Buses}

The main stops for buses travelling to the north of the city are on Magdalen Street, between Debenhams department store, and the cinema; the main stops for buses travelling south and east are on Castle Street and St Aldate's. Buses run often, so you're never left standing for too long. Pay the driver when you get on, and tell him/her if you 
want a return ticket or a single ride. There are often printed schedules near the driver if you want to take it with you to plan your return trip. Note that if you are not standing at a main bus stop (i.e. on Magdalen Street), but are at a marked bus stop, you must 'hail' the bus by waving at the driver.

There are two bus operators in Oxford. For maps and timetables, visit their websites: http://www.oxfordbus.co.uk/ and https://www.stagecoachbus.com/timetables (note that Stagecoach is a national bus company and their website is not limited to Oxford); both companies have downloadable apps. The Oxford Bus Company also has a new ondemand minibus service called PickMeUp: download the app from https://pickmeup. oxfordbus.co.uk/.

\section{A Taxis}

There are several taxi companies operating in Oxford. 'Black cabs' can be hailed on the street, all other taxis ('private hire cars') have to be pre-booked or found at a taxi rank the main ranks are at Gloucester Green (near the bus station), the railway station, and at Carfax Tower. Only get in a car that you know for sure to be a licensed taxi. All the companies have apps for Apple and Android operating systems, or can be called from the numbers below. Note that Uber does not operate in Oxford.

\section{TAXIS}

001 Taxis - 01865240000

ABC Radio Cars - 01865770077 / 775577 / 242424

Royal Cars - 01865777333

City Taxis - 01865703030

Go Green Taxis - 01865922222

\section{¥1 Restaurants \& cafes}

\section{f.f. PRICEY}

\section{Cherwell Boathouse}

Bardwell Road, Oxford OX2 6ST, T: 01865 552746, http://www.cherwellboathouse.co.uk Classic French/British food. Lovely setting by the Cherwell river; punts can also be hired here.

Buses number 2 or 7 from Magdalen Street (destination stop is St Margaret's Road). Or walk via the University Parks (closes at dusk). 


\section{Brasserie Blanc}

71-72 Walton Street, Oxford OX2 6AG, T: 01865 510999, http://brasserieblanc.com/ restaurants/oxford

French food in the lively Jericho area. Part of the group of restaurants established by chef Raymond Blanc.

Walking distance: about 20 minutes.

\section{Gees}

61 Banbury Road, Oxford OX2 6PE, T: 01865 553540, http://www.gees-restaurant.co.uk Simple British food. Nice location in a converted glasshouse, and right next door to the School of Anthropology and Museum Ethnography!

Walking distance: about 15 minutes.

\section{ff MID-RANGE}

\section{Quod}

92-94 High Street, Oxford OX1 4BJ, T: 01865 202505, http://www.quod.co.uk Large brasserie in a former banking hall, with courtyard garden; very handy for Examination Schools, but drinks at the bar can be pricey.

City centre.

\section{Chiang Mai Kitchen}

Kemp Hall Passage, 130a High Street, Oxford OX1 4DH, T: 01865 202233, http://www. chiangmaikitchen.co.uk

Well-loved Thai restaurant in former college building.

City centre.

\section{Sojo}

6-9 Hythe Bridge St, Oxford OX1 2EW, T: 01865 202888, http://sojooxford.co.uk Authentic Chinese food with friendly service.

Walking distance: about 10 minutes.

\section{My Sichuan}

Old Schoolhouse, Gloucester Green, Oxford OX1 2DA, T: 01865236899

Spicy Sichuanese food; has attracted rave reviews from national press.

Walking distance: about 10 minutes.

\section{Kazbar}

25-27 Cowley Road, Oxford OX4 1JB, T: 01865 202920, http://www.kazbar.co.uk Moroccan-inspired décor; serves tapas and mezze.

Walking distance: about 15 minutes 


\section{Al-Shami}

25 Walton Crescent, Oxford OX1 2JG, T: 01865 310066, http://www.al-shami.co.uk A longstanding favourite; good-quality Lebanese food.

Walking distance: About 15 minutes.

\section{Branca}

111 Walton Street, Oxford OX2 6AJ, T: 01865 556111, http://www.branca.co.uk Chic Italian restaurant in Jericho.

Walking distance: about 20 minutes.

\section{Arbequina}

74 Cowley Road, Oxford OX4 1JB, T: 01865 792777, https://arbequina.co.uk

Fantastic tapas and small plates.

Walking distance: about 20 minutes.

\section{Magdalen Arms}

243 Iffley Rd, Oxford OX4 1SJ, T: 01865 243159, http://www.magdalenarms.co.uk Classic British food with imagination.

Get the No 3 bus opposite Examination Schools (destination stop is Magdalen Road).

\section{$£$ GOOD VALUE}

\section{Vaults \& Garden}

University Church, 1 Radcliffe Square, Oxford OX1 4AH, T: 01865 279112, http://www. thevaultsandgarden.com

Located in the crypt of the University Church. Outdoor seating and lots of vegetarian options.

City centre.

\section{The White Rabbit}

Friars Entry, Oxford OX1 2BY, T: 01865 241177, http://www.whiterabbitoxford.co.uk Cosy pub with good pizza.

City centre.

\section{Turl Street Kitchen}

16 Turl St, Oxford OX1 3DH, T: 01865 264171, http://www.turlstreetkitchen.co.uk Good for coffee but also breakfast, lunch and dinner. If you only eat at one restaurant during your time in Oxford, eat here and benefit the local community: all profits support student-led volunteering charity, The Oxford Hub: https://www.oxfordhub.org City centre. 


\section{Jericho Café}

112 Walton St, Oxford OX2 6AJ, T: 01865 310840, http://www.thejerichocafe.co.uk Relaxed atmosphere, plenty of room, quick service and good simple food.

Walking distance: about 20 minutes.

\section{Big Society}

95 Cowley Rd, Oxford OX4 1HR, T: 01865 792755, http://www.bigsocietyoxford.com

US-style burgers, wings etc. Lively atmosphere - can get crowded.

Walking distance: about 20 minutes.

\section{Dosa Park}

25 Park End St., Oxford OX1 1HU, T: 01865 791197, http://dosapark.com

Indian restaurant, specialising in South Indian dishes, and snacks such as idli and dosa; very close to the train station.

Walking distance: about 20 minutes.

\section{Pint Shop}

27-29 George Street Rd, Oxford OX1 2AY, T: 01865 251194, http://pintshop.co.uk/

locations/oxford

Simple (but good) pub food, and huge range of keg and cask beers.

City centre.

\section{Oli's Thai}

38 Magdalen Rd, Oxford OX4 1RB, T: 01865 790223, http://olisthai.com

One of the best restaurants in Oxford. Very small so best to book in advance for lunches only as evenings are booked up weeks if not months in advance.

Get the No 3 bus opposite Examination Schools (destination stop is Magdalen Road).

In addition, the newly-opened Westgate shopping centre, at the bottom of Queen Street, contains over 20 restaurants and food outlets, many open in the evening: https:// westgateoxford.co.uk/food-and-drink

George St, in the city centre, has a wide variety of chains (Pizza Hut, Yo Sushi! etc.) and moderately-priced coffee shops and small cafes. Cowley Road, east of the city centre, has many small and quirky restaurants. Walking distance: anything between 10 and 30 minutes.

\section{PUBS/BARS}

\section{The Turf Tavern}

4-5 Bath Place, Oxford OX1 3SU, T: 01865 243235, http://www.turftavern-oxford.co.uk Touristy but an Oxford institution; stunning setting under the old city walls City centre. 


\section{The Bear}

6 Alfred St, Oxford OX1 4EH, T: 01865 728164, http://www.bearoxford.co.uk Tiny. Note the collection of ties.

City centre.

\section{Kings' Arms}

40 Holywell Street, Oxford OX1 3SP, T: 01865 242369, http://kingsarmsoxford.co.uk The oldest pub in Oxford, built in 1607, with plenty of room and basic food.

City centre.

\section{The Old Bookbinders}

17-18 Victor St, Oxford OX2 6BT, T: 01865 553549, http://oldbookbinders.co.uk

Good selection of beers - also serves crepes.

Walking distance: about 20 minutes.

\section{The Rickety Press}

67 Cranham St, Oxford OX2 6DE, T: 01865 424581, http://www.thericketypress.com Lively atmosphere with good bar food, including tasty pizzas and burgers.

Walking distance: about 20 minutes. Or visit their sister pub in East Oxford:

\section{The Rusty Bicycle}

28 Magdalen Road, Oxford OX4 1RB, T: 01865 435298, http://www.therustybicycle.com Get the No 3 bus opposite Examination Schools (destination stop is Magdalen Road).

\section{The Jolly Farmers}

20 Paradise St, Oxford OX1 1LD, T: 01865 427627, https://www.facebook.com/ JollyFarmersOxford

Oxford's only LGBTQ+ pub, also one of the oldest pubs in Oxford; friendly, with large beer garden (NB: does not serve food, but there are many restaurants in the Westgate Centre across the road).

City centre.

\section{The Punter}

7 South Street, Osney Island, Oxford OX2 OBE, Tel: 01865 248832, http://www. thepunteroxford.co.uk

Good food, good atmosphere, right on the river by Osney lock.

Walking distance: about 20 minutes.

\section{JUST OUTSIDE OXFORD}

\section{Jacob's Inn}

130 Godstow Rd, Oxford OX2 8PG, T: 01865 514333, http://jacobs-inn.com

Nice garden, including pet pigs. Nose-to-tail dining.

Get the No 6 bus from Magdalen Road (nearest destination stop is Elmthorpe Road). 


\section{The Trout}

195 Godstow Rd, Oxford OX2 8PN, T: 01865 510930, http://thetroutoxford.co.uk Picturesque setting just by the river. Much used as a location in Inspector Morse/Lewis. Get the No 6 bus from Magdalen Road (nearest destination stop is Webbs Close).

\section{The Perch}

Binsey Lane, Binsey, Oxford OX2 ONG, T: 01865 728891, http://the-perch.co.uk Lovely large garden and good food. Walk from Jericho/North Oxford across Port Meadow to the back gate.

Not easily accessible by public transport.

\section{Visitor attractions}

\section{ARTS, CULTURE \& SITES}

\section{Pitt Rivers Museum}

Parks Road, Oxford OX1 3PW (entrance through the Natural History Museum, see below), http://www.prm.ox.ac.uk

The Pitt Rivers Museum houses an internationally important collection of ethnographic and archaeological artefacts, unusually grouped by type or function (body adornment, weapons, etc.) rather than by era or geographical location.

City centre. Free entry; optional donation.

\section{Ashmolean Museum}

Beaumont Street, Oxford OX1 2PH, http://www.ashmolean.org

The Ashmolean is the University of Oxford's museum of art and archaeology, founded in 1683. Its world famous collections range from Egyptian mummies to contemporary art. The main exhibition during the conference period is, appropriately for anthropologists, called 'Spellbound' and explores magical thinking across the centuries.

City centre. Free entry to museum; admission charge for exhibition.

\section{Museum of Natural History}

Parks Road, Oxford OX1 3PW, http://www.oum.ox.ac.uk

The Museum of Natural History houses the University's collections of zoological, entomological, palaeontological and mineral specimens in a Grade 1-listed Victorian Gothic building.

City centre. Free entry; optional donation.

\section{Museum of The History of Science}

Broad Street, Oxford OX1 3PW, http://www.mhs.ox.ac.uk

The Museum of the History of Science houses unparalleled collections of scientific instruments in the world's oldest purpose built museum building.

City centre. Free entry; optional donation. 


\section{Modern Art Oxford}

30 Pembroke Street, Oxford OX1 1BP, https://www.modernartoxford.org.uk Founded in the 60s, Modern Art Oxford is a leading contemporary art space with an international reputation for inspirational and innovative programmes.

City centre. Free entry.

\section{Bodleian Library}

Broad Street, Oxford OX1 3BG, http://www.bodleian.ox.ac.uk/whatson

You can take a paid guided tour of the Old Bodleian Library that takes in the 15thcentury Divinity School, famous for its beautiful fan-vaulted ceiling (and, yes, as a Harry Potter location), the medieval Duke Humfrey's Library, and the Radcliffe Camera.

City centre.

\section{University Church of St Mary}

High St, Oxford OX1 4BJ, http://www.university-church.ox.ac.uk

This thousand-year old church was originally also a lecture hall for the University, and was also the venue for the founding of Oxfam. Its tower with famous gargoyles provides a view across the city centre and into the surrounding colleges.

City Centre. Free entry, Tower $£ 4 / £ 3$ concs

\section{Botanic Garden}

Rose Lane, Oxford OX1 4AZ, https://www.botanic-garden.ox.ac.uk The first university botanic garden in the UK, founded in 1652. Beautiful borders, including the experimental Merton Borders, and glasshouses. Nice place for a picnic! City centre. Admission charge.

\section{The Colleges}

Most Oxford colleges are open to visitors outside term. Many have beautiful gardens, dining halls, and chapels; University College is the oldest, founded in 1294. At the far end of the High Street Magdalen College has a deer park and Christ Church houses both the city's cathedral and a picture gallery featuring renaissance sketches. Find out more about opening times and charges: https://www.ox.ac.uk/visitors/visiting-oxford/visiting-thecolleges

\section{CINEMAS}

There are two art cinemas in Oxford:

\section{The Phoenix Picturehouse}

57-58 Walton Street, Oxford OX2 6AE, https://www.picturehouses.com/cinema/Phoenix Picturehouse

Walking distance: about 20 minutes. 


\section{The Ultimate Picture Palace}

Cowley Rd, Oxford OX4 1BN, http://www.uppcinema.com

Walking distance: about 20 minutes.

\section{SHOPPING}

All major high street chains have branches in Oxford, mostly in Cornmarket St and the newly opened Westgate shopping centre at the bottom of Queen St. There are also a variety of slightly high end restaurants on the top floor of the Westgate centre, several with open terraces overlooking the city and the surrounding area. In the city centre, find time to visit the Covered Market (entrances in High Street and Market Street: http:// oxford-coveredmarket.co.uk) housed in a beautiful 18th century building. There is an open air market at Gloucester Green on Wednesdays (fruit and veg), Thursdays (antiques and bric-a-brac), and Saturdays (bric-a-brac and street food).

\section{WALKING TOURS}

Oxford Walking Tours visit the oldest colleges and experienced university-educated guides provide information on both the history of the city and the university. Meet at the blue gates of Trinity College on Broad Street on the hour from $11 \mathrm{am}$ to $4 \mathrm{pm}$. The tour takes approx. 90 minutes and involves less than one mile of walking. For more information: http://www.oxfordwalkingtours.com.

There is a self-guided walking tour available at https://freetoursbyfoot.com/self-guidedoxford-tour, and a Harry Potter 'trail' at https://www.locationoxfordshire.co.uk/docs/ Trails-HarryPotter.pdf.

\section{PUNTING}

There are two punting stations in Oxford: at the Cherwell Boathouse restaurant (Bardwell Road, Oxford OX2 6ST, http://cherwellboathouse.co.uk/punting - see directions above to get to the restaurant), and at Magdalen Bridge (High St, OX1 4AU, http://www. oxfordpunting.co.uk). Magdalen Bridge punts are more expensive but easier to get to.

\section{SIGHTSEEING OUTSIDE OF OXFORD}

\section{Blenheim Palace}

Woodstock, Oxfordshire OX20 1PP, www.blenheimpalace.com

An 18th century Baroque palace, birthplace of Winston Churchill, set in huge grounds landscaped by Capability Brown.

Get the S3 bus from Gloucester Green. The journey takes about 30 minutes. 
Notes 


\section{Events and meetings}

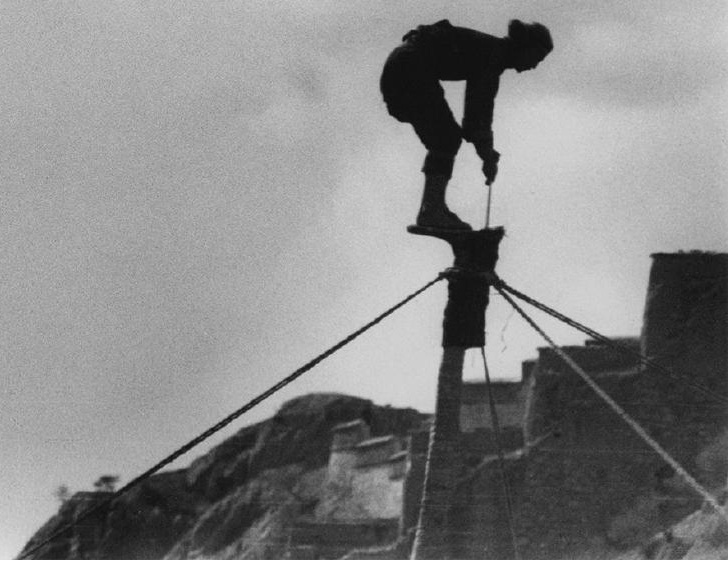

\section{Throughout the conference}

\section{Exhibitions}

\section{Uganda Stories, by Sunil Shah}

Special Exhibition Gallery, Pitt Rivers Museum

17 February - 23 September 2018

In this photography exhibition, Shah explores very personal themes linked to his family's roots and heritage as Ugandan Asians, and offers wider narratives around exile, displacement and dispossession. In 1972 Idi Amin expelled 80,000 Asians from Uganda. Shah was three years old when his family were made refugees and forced to endure an unexpected journey, leaving their lives and possessions behind and move to the UK. Shah investigates the past and extracts fragments, narratives and meanings to re-imagine his own family's tale. The exhibition also alludes to the fading of memories, the blindspots in representing history and to the legacies of colonialism. 


\section{Performing Tibetan Identities: Photographic Portraits by Nyema Droma}

In the Court and Clore Balcony of the Pitt Rivers Museum

September 2018 - May 2019

This innovative exhibition features stunning contemporary images made by the Tibetan photographer, Nyema Droma. Taking inspiration from the historic collections of the Pitt Rivers Museum, she has created portraits of other young Tibetans that celebrate their experiences and challenge stereotypes. The exhibit includes an installation in the heart of the museum, as well as film and digital displays which explore the interplay between past and present, diaspora and homeland, the local and the global, in Tibetan identity formation.

During the ASA18 conference, the first phase of this exhibition will be on view. The full exhibition officially opens on 13th October 2018.

\section{Diversifying Portraiture in Anthropology, curated by Helen Worrell} Examination Schools

The Tylor Library, part of the Bodleian Libraries, currently has busts of Evans-Pritchard, Frazer, and Godfrey Lienhardt. Whilst their contribution to the discipline remains invaluable, the Library is keen to showcase anthropologists from communities that have been historically under-represented, for example people of colour, women, LGBTQ+ communities. Staff and students in the School of Anthropology and Museum Ethnography were invited to nominate an anthropologist who has inspired them from communities currently under-represented and to submit a statement explaining the importance of the chosen anthropologist to them and/or the discipline. This exhibition showcases these anthropologists. After the conference the portraits will be displayed in the School and the Tylor Library thus ensuring their lasting impact.

Further information at https://www.bodleian.ox.ac.uk/anthropology/diversifying portraiture

\section{The Legend of Ponnivala Nadu, by Brenda Beck Examination Schools}

People resident in a unique geographic area sometimes develop what can be called a KEYSTONE story. This term can be used to describe a major legend that knits together history, social values, mythical themes, heroic acts and more, in a way that creates a lasting tapestry of linked scenes. Such keystone stories help to define a culture's very essence. Keystone stories are widely recognized, are referenced in popular culture and are usually celebrated by repeated ritual events or festivals as well. This exhibition uses seven labeled panels (Roots, Reclamation, Resistence, Resilience, Relationships, Reflection and Revelation) to express the core story ideas connected to a specific Tamil Keystone legend known throughout the Kongu Nadu of Tamilnadu. In Lab \#2 the social anthropologist who collected this 38 hour oral epic back in 1965 will discuss its significance and invite debate about various techniques of story-sharing available to researchers who want to "give-back" some of what they have learned from years of extensive fieldwork. In this 
particular case the Legend of Ponnivala Nadu is now being shared successfully with Indian émigrés living in the North American Diaspora. Retelling experiments have also been undertaken in Sri Lanka and Malaysia, as well as in the original fieldwork region of Kongu Nadu.

\section{Tuesday 18th September}

$13: 30-15: 00$

Film screening: With This Ring, director-producers Ameesha Joshi and Anna Sarkissian

Pitt Rivers Museum Lecture Theatre

2016, 90 minutes

Filmed over the course of six years, With This Ring follows the meteoric rise of three Indian women who sidestep traditional roles to become world champion boxers. Worried that boxing will disfigure their faces and hurt their chances of getting married, their parents are reluctant to embrace their chosen careers. Facing pressure to conform, Mary, Sarita and Chhoto test boundaries as they become the primary wage earners in their families. While the team dominates at world championships, they continue to train in oblivion in India. Boxing becomes their lifeline, their source of income, their community, and ultimately what rips them apart. www.withthisringfilm.com

19:00-21:00

\section{Welcome reception}

Pitt Rivers Museum

The Pitt Rivers Museum museum has an important and longstanding connection with anthropology in Oxford - it was founded in 1884 by Lt-General Augustus Pitt Rivers, who donated his collection to the University of Oxford with the condition that a permanent lecturer in anthropology must be appointed. Museum staff are involved in teaching Archaeology and Anthropology at the University even today as well as research. The organisers of ASA18 would like to invite all delegates to celebrate the start of the conference with some wine and snacks and to look around in the extraordinary museum. 


\section{Wednesday 19th September}

\section{2:45-14:15}

Heads of Departments (HODs) meeting

Examination Schools, Room 13

ASA invites the Heads of Departments and their representatives to this annual meeting. All those planning to attend should notify the organisers by email to secretary(at)theasa. org

\section{3:00-14:15}

\section{APPLY network meeting}

\section{Examination Schools Room 12}

The APPLY network is for all those seeking to use anthropological theory and practice to applied ends, both inside and outside the academy. Recognising the wide range of contexts in which anthropology is practised, and the diverse conditions and constraints under which practising anthropologists work, we aim to explore ways in which the network can best reach its constituency and support anthropologists working in applied fields. Please join us in discussing proposals for taking the network forward.

\section{3:00-14:15}

\section{\#MeTooAnthro: Supporting students in the field}

Examination Schools, East School

Anthropologists face unique working conditions - both inside and outside the university - that increase our exposure to the risk of sexual assault and harassment. However, this potential for sexual assault, harassment, and gender-based violence to occur in the field can go unacknowledged in pre-fieldwork planning for anthropology students and researchers. Gendered travel advice is too often well-meaning, but not conducive to nuanced and explorative ethnographic enquiry (Williams 2009).

This seminar, developed by the MeTooAnthro collective, provides teaching and mentoring tools for faculty and students to address these issues prior to entering the field. This training program is intended to complement an online resource with countryspecific information (including where to report sexual violence, dealing with authorities, the existence of local support systems), as well as mentor networks to support young scholars in specific field sites. In particular, we aim to ensure that all resources and training programs produced address the intersections between gender, ethnicity, and sexuality, and are accessible to as many as possible.

MeTooAnthro invites feedback on this training program prior to its distribution, whilst the session will allow participants to engage with the training materials directly.

Contact: metooanthro@gmail.com 
Film screening: The block/Blocul, director Maria Salaru (Durham University) Pitt Rivers Museum Lecture Theatre

2016, 60 minutes

From neighbourly disputes over garlic-heavy cooking to memories of Ceaușescu's heatless winters, this film explores the rich social and material universe of a Romanian apartment building. It follows the story of the block's administrator, in his effort to mediate relationships between neighbours and maintain peace and order. In doing so, it captures the rich nuances of the inhabitants' everyday lives. The block comes to life, as its inhabitants constantly reshape it to defy the passing of time, while its failing infrastructure encroaches on their neighbourly relations. This is a film about people's homes, and the spaces in between. In those spaces, the pipes don't only carry hot water they carry meanings from one inhabitant to the next.

\section{Thursday 20th September}

13:00-14:15

\section{ASA's Annual General Meeting}

Examination Schools, South School

All members of the ASA are invited to attend the association's AGM. Come and have your say in ASA business. Those attending this meeting will be given priority in the lunch queue so as to manage lunch before the meeting begins.

14:15-15:45

Film screening: Nightfall on Gaia, director Juan Francisco Salazar (Western Sydney University)

Pitt Rivers Museum Lecture Theatre

2015, 92 minutes

In April 2043, astrobiologist Xue Noon [Victoria Hunt] finds herself stranded in the GAIA International Antarctic Station. As the polar night closes in, she connects herself to the Ai-system. She scavenges digital memories and archives of the time she spent at King George Island with her father back in 2015. She struggles between her scientist mind and her Indigenous soul. She looks for old friends, places, atmospheres, only to find herself again. Nightfall on Gaia is a speculative documentary that depicts the lives and visions of human communities living transiently in the Antarctic Peninsula. Grounded in ethnographic fieldwork conducted in Antarctica between 2011 and 2014, the film is an experimental meditation on the future of the Antarctic as a new extreme frontier for human habitation, exposing the complexities of a fragile planet at the verge of ecological collapse, our relationship to the Ice, and the uncertain future for the region. 


\section{9:00-21:00}

\section{Conference dinner}

Dining Hall of Keble College, Parks Road, Oxford, OX1 3PG

The conference gala dinner is an extra, booked at the time of registration. The dinner will be held in the magnificent Victorian Gothic Dining Hall of Keble College, and includes excellent food and wine. The menu is as follows:

- Marinated Beetroot Carpaccio with Feta and Toasted Pine Nuts

- Supreme of Roast Guinea Fowl with Duaphinoise Potatoes, Green beans, Red Pepper Coulis and Balsamic Reduction

- (Vegetarian option) Timbale of Mushroom filled with Vegetable and Herb Risotto, Sun Blushed Tomato Coulis, Aubergine Caviar and Root Vegetables

- Summer Pudding with Strawberries and Chantilly Cream

N.B. As the ASA has paid for all dinner tickets before the conference begins, we cannot reimburse unwanted tickets.

\section{1:00-23:00}

\section{Conference dance in Keble bar}

Dining Hall of Keble College, Parks Road, Oxford, OX1 3PG

This party is free for all delegates - come and join us for a few hours of dancing to celebrate the conference! 


\section{Book Exhibit}

There will be a Book exhibit in the North School of the Examinations School. Delegates are invited to browse the various book and journal titles, and talk to the publisher and institutional representatives. The support of publishers, universities and other institutions is an important part of putting on the conference, so please do take the time to visit their stands, and talk to their staff.

The hours of the Book exhibit will be as follows: Tue 12:00-17:00; Wen, Thu 9:00-17:00; Fri 9:00-16:00.

The following publishers and institutions will be in attendance: Berghahn Books, Bloomsbury Academic, Cambridge University Press, Combined Academic Publishers, Liverpool University Press, MIT Press, RAI, Rowman \& Littlefield International, Sean Kingston Publishing, Taylor and Francis Group, UCL Press, White Horse Press.
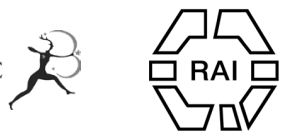

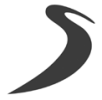

L IVER POOL

U N I V E R S I T Y P R E S S

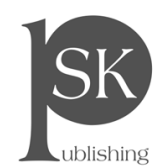

ROW M A E

L I T T L E F I E L D

INTERNATIONAL

\section{$\Longrightarrow$ Taylor \& Francis Group}

an informa business
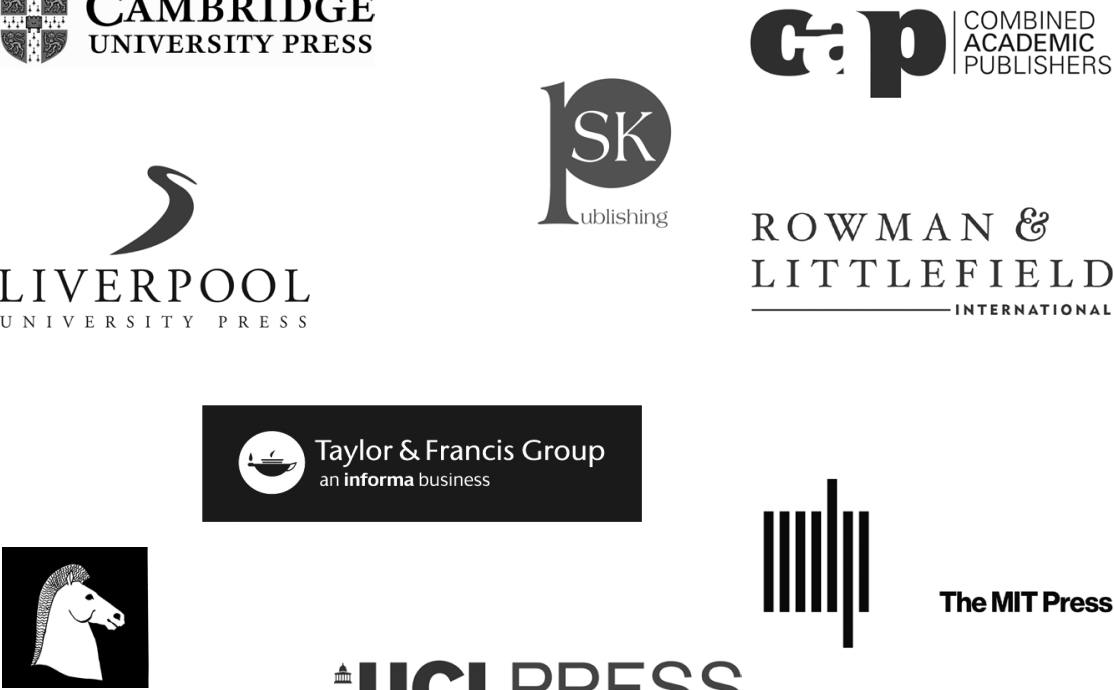

ACADEMIC
PUBLISHERS 
Notes

36 


\section{Daily timetable}

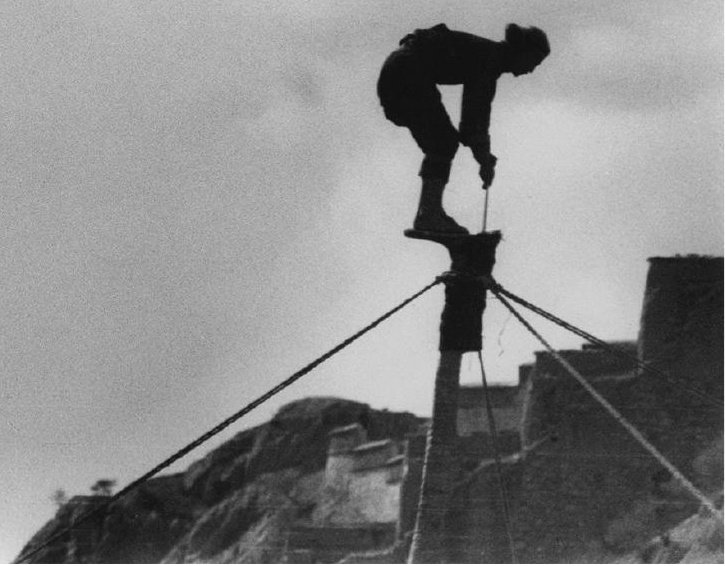

\section{Tuesday 18th September}

Throughout the day

Exhibition: Uganda Stories, by Sunil Shah

Special Exhibition Gallery, Pitt Rivers Museum

Throughout the day

Exhibition: Performing Tibetan Identities, by Nyema Droma

In the Court and Clore Balcony of the Pitt Rivers Museum

Throughout the day

Exhibition: Diversifying Portraiture in Anthropology, curated by Helen Worrell Examinations Schools 
Throughout the day

Exhibition: The Legend of Ponnivala Nadu, by Brenda Beck

Examinations Schools

\section{1:30-18:00}

Registration desk open

Examinations Schools

\section{3:30-15:00}

Film screening: With this ring, by Ameesha Joshi and Anna Sarkissian

Convenor: Marcus Banks (University of Oxford)

Pitt Rivers Museum Lecture Theatre

\section{3:30-15:00}

\section{PANEL SESSION 1}

Ant01 The changing faces and use of ethnography (ASA apply)

Convenors: Julie Scott; Sarah Buckler (Robert Gordon University)

Examination Schools Room 11: first of two sessions

Body08 Feeling gender: the power of gendered embodiment

Convenor: Jessica Sandelson (University of Oxford)

Magdalen Summer Common Room: first of two sessions

Body09 Playful bodies, bodies at play

Convenors: Shireen Walton (University College London); John McManus (British Institute at Ankara)

Discussant: Allen Abramson (University College London)

Magdalen Old Law Library: single session

\section{Cog03 Cultures of metacognition}

Convenors: Jonathan Mair (University of Kent); Joanna Cook (UCL)

Examination Schools Room 10: first of two sessions

Cre03 Play things: materiality, time, and imagination

Convenors: Thomas Boylston (University of Edinburgh); Anne Dippel (Friedrich-Schiller-

Universität Jena)

Examination Schools Room 9: first of two sessions 
Cre08 Time and tradition: theorising the temporalities in and of cultural production

Convenors: Georgina Born (University of Oxford); Jonas Tinius (Humboldt-Universität zu Berlin)

Examination Schools Room 8: first of three sessions (third session on Wed 19th Sept 09:00-10:30, Examination Schools East School)

Env01 Mobilizing the environment: reimagining nature and nation in unsettled times

Convenors: Elizabeth Turk (University of Cambridge); David Sneath (Cambridge

University); Thomas White (University of Cambridge)

Queen Elizabeth House (QEH) SR2: first of two sessions

Env14 Whose green? Imagining socio-ecological transitions

Convenors: Laura Rival (University of Oxford); Nina Moeller (University of Manchester) Queen Elizabeth House (QEH) SR1: first of two sessions

\section{Inf01 Homo faber revisited}

Convenors: Penny Harvey (University of Manchester); Petra Tjitske Kalshoven (University of Manchester)

Examination Schools Room 15: first of two sessions

\section{Inf06 The times of infrastructure}

Convenors: Luke Heslop (London School of Economics); Elisa Tamburo (SOAS, University of London)

Discussants: Laura Bear (London School of Economics and Political Science), Edward Simpson (SOAS)

Examination Schools Room 14: first of three sessions (third session on Thu 20th Sept 14:15-15:45)

\section{Lab01 Fomenting fermentation}

Convenors: Salla Sariola (University of Helsinki); Matthäus Rest (Max Planck Institute for the Science of Human History)

Private Dining Room, Wolfson College: first of two sessions

Lab05 Hard and disagreeable labour: a laboratory exploring drawing conventions Convenor: Ray Lucas (University of Manchester)

Pitt Rivers Museum Seminar Room: single session

Lang02 Imagining language: ethnographic approaches

Convenors: Guilherme Heurich (UCL); Jan David Hauck (University of California, Los Angeles)

Discussants: Alessandro Duranti (University of California, Los Angeles); Sinfree Makoni (Pennsylvania State University)

Examination Schools Room 6: first of two sessions 
Med04 Reimagining urban health: infrastructures, economies and human-animal relations in the Global South

Convenors: Jamie Lorimer (University of Oxford); Michelle Pentecost (Kings College

London); Thomas Cousins (University of Oxford)

Magdalen Daubeny: first of two sessions

Med07 Temporalities in the postgenomic era

Convenors: Bastien Llamas (University of Adelaide); Michael Davies (Robinson Institute,

University of Adelaide); Megan Warin (University of Adelaide)

Magdalen Oscar Wilde Room: first of two sessions

\section{5:00-15:30}

\section{Refreshments}

Examinations Schools, North School and marquee

\section{5:30-17:00}

\section{PANEL SESSION 2}

Ant01 The changing faces and use of ethnography (ASA apply)

Convenors: Julie Scott; Sarah Buckler (Robert Gordon University)

Examination Schools Room 11: second of two sessions

Body04 Indigenous imaginations: creative bodies and embodied resistance

Convenors: Monica Mottin (Ruskin College, Oxford); Mara Matta (University of Rome 'La Sapienza'); Markus Schleiter (University of Münster)

Magdalen Old Law Library: single session

Body08 Feeling gender: the power of gendered embodiment

Convenor: Jessica Sandelson (University of Oxford)

Magdalen Summer Common Room: second of two sessions

\section{Cog03 Cultures of metacognition}

Convenors: Jonathan Mair (University of Kent); Joanna Cook (UCL)

Examination Schools Room 10: second of two sessions

Cre03 Play things: materiality, time, and imagination

Convenors: Thomas Boylston (University of Edinburgh); Anne Dippel (Friedrich-Schiller-

Universität Jena)

Examination Schools Room 9: second of two sessions 
Cre08 Time and tradition: theorising the temporalities in and of cultural production

Convenors: Georgina Born (University of Oxford); Jonas Tinius (Humboldt-Universität zu Berlin)

Examination Schools Room 8: second of three sessions (third session on Wed 19th Sept 09:00-10:30, Examination Schools East School)

Env01 Mobilizing the environment: reimagining nature and nation in unsettled times

Convenors: Elizabeth Turk (University of Cambridge); David Sneath (Cambridge

University); Thomas White (University of Cambridge)

Queen Elizabeth House (QEH) SR2: second of two sessions

Env14 Whose green? Imagining socio-ecological transitions

Convenors: Laura Rival (University of Oxford); Nina Moeller (University of Manchester) Queen Elizabeth House (QEH) SR1: second of two sessions

\section{Inf01 Homo faber revisited}

Convenors: Penny Harvey (University of Manchester); Petra Tjitske Kalshoven (University of Manchester)

Examination Schools Room 15: second of two sessions

\section{Inf06 The times of infrastructure}

Convenors: Luke Heslop (London School of Economics); Elisa Tamburo (SOAS, University of London)

Discussants: Laura Bear (London School of Economics and Political Science), Edward Simpson (SOAS)

Examination Schools Room 14: second of three sessions (third session on Thu 20th Sept 14:15-15:45)

\section{Lab01 Fomenting fermentation}

Convenors: Salla Sariola (University of Helsinki); Matthäus Rest (Max Planck Institute for the Science of Human History)

Private Dining Room, Wolfson College: second of two sessions

Lab02 Language, story and the visual imagination as anthropological communication

Convenor: Brenda Beck (University of Toronto)

Examination Schools Room 12: single session

Lang02 Imagining language: ethnographic approaches

Convenors: Guilherme Heurich (UCL); Jan David Hauck (University of California, Los Angeles)

Discussants: Alessandro Duranti (University of California, Los Angeles); Sinfree Makoni (Pennsylvania State University)

Examination Schools Room 6: second of two sessions 
Med04 Reimagining urban health: infrastructures, economies and human-animal relations in the Global South

Convenors: Jamie Lorimer (University of Oxford); Michelle Pentecost (Kings College

London); Thomas Cousins (University of Oxford)

Magdalen Daubeny: second of two sessions

Med07 Temporalities in the postgenomic era

Convenors: Bastien Llamas (University of Adelaide); Michael Davies (Robinson Institute,

University of Adelaide); Megan Warin (University of Adelaide)

Magdalen Oscar Wilde Room: second of two sessions

Pol09 Revolutions and activism in retrospect: the material and immaterial production of legacies and meanings

Convenors: Charis Boutieri (King's College London); Alice Wilson (University of Sussex)

Chair: Sian Lazar (University of Cambridge)

Discussant: Frances Pine (University of London)

Examination Schools Room 7: single session

17:00-17:15

Break

$17: 15-18: 30$

Welcome and ASA's Firth Lecture (opening keynote)

The paradox of the long term: human evolution and entanglement, by Ian Hodder (Stanford University)

Chair: Nigel Rapport (St. Andrews University)

Examinations Schools, South School

19:00-21:00

Welcome reception

Pitt Rivers Museum

\title{
Wednesday 19th September
}

\author{
Throughout the day \\ Exhibition: Uganda Stories, by Sunil Shah \\ Special Exhibition Gallery, Pitt Rivers Museum
}


Throughout the day

Exhibition: Performing Tibetan Identities, by Nyema Droma

In the Court and Clore Balcony of the Pitt Rivers Museum

Throughout the day

Exhibition: Diversifying Portraiture in Anthropology, curated by Helen Worrell

Examinations Schools

Throughout the day

Exhibition: The Legend of Ponnivala Nadu, by Brenda Beck

Examinations Schools

08:00-16:15

Registration desk open

Examinations Schools

09:00-10:30

\section{PANEL SESSION 3}

Ant04 Reimagining difference: diversity in anthropology

Convenors: Alice Elliot (Goldsmiths, University of London); Alison Macdonald (UCL)

Examination Schools Room 11: first of two sessions

Body01 Skills of feeling with the world: affective imagination, embodied memories and materiality in the emergence of sociality

Convenors: Andrea De Antoni (Ritsumeikan University); Emma Cook (Hokkaido

University)

Magdalen Summer Common Room: first of three sessions

Body02 Yoga bodies and the transformation of the self

Convenors: Alison Shaw (Oxford University); Esra Kaytaz (Coventry University)

Magdalen Daubeny: first of three sessions

Body10 The creative birthing body

Convenors: Cassandra Yuill (City, University of London); Maria Paula Prates (UFCSPA-

Brazil/ City University of London)

Magdalen Old Law Library: single session 
Body11 Rethinking the anthropology of dance

Convenors: Hélène Neveu Kringelbach (University College London); Georgiana Gore

(University of Clermont Auvergne)

Discussant: Michael Houseman (Ecole Pratiques des Hautes Etudes, PSL)

Magdalen Oscar Wilde Room: first of three sessions

\section{Cog05 The evolutionary origins of ritual}

Convenors: Rohan Kapitany (University of Oxford); Harvey Whitehouse (Oxford

University)

Examination Schools Room 10: first of two sessions

Cre04 Recognition and innovation: how creativity is evaluated and envisaged Convenors: Iza Kavedzija (University of Exeter); Dolores Martinez (SOAS)

Examination Schools Room 8: first of three sessions

Cre08 Time and tradition: theorising the temporalities in and of cultural production

Convenors: Georgina Born (University of Oxford); Jonas Tinius (Humboldt-Universität zu Berlin)

Examination Schools East School: third of three sessions

Env04 Energising social worlds

Convenor: Ben Campbell (Durham University)

Examination Schools Room 12: single session

Env05 Towards an anthropology of un/making: affective encounters in abandonment, ruination, and creative destruction

Convenor: Arvid van Dam (University of Leeds)

Chair: Leila Dawney (University of Brighton)

Discussant: Yael Navaro-Yashin (Cambridge University)

Queen Elizabeth House (QEH) SR2: first of two sessions

Inf02 Logistics, time and environment

Convenors: Scott Lash (Oxford University); Sophie Haines (University of Oxford)

Discussant: Biao Xiang (Oxford University)

Examination Schools Room 9: first of two sessions

Inf03 Water futures: making a living in times of environmental uncertainty

Convenors: Tom Boyd (University of Manchester); Noah Walker-Crawford (University of

Manchester)

Discussant: Veronica Strang (Durham University)

Examination Schools Room 14: first of three sessions 
Lab09 Messy realities: the secret life of technology

Convenors: Gemma Hughes (University of Oxford); Caitlin Pilbeam (University of Oxford); Sara Shaw (University of Oxford)

Pitt Rivers Museum Main Gallery: first of three sessions

Lang03 Language, justice and belonging

Convenors: Kinga Kozminska (Birkbeck, University of London); Leonie Schulte (University of Oxford); Alessandro Duranti (UCLA); Nancy Hawker (University of Oxford); Rosemary Hall (University of Oxford)

Magdalen Lecture Room A: first of three sessions

Mor02 The moral language of economic imagination

Convenors: Patrice Ladwig (Max Planck Institute for the Study of Religious and Ethnic

Diversity); Patrick McKearney (University of Cambridge); Rachel Smith (Cambridge);

Anna-Riikka Kauppinen (University of Cambridge)

Chair: Laura Bear (London School of Economics)

Queen Elizabeth House (QEH) SR1: first of three sessions

Pol02 Imagining and creating walls, utopias, and co-fragile formations Convenors: Teruko Mitsuhara (University of California, Los Angeles); Matthew McCoy (Anthropology)

All Souls Wharton Room: first of three sessions

Pol04 Cosmopolitics of land: engagement and negotiation in the lived world Convenors: Susana Viegas (Institute of Social Sciences, University of Lisbon); Elizabeth Ewart (University of Oxford); Alejandro Reig (University Of Oxford)

All Souls Old Library: first of three sessions

Pol08 The humanitarian imagination: socialities and materialities of voluntarism Convenors: Tess Altman (University College London); Katerina Rozakou (University of Amsterdam)

Discussants: Mary Mostafanezhad (University of Hawaii at Manoa), Roger Norum Examination Schools Room 15: first of three sessions

Pol10 Dalits and other stigmatized groups: imagining changed lives and livelihoods

Convenors: Krishna Adhikari (University of Oxford); David Gellner (University of Oxford) Discussant: Clarinda Still (University of Oxford)

All Souls Hovenden Room: first of three sessions

Time01 Imagination, migration \& (im)mobility

Convenors: Ross Wignall (Oxford Brookes University); Thomas Chambers (Oxford Brookes University)

Examination Schools Room 7: first of three sessions 
Time02 Resource temporalities: anticipations, retentions and afterlives

Convenors: Kärg Kama (University of Birmingham); Gisa Weszkalnys (London School of Economics)

Examination Schools South School: first of three sessions

Time06 Aftermaths of disaster: individual/collective futures and the brutal logics of the past

Convenors: Mitchell W. Sedgwick (London School of Economics); Susanna Hoffman

(International Commission on Risk and Disaster)

Examination Schools Room 6: first of three sessions

\section{0:30-11:00}

\section{Refreshments}

Examination Schools, North School and marquee

\section{0:55-11:15}

\section{Walking to the Oxford University Natural History Museum}

Those going to Semi-plenary 2, please use this time to walk from the Examination Schools to the Oxford University Natural History Museum

\section{$11: 15-12: 45$}

\section{Semi-plenary 1 - Environmental imaginations}

Anthropocenic reconfigurations: re-imagining and re-enacting environment-health relations in a new era, by Melissa Leach (University of Sussex)

Chair: Laura Rival (University of Oxford)

Examination Schools, South School

\section{$11: 15-12: 45$}

\section{Semi-plenary 2 - Transformation and time}

Placing time, by Caitlin DeSilvey (University of Exeter)

Passing: duration, permanence and time, by Michael Rowlands (University College

London)

Chair: Dan Hicks (University of Oxford)

Oxford University Natural History Museum, Lecture Theatre

\section{2:45-14:15}

\section{Lunch}

Examination Schools, North School and marquee 
Heads of Departments (HODs) meeting

Examinations Schools Room 13

13:00-14:15

APPLY network meeting

Examination Schools Room 12

13:00-14:15

\#MeTooAnthro: Supporting students in the field

Examination Schools East School

14:15-15:45

\section{PANEL SESSION 4}

Ant04 Reimagining difference: diversity in anthropology

Convenors: Alice Elliot (Goldsmiths, University of London); Alison Macdonald (UCL)

Examination Schools Room 11: second of two sessions

Body01 Skills of feeling with the world: affective imagination, embodied memories and materiality in the emergence of sociality

Convenors: Andrea De Antoni (Ritsumeikan University); Emma Cook (Hokkaido

University)

Magdalen Summer Common Room: second of three sessions

Body02 Yoga bodies and the transformation of the self

Convenors: Alison Shaw (Oxford University); Esra Kaytaz (Coventry University)

Magdalen Daubeny: second of three sessions

Body11 Rethinking the anthropology of dance

Convenors: Hélène Neveu Kringelbach (University College London); Georgiana Gore

(University of Clermont Auvergne)

Discussant: Michael Houseman (Ecole Pratiques des Hautes Etudes, PSL)

Magdalen Oscar Wilde Room: second of three sessions

Cog05 The evolutionary origins of ritual

Convenors: Rohan Kapitany (University of Oxford); Harvey Whitehouse (Oxford

University)

Examination Schools Room 10: second of two sessions 
Cre04 Recognition and innovation: how creativity is evaluated and envisaged Convenors: Iza Kavedzija (University of Exeter); Dolores Martinez (SOAS)

Examination Schools Room 8: second of three sessions

Env05 Towards an anthropology of un/making: affective encounters in abandonment, ruination, and creative destruction

Convenor: Arvid van Dam (University of Leeds)

Chair: Leila Dawney (University of Brighton)

Discussant: Yael Navaro-Yashin (Cambridge University)

Queen Elizabeth House (QEH) SR2: second of two sessions

\section{Inf02 Logistics, time and environment}

Convenors: Scott Lash (Oxford University); Sophie Haines (University of Oxford)

Discussant: Biao Xiang (Oxford University)

Examination Schools Room 9: second of two sessions

Inf03 Water futures: making a living in times of environmental uncertainty

Convenors: Tom Boyd (University of Manchester); Noah Walker-Crawford (University of Manchester)

Discussant: Veronica Strang (Durham University)

Examination Schools Room 14: second of three sessions

Lab03 Caring in movement: anthropology as contemplation

Convenors: Krzysztof Bierski (Durham University); Elizabeth Rahman (University of

Oxford); Paolo Maccagno (University of Aberdeen)

Examination Schools East School: single session

Lab10 Listening and performing together: emotions, experience, and ethnopoetry Convenor: Asif Majid (The University of Manchester)

Pitt Rivers Museum Seminar Room: single session

Lab13 Imagination and materiality: exploring geometry through the making of fabric bowls

Convenors: Ricardo Nemirovsky (MMU); Tam Dibley (Manchester Metropolitan

University)

Pitt Rivers Museum Lecture Theatre: single session

Lang03 Language, justice and belonging

Convenors: Kinga Kozminska (Birkbeck, University of London); Leonie Schulte (University of Oxford); Alessandro Duranti (UCLA); Nancy Hawker (University of Oxford); Rosemary Hall (University of Oxford)

Magdalen Lecture Room A: second of three sessions 
Mor02 The moral language of economic imagination

Convenors: Patrice Ladwig (Max Planck Institute for the Study of Religious and Ethnic Diversity); Patrick McKearney (University of Cambridge); Rachel Smith (Cambridge); Anna-Riikka Kauppinen (University of Cambridge)

Chair: Laura Bear (London School of Economics)

Queen Elizabeth House (QEH) SR1: second of three sessions

Pol02 Imagining and creating walls, utopias, and co-fragile formations Convenors: Teruko Mitsuhara (University of California, Los Angeles); Matthew McCoy (Anthropology)

All Souls Wharton Room: second of three sessions

Pol04 Cosmopolitics of land: engagement and negotiation in the lived world Convenors: Susana Viegas (Institute of Social Sciences, University of Lisbon); Elizabeth Ewart (University of Oxford); Alejandro Reig (University Of Oxford)

All Souls Old Library: second of three sessions

Pol08 The humanitarian imagination: socialities and materialities of voluntarism Convenors: Tess Altman (University College London); Katerina Rozakou (University of Amsterdam)

Discussants: Mary Mostafanezhad (University of Hawaii at Manoa), Roger Norum Examination Schools Room 15: second of three sessions

Pol10 Dalits and other stigmatized groups: imagining changed lives and livelihoods

Convenors: Krishna Adhikari (University of Oxford); David Gellner (University of Oxford) Discussant: Clarinda Still (University of Oxford)

All Souls Hovenden Room: second of three sessions

Time01 Imagination, migration \& (im)mobility

Convenors: Ross Wignall (Oxford Brookes University); Thomas Chambers (Oxford Brookes University)

Examination Schools Room 7: second of three sessions

Time02 Resource temporalities: anticipations, retentions and afterlives Convenors: Kärg Kama (University of Birmingham); Gisa Weszkalnys (London School of Economics)

Examination Schools South School: second of three sessions

Time06 Aftermaths of disaster: individual/collective futures and the brutal logics of the past

Convenors: Mitchell W. Sedgwick (London School of Economics); Susanna Hoffman

(International Commission on Risk and Disaster)

Examination Schools Room 6: second of three sessions 


\section{5:45-16:15}

\section{Refreshments}

Examination Schools, North Schools and marquee

\section{6:15-17:45}

Film screening: The block/Blocul, by Maria Salaru (Durham University)

Convenor: Marcus Banks (University of Oxford)

Pitt Rivers Museum Lecture Theatre

\section{6:15-17:45}

\section{PANEL SESSION 5}

Body01 Skills of feeling with the world: affective imagination, embodied memories and materiality in the emergence of sociality

Convenors: Andrea De Antoni (Ritsumeikan University); Emma Cook (Hokkaido

University)

Magdalen Summer Common Room: third of three sessions

Body02 Yoga bodies and the transformation of the self Convenors: Alison Shaw (Oxford University); Esra Kaytaz (Coventry University) Magdalen Daubeny: third of three sessions

Body11 Rethinking the anthropology of dance

Convenors: Hélène Neveu Kringelbach (University College London); Georgiana Gore

(University of Clermont Auvergne)

Discussant: Michael Houseman (Ecole Pratiques des Hautes Etudes, PSL)

Magdalen Oscar Wilde Room: third of three sessions

Cog07 Throwing together ways of being/meaning: recursive anthropology at the cusp of a paradigm change [Roundtable]

Convenor: César Enrique Giraldo Herrera (University of Oxford)

Discussant: Tim Ingold (University of Aberdeen)

Examination Schools Room 10: single session

Cre04 Recognition and innovation: how creativity is evaluated and envisaged Convenors: Iza Kavedzija (University of Exeter); Dolores Martinez (SOAS)

Examination Schools Room 8: third of three sessions

Cre07 Blending, meaning and imagination

Convenors: Jordi Vallverdu (Universitat Autònoma de Barcelona); David Eubelen

(Université Libre de Bruxelles); Corentin Chanet (ULB (Université Libre de Bruxelles))

Examination Schools Room 9: single session 
Daily timetable: Wednesday 19th September

Env13 Vectors of latent potential: material traces' unpredictable futures Convenors: Caitlin DeSilvey (University of Exeter); Paul Wenzel Geissler (University of Oslo)

Discussant: Penny Harvey (University of Manchester)

Examination Schools Room 11: first of three sessions (two sessions on Thu 20th Sept)

Env15 Coastal encounters: temporality, memory and morality

Convenors: Nadine Beckmann (University of Roehampton); Ana Santos (Roehampton

University)

Queen Elizabeth House (QEH) SR2: single session

Inf03 Water futures: making a living in times of environmental uncertainty Convenors: Tom Boyd (University of Manchester); Noah Walker-Crawford (University of Manchester)

Discussant: Veronica Strang (Durham University)

Examination Schools Room 14: third of three sessions

Lab06 Citizens of photography: the camera and the political imagination Convenors: Sokphea Young (University College London); Christopher Pinney (University College, London); Konstantinos Kalantzis (University College, London); Ileana Lucia Selejan (University College London); Naluwembe Binaisa (University College London); Vindhya Buthpitiya (UCL)

Examination Schools East School: single session

Lab08 People-centred development: what is a meter?

Convenors: Maria Salaru (Durham University); Simone Abram (Durham University);

Hannah Knox (University College London)

58 Banbury Road, COMPAS visitors' room: single session

Lang03 Language, justice and belonging

Convenors: Kinga Kozminska (Birkbeck, University of London); Leonie Schulte (University of Oxford); Alessandro Duranti (UCLA); Nancy Hawker (University of Oxford); Rosemary Hall (University of Oxford)

Magdalen Lecture Room A: third of three sessions

Med02 Embodied ecologies: materiality, environments, and health Convenor: Andrea Ford (University of Chicago)

Discussant: Theresia Hofer (University of Bristol)

Magdalen Old Law Library: single session 
Mor02 The moral language of economic imagination

Convenors: Patrice Ladwig (Max Planck Institute for the Study of Religious and Ethnic Diversity); Patrick McKearney (University of Cambridge); Rachel Smith (Cambridge); Anna-Riikka Kauppinen (University of Cambridge)

Chair: Laura Bear (London School of Economics) Queen Elizabeth House (QEH) SR1: third of three sessions

Pol02 Imagining and creating walls, utopias, and co-fragile formations Convenors: Teruko Mitsuhara (University of California, Los Angeles); Matthew McCoy (Anthropology)

All Souls Wharton Room: third of three sessions

Pol04 Cosmopolitics of land: engagement and negotiation in the lived world Convenors: Susana Viegas (Institute of Social Sciences, University of Lisbon); Elizabeth Ewart (University of Oxford); Alejandro Reig (University Of Oxford)

All Souls Old Library: third of three sessions

Pol08 The humanitarian imagination: socialities and materialities of voluntarism Convenors: Tess Altman (University College London); Katerina Rozakou (University of Amsterdam)

Discussants: Mary Mostafanezhad (University of Hawaii at Manoa), Roger Norum Examination Schools Room 15: third of three sessions

Pol10 Dalits and other stigmatized groups: imagining changed lives and livelihoods

Convenors: Krishna Adhikari (University of Oxford); David Gellner (University of Oxford) Discussant: Clarinda Still (University of Oxford)

All Souls Hovenden Room: third of three sessions

\section{Time01 Imagination, migration \& (im)mobility}

Convenors: Ross Wignall (Oxford Brookes University); Thomas Chambers (Oxford Brookes University)

Examination Schools Room 7: third of three sessions

Time02 Resource temporalities: anticipations, retentions and afterlives Convenors: Kärg Kama (University of Birmingham); Gisa Weszkalnys (London School of Economics)

Examination Schools South School: third of three sessions

Time06 Aftermaths of disaster: individual/collective futures and the brutal logics of the past

Convenors: Mitchell W Sedgwick (London School of Economics); Susanna Hoffman

(International Commission on Risk and Disaster)

Examination Schools Room 6: third of three sessions 
Roundtable: Anthropology and the imagination

Participants: Dolores Martinez (University of Oxford), Tim Ingold (University of Aberdeen), Lisette Josephides (Queen's University Belfast), Peter Pels (Leiden University)

Examination Schools, South School

\section{Thursday 20th September}

Throughout the day

Exhibition: Uganda Stories, by Sunil Shah

Special Exhibition Gallery, Pitt Rivers Museum

Throughout the day

Exhibition: Performing Tibetan Identities, by Nyema Droma

In the Court and Clore Balcony of the Pitt Rivers Museum

Throughout the day

Exhibition: Diversifying Portraiture in Anthropology, curated by Helen Worrell

Examinations Schools

Throughout the day

Exhibition: The Legend of Ponnivala Nadu, by Brenda Beck

Examinations Schools

08:00-16:15

Registration desk open

Examinations Schools

09:00-10:30

\section{PANEL SESSION 6}

Ant02 \#MeTooAnthro: sexual assault and harassment in anthropology

Convenor: Esther Anderson (University of Southern Queensland)

Examination Schools Room 6: first of two sessions 
Ant06 Ethical research and ethical review

Convenors: Jude Robinson (University of Liverpool); Bob Simpson (Durham University); Margaret Sleeboom-Faulkner (University of Sussex)

Examination Schools South School: single session

Body03 Corporeality \& material ecology: the affordances of stuff and wellbeing Convenors: Kelly Fagan Robinson (UCL); Timothy Carroll (UCL)

Magdalen Old Law Library: first of two sessions

Body05 Problematizing humanity: creative bodies and spirits

Convenors: Mally Stelmaszyk (University of Edinburgh); Alysa Ghose (University of

Edinburgh)

Magdalen Summer Common Room: first of two sessions

Cog01 Locating the mind: social and material agencies in the matter of the mind Convenors: Veronica Strang (Durham University); Robert Barton (Durham University)

Discussant: Noah Walker-Crawford (The University of Manchester)

Examination Schools Room 10: single session

Cre05 Making accounts count: imagination, creativity, and (in)coherence

Convenors: Christina Woolner (University of Cambridge), Rosie Jones McVey (University of Cambridge), Amy Binning (University of Cambridge)

Chair: Alessandro Duranti (UCLA)

Examination Schools Room 9: first of two sessions

Cre06 Creativity in crisis: arts in the age of austerity

Convenors: Ioannis Tsioulakis (Queen's University, Belfast); Evropi Chatzipanagiotidou

(Queen's University Belfast); Fiona Murphy (Queens University Belfast)

Examination Schools Room 8: first of two sessions

Env02 Dirty stories: towards an narrativist anthropology of pollution

Convenors: Mary Mostafanezhad (University of Hawaii at Manoa); Roger Norum

Discussant: Anna Lora-Wainwright (University of Oxford)

Queen Elizabeth House (QEH) SR2: first of three sessions (third session on Fri 21 th Sept, 09:00-10:30)

Env03 Tower block failures: high-rise anthropology

Convenors: Constance Smith (University of Manchester); Saffron Woodcraft (UCL)

Discussant: Gillian Evans (University of Manchester)

Examination Schools Room 15: first of two sessions

Env13 Vectors of latent potential: material traces' unpredictable futures

Convenors: Caitlin DeSilvey (University of Exeter); Paul Wenzel Geissler (University of Oslo)

Discussant: Penny Harvey (University of Manchester)

Examination Schools Room 11: second of three sessions 
Inf04 Towards computing anthropology: imagination, cooperation, and future infrastructures of trust

Convenors: Roxana Moroşanu Firth (University of Cambridge); Razvan Nicolescu (Imperial College London)

Discussant: Kathleen Richardson (Centre for Computing and Social Responsibility, De

Montfort University)

All Souls Old Library: first of two sessions

Inf05 The sociality of taxes: state-citizen imaginaries

Convenors: Robin Smith (Leiden University); Nicolette Makovicky (University of Oxford)

Discussant: Lotta Björklund Larsen (Linköping University)

Examination Schools Room 14: single session

Lab11 From postcards to Instagram: image, text and social media

Convenors: Stephen Hughes (SOAS); Emily Stevenson (SOAS)

Examination Schools Room 12: single session

Lab15 The geometry of a single line

Convenor: Jaime Refoyo

Pitt Rivers Museum Lecture Theatre: single session

Med05 Understanding health workers at the interface of community and development

Convenors: Juli Huang (LSE); Jeevan Sharma (University of Edinburgh); Sumeet Jain

(University of Edinburgh); Ian Harper (University of Edinburgh)

Magdalen Oscar Wilde Room: first of two sessions

Med06 Hermeneutical injustice, clinical imagination and patient discontent in mental healthcare

Convenors: Edward Harcourt (University of Oxford); Neil Armstrong (Magdalen College, Oxford)

Magdalen Daubeny: single session

\section{Med08 Movement for mental health}

Convenors: Eline Kieft (Coventry University); Elisabeth Hsu (University of Oxford); Paola Esposito (University of Oxford)

Magdalen Lecture Room A: first of two sessions

Mor05 Valences of sociality: unpacking sociality through values

Convenor: Kenneth Sillander (University of Helsinki)

Chair: Signe Howell (University of Oslo)

Discussant: Harry Walker (London School of Economics and Political Science)

Queen Elizabeth House (QEH) SR1: first of two sessions 
Pol01 From managed change to utopian disjuncture: socio-environmental transitions in a fluctuating world

Convenors: Agustin Diz (London School of Economics); Andrea Enrico Pia (London School of Economics)

Examination Schools Room 7: single session

Pol03 On anthropological frontiers: divisions and intersections between environment, personhood and sociality

Convenors: Julia Sauma (University of Bergen); Antonia Walford (University College

London/University of Copenhagen); Lewis Daly (University College London)

All Souls Wharton Room: first of two sessions

Time04 Insuring inbetween governing and being governed, for crisis of today and catastrophic future

Convenors: Irmelin Joelson (University of Oxford); Marissa Smith (San Jose State

University)

Examination Schools East School: first of two sessions

10:30-11:00

Refreshments

Examination Schools, North School and marquee

\section{0:55-11:15}

\section{Walking to the Oxford University Natural History Museum}

Those going to Semi-plenary 3, please use this time to walk from the Examination

Schools to the Oxford University Natural History Museum

\section{1:15-12:45}

Semi-plenary 3 - Creative bodies

The light of the piece: an exploration of materiality and creative practice in a Maine landscape, by Anna Grimshaw (Emory University)

Chair: Elizabeth Hallam (University of Oxford)

Oxford University Natural History Museum, Lecture theatre

\section{1:15-12:45}

Semi-plenary 4 - Language and imagination

Failures in intersubjective attunement and their implications for a theory of collective action, by Alessandro Duranti (University of California, Los Angeles) Chairs: Ramon Sarró (University of Oxford) and David Zeitlyn (University of Oxford) Examination Schools South School 
Lunch

Examination Schools North School and marquee

13:00-14:15

ASA's Annual General Meeting

Examination Schools South School

14:15-15:45

Film screening: Nightfall on Gaia, by Juan Francisco Salazar (Western Sydney University)

Convenor: Marcus Banks (University of Oxford)

Pitt Rivers Museum Lecture Theatre

14:15-15:45

\section{PANEL SESSION 7}

Ant02 \#MeTooAnthro: sexual assault and harassment in anthropology

Convenor: Esther Anderson (University of Southern Queensland)

Examination Schools Room 6: second of two sessions

Body03 Corporeality \& material ecology: the affordances of stuff and wellbeing Convenors: Kelly Fagan Robinson (UCL); Timothy Carroll (UCL)

Magdalen Old Law Library: second of two sessions

Body05 Problematizing humanity: creative bodies and spirits

Convenors: Mally Stelmaszyk (University of Edinburgh); Alysa Ghose (University of

Edinburgh)

Magdalen Summer Common Room: second of two sessions

Body07 Animals' matter: anthropological conceptions of animal bodies as material Convenors: Eimear Mc Loughlin (University of Exeter); Julien Dugnoille (University of

Exeter); Elizabeth Vander Meer (University of Exeter)

Magdalen Daubeny: single session

Cog04 Laughter, bodies and the evolution of morality

Convenors: Camilla Power (University of East London); Morna Finnegan

Examination Schools Room 10: single session 
Cre05 Making accounts count: imagination, creativity, and (in)coherence Convenors: Christina Woolner (University of Cambridge), Rosie Jones McVey (University of Cambridge), Amy Binning (University of Cambridge)

Chair: Alessandro Duranti (UCLA)

Examination Schools Room 9: second of two sessions

Cre06 Creativity in crisis: arts in the age of austerity

Convenors: Ioannis Tsioulakis (Queen's University, Belfast); Evropi Chatzipanagiotidou

(Queen's University Belfast); Fiona Murphy (Queens University Belfast)

Examination Schools Room 8: second of two sessions

Env02 Dirty stories: towards an narrativist anthropology of pollution Convenors: Mary Mostafanezhad (University of Hawaii at Manoa); Roger Norum

Discussant: Anna Lora-Wainwright (University of Oxford)

Queen Elizabeth House (QEH) SR2: second of three sessions (third session on Fri 21th Sept, 09:00-10:30)

\section{Env03 Tower block failures: high-rise anthropology}

Convenors: Constance Smith (University of Manchester); Saffron Woodcraft (UCL)

Discussant: Gillian Evans (University of Manchester)

Examination Schools Room 15: second of two sessions

Env11 Sensing and making with microbial worlds: anthropological engagements with microorganisms

Convenors: Elise Demeulenaere (CNRS); Germain Meulemans (Centre Alexandre Koyré)

Discussant: Jamie Lorimer (University of Oxford)

Examination Schools Room 7: single session

Env13 Vectors of latent potential: material traces' unpredictable futures

Convenors: Caitlin DeSilvey (University of Exeter); Paul Wenzel Geissler (University of Oslo)

Discussant: Penny Harvey (University of Manchester)

Examination Schools Room 11: thirds of three sessions

Inf04 Towards computing anthropology: imagination, cooperation, and future infrastructures of trust

Convenors: Roxana Moroșanu Firth (University of Cambridge); Razvan Nicolescu (Imperial College London)

Discussant: Kathleen Richardson (Centre for Computing and Social Responsibility, De Montfort University)

All Souls Old Library: second of two sessions 
Inf06 The times of infrastructure

Convenors: Luke Heslop (London School of Economics); Elisa Tamburo (SOAS, University of London)

Discussants: Laura Bear (London School of Economics and Political Science), Edward Simpson (SOAS)

Examination Schools Room 14: third of three sessions

Lab04 Envisioning ethnographies of the future: lab exercises for the imagination Convenor: Jessica Symons (University of Manchester)

Examination Schools South School: single session

\section{Lab16 Data objects re-designed}

Convenor: Polly Macpherson (University of Plymouth)

Pitt Rivers Museum Seminar Room: single session

Med05 Understanding health workers at the interface of community and development

Convenors: Juli Huang (LSE); Jeevan Sharma (University of Edinburgh); Sumeet Jain

(University of Edinburgh); Ian Harper (University of Edinburgh)

Magdalen Oscar Wilde Room: second of two sessions

\section{Med08 Movement for mental health}

Convenors: Eline Kieft (Coventry University); Elisabeth Hsu (University of Oxford); Paola Esposito (University of Oxford)

Magdalen Lecture Room A: second of two sessions

Mor05 Valences of sociality: unpacking sociality through values

Convenor: Kenneth Sillander (University of Helsinki)

Chair: Signe Howell (University of Oslo)

Discussant: Harry Walker (London School of Economics and Political Science)

Queen Elizabeth House (QEH) SR1: second of two sessions

Pol03 On anthropological frontiers: divisions and intersections between environment, personhood and sociality

Convenors: Julia Sauma (University of Bergen); Antonia Walford (University College

London/University of Copenhagen); Lewis Daly (University College London)

All Souls Wharton Room: second of two sessions

Time04 Insuring inbetween governing and being governed, for crisis of today and catastrophic future

Convenors: Irmelin Joelson (University of Oxford); Marissa Smith (San Jose State

University)

Examination Schools East School: second of two sessions 


\section{5:45-16:15}

\section{Refreshments}

Examination Schools, North School and marquee

\section{6:15-17:45}

\section{Roundtable: Interdisciplinarity}

Participants: Charlotte Roberts (Durham University), Sarah White (University of Bath), Chris Gosden (University of Oxford), David Shankland (Royal Anthropological Institute)

Chair: Nigel Rapport (St. Andrews University)

Examination Schools, South School

\section{9:00-21:00}

\section{Conference dinner}

Dining Hall of Keble College, Parks Road, Oxford, OX1 3PG

\section{1:00-23:00}

Conference dance in Keble bar

Dining Hall of Keble College, Parks Road, Oxford, OX1 3PG

\section{Friday 21st September}

\section{Throughout the day}

Exhibition: Uganda Stories, by Sunil Shah

Special Exhibition Gallery, Pitt Rivers Museum

\section{Throughout the day}

Exhibition: Performing Tibetan Identities, by Nyema Droma

In the Court and Clore Balcony of the Pitt Rivers Museum

\section{Throughout the day}

Exhibition: Diversifying Portraiture in Anthropology, curated by Helen Worrell

Examinations Schools 
Exhibition: The Legend of Ponnivala Nadu, by Brenda Beck

Examinations Schools

08:00-16:15

Registration desk open

Examination Schools

09:00-10:30

Debate: Morality and evolution, part 1

Participants: Oliver Scott Curry (University of Oxford), Mark Alfano (University of Delft), Soumhya Venkatesan (University of Manchester), Jo Cook (UCL)

Examination Schools, South School

09:00-10:30

\section{PANEL SESSION 8}

Ant03 The new ethnographer: contemporary challenges in anthropological research

Convenors: Branwen Spector (London School of Economics); Caitlin Procter (University of Oxford)

Examination Schools Room 11: single session

\section{Cog02 Creative environments, social minds}

Convenors: Kåre Poulsgaard (University of Oxford); Chris Goldsworthy (University of Oxford)

Chair: Lambros Malafouris (University of Oxford)

Discussant: João de Pina-Cabral (University of Kent)

Examination Schools Room 10: first of three sessions

\section{Cre01 Anthropology of light: art, skill and practices}

Convenors: Cathy Greenhalgh (Central Saint Martins, University of the Arts London); Eni Bankole-Race (Royal College of Art); Lucy Williams (University of the West of England) Examination Schools Room 9: first of two sessions

\section{Cre09 Sounding and performing resistance and resilience}

Convenors: Hastings Donnan (Queen's University of Belfast); Fiona Magowan (Queen's University Belfast)

Examination Schools Room 8: first of two sessions 
Env02 Dirty stories: towards an narrativist anthropology of pollution Convenors: Mary Mostafanezhad (University of Hawaii at Manoa); Roger Norum Discussant: Anna Lora-Wainwright (University of Oxford) Queen Elizabeth House (QEH) SR2: third of three sessions

Env06 Geometry and anthropology: description, projection, and measurement Convenor: Ray Lucas (University of Manchester)

Discussant: Tim Ingold (University of Aberdeen)

Queen Elizabeth House (QEH) SR1: first of two sessions

Env07 Constructing conservation narratives: indigenous imaginings and environmental changes

Convenors: Lydia Gibson (UCL); Sahil Nijhawan (University College London (UCL))

Discussants: Survival International, Amy Dickman (University of Oxford), Sarah Durant (Zoological Society of London)

Examination Schools Room 12: first of two sessions

\section{Env09 Ethnographic Cli-fi in the 'New Pangea'}

Convenors: Pavel Borecký (University of Bern); Blake Kendall (Freie Universitat Berlin)

Examination Schools Room 15: single session

Lab12 Learning from art practices?

Convenors: Alex Flynn (Durham University); Giulia Battaglia (EHESS/Paris 3)

Examination Schools Room 14: first of three sessions

Lang01 Semiosis as orchestration

Convenors: David Parkin (Oxford University); Theresia Hofer (University of Bristol); Alex Pillen (DR)

Discussant: Adam Kendon (University College London)

Magdalen Lecture Room A: first of three sessions

Med01 When psychotherapy goes awry: theorising the unexpected in therapeutic encounters

Convenor: Nicholas Long (London School of Economics and Political Science) Magdalen Daubeny: first of two sessions

Med03 Food as medicine: biosocialities of eating in health and illness Convenors: Anna Lavis (University of Birmingham); Heather Howard (Michigan State University); Narelle Warren (Monash University); Karin Eli (University of Oxford) Magdalen Oscar Wilde Room: first of three sessions

Pol05 For an anthropology of political ideas

Convenors: Anastasia Piliavsky (University of Cambridge); Judith Scheele (Zentrum Moderner Orient)

Examination Schools Room 6: first of three sessions 
Pol06 Diagrams of revolution: an experiment with social and material morphologies

Convenor: Martin Holbraad (University College, London)

Examination Schools East School: first of three sessions

Pol11 Conviviality and religious coexistence: theoretical and comparative persectives

Convenors: Ruy Blanes (University of Gothenburg/Spanish National Research Council); José Mapril (Universidade Nova de Lisboa and Center for Research in Anthropology (CRIA));

Ambra Formenti (FCSH/NOVA)

Discussant: Ramon Sarró (University of Oxford)

Examination Schools Room 7: first of three sessions

Pol12 The good in 'bad Buddhism: beyond ancient wisdom for contemporary woes Convenors: Melyn McKay (University of Oxford); Hannah Gould (The University of Melbourne)

All Souls Old Library: first of three sessions

\section{Time03 Chronotopic materialities}

Convenors: Safet HadziMuhamedovic (University of Bristol); Magdalena Buchczyk

(University of Bristol)

Discussant: Tom Selwyn (SOAS University of London)

Magdalen Old Law Library: first of three sessions

Time05 Temporalities of work, money, and fantasy

Convenors: Patrick Alexander (Oxford Brookes University); John Loewenthal (Oxford Brookes University)

Magdalen Summer Common Room: first of three sessions

10:30-11:00

\section{Refreshments}

Examination Schools, North School and marquee

Debate: Morality and evolution, part 2

Participants: Oliver Scott Curry (University of Oxford), Mark Alfano (University of Delft), Soumhya Venkatesan (University of Manchester), Jo Cook (UCL)

Examination Schools, South School 


\section{PANEL SESSION 9}

Cog02 Creative environments, social minds

Convenors: Kåre Poulsgaard (University of Oxford); Chris Goldsworthy (University of Oxford)

Chair: Lambros Malafouris (University of Oxford)

Discussant: João de Pina-Cabral (University of Kent)

Examination Schools Room 10: second of three sessions

\section{Cre01 Anthropology of light: art, skill and practices}

Convenors: Cathy Greenhalgh (Central Saint Martins, University of the Arts London); Eni Bankole-Race (Royal College of Art); Lucy Williams (University of the West of England) Examination Schools Room 9: second of two sessions

\section{Cre09 Sounding and performing resistance and resilience}

Convenors: Hastings Donnan (Queen's University of Belfast); Fiona Magowan (Queen's University Belfast)

Examination Schools Room 8: second of two sessions

\section{Env06 Geometry and anthropology: description, projection, and measurement} Convenor: Ray Lucas (University of Manchester)

Discussant: Tim Ingold (University of Aberdeen)

Queen Elizabeth House (QEH) SR1: second of two sessions

\section{Env07 Constructing conservation narratives: indigenous imaginings and environmental changes \\ Convenors: Lydia Gibson (UCL); Sahil Nijhawan (University College London (UCL)) \\ Discussants: Survival International, Amy Dickman (University of Oxford), Sarah Durant (Zoological Society of London) \\ Examination Schools Room 12: second of two sessions}

\section{Env08 Emptiness: experiences, perceptions, and temporalities}

Convenors: Dace Dzenovska (University of Oxford); Andreza Aruska De Souza Santos (University of Oxford)

Chair: Daniel Knight (University of St. Andrews)

Discussants: Session 1 - Daniel Knight (University of St. Andrews, Session 2 - Jeremy

MacClancy (Oxford Brookes University)

Queen Elizabeth House (QEH) SR2: first of two sessions

Env10 Closed loops, loopholes, and profit: interpreting geographical imaginaries of material conversion

Convenors: Yvan Schulz (University of Oxford); Peter Kirby (University of Oxford); Anna Lora-Wainwright (University of Oxford)

Examination Schools Room 15: first of two sessions 
Lab12 Learning from art practices?

Convenors: Alex Flynn (Durham University); Giulia Battaglia (EHESS/Paris 3)

Examination Schools Room 14: second of three sessions

Lang01 Semiosis as orchestration

Convenors: David Parkin (Oxford University); Theresia Hofer (University of Bristol); Alex Pillen (DR)

Discussant: Adam Kendon (University College London)

Magdalen Lecture Room A: second of three sessions

Med01 When psychotherapy goes awry: theorising the unexpected in therapeutic encounters

Convenor: Nicholas Long (London School of Economics and Political Science)

Magdalen Daubeny: second of two sessions

Med03 Food as medicine: biosocialities of eating in health and illness

Convenors: Anna Lavis (University of Birmingham); Heather Howard (Michigan State

University); Narelle Warren (Monash University); Karin Eli (University of Oxford)

Magdalen Oscar Wilde Room: second of three sessions

Pol05 For an anthropology of political ideas

Convenors: Anastasia Piliavsky (University of Cambridge); Judith Scheele (Zentrum

Moderner Orient)

Examination Schools Room 6: second of three sessions

Pol06 Diagrams of revolution: an experiment with social and material morphologies

Convenor: Martin Holbraad (University College, London)

Examination Schools East School: second of three sessions

Pol11 Conviviality and religious coexistence: theoretical and comparative persectives

Convenors: Ruy Blanes (University of Gothenburg/Spanish National Research Council); José Mapril (Universidade Nova de Lisboa and Center for Research in Anthropology (CRIA));

Ambra Formenti (FCSH/NOVA)

Discussant: Ramon Sarró (University of Oxford)

Examination Schools Room 7: second of three sessions

Pol12 The good in 'bad Buddhism: beyond ancient wisdom for contemporary woes Convenors: Melyn McKay (University of Oxford); Hannah Gould (The University of Melbourne)

All Souls Old Library: second of three sessions 


\section{Time03 Chronotopic materialities}

Convenors: Safet HadziMuhamedovic (University of Bristol); Magdalena Buchczyk (University of Bristol)

Discussant: Tom Selwyn (SOAS University of London)

Magdalen Old Law Library: second of three sessions

Time05 Temporalities of work, money, and fantasy

Convenors: Patrick Alexander (Oxford Brookes University); John Loewenthal (Oxford

Brookes University)

Magdalen Summer Common Room: second of three sessions

\section{2:30-14:00}

\section{Lunch}

Examination Schools, North School and marquee

\section{4:00-15:30}

\section{Closing keynote}

Anthropology and psychology: finding common grounds, by Rita Astuti (LSE)

Chair: Harvey Whitehouse (University of Oxford)

Examination Schools, South School

\section{5:30-16:00}

\section{Refreshments}

Examination Schools, North School and marquee

\section{$16: 00-17: 30$}

\section{PANEL SESSION 10}

\section{Ant05 One discipline or many?}

Convenors: David Shankland (Royal Anthropological Institute)

Examination Schools Room 11: single session

\section{Cog02 Creative environments, social minds}

Convenors: Kåre Poulsgaard (University of Oxford); Chris Goldsworthy (University of

Oxford)

Chair: Lambros Malafouris (University of Oxford)

Discussant: João de Pina-Cabral (University of Kent)

Examination Schools Room 10: third of three sessions 
Cre02 Tracking bodies, tracking relationships: from self-control to quantified subjectivities and creative communities

Convenors: Michael Crawley (Edinburgh University); Alexandra Oanca (Universidade do

Vale do Taquari - Univates)

Examination Schools Room 8: single session

Env08 Emptiness: experiences, perceptions, and temporalities

Convenors: Dace Dzenovska (University of Oxford); Andreza Aruska De Souza Santos

(University of Oxford)

Chair: Daniel Knight (University of St. Andrews)

Discussants: Session 1 - Daniel Knight (University of St. Andrews, Session 2 - Jeremy

MacClancy (Oxford Brookes University)

Queen Elizabeth House (QEH) SR2: second of two sessions

Env10 Closed loops, loopholes, and profit: interpreting geographical imaginaries of material conversion

Convenors: Yvan Schulz (University of Oxford); Peter Kirby (University of Oxford); Anna Lora-Wainwright (University of Oxford)

Examination Schools Room 15: second of two sessions

Lab12 Learning from art practices?

Convenors: Alex Flynn (Durham University); Giulia Battaglia (EHESS/Paris 3)

Examination Schools Room 14: third of three sessions

Lab17 Crafting non-human characters: unorthodox vistas for ethnographic film Convenors: Pedro Afonso Branco Ramos Pinto (University of Brasília); Guilherme Moura Fagundes (Universidade de Brasília)

Pitt Rivers Museum Lecture Theatre: single session

Lang01 Semiosis as orchestration

Convenors: David Parkin (Oxford University); Theresia Hofer (University of Bristol); Alex Pillen (DR)

Discussant: Adam Kendon (University College London)

Magdalen Lecture Room A: third of three sessions

Med03 Food as medicine: biosocialities of eating in health and illness

Convenors: Anna Lavis (University of Birmingham); Heather Howard (Michigan State

University); Narelle Warren (Monash University); Karin Eli (University of Oxford)

Magdalen Oscar Wilde Room: third of three sessions

Mor01 Objects of mistrust. The relationship between material environment, culture, and beliefs

Convenor: Radu Umbres (Faculty of Political Sciences, SNSPA)

Examination Schools Room 9: single session 
Mor04 Rules, ethics, and the everyday

Convenors: Morgan Clarke (University of Oxford); Fernanda Pirie (University of Oxford) Magdalen Daubeny: single session

\section{Pol05 For an anthropology of political ideas}

Convenors: Anastasia Piliavsky (University of Cambridge); Judith Scheele (Zentrum

Moderner Orient)

Examination Schools Room 6: third of three sessions

Pol06 Diagrams of revolution: an experiment with social and material morphologies

Convenor: Martin Holbraad (University College, London)

Examination Schools East School: third of three sessions

\section{Pol11 Conviviality and religious coexistence: theoretical and comparative} persectives

Convenors: Ruy Blanes (University of Gothenburg/Spanish National Research Council); José Mapril (Universidade Nova de Lisboa and Center for Research in Anthropology (CRIA)); Ambra Formenti (FCSH/NOVA)

Discussant: Ramon Sarró (University of Oxford)

Examination Schools Room 7: third of three sessions

Pol12 The good in 'bad Buddhism: beyond ancient wisdom for contemporary woes Convenors: Melyn McKay (University of Oxford); Hannah Gould (The University of Melbourne)

All Souls Old Library: third of three sessions

\section{Time03 Chronotopic materialities}

Convenors: Safet HadziMuhamedovic (University of Bristol); Magdalena Buchczyk

(University of Bristol)

Discussant: Tom Selwyn (SOAS University of London)

Magdalen Old Law Library: third of three sessions

\section{Time05 Temporalities of work, money, and fantasy}

Convenors: Patrick Alexander (Oxford Brookes University); John Loewenthal (Oxford Brookes University)

Magdalen Summer Common Room: third of three sessions 


\section{Plenaries, roundtables and debates}

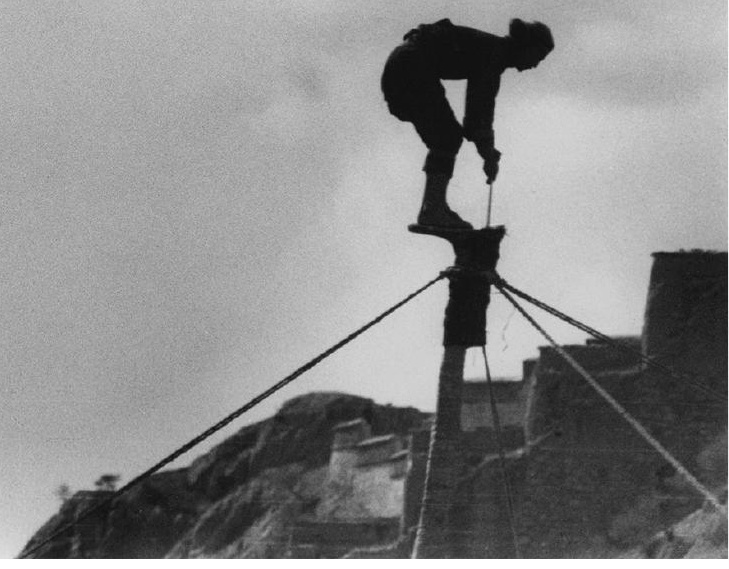

Opening keynote ASA's Firth lecture

Chair: Nigel Rapport (St. Andrews University)

Examination Schools, South School: Tue 18th Sept, 17:15-18:30

The Paradox of the Long Term: Human Evolution and Entanglement

Ian Hodder (Stanford University)

Over recent decades many archaeologists have eschewed evolutionary theories, and in doing so they have turned away from the identification of long-term trends that are of great relevance to present-day matters of concern. In particular, there is clear evidence for an overall long-term increase in the amount of human-made material and associated human-thing entanglements, an increase tied up with environmental impact and global inequalities. The directionality of these long-term changes is clear and yet evolutionary theory largely eschews notions of overall directional change. This paradox and its implications are the subject of this talk, with the suggestion made that, for human evolution at least, notions of directionality and path dependence need to be embraced, with concomitant changes in human evolutionary theory, and with implications for environmental and social policy. 
Ian Hodder was trained at the Institute of Archaeology, University College London and at Cambridge University where he obtained his $\mathrm{PhD}$ in 1975. After a brief period teaching at Leeds, he returned to Cambridge where he taught until 1999. During that time he became Professor of Archaeology and was elected a Fellow of the British Academy. In 1999 he moved to teach at Stanford University as Dunlevie Family Professor in the Department of Anthropology and Director of the Stanford Archaeology Center. His main large-scale excavation projects have been at Haddenham in the east of England and at Çatalhöyük in Turkey where he has worked since 1993. He has been awarded the Oscar Montelius Medal by the Swedish Society of Antiquaries, the Huxley Memorial Medal by the Royal Anthropological Institute, the Fyssen International Prize, has been a Guggenheim Fellow, and has Honorary Doctorates from Bristol and Leiden Universities. His main books include Symbols in action (1982 CUP), Reading the Past (1986 CUP), The Domestication of Europe (1990 Blackwell), The Archaeological Process (1999 Blackwell), The Leopard's Tale: Revealing the Mysteries of Çatalhöyük (2006 Thames and Hudson), Entangled: An Archaeology of the Relationships Between Humans and Things (2012 Wiley Blackwell).

\section{Semi-plenary 1 Environmental imaginations}

Chair: Laura Rival (University of Oxford)

Examination Schools, South School: Wed, 19th of Sept, 11:15-12:45

\section{Anthropocenic Reconfigurations: Re-imagining and Re-enacting Environment- Health Relations in a New Era}

Melissa Leach (University of Sussex)

Our entry into the Anthropocene (and associated 'cenes' - from Capitalocene to Chthulucene) arguably signal new ways of being in/with nature, and understanding and imagining our past, present and future - not least by anthropologists. In previous eras relations and anxieties were often configured in terms of a (biblical) 'fall' from grace or harmony, with (divine) intervention disrupting natural orders, or in terms of 'progress' towards modernity, harnessing or overcoming natural forces. Yet the Anthropocene suggests an era of co-emerging socio-natures, in which as humans we cannot escape our agency and responsibility, but must acknowledge its inter-negotiation with multiple species, ecological and atmospheric processes. Is this indeed a fundamental shift- and what are its ontological, cosmological and political dimensions and connotations? What imaginations and practices are implied around time and its (non) linearity, and placebased socialities (one anthropocene or many?) How and how far are discourses and practices around environment and health - as a central focus of public, political and indeed anthropological concern - being reconfigured anthropocenically - for instance as ideas of epidemic as fall and disease control as progress are joined by, inter alia, notions of planetary health, one health, and multi-species socio-ecologies of zoonosis? What social and political implications follow - for our relations with each other and with nonhuman nature? 
Melissa Leach is Director of the Institute of Development Studies (IDS) at the University of Sussex. She founded and directed the ESRC STEPS (Social, Technological and Environmental Pathways to Sustainability) Centre (www.steps-centre.org) from 20062014. As a social anthropologist she has carried out long-term ethnographic fieldwork in West Africa while engaging with global discourses and debates around environment, health and development. She has led numerous interdisciplinary, policy-engaged research programmes in Africa and beyond. Amongst external roles, she was vice-chair of the Science Committee of Future Earth 2012-2017, lead author of the 2016 World Social Science Report 2016 on Challenging Inequalities and the UN Women's World Survey on the Role of Women in Economic Development 2014, and is a member of the International Panel of Experts on Sustainable Food Systems (IPES-Food). In 2014-16 she co-led the award-winning Ebola Response Anthropology Platform.

\section{Semi-plenary 2 Transformation and time} Chair: Dan Hicks (University of Oxford)

Oxford University Natural History Museum: Wed, 19th of Sept, 11:15-12:45

\section{Placing Time}

Caitlin DeSilvey (University of Exeter)

Caitlin DeSilvey will speak on the relationship between temporality and perceptions of (past and future) place. Drawing on research in heritage contexts, she will explore how material transformation and ruination afford a continuous relation with past time, in contrast with the discontinuity introduced by efforts to restore or conserve. She will also discuss the complex temporalities invoked in landscape-scale rewilding initiatives, in which radical landscape transformation is often indexed to deep ecological time, but through an iterative, experimental (rather than a restorative) framework.

Caitlin DeSilvey is Associate Professor of Cultural Geography at the University of Exeter, where she has been employed since 2007. Her research explores the cultural significance of material and environmental change, with a particular focus on heritage contexts. She has worked on a range of interdisciplinary projects, supported by funding from UK research councils (AHRC, EPSRC, NERC), the Royal Geographical Society, the Norwegian Research Council and the European Social Fund. Recent publications include Anticipatory History (2011, with Simon Naylor and Colin Sackett), Visible Mending (2013, with Steven Bond and James R. Ryan), and Curated Decay: Heritage Beyond Saving (2017). 
Plenaries, roundtables and debates

\section{Passing: Duration, Permanence and Time}

Michael Rowlands (University College London)

My lecture will focus on different senses of passing. I make a distinction between duration and time: I associate duration with permanence/perpetuity and time with transformation. The perception of permanence is that things will continue to exist. A familiar cognitive example is the first experience of the mother-child relation, created by touching and sucking the breast, relating to the child touching, feeling, and handling and manipulating objects before speech and language. This gives us a clue as to the origin of the ideal of permanence over change - the famous Freudian observation of fort/da. The ideal is materialised as struggles to create permanence, for example, the attachment to furnishing, decorating, cleaning, and cooking, or the ideal of curating to create a sense of permanence. But if duration is permanence, the former is active; or, as Bergson taught us, duration involves redefinition of memory, an investment which in turn involves creativity and the acceptance of transience and movement. Fashioning provisionally stable lives out of instability also requires access to social and economic lives and relationships outside the immediate conditions of unstable futures, as for instance in the struggle to maintain ancestral continuity alongside modernisation in Africa, China, Europe, or North America. This implies the possibility of time or the control of time. Control of time implies control of futures, but who has this? I will therefore limit the notion of transformation to a more absolute idea of time as breaks and ruptures that destroy the sensibility of futures.

Michael Rowlands is Emeritus Professor of Anthropology and Material Culture at University College London. Most recently he has completed field research on heritage and locality in South-West China. He is completing a book with Stephan Feuchtwang entitled Civilisation Recast.

\section{Roundtable Anthropology and the imagination}

Participants: Dolores Martinez (University of Oxford), Tim Ingold (University of Aberdeen), Lisette Josephides (Queen's University Belfast), Peter Pels (Leiden University)

Examination Schools, South School: Wed, 19th of Sept, 18:00-19:30

This round table seeks to consider the question of renewing and re-creating anthropology through a discussion of how we might begin to situate 'the imagination' within our discipline. Anthropology has always dealt with the human imagination both as an object of inquiry and as a method: it has studied the products of the imagination and, as a discipline, it has demanded that the observer make imaginative leaps in order to begin to grasp the intricacies of others' inventiveness. Thus our panellists ask a variety of different questions, such as: How far does this 'renewal' of the imagination within the discipline extend, particularly in light of the critiques posited by first orientalism and feminism, and now by post-colonialism? Does this involve, or should it still involve, a critique of the ways in which people might imaginatively restrict what counts as 'fully' 
human to people living in the global North? In what sense, or senses, is imagination inventive, improvisatory or creative? How does it relate to perception, to memory, and to experience? Is imagination even unique to humans? How can the nimbleness of the imagination, as it 'leaps' and 'roams' and 'pictures', be matched by a lightness in writing style that brings anthropological writing to life? How might we work across, and with, other disciplines to gain a better understanding of this concept? We look forward to a lively discussion.

\section{Semi-plenary 3 Creative bodies}

Chair: Elizabeth Hallam (University of Oxford)

Oxford University Natural History Museum, Lecture theatre: Thu, 20th of Sept, 11:1512:45

\section{The Light of the Piece: An Exploration of Materiality and Creative Practice in a Maine Landscape \\ Anna Grimshaw (Emory University)}

In this presentation, I will screen a short film in order to raise questions about how the medium can be used to explore embodied practice within a material landscape. How might anthropologists work with image, sound and movement to explore the creative body and how might the medium render imaginative dimensions of experience? What does a filmic engagement ask of subjects, audiences, and, crucially, the anthropological filmmaker herself?

Anna Grimshaw teaches anthropology at Emory University. She is the author of The Ethnographer's Eye and co-author of Observational Cinema. Her films, $\mathrm{Mr}$ Coperthwaite: A Life in the Maine Woods and At Low Tide are distributed by Berkeley Media and the Royal Anthropological Institute.

\section{Semi-plenary 4 Language and imagination}

Chairs: Ramon Sarró (University of Oxford) and David Zeitlyn (University of Oxford)

Examination Schools, South School: Thu, 20th of Sept, 11:15-12:45

\section{Failures in Intersubjective Attunement and their Implications for a Theory of Collective Action}

Alessandro Duranti (University of California, Los Angeles)

The conditions for collective action have long been a major focus of speculation for philosophers and cognitive scientists who introduced the notion of 'collective' or 'shared intentionality' as an alternative to the earlier phenomenological notion of intersubjectivity (Tuomela \& Miller 1985; Searle 1990; Bratman 1993; Tomasello 2007; etc.). The models proposed by these authors have been based on situations in which the joint activity under consideration (e.g., participating in a toast, playing music in a band, 
dancing with others) occurs smoothly, that is, without interruptions or errors. In this talk I examine a number of audio- and video-recorded interactions where 'glitches' or full-blown errors occur. I show that participants miss seeing or hearing the contextually relevant 'aspect' - a notion introduced by Wittgenstein in the late 1940s - because of socio-historically rooted and typically embodied expectations about what should be happening next in the context at hand. Within the temporal unfolding of the collective activity, certain sonic, musical, visual, linguistic, or textual qualities of the event acquire an attentional pull (Throop \& Duranti 2014) that overwhelms key participants leading them into interactional trouble.

Alessandro Duranti is Distinguished Professor of Anthropology at the University of California, Los Angeles, where he teaches courses in linguistic anthropology phenomenology, and jazz aesthetics. His current theoretical focus is the role of the unexpected in human interaction.

\section{Roundtable Interdisciplinarity}

Participants: Charlotte Roberts (Durham University), Sarah White (University of Bath), Chris Gosden (University of Oxford), David Shankland (Royal Anthropological Institute) Chair: Nigel Rapport (University of St.Andrews)

Examination Schools, South School: Thu, 20th of Sept, 16:15-17:45

The idea for our conference, Sociality, Matter, and the Imagination: Re-Creating Anthropology, has been to make interdisciplinarity a principal focus: to encourage as wide debate as possible across sociocultural, material, visual, biological, forensic, cognitive, evolutionary, developmental and linguistic anthropologies, and from archaeology and museum studies too. Could and should we renew anthropology in an interdisciplinary and holistic ambition, reconsider the human condition from a diversity of perspectives? There are challenges to this, both institutional and intellectual that this Plenary Roundtable hopes to discuss...

\section{Debate Morality and Evolution}

Participants Oliver Scott Curry (University of Oxford), Mark Alfano (University of Delft), Soumhya Venkatesan (University of Manchester), Jo Cook (UCL)

Examination Schools, South School: Fri, 21st of Sept, 09:00-10:30, 11:00-12:30

Oliver Scott Curry (University of Oxford) will propose and Mark Alfano (University of Delft) will second the motion that 'morality is fundamentally an evolved solution to problems of social cooperation'. Soumhya Venkatesan (Manchester University) and Jo Cook (UCL) will oppose the motion. There will be plenty of time for interventions from the floor and the debate will close with a vote by show of hands. The debate brings together two dynamic sub-fields within contemporary anthropology, cognitive/ 
evolutionary anthropology and the anthropology of morality, which arguably should have had more dialogue with each other than has so far been the case. It will address a theory that Oliver, in collaboration with others in Oxford and elsewhere, has advanced on the basis of systematic global comparison (Curry et al. 2018, Curry 2016).

Curry, O.S. 2016. 'Morality as Cooperation: A Problem-Centred Approach', in The Evolution of Morality, (eds) T.K. Shackelford and R.D. Hansen, pp. 27-51. Springer. (https://link.springer.com/chapter/10.1007\%2F978-3-319-19671-8_2)

Curry, O.S., D.A. Mullins, \& H. Whitehouse in press. 'Is it Good to Cooperate? Testing the Theory of Morality-as-Cooperation in 60 Societies' Current Anthropology. (https:// osf.io/9546r/)

\section{Closing keynote}

20ththChair: Harvey Whitehouse (University of Oxford)

Examination Schools, South School: Fri, 21st of Sept 14:00-15:30

\section{Anthropology and Psychology: Finding Common Grounds}

Rita Astuti (London School of Economics)

Anthropology and psychology have had a cold relationship (with some notable exceptions on both sides). As a result, extreme and seemingly irreconcilable positions have emerged, in ignorance of each other's empirical findings and theoretical advances. In this lecture, I will illustrate ways in which both disciplines can re-engage with each other constructively and respectfully, thus providing a better analysis of how human beings understand and act in the world.

Rita Astuti is Professor of Anthropology the London School of Economics. Her research has focused on a fishing village in Madagascar. She has published an ethnographic monograph on kinship, death and identity (People of the Sea 1995, CUP). In collaboration with developmental psychologists, she has reanalysed her ethnographic findings through the use of experimental techniques (for example, in Constraints on Conceptual Development, 2004, SRCD Monographs). In her publications and in her teaching, she has advocated a closer integration between anthropology and psychology. 
Notes 


\section{Panel streams}

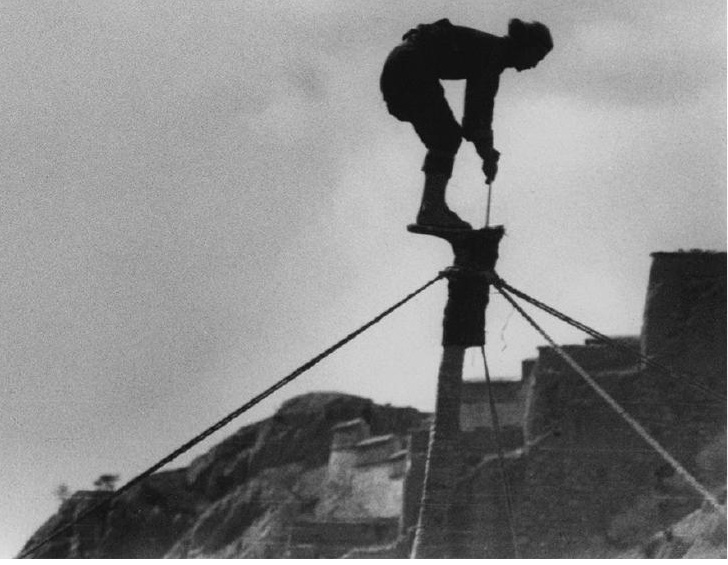

ASA18 panels have been organised into the following thematic streams:

\section{Ant Anthropology}

Several panels examine the changing nature of anthropology itself. How has the practice of ethnography changed? How should it change? Do anthropologists need to examine their own profession in the way that so many other professions are being challenged to do?

\section{Body Bodies}

How are imaginative processes grounded in embodied action, and how are bodies enmeshed in wider social and ecological relationships? How are shifting relations between the human and the non-human affecting bodies, and indeed redefining the 'human'? 


\section{Cog Cognition \& Evolution}

Adapting tools and methods from psychology and biology, cognitive and evolutionary anthropology has proposed new approaches to old anthropological questions about relationships between minds, bodies, culture, landscape, and change. How far can sociality, including morality, be explained in terms of long-term, deeply embedded constraints as they interact with the human imagination?

\section{Cre Creativity}

In foregrounding imagination, some panels focus directly on trying to understand human creativity and performativity. Others look at artistic production as a means for imagining alternative futures.

\section{Env Environment}

'Nature', which has always functioned as a repository of social ideas and political values, is being recast through a multiplicity of global environmental change discourses. Is environmental change limiting the human imagination, or are people using their imagination to adapt to the changing climate?

\section{Inf Infrastructure}

So much of what is constructed and social appears natural or given, including and especially the various forms of infrastructure that so many people take for granted. In what ways do infrastructures become both conceptual and material? What role does imagination play in the creation of possible future infrastructures?

\section{Lang Language}

From cognitivist sciences to the anthropology of art, of politics, of religions, of kinship, etc., understanding the capacity of humans (and perhaps non-human primates too) to create potential scenarios is a key part of what we find in the field and a key part of the representations we document in our writings. What are the effects of imagination in life and in anthropology?

\section{Med Medical}

Anthropological work on medical practices and technologies continues to contribute to the rethinking of human bodies and their construction in health, illness, and well-being. A medical framing brings questions of sociality and personhood into clear, and distinctly material, focus. 


\section{Mor Morality}

A renewed focus on morality or ethics has recently revivified or reformed much work within anthropology. How does moral language re-imagine (even if negatively, as in mistrust) the economy, politics, social arrangements, or social rules?

\section{Pol Politics}

Human political life is played out in the space between what is (current material and political constraints), what should be (the ethical or moral), and what could be (imagined alternatives). At a time when global forces and negative path dependencies seem more powerful than ever, and yet, simultaneously, imagined possibilities are more various and more communicable than ever before, it is timely to ask what anthropology can contribute to rethinking the politics of sociality and of the imagination.

\section{Time Time}

How do sociality, matter, and the imagination transform over time? Whether addressing short- or long-term processes, anthropologists and archaeologists are confronted with questions relating to the temporal nature of the phenomena they analyse. 


\section{Panel and paper abstracts}

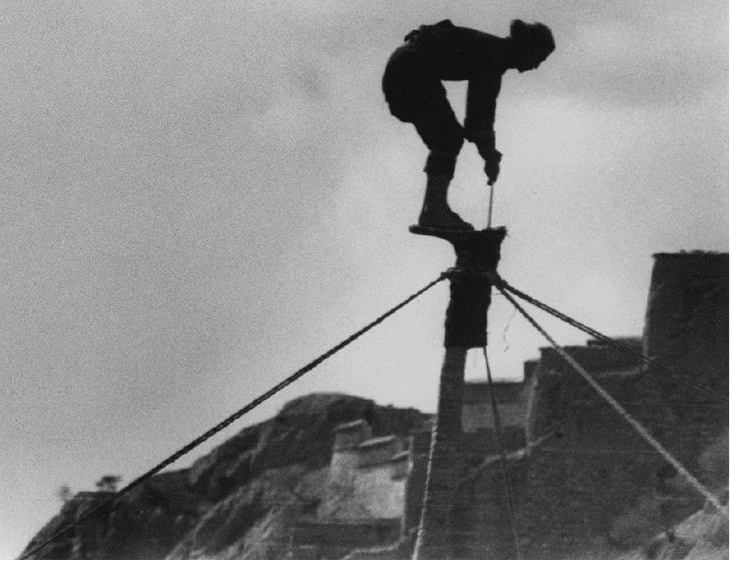

\section{Panel and paper abstracts}

\section{Ant01 The changing faces and use of ethnography (ASA apply)}

Convenors: Julie Scott; Sarah Buckler (Robert Gordon University)

Examination Schools Room 11: Tue 18th Sept, 13:30-15:00, 15:30-17:00

This panel is proposed by Apply, the Applied Anthropology Network of ASA. We will explore how ethnography has changed and what different uses it is being put to both inside and outside the academy.

Recovering the utility of anthropology: Eric Miller and the application of anthropology to improving industrial and urban lives

Elizabeth Cory-Pearce (Tavistock Institute of Human Relations)

My paper introduces a new piece of research tracing the career of Eric J. Miller to recover a post-war 'expansive moment' when anthropologists were applying their skills to 
Panel and paper abstracts: Ant01

understanding industrial working conditions and urban life, with the express purpose of making improvements.

Practicing "development anthropology": an ethnography of project dynamics in cultural heritage and development

Stefania Cardinale (London Metropolitan University)

A debated issue of anthropology applied "to" development remains the engagement of the researcher and ethnographic fieldwork. Based on the 'case' of a project and my experience working as part of the research team, the paper reflects upon the roles and expectations placed on research activities.

'Living attentionally with others' in applied contexts. Knowledge beyond 'problems and how to fix them'

Cicilie Fagerlid (Oslo Metropolitan University)

A small but rapidly growing part of research done on libraries is ethnographic. What knowledge can we gain if we gaze upwards from instrumental, 'ethnographish' problemfixing and employ open, explorative approaches and fuller participation in applied research and settings like the library?

\section{5:30-17:00}

Who needs Foucault? Applying anthropology ... or common sense? Siew-Peng Lee (Brunel University)

Questioning the assumption that anthropologists have a special 'way of seeing', I explore whether other practitioners of ethnography could do the work that anthropologists do, and if applying anthropology is not the same as applying common sense.

Feminist activist ethnography and the development of midwifery identity in student midwives.

Nessa McHugh (University of St Andrews); Connie Mcluckie (Edinburgh Napier University) This paper will explore how feminist activist ethnography is used within midwifery education to enable sudent midwives to prepare for professional life and critically review the realities of practice through the narratives of women who have recently given birth.

Anthropologists working on an anti-microbial resistance study?

Meixuan Chen (University of Bristol)

This paper aims to explore the tension between "proper ethnography" and "quick and small ethnography" in applied context, and the value of the latter. 
Ant02 \#MeTooAnthro: sexual assault and harassment in anthropology

Convenor: Esther Anderson (University of Southern Queensland)

Examination Schools Room 6: Thu 20th Sept, 09:00-10:30, 14:15-15:45

Anthropologists face unique working conditions that can increase exposure to sexual assault and harassment, however scholars are often given little disciplinary space to reflect on its impact in their work. \#MeTooAnthro invites discussion on how to make our discipline a safer and more just space.

09:00-10:30

How far will we go? Fieldwork and sexual harassment

Tanja Kubes (TU Munich)

How can we handle sexual harassment, when it is an integral part of our field's reality and the only way to collect field data? Drawing from my fieldwork among car show hostesses, my talk discusses the fragile balance between immersion in the field and the need for distancing self-protection.

What metaphors we have: making sense of sexual violence in and out of the field Megan Steffen (Tsinghua University)

This paper analyzes the figurative language anthropologists have used and currently use to make sense of sexual violence during fieldwork and outside of it. It draws on examples from Central China and 1930s American anthropology.

'Blurred lines?': navigating professional relationships in the field

Danielle Bradford (University of Cambridge)

My paper examines the way in which perceived 'blurred boundaries' within fieldwork contexts foster a dangerous environment for women and other marginalised identities, and presents suggested guidelines on how such professional relationships should be maintained and managed.

Preparing cultural anthropology graduate students to enter the field: issues and considerations to establish pre-fieldwork training to address sexual assault/ harassment

Melina Taylor (University of South Florida)

Cultural anthropologists are particularly vulnerable to sexual assault/harassment while conducting fieldwork. This paper will address these issues from the graduate student perspective; providing potential training topics that universities can implement to better prepare students for the field. 
Panel and paper abstracts: $\quad$ Ant03

\section{4:15-15:45}

\section{Me Too anthropology}

Elizabeth Beckmann (The University of Sussex)

"The \#MeToo campaign has certainly caused a storm, but will this storm pass and its population revert to the way it was before, and what can modern anthropology do to ensure that it doesn't?"

\section{Best practices to improve fieldwork experiences for $\mathrm{PhD}$ students}

Megan Jane Douglas (University of Edinburgh)

PhD students undertaking fieldwork are often vulnerable to sexual misconduct and mental health challenges, yet receive limited preparation prior to the field. This paper reports on the ongoing work of a cross-disciplinary team at the University of Edinburgh developing best practices in this area.

The personal is structural: ending violence against women by re-creating the academy Jennifer Wies (Ball State University); Hillary Haldane (Quinnipiac University) Anthropology is practiced across varied sites, however, the main locus of its social reproduction is within the academy. This paper explores sexual misconduct to understanding the constraints in anthropology to address and respond to sexual misconduct demonstrates the potential for re-creation.

\section{Ant03 The new ethnographer: contemporary challenges in anthropological} research

Convenors: Branwen Spector (London School of Economics); Caitlin Procter (University of Oxford)

Examination Schools Room 11: Fri 21st Sept, 09:00-10:30

This panel invite contributions from ethnographers on challenges in contemporary anthropological research addressing the themes of safety, mental health and wellbeing, gender, radical research methods and ethics in fieldwork.

\section{9:00-10:30}

Dilemmas and vulnerabilities of anthropological work: a reflection about violence, limits and ethical questions

Carolina Parreiras Silva (University of São Paulo - USP)

This proposal focuses on a reflection about the vulnerabilities of the researcher while conducting fieldwork I use ethnographical examples from my postdoctoral research about sexual violence against teenagers in favelas situated in Rio de Janeiro - Brazil. 
Panel and paper abstracts: $\mathrm{Ant04}$

Navigating and embodying the field as native anthropologist: class and gender in India

Smita Yadav (University of Sussex)

How does an ethnographer be neutral to the social context of doing the fieldwork?

How does the ethnographer contest and navigate the production of gender, class, and education while also being conscious of their poistionality as a native researcher?

Emotions of friendship: the psychological challenges of doing fieldwork in Xinjiang Lisa Ernst (Humboldt-Universität zu Berlin)

This paper discusses the ethical implications of forming friendships and trust relationships as a research method under extreme political pressure in contemporary Xinjiang and the resulting impact for the mental wellbeing of the anthropologist during and after fieldwork.

\section{Exploring the advantages and limitations of fieldwork training}

Keiko Kanno (University of Oxford)

I examine safety information, training, and instruction available through academic institutions in the Global North preceding field research in the Global South and discuss how such resources could lead to safety, wellbeing, and effective communication in the field.

Ethics in bioprospecting fieldwork: the ethnobotanist's role in protecting cultural heritage rights of traditional plant use-knowledge within drug discovery research Marianne Jennifer Datiles (UCL); Francesca Scotti (UCL); Michael Heinrich (UCL School of Pharmacy)

Drawing on fieldwork among indigenous groups in the Philippines, Mexico, and Bangladesh, we highlight specific challenges ethnobotanists face to ensure the protection of biodiversity and intangible cultural heritage rights while researching traditional foodmedicines and pharmaceutical development.

\section{Ant04 Reimagining difference: diversity in anthropology}

Convenors: Alice Elliot (Goldsmiths, University of London); Alison Macdonald (UCL)

Examination Schools Room 11: Wed 19th Sept, 09:00-10:30, 14:15-15:45

"Diversity" is one of anthropology's key concerns, yet it is strikingly scarce in the practical experience of teaching and learning the discipline. The panel opens a critical conversation about diversity in anthropology as a way to creatively reimagine what anthropology may be and could become. 
Panel and paper abstracts: Ant04

\section{9:00-10:30}

Reimagining the researcher-informant relationship: reflections of a blind ethnographer navigating the field with theatre audio describers

Harshadha Balasubramanian (UCL)

Doing fieldwork with sight loss sometimes forces researchers to ask informants for support with describing visual details and getting around. This paper considers how building this familiar rapport may add rather than detract value from any research- as both disabled and non-disabled scholars.

\section{Enacting indigenous anthropology - decolonising the field from self to practice} Sarah Bourke (University of Oxford)

This paper presents part of the research I have conducted for my DPhil in Anthropology at the University of Oxford, and the perspectives I have developed on how to decolonise anthropological research as an Aboriginal Australian working for and with other Indigenous peoples.

\section{Doing diversity, being diversity}

Toyin Agbetu (UCL)

For many public institutions, 'doing diversity' exists as a policy writing act espousing egalitarian principles without wholesale implementation. Can anthropology's failure to move from theory to praxis be solved by a pedagogic rebalancing with 'native' staff employed to decolonise the 'white' gaze?

\section{Scholarship boy: microstories of the uprooted and the anxious}

Chloe Harrison (University College London)

This paper draws on personal experience of being a working-class anthropology student. Through a critical reflection of diversity, I argue that through the notion of intersectionality we are able to avoid the trap of tokenised diversity.

\section{4:15-15:45}

Admitting otherwise: exploring contextuality in higher education admissions David Mills (University of Oxford)

This paper explores the challenge of attracting and recruiting a more diverse community

of undergraduate and research postgraduates to study anthropology. What counts as 'contextuality' within 'contextual admissions' and how might anthropological insights help us understand this differently? 
Panel and paper abstracts: Ant05

Whose diversity is it anyway? Reconsidering widening participation from the perspective of its participants

Chima Michael Anyadike-Danes (University of Warwick)

This presentation takes seriously Ulf Hannerz's suggestion that diversity is anthropology's business and analyses how it has come to matter in England's higher education system. Specifically, it examines how participants in a university's diversity initiatives theorise diversity.

Miss, is anthropology about studying ants?

Sally Dennehy (UCL)

This paper explores how the current wider educational context might contribute to the debate about the lack of diversity among anthropology students at university. This paper explores some of the obstacles to selecting Anthropology along with potential solutions to facilitate change.

How to do diversity in the anthropology classroom and curriculum: a practical toolbox for university teachers/lecturers

Elke Linders (Utrecht University); Kathrine (C.E.) van den Bogert (Utrecht University);

Nicole Sanches (Utrecht University)

We argue that to study and 'do' diversity in anthropology, three theoretical perspectives that take power relations into account are crucial: unlearning, decoloniality, and intersectionality. With these as starting point, we develop a practical toolbox to enhance diversity in anthropology teaching.

\section{Toward an anthropology of inclusion: on decolonizing a discipline} Julie Botticello (UEL)

This paper addresses the challenge of inclusion in current anthropological theorizing. It proposes that decolonizing its tenets and widening notions of expertise will create spaces for multiple voices and understandings currently marginal to its epistemological repertoire.

\section{Ant05 One discipline or many?}

Convenors: David Shankland (Royal Anthropological Institute)

Examination Schools Room 11: Fri 21st Sept, 16:00-17:30

This panel invites consideration of how and when anthropology has appeared to have divided into sub-disciplines, and whether such sub-divisions are still relevant today. Submissions are welcome from the historical, methodological, or theoretical point of view. 
Panel and paper abstracts: Ant06

\section{6:00-17:30}

Four subdisciplines in one career, four styles of imagination

Nicholas Allen (Oxford University)

Over the last half century the writer has engaged in four branches of anthropology.

The different styles of imagination involved are here explored, and it is argued that an anthropological education can and should continue to allow for such variety.

\section{One discipline or many?}

David Shankland (Royal Anthropological Institute)

This paper concentrates on the creation of separate fields of anthropological enquiry in the first half of the twentieth century, and reflects upon the lessons that this can teach us in the present day.

Constructing an 'age of excavation': re-examining contexts for the professionalization of archaeology in Britain

Katie Meheux (UCL Institute of Archaeology)

Conventional histories of the professionalization of Archaeology in Britain have ignored the major contribution of late Victorian scholars and the enduring influence and colonial context of their practice and ideas about progress, science, class, race, modernity and rational recreation.

\section{Ant06 Ethical research and ethical review}

Convenors: Jude Robinson (University of Liverpool); Bob Simpson (Durham University); Margaret Sleeboom-Faulkner (University of Sussex)

Examination Schools South School: Thu 20th Sept, 14:15-15:45

Are the principles underpinning ethical research in Anthropology adequately recognised by institutional ethical review panels? What is needed to support anthropologists to develop their research and teaching as part of the response by the humanities and social sciences to global societal challenges?

\section{4:15-15:45}

\section{The ethical researcher}

Jude Robinson (University of Liverpool)

If ethical committees focussed on the ethics of the researcher, rather than the research and the researched, what would this mean for future anthropological research in terms of training and ethical review? 
Panel and paper abstracts: Body01

Datamanagement for anthropologists: changing ethics governance and principles

Peter Pels (Leiden University)

Datamanagement policies introduce new forms of academic governance. Their demands for transparency in the name of integrity can upset qualitative researchers because they may violate principles of maintaining social relationships during and after ethnographic research. This paper argues that such issues require anthropologists globally to clarify such principles.

Clashes between anthropology and research ethics committees - and getting new data protection requirements to work for anthropology

Margaret Sleeboom-Faulkner (University of Sussex)

The ethics of anthropological research is incongruent with formalised research ethics. The implementation of the new EU data protection regulation has the potential to make matters worse. BUT there are also ways in which anthropology can negotiate to acquire more suitable ethics review.

\section{An introduction to Eth Nav: an ethical navigation tool for social anthropologists} Bob Simpson (Durham University)

For researchers using ethnographic methods issues of ethics, governance and regulation have become extremely complex. The aim of this tool is to help social anthropologists navigate their way through the landscape of research engagement as it has developed in the UK.

Body01 Skills of feeling with the world: affective imagination, embodied memories and materiality in the emergence of sociality

Convenors: Andrea De Antoni (Ritsumeikan University); Emma Cook (Hokkaido

University)

Magdalen Summer Common Room: Wed 19th Sept, 09:00-10:30, 14:15-15:45, 16:15$17: 45$

This panel explores imagination and memories as "affective practices" (Wetherell 2012) that rely on skills of the body moving-in-the-world. It aims to link them to materiality and the emergence of sociality through practice and correspondences between bodies and environments. 
Panel and paper abstracts: Body01

\section{9:00-10:30}

Bodily ethnography: some epistemological challenges of participation Till Förster (University of Basel)

Bodily participation is mostly conceived as a partial aspect of participant observation but seldom studied in its own right. Building on an example from West Africa, this paper examines how the epistemological advantages, insights and potentials of participation affect the ethnographic imagination.

The archaeometry of us things: from the world, passing through the body, and becoming together

Gabriela Oppitz (Stanford)

What if we take seriously the materiality and thingness of the atoms that dwell in our bodies? Then we realize that archaeologists are not using isotopes to assess information on mobility, diet and chronology; instead, these isotopes are expressing their own roots, bonds, becomings, and times.

She talks to angels: spirit becomings, embodied memories and affective imagination skills in catholic exorcism in contemporary Italy

Andrea De Antoni (Ritsumeikan University)

In this paper I focus on phenomena of possession and Roman Catholic exorcism in contemporary Italy. I argue that imagination skills related to bodily perceptions, embodied memories, "affective correspondences" and processes of enskilment play a major role in the emergence of spirit realities.

\section{4:15-15:45}

\section{Sociality and imagination: food allergy enskilment in Japan}

Emma Cook (Hokkaido University)

This paper looks at the ways in which people dealing with severe food allergies in Japan develop and enact embodied skill-sets, built on embodied memory, affective imagination, and their wider social and material environments.

\section{Affective and performative subjectivity at breakfast}

Jong-Min Jeong (University of Manchester)

This study does not aim to identify body sensations, movements and affects of people living with dementia as pathological, nor does it seek 'meaning' per se. Instead, it shows the ways in which people living with dementia engages with their immediate surroundings within the illness capacities. 
Panel and paper abstracts: Body02

Augmented reality in the affect-emotion gap: technological interventions in sensation and memory in Japan

Daniel White (Institute for Japanese Studies)

In the emerging field of human-computer integration, understanding affect depends on the technological modes through which experts investigate it. Drawing on fieldwork in affective computing labs in Japan, this paper explores the sociality of digital experiments with sensation and memory.

On fellow-feeling, imagined identification, and the (un)making of an imagined community

Rosa Cordillera A. Castillo (Humboldt University Berlin)

I explore particular Maguindanaon emotions borne out of remembering and imagining violence as manifestations of fellow-feeling, which are emergent from and shaped by historical, political, and sociocultural contexts.

16:15-17:45

Chinatowns as technologies of imagination: a Japanese case study

Jamie Coates

This paper draws from fieldwork in Tokyo's unofficial 'Chinatown', Ikebukuro, to discuss the ways Chinatowns can be conceived as 'technologies of imagination' (Sneath et al. 2009) producing new ways of imagining contemporary Chinese sociality

\section{The ethical pedagogy of balance in a Timor-Leste fishing hamlet}

Prash Naidu (University of Michigan)

This paper examines the ethical pedagogy of balance among male fishers in pelagic fishing. By analyzing proprioceptive training repertoires while fishing,I argue that fishers cultivate an ethical project premised upon individual and collective capacity to acquire and sustain techniques of balance.

\section{Body02 Yoga bodies and the transformation of the self}

Convenors: Alison Shaw (Oxford University); Esra Kaytaz (Coventry University)

Magdalen Daubeny: Wed 19th Sept, 09:00-10:30, 14:15-15:45, 16:15-17:45

The biological, social and material converge in the creation of yoga bodies. This panel invites submissions explore the creation of the self through this increasingly global embodied practice, with perspectives from history, material culture, medicine, religion and gender. 
Panel and paper abstracts: Body02

09:00-10:30

The self and body of the Hindu ascetic yogi

Daniela Bevilacqua (SOAS)

This paper considers the body of the yogi, his physical practice and how yoga is taught.

To follow, it analyses who is a yogi raj, a ha囚ha yogi and a yogi in the ascetic context to deal then with the idea of Yoga and self. Eventually, a confrontation with modern yoga practitioners is made.

\section{Breathing out India: a sociopolitical history of globalised Prā̄āyāma}

Mark Singleton (SOAS, University of London)

This paper examines the socio-political history of globalised prā̄āyāma at the turn of the nineteenth century, proposing that the various methodologies that abounded in the self-help literature of the day function to delineate an embodied, moral orthopraxis of breathing for modern men and women.

'Practice and all is coming': techniques of asana and the threat of deethicalization at a yoga school in southern India

Jack Sidnell (University of Toronto)

Based on extensive field research at a school in southern India, I discuss students' responses to a pervasive threat of "deethicalization" by which the poses (asana) they perform are reduced to "mere" physical exercise.

(In)visible bodies: skeletons and 'yogic bodies' in the West

Cassandre Campeau-Bouthillier (University of Victoria)

This paper presents preliminary results of research that attempts to describe the skeletal experiences of yoga practitioners in western Canada. Although yoga is a vehicle to embodied experiences the skeleton remains excluded from discourses of embodiment outside of injury and pathology.

\section{4:15-15:45}

"A tool to help me through the darkness": healing and self-transformation in online memoirs by practitioner-teachers of Ashtanga yoga

Alison Shaw (Oxford University)

Drawing from online memoirs of Ashtanga teacher/practitioners, this paper discusses structural elements of Ashtanga practice and accreditation as influences on narratives of self-transformation and suggests that Ashtanga also offers a microcosm for examining aspects of healing through yoga.

\section{The health imaginary of postural yoga}

Beatrix Hauser (Universität Bremen)

In this paper, yoga narratives and practices are considered in their capacity to contribute and relate to a particular health imaginary. Shedding light on various elements in this health imaginary will help us reconsider the category of (modern) postural yoga itself. 
Panel and paper abstracts: Body02

The academic body: yoga and mindfulness as pedagogy and practice for academic resilience

Elizabeth Maynard

This paper addresses the social and philosophical construct of the "yoga body" as a potential locus for critiquing the dichotomous mind-body hierarchy dominant in academia, and works towards developing an embodied methodology for thoughtful and sustainable scholarship.

'Nice stretching' or more than bodily practice: doing yoga in a fitness club Warsaw Natallia Paulovich (Polish Academy of Sciences)

Often perceived as 'nice stretching' that allows middle and upper class people to demonstrate their social status through fashionable yoga clothes and comfortable yoga mats, among women with average incomes attending small fitness clubs on Warsaw's periphery yoga is becoming a therapeutic practice.

16:15-17:45

Auto-ethnography, embodiment and the idea of the self: a phenomenology of yoga teacher training

Gillian Evans (University of Manchester)

Drawing on an auto-ethnography of a two year yoga teacher training, and ethnographic interviews with other trainees, this paper gives a phenomenological analysis of the embodied transformation of self that characterises becoming a yoga teacher as a particular kind of rite of passage.

Lost \& found in translation - French scapes of body-self connection Mahé BEN HAMED (CNRS)

Drawing on ethnographic fieldwork in France, this paper explores the transmission of yoga as an experience of body-self connection and transformation in 3 modern yoga styles - Bikram, Forrest and Iyengar - that differ in philosophy and form as much as in their history, circulation and reception.

Methodological challenges in researching the potential transformation of the self through the creation of a Yoga body among refugee women

Claire Collison (University of Brighton)

This paper explores the methodological challenges of research investigating the potential transformation of the self through the creation of a Yoga body among refugee women. The refugee women are enrolled on Yoga courses in Sweden. 
Panel and paper abstracts: Body03

Beyond the fit body: yoga as a connector in the everyday lives of middle class households in Providence, Rhode Island, USA

Tess Bird (Wesleyan University)

This paper situates yoga within a greater evolution of wellness practices in the neoliberal era. Drawing on ethnographic encounters in households in the US, the paper proposes that yoga can help facilitate intimate relations within the home.

\section{Body03 Corporeality \& material ecology: the affordances of stuff and wellbeing} Convenors: Kelly Fagan Robinson (UCL); Timothy Carroll (UCL)

Magdalen Old Law Library: Thu 20th Sept, 09:00-10:30, 14:15-15:45

The maintenance of health and wellbeing demands a continual engagement with the material of the body and its environment. What does this mean practically and analytically?

\section{9:00-10:30}

\section{On the surface of oil}

Timothy Carroll (UCL)

This paper looks at the relationship between oil and skin within the ritual practice of Orthodox Christianity in order to explore the material constitution for ritual health practices.

\section{Lift, drag, weight and snow: a biosocial analysis of ski-jumping} Aaron Parkhurst (University College London)

Through a biosocial analysis of ski-jumping, and the politics of building the women's event in the Olympics, this paper argues that bodily and material ecology offers insight into how gender relations are made and contested.

\section{Bodies and screens: imagined affordances and metaphors in the pursuit of wellbeing} Theodora Sutton (University of Oxford)

This paper examines intersections between technology, body, and health in a digital detoxing community. It discusses how metaphors shape imagined affordances of the digital, as well as material ecologies of body, personhood, and wellbeing.

\section{The urban health: fitting bodies into the city of Tehran}

Marzieh Kaivanara (University of Bristol)

This study focuses on how the body surface and urban spaces have become the foundation of (experiences of) health in Tehran. The body surface is used as a platform to materialise the understanding, and to provoke the experiences, of health; and the built environment reproduces such experiences. 
Panel and paper abstracts: Body04

14:15-15:45

Lifeblood: water, psychological suffering, and the end of time in Ethiopia's lower Omo valley

Edward Stevenson (UCL)

The end of the flood of the Omo River as a result of a large dam has rendered local people's lives newly precarious. Understanding the implications of this change for mental health and well-being requires us to think anew about the relationships among bodies, minds, environments and food systems.

\section{The house as a medium of Andean consubstantiality}

Jonathan Alderman (St Andrews)

In the rural Andes, personhood is defined by intersubjective relationships with nonhuman beings. This paper will examine the role of the house as a nonhuman being itself and as a conduit between its inhabitants and local place deities.

Body04 Indigenous imaginations: creative bodies and embodied resistance Convenors: Monica Mottin (Ruskin College, Oxford); Mara Matta (University of Rome 'La Sapienza'); Markus Schleiter (University of Münster)

Magdalen Old Law Library: Tue 18th Sept, 15:30-17:00

This panel aims to explore the materiality of resistance, in particular how indigenous people challenge dominant paradigms by bringing imagined worlds into existence through their bodies.

$15: 30-17: 00$

Producing indigeneity - the social field of indigenous video production, cultural criticism and "tradition" of romancing based on the example of a Santali video song Markus Schleiter (University of Münster)

Together with artists from the Santal 'indigenous' community in Odisha, India, I participated in the production of a music video album. Focusing on one video from the album, I will show how, through this song, young listeners relive the very ambivalent meaningfulness of a village dance night.

\section{A linguistic study of identity, belonging and honorification in Santal society Tanima Bagchi (Indian Institute of Technology Madras)}

This paper investigates how younger Santali speakers of Jharkhand use honorification as the medium of indigenous identity affirmation and preservation through the linguistic tool of address pronouns, as a result of their exposure to a wider world of co-existing and mutually benefiting identities. 
Panel and paper abstracts: Body05

Habeas corpus: performing the indigenous woman body as a symbol of r/esistance against injustice in Bangladesh.

Mara Matta (University of Rome 'La Sapienza')

It has been more than twenty years since Bangladesh State has turned Kalpana Chakma into a 'ghost'. However, her presence and her voice have never faded. This paper looks at the creative strategies employed by indigenous artists and filmmakers for 'resurrecting' her body and reclaiming justice.

"Not an ornament but a body part of the nation": cultural art mediating ancestral belonging and social change in Nepal

Monica Mottin (Ruskin College, Oxford)

This paper examines how cultural art mediates past oppression and present emancipatory action in Nepal.

\section{Body05 Problematizing humanity: creative bodies and spirits}

Convenors: Mally Stelmaszyk (University of Edinburgh); Alysa Ghose (University of

Edinburgh)

Magdalen Summer Common Room: Thu 20th Sept, 09:00-10:30, 14:15-15:45

Bodies transcend humanity and open up a sociality between humans and spirits that challenges conceptualizations of being human. In this panel, we invite papers that focus on human and non-human interactions and the ways in which these are grounded in diverse embodied practices of communication.

\section{9:00-10:30}

\section{Possession and psychosis}

Christian Suhr (Aarhus University)

What is it like to be a Muslim possessed by a jinn spirit? How do you find refuge from madness and evil in a place like Denmark? In this presentation I discuss some of the ways in which Danish Muslims have sought to protect themselves.

\section{Enskilling the mediumistic body in the Brazilian Vale do Amanhecer}

Emily Pierini (University of Wales Trinity Saint David)

The process of learning spirit mediumship in the Brazilian Vale do Amanhecer develops a specific way of knowing through bodily enskillment. This paper addresses the cognitive, bodily and affective aspects of this process to explore the intersubjective definition of a 'mediumistic body'. 
Panel and paper abstracts: Body05

From the paradox of "breathing life" into bodies in US-based anatomical collections to the search of the bones of Croatia's Defense War 'missing' - a quest of a spiritual journey

Sanja Špoljar Vržina (Institute of Social Sciences Ivo Pilar); Rachel Watkins (American University)

Authors argue that recent discussions of "decolonizing" movements within anthropology need the incorporation of the humanistic scholarship from African Diaspora to the study of human biology which will in turn enable a more firm approach to the authentic talk and respect towards spirituality.

(Re)productive bodies and creative capacities: gender and Cuban religiosity of African origin

Alysa Ghose (University of Edinburgh)

Practices relevant to the matrix of Cuban religiosity of African origin are often gendered. This paper investigates the gendering of these religious traditions and the implications it has on practitioners across gendered lines.

14:15-15:45

In the spirit, in the flesh: humanity and the saved body in the American Bible Belt Alice Nagle

This paper explores the relationship between the body and the Holy Spirit, and how, given the nature of salvation, American Evangelical Christians manage manage contentious notions of the human.

Developing cursed person(hood). Curse infliction in Tuva

Mally Stelmaszyk (University of Edinburgh)

This article is concerned with cursed personhood and spirits. It illuminates how bodily transformations reflect dynamics of human and non-human interactions, exemplified through the instances of curse infliction.

The trancing body as a site for material and immaterial sociality Tamara Turner (Max Planck Institute for Human Development)

In Algerian rituals, trance provides the social recalibration of material, human bodies and immaterial, energetic ones. This paper explores the body as a creative site where the biological, social, and material are managed through the temporal, social ecosystem of ritual.

\section{Saami joik and the singing body as a more-than-human ecology}

Stephane Aubinet (University of Oslo)

This paper explores how the joik, a singing tradition practised by the Sámi, engages spiritual presences and the singing body in the emergence of a 'more-than-human' sociality within the performers and auditors. 'Humanity' is thus problematised in terms of what the human body can do. 
Panel and paper abstracts: Body07

Body07 Animals' matter: anthropological conceptions of animal bodies as material Convenors: Eimear Mc Loughlin (University of Exeter); Julien Dugnoille (University of Exeter); Elizabeth Vander Meer (University of Exeter)

Magdalen Daubeny: Thu 20th Sept, 14:15-15:45

This panel explores (1) the ways humans control animals as material before life, (2) how through intersubjectivity, other animals can communicate vulnerability and resistance, and (3) how anthropologists, through embodied action and experience, can imagine themselves into the lives of other animals.

\section{4:15-15:45}

Knowing cows: transformative mobilizations of human and non-human bodies in an emotionography of the slaughterhouse

Eimear Mc Loughlin (University of Exeter)

The paper will explore the complex emotions that emerge in the killing of cattle in an industrial slaughterhouse. These emotions complicate the commodification of bovine bodies as workers recognize the individuality of, while simultaneously objectifying, the cattle in their care.

\section{Disappearing lions? Wild animals in circus performance, apparatuses and attunement \\ Elizabeth Vander Meer}

This paper explores ways in which individual lions disappear or become visible within the entertainment spectacle of a French circus, considering apparatuses, the idea of "actuals" in performance theory and expressions of vulnerability and resistance.

"Save time, save money ...grow profitable deer!" - breedwealth and deer Christopher Ward (University of Nottingham)

This paper explores the breeding of deer to achieve certain perfected deer bodies, and what role such practices has had in the creation of new ideals and marketable assets.

\section{Body08 Feeling gender: the power of gendered embodiment}

Convenor: Jessica Sandelson (University of Oxford)

Magdalen Summer Common Room: Tue 18th Sept, 13:30-15:00, 15:30-17:00

This panel focuses on gender at the level of the creative body, moving past debates about its origin (as social/biological, performance/essence). Papers address gender as a bodily feeling, and explore its power to move us. 
Panel and paper abstracts: Body08

13:30-15:00

Beyond the gaze: disordered eating among trans adults in the UK

Jessica Sandelson (University of Oxford)

Drawing on fieldwork with trans adults with disordered eating in the UK, this paper re-considers the relationship between gender, the body and appearance. It explores the power of bodily histories, feelings, and social relationships, to move beyond a focus on the visual.

\section{Dress, photographs and gender among young Bamileke woman in Yaounde} (Cameroon)

Ewa Majczak (Oxford University)

In this paper I explore how young Bamileke women living in Yaounde (Cameroon)

embody gender in practices of photography and dress

\section{Endometriosis and transgender men}

Veronique Griffith (Durham University)

This paper discusses how the enactment of endometriosis (traditionally a gynaecological condition) as a disease of 'women' attempts to cohere with an enactment of endometriosis (largely described by transgender men) who want to move away from the disease's link to 'womanhood'.

$15: 30-17: 00$

Gossip and social control beyond borders: targeting gender and social media in Sahrawi refugee diaspora

Silvia Almenara Niebla (Universidad de La Laguna)

This presentation offers intimate experiences of Sahrawi refugee diaspora and the implication of digital transnational gossip in their everyday media usage practice.

Through a social media ethnography, this proposal analyzes the relevance of gossip as a transnational mechanism of community control.

Injured body and gender: absence of feminine body in the UN's documents of chemical attack in Iran-Iraq war.

Maryam Pirdehghan (the Graduate Institute of International and Development Studies) The study explores the relationships that have caused the marginalization of women, injured in chemical attacks during the Iran-Iraq war and the continuation of violence against them by ignoring their bodies in official documents. 
Panel and paper abstracts: Body09

\section{Body09 Playful bodies, bodies at play}

Convenors: Shireen Walton (University College London); John McManus (British Institute at Ankara)

Discussant: Allen Abramson (University College London)

Magdalen Old Law Library: Tue 18th Sept, 13:30-15:00

This panel attempts a rethink of the theoretical and methodological potential of bodies by considering their role in the realm of leisure. Topics up for consideration include (but are not limited to): rest, play, relaxation, wellness, inequality, the environment and the (im)materialities of leisure.

\section{3:30-15:00}

Slacking, cheating and pretending: creative bodies in kickboxing training Jasmijn Rana (Leiden University)

The enksilment of kickboxing entails more than just training how to fight. This paper discusses how creative ways of wilfully resisting full and active participation and full effort in ladies-only kickboxing training contribute to creating a fun, sociable and leisurely group feeling.

Playing with pain for a chance to grapple with God: evangelical fight ministries in Rio de Janeiro

Jessica Rivers (SUNY Polytechnic, The Dartmouth Institute)

Evangelical fight ministries combine worship with combat sport. In offering a safe space for Christians to play with consensual violence, they provide a unique opportunity to see how Christians invoke voluntarism to imbue with moral significance unChristlike behaviors, like hurting others for fun.

Mauss-tramper $=$ 2nd parking (car-poreality vs. cartesian ethnography). keywords: time; waiting; boredom; adventurous bodies; acceleration and slowness; alternative trans-port

Patrick Laviolette (Tallinn University/UCL)

In Milan, at the EASA conference two years ago, I presented some ethnological workin-progress material based on hitchhiking. The paper was clouded in theory. So before putting the cart before the 'tramper' yet again, this version sketches out some fieldwork data collected since that summer.

Bodies in play: regulation, convention and taboo in representations of the the human body in video games in Japan

William Kelly (University of Oxford)

This paper explores the treatment of the human body in the rating and censorship of video games, focusing specifically on the 'problem' of depictions of hands with four digits and the cultural, historical, political and economic context within which this prohibition has developed and persists. 
Panel and paper abstracts: Body 10

Body10 The creative birthing body

Convenors: Cassandra Yuill (City, University of London); Maria Paula Prates (UFCSPA-

Brazil/ City University of London)

Magdalen Old Law Library: Wed 19th Sept, 09:00-10:30

We invite speakers to discuss reproduction and birth as creative phenomena, focusing on the language, actions and spaces where they converge with broader social and ecological contexts and tensions.

09:00-10:30

Making bodies: childbirth among Mehinaku women

Aline Regitano (State university of Campinas)

Childbirth among Mehinaku women is a process shared with many. Mehinaku women have been chosen the hospitals to have their babies. This paper aims to explore, from bibliographic research and preliminar fieldwork data results how women make sense and experience these processes through their bodies.

Redefining homebirth: ethnographic insights on trusting in Caeté-Açú, Bahia Aischa Schut (Federal University of Bahia, Brazil)

This paper provides ethnographic insights on practices of (embodied) trusting and intimacy surrounding the processes of pregnancy and birth in a particularly homebirthoriented village, focussing on how such practices contribute to the production and redefinition of knowledges about (home)birth.

'Straight Outta Vagina' - how depictions of violence and abuse towards women's bodies, in Western art \& culture, can be seen to influence and perpetuate the incidence of 'obstetric violence'

Laura Godfrey-Isaacs (King's College Hospital)

This interdisciplinary presentation uses feminist film, media and visual arts theory and examples of abusive and violent depictions of women's bodies to suggest how these can be seen to inform our understanding of 'obstetric violence'.

"My son was born sleeping": giving birth to death as a valuable experience Karolina Kuberska (University of Birmingham)

Using interviews with women in England who have experiences stillbirth or late miscarriage, I would like to explore the significance they attach to the labour process, including physical pain, in the construction of familial bonds with their babies. 
Panel and paper abstracts: Body 11

\section{Body11 Rethinking the anthropology of dance}

Convenors: Hélène Neveu Kringelbach (University College London); Georgiana Gore

(University of Clermont Auvergne)

Discussant: Michael Houseman (Ecole Pratiques des Hautes Etudes, PSL)

Magdalen Oscar Wilde Room: Wed 19th Sept, 09:00-10:30, 14:15-15:45, 16:15-17:45

This panel pays tribute to the late Andrée Grau's engagement with dance as fundamental to human sociality (Grau 2016) and interrogates advancements in the anthropology of dance since Gertrude Kurath's 1960 article Panorama of dance ethnology published in the first volume of Current Anthropology.

\section{9:00-10:30}

\section{Dance as an experimental modeling of worlds to come}

Georgiana Gore (University of Clermont Auvergne)

This presentation explores the idea that dancing was and is, as John Blacking stated 'a primary modelling system' (1984:4) or, in other terms, a means of inventing worlds to come in a context where novel relational configurations and innovative ideas may be tested without any stakes at play.

Unifying pleasure, knowledge, creativity and choreography through couple dancing in Norway

Siri Moeland (Norwegian Centre for Traditional Music and Dance)

Based on a specific case study, this paper aims to show how the combination of dance competency and practical dance knowledge in Norwegian couple dancing created '"transcendental" experiences' (Grau 2016) or peak moments for its practitioners.

Embodied negotiations in free-form, transformative dance. Redefining contemporary Western modes of relationship to oneself and to others

Marie Mazzella (LESC - Laboratoire d'Ethnologie et de Sociologie Comparative - Paris Nanterre)

Based on a pragmatic and sensory ethnography of dancing partnerships in free-form, transformative dance, this paper considers practices that dance anthropology has left largely unexplored, and offers a new perspective on contemporary Western modes of relationship to oneself and to the others. 
Panel and paper abstracts: Body 11

14:15-15:45

Connecting ijó dùndún and èdè Yorùbá: dance anthropology as a tool for exploring embodied interpretations of a drum language in South West Nigeria

Natasa Chanta-Martin

This paper discusses social manifestations of the body and its ability to express cultural knowledge through dancing. It focuses on how dance anthropology as a school of thought and methodological approach reaches in-depth understanding of individual experiences in a Nigerian performative context.

The gestorial third - bodies, gesture and the archive Anne Dubos (IAS, Nantes)

In this panel, I will question the negative hands and the mudras as case studies for the 'gestorial third': What happens in-between gestures and images? Between images of gestures (such as archives of theatre, mudras) and images originating from gestures (such as negative hands)?

Between neighbours: the role of Bii Biyelgee dance in the construction of Oirad ethnic categories in contemporary Mongolia

Raphaël Blanchier (Ecole Pratique des Hautes Etudes)

The paper discusses the role of bii biyelgee dance in the construction of Oirad (Western Mongol) ethnic categories through the case of the dance "Brown Silk Dress", a dance shared between neighbouring groups, and similar cases of cross-ethnic transmission of dances.

16:15-17:45

From Buddhist ritual to world healing: transforming cham dance in a diasporic context

Wanting Wu (home)

In this presentation, I describe a Tibetan Cham dance performed at a charity event hosted by a church in River City (pseudonym), a major European City with a significant Tibetan migrant population.

The Nguillatun Mapuche in Santiago of Chile. Modalities of participation and experience in the practice of ritual dances

Argelia Villegas Silva (Université Clermont Auvergne); Geraldine Rix-Lièvre (Blaise Pascal University)

This paper addresses the study of dancers' experience and the modalities of participation during the practice of traditional ritual dances of the Mapuche people in a contemporary urban context. 
Panel and paper abstracts: $\quad$ Cog01

Dancing in the waiting room: appropriating the impermanence of belonging in a refugee camp

Krystel Khoury (Clermont-Ferrand University)

The paper discusses how dance practice in a multiethnic refugee camp in Greece transformed the relationship to oneself and to this off-site (out of sight) space: it generated a paradoxal and new relational dynamics of appropriation of an impermanent territoriality in which belonging is temporary.

\section{Cog01 Locating the mind: social and material agencies in the matter of the mind} Convenors: Veronica Strang (Durham University); Robert Barton (Durham University) Discussant: Noah Walker-Crawford (The University of Manchester)

Examination Schools Room 10: Thu 20th Sept, 09:00-10:30

This panel seeks to reconcile social and material perspectives on the mind and their diverse spatial and temporal scales. Via a question as to where the mind is located, it will explore different disciplinary and cultural understandings about the internal and external agencies that compose the mind.

\section{9:00-10:30}

\section{Locating 'mind' cross-culturally}

Frances Morphy (Australian National University); Howard Morphy (Australian National University)

Is it productive to take 'mind' as a starting point for cross-cultural or cross-temporal comparison? The answer is a qualified 'yes', if mind is seen not as a 'thing' but as a metacategory for analysing how different cultures conceptualise mental states and processes in language-specific ways.

The mind reflected in water: cultural and evolutionary perspectives on cognitive engagement with social and material worlds

Veronica Strang (Durham University); Robert Barton (Durham University)

Supporting an interdisciplinary discussion bringing evolutionary and cultural anthropology together, this paper considers how systematic consideration might be given to cognitive engagements with social and material agencies, and the processes through which the mind is composed.

\section{Bodies, minds and automated vehicles}

Elia Vardaki (Technical University of Crete)

My interest is to explore the effects of the Automated Vehicles in human cognition, in knowledge transmission, memory practices, spatial and temporal perception. 
Is mind the 'gap' in early years intervention? Preliminary reflections on the relationships between neuroscience and adoption

Nayanika Mookherjee (Durham University)

This paper seeks to make preliminary explorations into the process through which a baby's mind is 'scanned', assumed to be 'hardwired' and how that is translated into government policies on adoption.

\section{Cog02 Creative environments, social minds}

Convenors: Kåre Poulsgaard (University of Oxford); Chris Goldsworthy (University of Oxford)

Chair: Lambros Malafouris (University of Oxford)

Discussant: João de Pina-Cabral (University of Kent)

Examination Schools Room 10: Fri 21st Sept, 09:00-10:30, 11:00-12:30, 16:00-17:30

New embodied and enactive approaches to cognition highlight how humans inhabit relational worlds that vitally shape our capacity for thought and action. How can these approaches help us study creativity and imagination as fundamentally situated within shifting synthetic and social environments?

09:00-10:30

\section{Haunted in Macau: the anthropology of participation}

Joao Pina-Cabral (University of Kent)

The notion of being haunted has a long history in anthropological literature. It is part of that fascination that twentieth century anthropologists have had with what they called "magic."

\section{Situated absence: creative spaces of uncertainty in master planning practice}

Shira de Bourbon Parme (Institute for Science, Innovation and Society, University of Oxford)

This paper asks how master planners collectively make sense of future imaginaries in everyday practice. Drawing on ethnographic research, it posits that the entanglements of distributed cognition enact contingent relationships and enfold uncertain conditions into coordinated creativity.

\section{Among imagined and experienced stability: ethnography of Ayurveda self-care practice}

Alžběta Wolfová (Charles University in Prague, Faculty of humaninites)

Ayurveda, a specific knowledge about human well-being, is translated into a different understanding of oneself and one's own life. Building upon an ethnographic research of Ayurveda self-care practice, I discuss how the imagined individual stability is contested through embodied and social practice. 
Panel and paper abstracts: $\quad$ Cog02

The tension between creativity and truth—the replication crisis and the structure of science

Alexander Bird (King's College London)

Scientific creativity is prized, but it is in tension with the aim of truth. We hypothesize that the structure of science overvalues creativity at the expense of truth/knowledge, as is shown, we argue, by the replication crisis. We consider means of rebalancing the social structures of science.

\section{1:00-12:30}

\section{Ecologies of creativity and a new cultural evolution}

Niels N. Johannsen (Aarhus University)

Cultural evolution studies have detailed factors allowing for the relatively faithful transmission of information, skills and practices. I explore how alternative forms of evolutionary thinking can be productive for understanding its dialectical opposite in culture, i.e. the role of creativity.

\section{“Blade Runner or Altered Carbon?" and the delegation of memory: revisiting old perspectives on technical objects.}

Ludovic Coupaye (University College London)

Starting from of recent interests in AI, Cyborgs and Enhanced Humanity, this paper uses Leroi-Gourhan's "delegation of memory" and Simondon's analysis of technical objects, to examine the type of (real and imagined) situated practices afforded and promoted by contemporary and future digital devices.

"The horses, they just know": the sensory correspondence of horses and humans in equine therapy practice

Roslyn Malcolm (University of Edinburgh)

This paper explores the correspondence of horses and humans across moments of movement and repose in the context of horseback therapy for autism in the UK.

The phenomenon suggests a highly embodied form of sociality enacted in temporal engagements across humans and horses.

Dynamics of embodiment, material culture, and the flesh of the world Tailer Ransom (University of Memphis)

I will be giving an account of how Merleau-Ponty's later works and its emphasis of the reversible structure between the flesh of the body and the flesh of the world can both enrich, and be enriched by Material Engagement Theory's entangled account of cognition. 
All the world's a stage: acting in the affordance space

Shaun Gallagher (University of Memphis)

I use the theatrical concept of blocking to investigate the role of affordances in everyday

life. This allows us to think of architectural and institutional design as in some way directing our actions, and provides a perspective on the normative constraints that guide our actions.

\section{Creative processes at the intersection of social cognitive forms}

Chris Goldsworthy (University of Oxford)

Drawing upon field work examining the research and clinical practice in the field of cardiac genetics, this paper will examine the consequences of understandings of the social mind on creative, productive processes across institutional boundaries defined by heterogeneous forms of cognition.

The men on the mountainside: an ethnography of solitude, silence and sheep bells Alex Archer (University of Cambridge)

Concerned with the lived experience of shepherding in the Carpathian Mountains, this paper engages with shepherd's experience of solitude and silence and the way the mountain environment shapes and is shaped by shepherds' interaction with the nonhuman phenomena that constitutes that environment.

\section{Flexibility of mind by design?}

Kåre Poulsgaard (University of Oxford)

This paper explores productive overlaps between anthropological theory and enactive and social concepts of mind. It asks how recent work in cognition can help us study creativity and imagination as fundamentally situated within shifting synthetic and social environments.

\section{Cog03 Cultures of metacognition}

Convenors: Jonathan Mair (University of Kent); Joanna Cook (UCL)

Examination Schools Room 10: Tue 18th Sept, 13:30-15:00, 15:30-17:00

Cultures of metacognition brings ethnographic focus on the ways in which people theorise, experience and otherwise relate to their minds. We will explore the ways people conceive of knowledge, belief, ignorance and expertise, to understand the consequences of specific modes of thought about thought. 
Panel and paper abstracts: $\quad \mathrm{Cog} 03$

\section{3:30-15:00}

\section{Cultures of metacognition}

Jonathan Mair (University of Kent); Joanna Cook (UCL)

This paper argues for the adoption of a psychological concept, 'metacognition', by anthropologists, on the basis that the phenomena it describes--thought about thought--is not only a characteristic of individuals, but can be learned and taught.

At the edge of disciplinary minds: meta-cognition and inter-disciplinary collaboration in a German university

Lianghao Dai (Georg-August-Universität Göttingen)

Based on a long-term fieldwork with biologists, statisticians, and physicists in a German university, this paper opens the'black box'of cognitive mechanics and explores how researchers negotiate different cultures of cognition collectively in interdisciplinary collaborative projects.

Mindful, mindless, absent-minded or thoughtlessly dangerous?: north-western amazonian reflections on embodied virtue

Elizabeth Rahman (University of Oxford)

Managing moods, attitudes and dispositions is a constant task for Amazonian bodies "that know". Mindless, flighty behaviours and not "knowing how to sit" indicate a lack of personal capacity, but thoughtless can be truly dangerous when it results in a complete lack of care and becomes malicious.

\section{5:30-17:00}

Studying psychological therapies: an ethnographic approach to 'metacognition' Mikkel Kenni Bruun (University of Cambridge)

This paper examines 'metacognition' ethnographically, based on fieldwork among practitioners of psychological therapies in the UK. It considers some theoretical and empirical tensions that arise in dealing with 'metacognition' in both psychology and anthropology.

'The ethics of experience': metacognition in mindfulness-based cognitive therapy and anthropology

Joanna Cook (UCL)

Taking Mindfulness-based Cognitive Therapy in the UK as its ethnographic focus, this paper argues that MBCT participants characterise metacognitive ability as constitutive of human flourishing and seek to develop a markedly committed relationship with their own objectified minds. 
Cog04 Laughter, bodies and the evolution of morality

Convenors: Camilla Power (University of East London); Morna Finnegan

Examination Schools Room 10: Thu 20th Sept, 14:15-15:45

Did morality evolve through Bakhtinian cultures of laughter expressed through the collective (female) body? Is the 'morality' of hierarchical societies in fact anti-morality for egalitarian societies, a result of - and attempt to justify - the failure to share properly?

14:15-15:45

\section{Corporeal morality}

Morna Finnegan

What connects cognitive and somatic intelligence? What drives the extraordinary human interest in sharing and caring? I use the Mbendjele and Ju/hoan terms "Ekila" and "N/ om" respectively to propose that morality is fundamentally a corporeal element: it must be experienced in order to remain live.

"Now he smells nicer (he returned with meat), I will cook his penis tonight" Daša Bombjaková

Transactions and transformations involving sex and meat have discomforted feminists dubious of this mode of women's empowerment. I examine Central African huntergatherer women's ways of asserting egalitarianism through a 'politics of eros'.

\section{The evolutionary emergence of laughter as a levelling mechanism}

Chris Knight (University College London)

Laughter is best conceptualized as the reverse image of primate-style aggressive mobbing - mobbing under relaxed, tension-free social conditions. Its emergence was bound up with the overthrow of dominance and its replacement by sexual-political reverse dominance.

\section{Sharing like sisters: ritual, egalitarianism and the morality of cosmetics exchange among Slovak women}

Elena Fejdiova (University of East London)

In the environment of direct sales cosmetics collectives of women in contemporary Slovakia created and maintained their morality of sharing through uproarious collective cosmetic rituals - an expression of the Bakhtinian 'culture of laughter'.

\section{The Hadza world turned upside down}

Camilla Power (University of East London)

Laughter and rough bodily provocation during maitoko initiation is crucial for Hadza women and girls in asserting gender egalitarianism. As girls 'hunt' men over several days of sport, they re-present an earlier 'matriarchal' moral order. 
Panel and paper abstracts: $\quad$ Cog05

Cog05 The evolutionary origins of ritual

Convenors: Rohan Kapitany (University of Oxford); Harvey Whitehouse (Oxford

University)

Examination Schools Room 10: Wed 19th Sept, 09:00-10:30, 14:15-15:45

How did ritual emerge in human evolution and how has it changed with the rise of social complexity in historical time?

\section{9:00-10:30}

\section{Rituals and groups}

Harvey Whitehouse (Oxford University)

There are compelling hypotheses about ritual in creating groups and fuelling conflict.

Research suggests that rituals not only demarcate groups but varying features of rituals produces different scales/intensities of group alignment, suited to addressing distinct collective action problems

\section{How religious rituals become emotional symbols}

Valerie van Mulukom (University of Oxford)

Memories of experiences of high-arousal religious rituals become important emotional symbols through unusually large increases in dopamine. This dopamine theory explains not only the ongoing motivation of participants, but also informs theories about the evolution of the earliest forms of religion.

\section{Psychological and physiological effects of synchronised dance} Bronwyn Tarr (ICEA)

Synchronised movement is a common component of rituals across cultures. Recent empirical evidence from lab-based studies demonstrates the psychological and physiological effects of group synchronised dance. Evidence will be discussed in the context of ritualized movement more broadly.

\section{Why do we say "goodbye"? A cross-species comparison of leave-taking}

Lucy Baehren (Cognitive and Evolutionary Anthropology)

Although greeting is well studied in many species leave-taking has been largely ignored. In the first cross-species study on leave-taking I seek to identify its evolutionary origins: does it relate to the risk of separation, or play a functional role in maintaining cohesion? 


\section{The ritual game}

Martha Newson (University of Oxford)

This talk uses football fans to illustrate cognitive understandings of ritual. How do shared ritual experiences (i.e. matches) facilitate group bonding? What effects do these bonds have on group behaviours? And can ritual be used to tackle football violence and disorder?

\section{Social bonding happens in time: interpersonal synchronisation in the silent disco} Joshua Bamford (Institute of Cognitive and Evolutionary Anthropology)

As a ritualised behaviour that brings people together in shared space and time, dance appears to serve a social bonding function with may have evolutionary value. This study investigates the contributions of shared experience and synchronisation of movement to the social bonding effect of dancing.

\section{Ritualized action and over-imitation}

Rohan Kapitany (University of Oxford)

I will discuss the role ritualized action has played in the development of human culture. Specifically, how the cognitive interpretation of ritualized actions may have facilitated the formation of groups and material culture, and led to 'ritual' itself.

\section{Cog07 Throwing together ways of being/meaning: recursive anthropology at the cusp of a paradigm change [Roundtable] Convenor: César Enrique Giraldo Herrera (University of Oxford) \\ Discussant: Tim Ingold (University of Aberdeen) \\ Examination Schools Room 10: Wed 19th Sept, 16:15-17:45 \\ As anthropologists we are increasingly taking seriously the onto/epistemologies of people we work with \& that nonhumans are creative \& make sense of the world. Through entanglements with other ways of being/meaning papers will explore what these may offer the recursive re-creation of anthropology.}

$16: 15-17: 45$

Land-mined landscape: war artifacts, embodiment, environment and territory Liliana Duica-Amaya (Universidad de los Andes)

The present paper is the result of the ethnographical fieldwork developed in Vista Hermosa, Meta (Colombia) aimed to identify a multiple set of connections among humans and non-humans, environment and war, whose axis is the landmine. This is what I have called land-mined landscapes 
Panel and paper abstracts: $\mathrm{CreO1}$

Eight-armed rebels: what octopus semiosis means for anthropologists

Amy Garey (University of California, Los Angeles)

Semiotician Thomas Sebeok argued in 1980 that apes could not learn human language.

But do they have languages of their own? This paper reads new biological research through the lens of Peircean sign theory to explore how intelligibility equals privilege when human and nonhuman codes collide.

The resonance of gratitude in creative practice and the spiritual wisdom of indigenous ways of knowing: a call for an enchanted anthropology Rodrigo Ferrari-Nunes (University of Aberdeen / Universidade Metropolitana de Santos) I posit that gratitude generates a positive resonance according to many indigenous ways of knowing and that we should reject materialist concepts from Freudian, Darwinian and Marxian theories.

\section{Cre01 Anthropology of light: art, skill and practices}

Convenors: Cathy Greenhalgh (Central Saint Martins, University of the Arts London); Eni Bankole-Race (Royal College of Art); Lucy Williams (University of the West of England) Examination Schools Room 9: Fri 21st Sept, 09:00-10:30, 11:00-12:30

This panel welcomes papers from practitioners and interdisciplinary researchers of light and investigates approaches to light requiring forms of artful and 'skilled vision' (Grasseni, 2009) and a "creative eye".

\section{9:00-10:30}

\section{The dark side of light: prolegomena to an anthropology of shadows}

Thomas Reinhardt (LMU Munich)

Based on the analysis of artists working with shadows (Yamashita, Kagan, Gallagher), the talk delimits the range of an anthropology of shadows and proposes an unbiased reassessment of 'light's dark sibling'.

Pinhole perceptions - an auto-ethnography of Venetian light using experimental camera obscura techniques.

Lucy Williams (University of the West of England)

The paper considers the capture of light with examples of my auto-ethnographic experimental video work in lens-less (pinhole) undertaken in Venice.

"leštění"/ "polishing": carving light with glassmakers in the Czech Republic. Elishka Stirton (University of Aberdeen)

In this paper I will describe the process of bringing a facet of glass to a high shine, exploring how this entails a requirement to attend to the material's relation with light. 
The luminous face: cinematographic lighting culture and practices.

Cathy Greenhalgh (Central Saint Martins, University of the Arts London)

This paper considers cinematographers' skilled vision and cultural approaches to lighting the face, eyes and skin in fiction cinema - using ethnographic research, pedogogic praxis on gender and diversity and recent diasporic and world cinema examples.

\section{1:00-12:30}

\section{Walking through Australian landscape with light}

Tim Edensor (Manchester Metropolitan University)

This paper seeks to explore how walking through a rural area of Victoria, Australia, is continuously characterised by encounters with light. Light solicits attention, usually unreflexively, in how it is deflected, absorbed or reflected, attuning bodies towards the close at hand or the distant

\section{The light art of Burning Man}

NK Guy

The Burning Man arts festival in Nevada, USA, is inextricably tied with the use of anthropogenic light as a form of artistic expression. This article explores the origins of this unorthodox use of light as a tool for individual artistic expression and social engagement

\section{Light on skin: cicatrisation and beauty among the Yoruba}

Eni Bankole-Race (Royal College of Art)

This paper investigates the symbolism and aesthetic value/significance of cicatrices in traditional Yoruba culture, and examines the secondary patterns formed by the play of light and shadows on these sculptures in the skin.

\section{Illumination and emanation: light as body adornment and the implications of wearable light. \\ Ulrike Oberlack (Central Saint Martins)}

This paper discusses findings and process of practice-based research into wearable light focusing on light as a medium in interaction with the body as a dynamic projection surface. A reflective and adaptive methodology characterises the process across a series of solo and collaborative projects.

\section{Cre02 Tracking bodies, tracking relationships: from self-control to quantified} subjectivities and creative communities

Convenors: Michael Crawley (Edinburgh University); Alexandra Oanca (Universidade do Vale do Taquari - Univates)

Examination Schools Room 8: Fri 21st Sept, 16:00-17:30

This panel invites proposals that consider the micro study of big data through self- 
Panel and paper abstracts: $\quad \mathrm{CreO3}$

tracking devices, the social construction of the market for wearable technology, and the way class, gender and race/ethnicity structure these aspects. Rather than focus on the commodification of data and the self, we examine collaborative bodies and the use of devices to connect with other (non-) humans.

\section{6:00-17:30}

Wearable cameras, in-visible breasts: reflections on doing feminist research with wearable camcorders

Asli Duru

Based on ethnographic work on everyday violence in Istanbul, the paper is a chestspecific analysis of using GoPro as research tool. The key questions are: how wearable camcorders as research tool co-constitute visibility, movement and gender and what responses emerge from these intersections.

'If we tie something to your hand it will be easier for you': the use of GPS technology by Ethiopian long distance runners.

Michael Crawley (Edinburgh University)

This paper explores the increasing use of GPS tracking devices by Ethiopian long distance runners, describing how they transform the socially valued skill of 'sharing the pace' and how they are drawn into wider relationships of control, submission and collective work

'To take control of your life, you must control your body through data': wearable devices, quantified subjectivities, and the limits of body hacking

Alexandra Oanca (Universidade do Vale do Taquari - Univates)

Individuals turn to digital wearable devices as creative tools to hack their bodies and their lives. In addition to the limitations imposed by the drive for profit of capitalist companies, the human body is a hacking site that is messy and constantly evades our attempts at total classification.

\section{Cre03 Play things: materiality, time, and imagination}

Convenors: Thomas Boylston (University of Edinburgh); Anne Dippel (Friedrich-SchillerUniversität Jena)

Examination Schools Room 9: Tue 18th Sept, 13:30-15:00, 15:30-17:00

How do playthings shape shared imaginations and social possibilities? 
Papua New Guinea slot machines and playing at loss

Anthony Pickles (University of Cambridge)

Windfall male slot machine players in Papua New Guinea are bled just like anyone else.

Their experience is of the joy of heavy transaction and lavish alcohol consumption, with loss as liberation from enduring obligation networks. How is this asymmetrical collaboration cordoned off as male 'play'?

One is never alone without a rubber duck": toys and their magic aura in science and technology

Anne Dippel (Friedrich-Schiller-Universität Jena)

This paper investigates materiality and imaginative quality of toys as magic objects. Based on ethnographic research of physics culture, it traces the pathways of rubber ducks out of their bathtub habitat, into the outskirts of science fiction universes and the heartlands of science at CERN.

Playing with the baby-oiled floor: the practice and imagination in the Taipei Dance Circle

Yu Chun Chen (University of Roehampton)

To develop new kinaesthesia in modern dance, the Taipei Dance Circle used baby oil to alter the friction between dancers' bodies and the floor, bringing about different sensory modes, self-imagination, aesthetic and human-object relationship.

Reborn dolls: valued replicas of babies or objects of revulsion?

Helen Driscoll (University of Sunderland); Rosalind Crawley (University of Sunderland);

Heidi Lindsay

Reborn dolls are hyperrealistic, resembling babies. Women owners often interact with them as real babies. Reborns evoke strong reactions, positive and negative. This first large-scale study of reborn ownership explores reasons for ownership and owners' accounts of reactions to them and their dolls.

$15: 30-17: 00$

\section{Gyroscopic thinking}

Lina Hakim (Kingston University)

This paper takes the gyroscopic spinning-top as a case study to explore the ways in which playthings shape the thinking that they put into play.

Playing with sound: new potentials of tangible audio interfaces for the museum mediation of culture and human agency

Sonja Grulke (Humboldt University Berlin / studio klv)

Since sound is not only able to capture the temporal and thus serve as storage of culture, playful actions can reveal this knowledge through its temporality. In the exhibition context tangible audio interfaces can therefore give new access to collective meanings. 
Panel and paper abstracts: $\quad \mathrm{CreO4}$

Hide and show: How Baining masks and pythons make relationships

Inna Yaneva-Toraman (University of Edinburgh)

The paper explores masks and pythons as playthings among the Baining and argues that through reconfiguring one's presence in terms of visibility and invisibility, and creating a break from everyday relations of shame and respect, they shape processes of social reproduction and self-presentation.

Toys, icons, and the anthropology of imagination

Thomas Boylston (University of Edinburgh)

Are toys like icons? A paper on religious kitsch, play, and imagination.

Cre04 Recognition and innovation: how creativity is evaluated and envisaged Convenors: Iza Kavedzija (University of Exeter); Dolores Martinez (SOAS)

Examination Schools Room 8: Wed 19th Sept, 09:00-10:30, 14:15-15:45, 16:15-17:45

This panel seeks to further the discussion of imagination and creativity by focusing on anthropological approaches to innovation. How does the imagined become real? How might anthropologists move beyond ontological discussions of 'being' and onto exploring processes of 'making' and 'becoming'?

\section{9:00-10:30}

Discourses and practices of creative recognition: Czech experiences of artistic becoming in times of political change

Maruska Svasek (Queen's University Belfast)

Rejecting simplistic oppositions of 'socialism' versus 'post-socialism', this paper will provide an insight into the making, unmaking and re-making of artistic reputations in the Czech artworld,examining dynamics of artistic in/visibility and people-thing dynamics from 1948 to 2018.

\section{Valuing music: creativity and Spotify's algorithm}

Thomas Hodgson (King's College London)

Drawing on rich ethnographic research, from rehearsal rooms, recording studios and record labels, this paper explores how the algorithms of digital streaming platforms, such as Spotify, are increasingly shaping the creative process of musicians and the kinds of value they produce.

\section{Small spaces of amplification: "island universes" of creativity in Tokyo street music} Robert Simpkins (SOAS, London)

This paper explores how street musicians in Tokyo restrict their musical practices to small spaces and tightly bounded social groups in order to create the conditions within which they become recognised as the artists they imagine themselves to be. 
Panel and paper abstracts: $\mathrm{CreO4}$

\section{Creativity, enskillment and recognition among Japanese contemporary artists}

Iza Kavedzija (University of Exeter)

This paper explores the role of recognition and enskilment in the creative activities of young contemporary artists in Osaka, Japan. It argues that making in this context is to a large extent a collective process, one that often occurs at the boundaries of recognizable genres.

14:15-15:45

Creativity in reproduction, circulation, and consumption of popular cultural products

Hoi Yan Yau (Lingnan University); Heung-wah Wong (The University of Hong Kong) This paper investigates anthropologically the social process in the spread of Japanese popular-cum-cultural products in Hong Kong. Creativity is defined by the historical effects, which depend on the reciprocal mediation between the Japanese popular cultural products and the Hong Kong society.

\section{Reification and recognition in Egyptian film production}

Chihab El Khachab (University of Oxford)

This paper examines how "invisible" labour is recognised among artistic and technical workers in the Egyptian film industry. Innovation, in this context, is the ability to avoid having one's work "reified", i.e., become invisible and forgotten once it is invested in concrete production practices.

16:15-17:45

Imaginative self-narratives, science fiction writing, and planetary ethnographies Lisette Josephides (Queen's University Belfast)

This paper considers the extent to which real worlds are created through imaginative narrative. I examine three kinds of narratives: the self narratives of village people, science fiction writing, and planetary ethnographies that consider how to live on other planets.

\section{The place of flying saucers in a genealogy of space flight}

Timothy Jenkins (Cambridge University)

Flying saucers are imaginary objects which, for a short period, shaped a scientific hypothesis - the 'interplanetary' hypothesis of early 50s Intelligence work - and then gained an independent afterlife with a variety of traceable effects: a case study of creativity and unintended consequences. 
Panel and paper abstracts: $\quad$ Cre05

The eureka moment: dreaming at the boundaries of ethnology, archaeology, and cosmography in Southwest China

Katherine Swancutt (King's College London)

This paper explores the dreams of 'native' ethnologists among the Nuosu, a Tibeto-

Burman group of Southwest China, who re-envision their animistic cosmology in light of priestly, ethno-historical, and archaeological evidence. It shows how dreams launch imaginative rewritings of cosmographic history.

Cre05 Making accounts count: imagination, creativity, and (in)coherence Convenors: Christina Woolner (University of Cambridge), Rosie Jones McVey (University of Cambridge), Amy Binning (University of Cambridge)

Chair: Alessandro Duranti (UCLA)

Examination Schools Room 9: Thu 20th Sept, 09:00-10:30, 14:15-15:45

This panel explores the creative work involved in making accounts of and for oneself and others in various ethnographic contexts. What and how are these accounts produced, and what are the ethical, political, and affective dynamics of imagining selves/others in order to produce such accounts?

09:00-10:30

Re-imagining oneself by reimagining Scotland; future orientated account making Gabriela Manley (University of St Andrews)

This paper explores the process of future orientated imaginations of Scotland and their role in making accounts of oneself and others within the SNP. It will focus on political accounts of identity and belonging in relation to the current volatile political climate in the UK.

Sacred texts, speaking gifts: imaginative labour in the making and giving of Tibetan Buddhist texts

Amy Binning (University of Cambridge)

This paper investigates the ways in which account-making is a critical practice in the creation and distribution of sacred Tibetan Buddhist texts. Sacred texts are often personified and understood as "speaking" objects, imaginative labour is essential in bringing these agentive objects to voice.

Giving love voice: imagination, empathy and "taste" in the making of Somali love songs

Christina Woolner (University of Cambridge)

This paper explores the imaginative, empathic and ethical work that goes into making a Somali love song - a multi-vocal account-making process in which a poet, musician and singer each have a part to play in conveying the "taste" of another's love(-suffering) experience. 
Panel and paper abstracts: $\mathrm{Cre05}$

Ethnographic account making from shared practical knowledge: how to write about collective intentionality

Anna Christen (University of Basel, University of Konstanz)

How do we account for intersubjectivities in ethnographies? Comparing writings of philosophical thought experiments about shared intentions with anthropological vignettes, I will explore the salient properties of two writing genres that both seek to capture the essence of collective intentionality.

14:15-15:45

“To look right, to fit in": teenage anorexia, the spiral of silence, and graphic medicine Anu Mary Peter (National Institute of Technology), Raghavi Ravi Kasthuri (National Institute of Technology, Trichy), Senthil Babu M K (Madanapalle Institute of Technology and Science)

This paper explores how the fear of isolation and rejection acts as a socio-cultural catalyst for the rise of teenage anorexia. Additionally, this paper also divulges how graphic medicine enables sufferers to make sense of their disintegrated socio-cultural world.

How much a dollar cost? Commensurability and coherence in the London neighbourhood of Kilburn

Farhan Samanani (University of Oxford)

This paper looks at how residents of the London neighborhood of Kilburn negotiate incoherence and emergence within their own biographies, by asserting various frames of coherence. Using this as a lens, it interrogates broader trends within anthropology which have tended to valorise incoherence.

\section{Infantilisation three ways; metalinguistic conflict and 'not-quite-real' framing in} British horsemanship

Rosie Jones McVey (University of Cambridge)

British equestrians are liable to describe their horses in child-like terms, yet also to critique that same practice. I demonstrate frictions between three language ideologies, and argue that contemporary horse owners must manage changing epistemological responsibilities of care.

Ways of knowing the past: territory and memories of Li and Han ethnicity in the island of Hainan

Ze Chen (School of Oriental and African Studies)

This paper compares accounts of ethnic unity/enmity in Li and Han ethnic communities in the southwestern island of Hainan, Southern China. It explains how politics of memorizing/forgetting past sustain the ethnic boundaries in present. 
Panel and paper abstracts: $\quad$ Cre06

\section{Cre06 Creativity in crisis: arts in the age of austerity}

Convenors: Ioannis Tsioulakis (Queen's University, Belfast); Evropi Chatzipanagiotidou

(Queen's University Belfast); Fiona Murphy (Queens University Belfast)

Examination Schools Room 8: Thu 20th Sept, 09:00-10:30, 14:15-15:45

The panel invites proposals that examine creative practice within conditions of economic and social crisis. We welcome papers addressing one of the following themes: languages of coping and articulation of crisis vocabularies, strategies of survival among artists, the emergence of crisis aesthetics.

\section{9:00-10:30}

'Arts matter': language, strategy, and value in protest

Kayla Rush (Queen's University Belfast)

Since 2010, austerity-led cuts to the Arts Council budget in Northern Ireland have devastated the region's arts scene. This paper examines the local art world's responses, focusing on the language used to argue for the value of increased funding and on the protest strategies employed.

\section{Precarious pathways to creativity: musicians navigating the Greek crisis} Ioannis Tsioulakis (Queen's University, Belfast)

The proposed paper will examine how professional musicians in Athens calibrate their employment strategies, creative outputs, and conceptualise their personhood within the context of the Greek financial and socio-political crisis.

Peril, petroleum, and passports: artistic responses to crisis and recession in the Gulf Melanie Janet Sindelar (Internationales Forschungszentrum Kulturwissenschaften Wien \& Max Planck Institute for Social Anthropology, Halle)

In this paper, I show how immigrant artists in Dubai navigate their art practice after the financial crisis that has hit Dubai in 2008. The city might have recovered, but how did it affect immigrant artists?

Learning music as a game: resisting the creative and socioeconomic crisis in Brazil with education and invention

Rodrigo Ferrari-Nunes (University of Aberdeen / Universidade Metropolitana de Santos) This paper focuses on the creative trajectory, practices and epistemology forged by a group of three collaborators who sought to resist the current creative and sociocultural crisis in Brazil by forging a multifaceted and growing music education project. 
What can art be in Palestine? Relating the discourse of the artist as an oppositional figure to the notion of 'resistance' and emancipatory politics in Palestine

Helen Underhill (SOAS, University of London)

This paper explores how artists conceive of their role in relation to the political struggles that characterise the social space in Palestine. How do they relate to attempts to either instrumentalise contemporary art as a nationalist endeavour, or to excoriate it for not contributing to the same?

\section{Viva la transition! Contemporary art and avant-gardism in Bosnia-Herzegovina's frozen crisis \\ Matthew Webber (UCL)}

For much of the last 20 years, contemporary art in Bosnia has been dependent on international support. As this support wanes, this paper will look at its legacy: the creation of new mechanisms for producing contemporary art, and a more recent resurgence of avant-garde artistic practices.

\section{Cre07 Blending, meaning and imagination}

Convenors: Jordi Vallverdu (Universitat Autònoma de Barcelona); David Eubelen (Université Libre de Bruxelles); Corentin Chanet (ULB (Université Libre de Bruxelles)) Examination Schools Room 9: Wed 19th Sept, 16:15-17:45

This panel explores perceptual and conceptual blending processes as the emergence and communication of meaning on various levels (cognitive, cultural, linguistic, etc.) and their crucial role in the comprehension of human imagination.

$16: 15-17: 45$

\section{Constructing a concept of number}

Karenleigh Overmann (University of Bergen)

Numbers are concepts influenced by material forms used to represent and manipulate them. The inclusion of multiple forms is the mechanism of numerical elaboration. Further, variety in forms explains the synchronic and diachronic variability exists between and within cultural number systems.

\section{Intertextuality and conceptual blending in endometriosis pain narratives}

Stella Bullo (Manchester Metropolitan University)

This paper investigates the conceptualisation process of endometriosis pain by drawing on conceptual blending theory. The article poses that pain narratives that rely on intertextual and interdiscursive references can be seen as evidence of the conceptual integration process. 
Panel and paper abstracts: $\quad$ Cre08

Synchronization, fictive interaction, and phatic communication: more phenomena relating conceptual blending, multilevel grounding, and emergence of creative meaning

Mihailo Antovic (University of Nis)

The paper extends my theory of "multi-level grounding", which constrains the process of emergence of meaning based on conceptual blending, to three new multimodal phenomena relating language, music and visual imagery: "embodied synchronization", "fictive interaction", and "phatic communication".

Imaginative blending in and through translation into a minority language Manuela Pellegrino (Smithsonian Institution)

In this paper I explore blending processes at play specifically in the context of translation from Italian into Griko -a minority language of Greek origins spoken in Southern Italyand investigate the social repercussions they produce on languages, speakers and their environment.

\section{Cre08 Time and tradition: theorising the temporalities in and of cultural} production

Convenors: Georgina Born (University of Oxford); Jonas Tinius (Humboldt-Universität zu Berlin)

Examination Schools Room 8: Tue 18th Sept, 13:30-15:00, 15:30-17:00

Examination Schools East School: Wed 19th Sept 09:00-10:30

How is time configured in processes of artistic and cultural production? And what does this tell us about ideas of history, tradition, and imagination? This panel invites papers that theorise the multiple temporalities of creative practices across the arts, music, and cultural production.

\section{Tue 18th Sept, 13:30-15:00}

Resonances - music of the past in the making of the future Alina Apostu (SOAS)

How much give does the past have in the making of a future?

Multiple temporalities in intercultural musical performance: imagining the future by bringing the past into the present

Kristina Kolbe (London School of Economics and Political Science)

Looking at music improvisation in an intercultural setting, I trace how different musical and migration histories are being articulated in the microsociality and microtemporality of the musical performance and how such articulations of the pasts make imaginations of postmigratory futures possible. 
Panel and paper abstracts: $\mathrm{CreO8}$

Recalibrating complex multi-temporality in musicking with contemporary views of complex systems

Juan M. Loaiza

The presentation highlights a heuristic view of the complex multi-temporality of musicking. It introduces concepts from contemporary complexity-based sciences that shed light on the emergence of patterns and regularities of experience and cultural production.

\section{Rituals of refurbishment: remembering/remediating Philip Rawson's Tantra exhibition}

Chris Dorsett (Northumbria University); Janaki Nair (Northumbria University)

The recent refurbishment of the Hayward Gallery prompts memories of the Indologist Philip Rawson curating the 1971 Tantra exhibition in what was then London's key art venue. Our paper remembers and remediates the gallery and the exhibits using rituals recognisable to the Indian diaspora 50 years on.

$15: 30-17: 00$

Curating the colonial past and a Pan-African future in the making of a reputable arts center in Johannesburg, South Africa

Lotte Nielsen (Basel University)

Colonial and apartheid pasts and convivial Pan-Africanist futures are at the centre of a curational process of "filling up" an arts centre in Johannesburg, SA. The politics of time entangles with art practices and architectural visions in presenting diverse imaginations of the art centre's future.

The Bright Wake: facing the past in post-colonial Fiji

Chloe Colchester (Oxford University)

Why does tapa-making continue in the South West Pacific, even now? By discussing the emergence of an Oceanic theory of space-time in the post-colonial literature we may be in a better position to understand how tapa imagery came to sustain rival temporalities in colonial and post-colonial Fiji.

Mesogenesis as the developmental scale of craftsmanship: the case of luthiery Pablo Rojas (EHESS-IMM)

I will argue that craftsmanship, as defined here, is home to a temporality or a developmental scale that is characteristic of skillful action. My short discussion will include a description of such 'mesogenetic' scale taking luthiery, including my practice as well as historical cases, as examples. 
Panel and paper abstracts: $\quad$ Cre09

The tempo of care in the paper swan folding ritual

Keren Mazuz (Hadassa academic college Jerusalem)

In Israel, folding paper swans is performed by migrant workers from the Philippines employed as live-in caregivers. Folding swans is an imaginative tool using the most immediate and accessible materials - paper and glue- for ordering the daily lived experienced as caregivers.

\section{Wed 19th Sept 09:00-10:30, Examination Schools East School}

Between nationalism and "creative minds": the multiple pasts of Margate, in England Ana Carolina Balthazar (Pontifícia Universidade Católica do Rio de Janeiro (PUC-Rio)) Based on long term ethnographic research, this paper analyses the two different constructions of time that emerge and collide among the practices to "regenerate" Margate, in England: the past as a marketable tool to attract tourists or as connected to nationalistic memories and local routines.

\section{Art and human evolution: connecting the time of art with the art of time} Brecht Govaerts (University of Oxford)

This paper examines how the production of time in art is related to the role of art within long-term processes of human evolution. This question is addressed through the intimate connection between aesthetics, ontology and human evolution present within the philosophy of Hegel and Whitehead.

\section{$\mathrm{Re} /$ mediating revolutionary history: the work of artist in the post-Fidel era} Yanina Gori (University of California Los Angeles (Ucla))

This presentation explores how political economic transformation in contemporary Cuba is re/mediated trough the work of artists and cultural producers.

\section{Cre09 Sounding and performing resistance and resilience} Convenors: Hastings Donnan (Queen's University of Belfast); Fiona Magowan (Queen's University Belfast)

Examination Schools Room 8: Fri 21st Sept, 09:00-10:30, 11:00-12:30

This panel explores entangled expressions of resistance and resilience through the emotional impacts of sound and performance from the everyday to ritual and the stage. Papers will address the uncertainties, disruptions and evocations in creating a politics of emotion among performers and audiences. 
Beating the drums of Santa Teresa: performing resistance in a Brazilian quilombo Katerina Chatzikidi (University of London)

This paper discusses materialities of resistance in a Black rural community (quilombo) in Maranhão, Brazil. Drum beating and singing, as part of a religious festivity, will be examined as privileged forms of performing popular Catholic resistance to Pentecostal Christianity in the region.

\section{'Obrigada, Shukran': Brazilian musical encounters in Lebanon}

Gabrielle Messeder (City, University of London)

Brazilian music and dance is performed and listened to in multiple settings in Lebanon today. Using findings from recently conducted field research, I shall examine how this music occupies a unique, ambivalent and sometimes contested space in the Lebanese musical milieu.

\section{Aesthetics, emotions and masculinities in Mexican narco rap}

Hettie Malcomson (University of Southampton)

This paper argues against scholarship that suggests that musicians servicing Mexican narcos have little agency due to the dangers of challenging orders. It interrogates how rappers shape narco aesthetics, emotions and masculinities in songs directly commissioned for and about Mexican narcos.

\section{Power, empathy and resilience in songs of asylum seekers}

Fiona Magowan (Queen's University Belfast)

This paper considers complex emotional dynamics in the musical lives of asylum seekers and the significance of these resonances in their songs as they navigate the structural constraints of mobility and immobility together with profound emotional effects of dislocation.

The serene romance of resistance: a comparative study of the emotions in war music of Iran between the 1980s and now

Amin Hashemi (SOAS)

This paper examines the differences and similarities between the war music and rituals of the Iran-Iraq war of the 1980s, and, the engagement of Iran in the war in Syria since 2010. It takes an alternative perspective in focusing on the creativity and emotions of religious beliefs.

\section{Resilient identities through musicking}

Craig Robertson (Nordoff Robbins)

This paper explores the relationship between musical engagement, group identity creation, maintenance and challenges and group resilience and resistance. 
Panel and paper abstracts: Env01

Restaging fear: affective translation and empathetic engagement through intercommunity performing arts practices

Samantha Dieckmann (The University of Melbourne)

This paper considers the intersection between everyday life and critical geopolitics, examining the ways in which intercultural and interfaith performing arts practices are functionalised to challenge narratives of fear and facilitate transformative empathy.

\section{Env01 Mobilizing the environment: reimagining nature and nation in unsettled} times

Convenors: Elizabeth Turk (University of Cambridge); David Sneath (Cambridge

University); Thomas White (University of Cambridge)

Examination Schools Room 7: Tue 18th Sept, 13:30-15:00, 15:30-17:00

In contrast to the longstanding conception of nations as fixed in place, this panel explores the ways in which projects of nation-building are increasingly forced to reckon with the flux and instability of nonhuman actors.

\section{3:30-15:00}

\section{Shifting states at Camp Gallipoli}

Sally Raudon (University of Auckland)

How is a rocky Turkish shore seemingly more sacred to Australians than the nation's own red centre or the monolith of Uluru? This ethnographic account of an immersive domestic pilgrimage illustrates state-sponsored efforts to forge a renewed national identity by retelling a heroic tragedy a century old - and very far away.

The soiled imagination: back to the land and unsettling settler common sense Julienne Obadia (King's College, University of Cambridge)

I explore how members of an American land-based intentional community embrace a romanticized ideal of "the land" as a stable place and time that could return after capitalist modernity fails, arguing that practical uses of and disputes about the soil destabilized settler imaginaries from within.

\section{Harnessing animal mobility: the politics of patriotic camels in western China} Thomas White (University of Cambridge)

The political strategies of Mongol elites in northwestern China involve portraying animal mobility as congruent with state spatiality, in order to defend pastoralism against state environmentalism. This invites us to reconsider the relationship between animal bodies and national geo-bodies. 


\section{Invading nature: the eco-politics of new nature in the Netherlands}

Anke Tonnaer (Radboud University)

Starting from the notion that politics both defines and is defined by perceptions of nature (Hastrup 2014), this paper explores the ambiguities surrounding the borders and boundaries of the increasing entanglement of the natural and human in a densely populated part of Europe.

$15: 30-17: 00$

Therapeutic or poisonous? Im/material confusion of body and landscape in postsocialist Mongolia

Elizabeth Turk (University of Cambridge)

This paper situates the increased incidence of poisoning from spiritual aspects of landscape with respect to the order and systemization central to Soviet-era moral and social progress, tracing the confusion of body and landscape today as index of acute concern for the health of both body and nation

\section{Env02 Dirty stories: towards an narrativist anthropology of pollution}

Convenors: Mary Mostafanezhad (University of Hawaii at Manoa); Roger Norum

Discussant: Anna Lora-Wainwright (University of Oxford)

Queen Elizabeth House (QEH) SR2: Thu 20th Sept, 09:00-10:30, 14:15-15:45, Fri 21th Sept, 09:00-10:30

This panel questions forms and systems of "pollutants" by exploring how narratives mediate social relations amidst socio-environmentally pollutive events, states and agents. Papers examine the narratives/imaginations that speak to sensory materialities of pollution in its multiple forms and spaces.

Thu 20th Sept, 09:00-10:30

Dust: rethinking urban natures of pollution in Nicaragua

Josh Fisher (Western Washington University)

Dust is a key "matter of concern" in Nicaragua, speaking volumes about issues of climate change, public health, the integrity of the household, and the politics of everyday social life. This paper explores the political ecology of dust as "pollution," broadly conceptualized, in urban Nicaragua. 
Panel and paper abstracts: Env02

Particulate Matters: the political ecology of seasonal air pollution in Northern Thailand

Mary Mostafanezhad (University of Hawaii at Manoa); Olivier Evrard (IRD)

Drawing on ethnographic and geospatial data from northern Thailand, this paper argues that the judgment of seasonal air pollution as a crisis is contingent on contestations over livelihoods and worldviews.

Put-or-pay: erasing impacts of waste-to-energy in Honolulu through corporatemunicipal narratives of sustainability and environmental health

Nicole Chatterson (University of Hawaii)

This paper challenges the municipal-corporate narrative of waste-to-energy (WTE) as the epitome of sustainable waste management for Honolulu. This narrative undermines alternative management approaches and silences the contested nature of the impacts of WTE's greenhouse gas and pollution emissions.

Chemical exposure and democratic dilution: moving corporeal citizens beyond the margins through sensing policy

Sarah Wiebe (University of Hawai'i, Manoa)

Canada's Chemical Valley surrounds the Aamjiwnaang First Nation. This paper examines the community's participation in a community health study and the representation of their health concerns. Informed by corporeal citizenship, the paper elaborates a sensing policy approach to environmental justice.

\section{$14: 15-15: 45$}

Squirrels gone wild: bio-acoustic pollution and the idea of wilderness along an Arctic mountain transect

Roger Norum

This talk reflects upon the normative understandings of sound as pollution and silence as purity in the context of wilderness spaces - in particular in the European High North. It analyses the shifting relationships between nature, culture and sound in the context of planetary environmental change.

Living with Fukushima's "polluted" sea: life and polluted leisure in the wake of disaster

Adam Doering (Wakayama University), Clifton Evers (Newcastle University), James Davoll (Newcastle University)

This paper examines how the local surfers in post-disaster Fukushima continue to live with a "polluted" sea through leisure. To give texture to the multi-sensory materialities of "polluted leisure" the paper is accompanied by a collection of sounds, objects and images of the Fukushima coastline. 
Panel and paper abstracts: Env03

The local soil: environmental narratives and the politics of hope in post-handover Hong Kong

Loretta Ieng Tak Lou (University of Warwick)

When and how does an environmental issue come to matter in people's everyday life? This article depicts the entanglement of local politics and environmental issues in posthandover Hong Kong and argues for a more holistic approach to research about the environments.

City of filters: pollution, politics, risk and opportunity in Delhi Martin Webb (Goldsmiths, University of London)

The paper focuses in on middle class 'pollution talk' and the marketing of domestic air purifiers in India's capital. By exploring the conceptualisation of environmental goods in the city we can understand better if smog is indeed 'democratic'(Beck 1991)in contemporary Delhi.

Fri 21 th Sept, 09:00-10:30

Bloody business: placing blood in the politics of purity and pollution in Ghana Kirsty Wissing (Australian National University)

By exploring Akwamu narratives about blood in Ghana, this paper will revisit the politics of purity and pollution. It will unpack how contained/uncontrolled flows of certain types of blood are imagined to uphold and/or collapse socio-environmental relationality, and ask who gains from this.

\section{The muddy semiotics of mud}

Luisa Cortesi (Yale University)

This article provides a semiotic analysis of mud, an ambiguous material in its physical combination of land and water, a substance with specific gendered and class dimensions, and a symbolic marker whose presence on bodies pollutes them and reveals their sociopolitical identity.

\section{Env03 Tower block failures: high-rise anthropology} Convenors: Constance Smith (University of Manchester); Saffron Woodcraft (UCL)

Discussant: Gillian Evans (University of Manchester)

Examination Schools Room 15: Thu 20th Sept, 09:00-10:30, 14:15-15:45

Whether as political category, site of collapse or shattered home, tower block failure exposes precarity but can also act as a catalyst for urban transformation. How are urban success and failure imagined and materialised in relation to the tower block? What would a high-rise anthropology look like? 
Panel and paper abstracts: Env03

\section{9:00-10:30}

Successful socialist verticality in the wild capitalist urban age

Michał Murawski (Queen Mary, University of London)

This paper considers the distinction between high-rise architecture in different political-economic regimes. What is the difference between state socialist, welfarist and wild capitalist verticality? Is the high-rise form inherently 'inhumane', or does it have progressive value?

\section{Pin-pointing failure: the tower block as 'social void' in London}

Saffron Woodcraft (UCL)

The Grenfell Tower fire and estate demolitions in London have refocused attention on the question of tower block form and failure. This paper argues a pre-occupation with failed architecture obscures a deeper concern with proper ways to live and the 'social void' where 'urban community' should be.

\section{High-rise as social critique: 1968 in West Berlin}

Laura Bowie (University of Edinburgh)

During the ' 68 protests, the desire to make the personal political was activated in the critique of the modernist high-rises; focusing on residents' experiences, protesters sought to negate a repressive and hierarchical society, dominated by the self-interests of those in positions of power.

\section{4:15-15:45}

\section{Collapse: grey development and failed tower blocks in Nairobi}

Constance Smith (University of Manchester)

In Nairobi, a recent spate of collapsed tenement housing has drawn attention to 'grey development', ad hoc property speculation neither fully legal nor illegal. This paper explores collapse and its socio-political afterlives, highlighting how urban assemblages are made and remade.

\section{Luminous verticality: the changing face of East London after hours of darkness} Casper Laing Ebbensgaard (Queen Mary University of London)

300 towers are planned for construction across London. This paper examines these residential towers within their wider context in East London at night, by questioning the role that light and darkness plays in making residents living in and nearby them feel at home, or not at home at night.

\section{Neo-Maoist highrises? Post-displacement space in Chongqing} Asa Roast (University of Leeds)

This paper reflects upon the construction of high rise housing estates on the edge of Chongqing, South-West China as a space of post-displacement which migrant workers, evicted urban residents and expropriated farmers are displaced to, and the framing of these projects through neo-Maoist rhetorics. 


\section{Env04 Energising social worlds}

Convenor: Ben Campbell (Durham University)

Examination Schools Room 12: Wed 19th Sept, 09:00-10:30

Concerns about rethinking consumerist technological habits and assumptions in the high-energy usage parts of the globe have collided with recognition of the failure to offer even a modicum of energy access in off-grid parts. This poses big questions for reimagining social relationships with energy.

09:00-10:30

The anthropology of energy: combining the technical and the human

Charlotte Ray (Independent Researcher)

This presentation will explore how social science methods are used in the Global South to better understand access to energy.

\section{Assembling social worlds - energy access as relationships}

Britta Turner (Durham University); Raihana Ferdous (Durham University)

Three ethnographies with Solar Home System users in India, Bangladesh and Sri Lanka show how new flows of energy assemble different social worlds.

Solar empowerment? The materialisation of social structures within off-grid energy Kirsten Campbell (University of Edinburgh)

Based on research in rural eastern India, this paper explores the social politics around off-grid solar energy systems. It examines the ways in which these technologies can embody and reproduce wider social structures, such as those relating to caste, gender, religion and ethnicity.

\section{Beirut and electricity: a flickering relationship}

Asli Altinisik (American University of Beirut)

Electricity cuts in Beirut may add up to more than three hours per day, and are only partially scheduled. This paper examines Beirutis' relationship with electricity as a source of energy.

Env05 Towards an anthropology of un/making: affective encounters in abandonment, ruination, and creative destruction Convenor: Arvid van Dam (University of Leeds) Chair: Leila Dawney (University of Brighton) Discussant: Yael Navaro-Yashin (Cambridge University) Queen Elizabeth House (QEH) SR2: Wed 19th Sept, 09:00-10:30, 14:15-15:45 
Panel and paper abstracts: Env05

This panel seeks to understand the processes of unmaking and ruination in terms of their affective and creative qualities. It sheds light on the intertwinements of affect and (derelict) materiality, asking what social forms and imaginations inspire and emerge from ruination.

\section{9:00-10:30}

\section{Experiences of the Anthropocene in Newfoundland's fisheries}

Joonas Plaan (Memorial University of Newfoundland)

The ocean ecosystem off the coast of Newfoundland is one of the most human impacted areas in the world, threatened by climate change and overfishing. Relying on long-term fieldwork in Newfoundland, I will discuss how the slow environmental degradation is experienced, reinforced and then forgotten.

\section{Good Bye Casa, an art project in Lima to creatively heal the lack of love from unmaking the city}

Orietta Marquina Vega (Pontificia Universidad Catolica del Peru (PUCP))

This paper seeks to recognize the intertwining of affect and derelict materiality emerged during artistic interventions of abandoned houses in process to be destroyed in Lima during 2008 to 2011. These acts of resistance helped to overcome dramatic changes of the urban face of the city.

\section{The ruination of ruins: creative destruction in the Islamic State} Sofya Shahab (Deakin University)

Through ethnographic encounters and analysis of the Islamic State's propaganda outlets, this paper will explore the creative-destructive processes of intentional unmaking undertaken by the Islamic State and its impacts on relationships to heritage, identity and community at the local levels.

An anthropology of un/making: abandonment, ruination, and affect Arvid van Dam (University of Leeds)

This paper addresses the potential for anthropology to address unmaking by reflecting on how the presence of, and life among ruins, reveals the affective character of abandonment.

\section{4:15-15:45}

\section{Abandoned fields and bureaucratic ruins: conservation and land use policy in rural Ireland}

Jodie Asselin (University of Lethbridge)

This paper uses the ruins of abandoned farm fields as a space to contemplate (over) growth and the effects of land use policy on how the material reality of ruralness changes together with its perception of conservation, productive space, and social value. 
Panel and paper abstracts: Env06

Chronicles from the wastelands. An exploration of the evental geographies of derelict urban areas

Eduardo Brito-Henriques (Universidade de Lisboa); Daniel Paiva (Universidade de Lisboa) In this paper we propose to explore the life of urban wastelands. That is, we will unveil the actions that take place in these spaces, their human and non-human authors, and the dynamism that those actions produce in the space itself, provoking sensitive changes in the landscape.

\section{Berries, tree stumps and deep tracks: living with logging in rural Estonia} Aet Annist (University of Tartu)

Based on fieldwork in South East Estonia, I will consider how indifference to and trivialisation of potentially damaging increase in logging arises in socially fragmented rural regions, and what role does the cultural heritage elite play in this.

Env06 Geometry and anthropology: description, projection, and measurement Convenor: Ray Lucas (University of Manchester)

Discussant: Tim Ingold (University of Aberdeen)

Queen Elizabeth House (QEH) SR1: Fri 21st Sept, 09:00-10:30, 11:00-12:30

The aim is to consider human aspects of geometry: how geometric understanding is mobilised in the world; the implications of alternatives; and what geometry allows us to do. Papers are invited which discuss geometry as a skilled way of knowing our bodies, our hands, and our place in the world.

09:00-10:30

\section{Geometries of anthropology}

Ricardo Nemirovsky (MMU)

Geometries of anthropology elucidate how things and the world appear to living beings. This paper overviews four geometries of anthropology and includes a case study framed by Steinbock's analysis of the lifeworld in terms of two transcendental modalities: worldas-horizon and earth-as-ground

Measuring symmetry in gesture and rhythm: geometry and the coppersmiths of Santa Clara del Cobre, Michoacán, México

Michele Feder-Nadoff (El Colegio de Michoacán)

For the coppersmith artisans of Santa Clara del Cobre, geometry is an essential tool in creating their symmetrical forms and designs. How is abstract geometry materialized through bodily gesture, tool-use and copper? This paper examines material geometry enacted in the symmetry of forging vessels. 
Panel and paper abstracts: Env06

Speculative anthropology: collective movement as sense-making for urban design Nick Dunn (Lancaster University); Dan Dubowitz

We use the term speculative anthropology to define spatial provocations which are made temporally by human collectives in the lived world. Our action-research practice of 'collaborative urbanism' is a means of defining and re-examining our sense of place in the world and how it can be transformed.

Anthropocene - global network, a world of invisibles lines. Mouvement, interconnections, inter-sections

Johanne Verbockhaven (University of Louvain/ University of Aberdeen)

This contribution is based on the ephemeral aerial weaving installation and the concept of global interconnectivity, movements, inter-sections about the Anthropocene period during the human being's influence on the biosphere became a major "ecological force" capable of marking the lithosphere.

\section{1:00-12:30}

\section{Geometry of thought}

Jaime Refoyo

This paper try to discuss about the relationship between body and space from the thesis of that we cannot know the meaning of our nature without previously knowing the geometry of our thought upon the nature which we tread.

\section{Taking a stick for a walk: spatial scores and lines of flight}

Oren Lieberman (University of Salford)

Architecture is performative through its entanglement of materials, discourses and bodies. Drawing on the project Taking an Object for a Walk, spatial scripts and scores, and choreographic objects, are discussed in terms of their production of 'lines of flight' in the becoming of the world.

\section{Setting off the landscape: the geometries of the setting out of buildings in coastal grounds}

Ester Gisbert Alemany (Universidad de Alicante)

For rethinking the tools of contemporary urban planning, I study the geometries used in the process of setting out buildings in different coastal grounds. I explore the relation between the controlling geometry of abstraction with the creative potential of material variations and misalignments.

\section{Wrong perspectives}

Robin Schaeverbeke (Faculty of Architecture KULeuven)

Can perspective be 'wrong'? Or is the supposed wrongness a matter of position, cultural heritage, or psychological state of mind? 'Wrong Perspectives' explores geometrical approaches to extend conventional perspective systems so that they are able to include rather than exclude. Co-authors: Dirk Huylebrouck and Ann Heylighen 


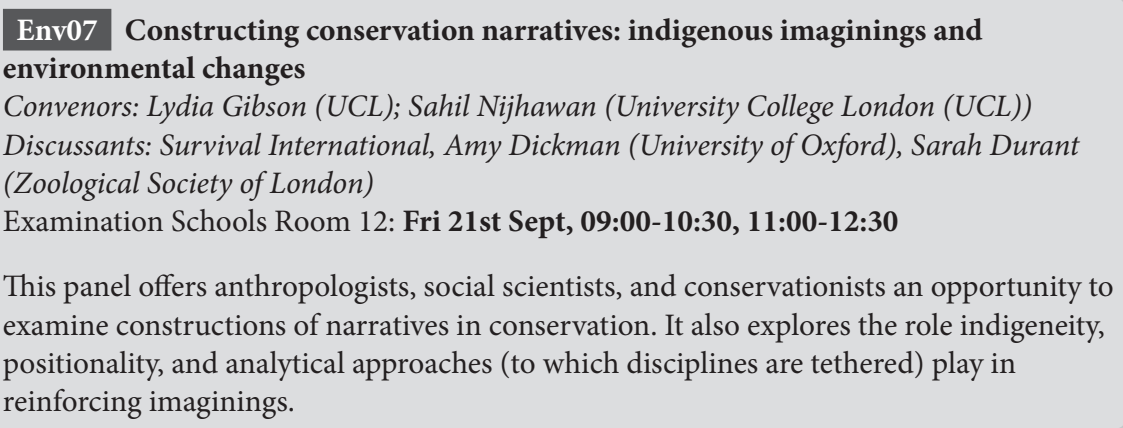

09:00-10:30

Beyond economic benefits: trophy hunting as a social affordance in the environment of the Khwe and Ju/'hoansi in Namibian CBNRM

Stasja Koot (Wageningen University)

Trophy hunting in Namibian CBNRM is critically scrutinised; a rather simplified discourse on economic benefits sells short to local realities of indigenous groups. I argue that the ontological concept of 'social affordances' to analyse trophy hunting provides for a much more complete debate.

The making of a crisis: the use of indigenous identity and psittacines in creating conservation priorities in the Caribbean

Lydia Gibson (UCL)

This presentation considers how the construction of conservation narratives both utilises and undermines indigenous identities. In particular, the use of neotropical parrots and indigenous communities as cornerstones of conservation efforts in the Caribbean and the wider Americas are expounded.

Ecogender: locating the Kuki women's traditional ecological knowledge in Northeast India

Ngamjahao Kipgen (IIT Guwahati)

This paper seeks to explain the relationship between nature and culture and argues that indigenous Kuki community - particularly women have close connection to nature and embedded knowledge to manage, nurture, and conserve the resources better. 
Panel and paper abstracts: Env08

\section{Imagining (re)practicing landcare practices in Haraway's Chthulucene}

Jess Martin

As a critical reflexive ethnography, this paper seeks to develop how we might repractice practices of environmental (land)care, enabling us to move from the era of the Anthropocene and towards a multispecies being-and-becoming-with as part of Haraway's (2016) the Chthulucene.

\section{1:00-12:30}

Unseen spirits and the piasan's eye: conservation frictions in Amazonian plantworlds

\section{Lewis Daly (University College London)}

This paper explores indigenous-conservationist collaborations and conflicts among the Makushi of Amazonian Guyana. Situated at the interface of shamanic cosmology and scientific conservation, the paper will investigate disjunctures in human-plant relations and concepts of life, death, and Otherness.

\section{Twenty one things everyone should know about "conservation"}

Stephen Corry (Survival International)

Headlines around the racist, colonial and anti-indigenous roots of conservation, much of which has been whitewashed from history, and which has resulted in the destruction of tribal peoples and continued violation of their rights. Militarised, or fortress conservation is harming tribal peoples and harming conservation. The lip service now paid to tribal and indigenous peoples as partners and allies in conservation is widely ignored. A real shift in perspective and practice is urgently needed.

\section{Env08 Emptiness: experiences, perceptions, and temporalities}

Convenors: Dace Dzenovska (University of Oxford); Andreza Aruska De Souza Santos (University of Oxford)

Chair: Daniel Knight (University of St. Andrews)

Discussants: Session 1 - Daniel Knight (University of St. Andrews, Session 2 - Jeremy MacClancy (Oxford Brookes University)

Queen Elizabeth House (QEH) SR2: Fri 21st Sept, 11:00-12:30, 16:00-17:30

This panel invites reflections on "emptiness" as an object of study and a lens for analyzing how people and places become disconnected from and attempt to reconnect with what they understand to be meaningful life. 


\section{Emptiness: shifting patterns of global (dis)connectivity}

Dace Dzenovska (University of Oxford)

Based on ethnographic work in the Latvian-Russian borderlands, this paper will reflect on "emptiness" as an object of study and a lens for analyzing how people and places become disconnected from and attempt to reconnect with what they understand to be meaningful life.

\section{Producing 'emptiness' in post-socialist Poland}

Jaro Stacul (Memorial University of Newfoundland)

Drawing upon research on urban renewal in the Polish city of Gdańsk, this paper examines the ways in which the production of empty spaces reconfigures the relationship between people and local history, and functions as political capital for those who promise to 'reorder' the city's past.

\section{Emptiness in the minds}

Miriam Driessen

In contemporary China, where a compelling discourse casts depopulating rural regions as devoid of life as well as meaning, emptiness resides not only in deserted homes, but also in people's minds.

\section{Temporal emptinesses in a transition economy: gaps between the social and} economic value of tea in a former Georgian collectivist farm

Jvan Yazdani

This paper is concerned with emptiness as gap between social and economic value in the status of tea within the local economy of a former collective farm in Georgia: from the centre of economy, to something devoid of economic value retaining social and symbolic value.

\section{Trading time and space in an empty Brazilian town}

Andreza Aruska De Souza Santos (University of Oxford)

I will explore conflicting notions of past, present and future in a series of mininggovernment meetings in Miguel Burnier, Brazil. Here, I ask whether imagining a different future for Miguel Burnier - through preserved architecture - may mitigate a troublesome present characterized by depopulation

\section{Four storeys of emptiness: living alongside empty homes in central London} Mayanka Mukherji (University of Oxford)

My paper will weave together four short stories emerging from my ongoing fieldwork in the Cadogan Square and the Sutton Estate, in London, wherein the former holds some of the wealthiest empty mansions in the city, and the latter is gradually being emptied/ decanted for regeneration. 
Panel and paper abstracts: Env09

\section{Landscapes of unknowing: emptiness as presence in Rousay, Orkney}

Richard Irvine (The Open University)

This paper explores emptiness as a presence in the landscape of Rousay, Orkney, the Westside of which was subject to clearance in the 19th century. I reflect on layers of unknowing in lived relationships with the terrain which are at the same time disconnecting and generative.

Lives suspended in rapid change: on emptiness and space in urban informality Julia Wedel (Oxford Brookes University)

This paper argues for the importance of the notion of emptiness in discourses on urban informality; and illustrates these proposals with data from an ethnographic study in Lima, Peru.

\section{Env09 Ethnographic Cli-fi in the 'New Pangea'}

Convenors: Pavel Borecký (University of Bern); Blake Kendall (Freie Universitat Berlin) Examination Schools Room 15: Fri 21st Sept, 09:00-10:30

This panel explores the employment of 'Fiction' and the 'Imagination' in ecological and environmental enquiries. Discursively rooted in experimentation with 'more-thanhuman' methods and modalities, we explore how materialist globalised systems are reimagined.

\section{9:00-10:30}

\section{The Southern Reach Trilogy and the Chernobyl Exclusion Zone}

Jonathon Turnbull (University of Cambridge)

This paper presents the Southern Reach Trilogy by Jeff VanderMeer and the ways it grapples with the place and role of humans in 'Nature'. Area X - the setting of The Trilogy - is an uninhabited and abandoned area in the USA that 'Nature' has begun to reclaim, much like the Chernobyl Exclusion Zone.

Resurrecting the discarded: fiction filmmaking post-deforestation in a contingent \#NOW

Blake Kendall (Freie Universitat Berlin)

When an anthropology student and his informants resurrect a script idea from a Hollywood Film Studio, what ethnographic insight is learnt about deforestation in Sarawak, Malaysia?

Exploring fiction filmmaking as a method and modality in ecological enquiries. 
Panel and paper abstracts: Env10

\section{Electronic Monitored Hives (E.M.Hives) : a technological enhancement of an interspecies relationship}

Aladin Borioli (F-U Berlin)

From an anthropological perspective and addressed in a polymorphous way mixing written and audio-visual materials, this survey investigates how the emergence of E.M.Hives in Western countries could enhance the age-old interspecies relationship of humans to honeybees and honeybees to humans.

In the Weird Garden: Of Ruptured Empiricism in Filmic Ethnographies of Ecology Pavel Borecký (University of Bern)

Could fictionality be the appropriate means of how to "rewild" ethnography and "reenchant" imagination in response to the new Climatic Regime (Latour)?

Env10 Closed loops, loopholes, and profit: interpreting geographical imaginaries of material conversion

Convenors: Yvan Schulz (University of Oxford); Peter Kirby (University of Oxford); Anna Lora-Wainwright (University of Oxford)

Examination Schools Room 15: Fri 21st Sept, 11:00-12:30, 16:00-17:30

This panel addresses calls to make material flows more circular and edifying through a critical analysis of the rise of the notion of 'circular economy'. We seek to better understand what counts as circular, who is allowed to trade on the margins, and how tidy theory is translated into practice.

11:00-12:30

Closed loop, silver bullet: biomass briquettes and moral labor in a Kampala slum Jacob Doherty (University of Oxford)

Biomass briquettes made of organic waste promise to solve African crises of livelihoods, sanitation and deforestation. Briquettes production reveals that the closed loop converting waste to wealth is predicated on producing and managing the imagined socio-moral difference between community and slum.

Edifying flows, leaky cycles: discourses of circularity in Japan's e-waste trade Peter Kirby (University of Oxford)

This paper presents much vaunted cycles of high-tech conversion in Japan and a largely disavowed side-loop of illicit export of wastes to China. The paper critiques both these systems while scrutinizing the symbiotic features they share and the leaky circularities they expose. 
Panel and paper abstracts: Env1 1

Used clothes, new lives: the techno-logistics politics of corporate recycling Ka-ming Wu (Chinese University of Hong Kong)

This paper examines the cultural politics of a used clothes recycling program led by the biggest online retailer in China that infuses the language of techno-logistics, infrastructural competence, and environmental sustainability.

\section{Radical incrementalism: political ecologies of waste in China}

Carlo Inverardi-Ferri

This paper investigates how NGOs and individual activists make sense and contest dominant ideas on 'circular economy' from the bottom. It contributes to recent debates on the need to provincialize political ecology, building upon and further developing the concept of 'radical incrementalism'.

\section{6:00-17:30}

In the name of circularity: business slowdown in a Chinese recycling hub Yvan Schulz (University of Oxford); Anna Lora-Wainwright (University of Oxford) Based on a case study of a "circular economy" industrial park located in a recycling town in China, this paper scrutinizes the concept and its implementation in that country. It points to the highly disruptive character of changes operated by the Chinese state in the name of increased circularity.

\section{Env11 Sensing and making with microbial worlds: anthropological engagements} with microorganisms

Convenors: Elise Demeulenaere (CNRS); Germain Meulemans (Centre Alexandre Koyré) Discussant: Jamie Lorimer (University of Oxford)

Examination Schools Room 7: Thu 20th Sept, 14:15-15:45

This panel invites papers that bring microbial creativities into anthropological conversation, and explore the methodological and ontological implications of working with microorganisms in making or unmaking food, artefacts, or materials.

\section{4:15-15:45}

\section{Microbiosocialities of making soil and cheese}

Elise Demeulenaere (CNRS); Germain Meulemans (Centre Alexandre Koyré)

This paper introduces the panel, drawing on our respective fieldworks with ecological engineers and cheese makers. We attend to the contradictory impulses of utility and attachment in making with microorganisms, and to the effect of sanitary norms and the emergence of a 'second modernity'. 
Panel and paper abstracts: Env13

Fermenting soil recuperation: the cow-soil-microbe complex in natural farming (India)

Daniel Münster (Heidelberg University)

Natural farming movements in India develop novel technologies of soil recuperation. I argue that the novel techniques (ferments) and understandings of the cow-soil-microbe complex are complicated by bionativism or the mapping of multispecies belonging onto narratives of Hindu Nationalism.

Haunting fungus. Re-imagining Philippine banana plantations as more-than-human interaction

Robin Thiers (Ghent University)

A fungus threatens Philippine banana plantations. I argue practices of "producing despite" push us to understand plantations as being shaped through more-than-human interactions. This in turn opens a window to imagine new and unknown futures.

Living-with microbes in the era of antimicrobial resistance Salla Sariola (University of Helsinki); Elina Oinas (University of Helsinki)

Analysing an ethnographic case of a vaccine trial against bacterial diarrohea taking place in West Africa, this paper analyses new social forms and living-with microbes at a time when microbes are becoming resistant to antibiotics.

\section{Env13 Vectors of latent potential: material traces' unpredictable futures}

Convenors: Caitlin DeSilvey (University of Exeter); Paul Wenzel Geissler (University of Oslo)

Discussant: Penny Harvey (University of Manchester)

Examination Schools Room 11: Wed 19th Sept, 16:15-17:45, Thu 20th Sept 09:0010:30, 14:15-15:45

Traces of human inhabitation and industry hold latent potential to affect future human and non-human life. Residual matters can alter life or destroy it, with a potency that is itself emergent and unpredictable. How can anthropology and neighbouring humanities attend to these dormant materialities?

Wed 19th Sept, 16:15-17:45

Searching for white birds in a ruined coal mine: landscapes of ecotoxicological field research in Ny-Ålesund, Spitzbergen

Paul Wenzel Geissler (University of Oslo)

Ny-Ålesund's arctic landscape is rich in legacy pollutants brought by long-range transport or released from melting mining debris. Observation of toxicologists' studies of pollutants' effects on bird populations invites reflection on the intertwining of heritage matter and future-making. 
Panel and paper abstracts: Env13

\section{Making life and a living from Montevideo's residues}

\section{Patrick O'Hare}

This paper focuses on the ruins, rubble, and residues found around Uruguay's largest landfill. Drawing on historical and ethnographic research with waste pickers and managers, it analyses three discarded materials whose affordances have given rise to particular socio-material practices and futures.

\section{Consumer electronics, foreclosed potentials and repair practices as forms of resistance \\ Christian Medaas (University of Oslo)}

Consumer electronics are designed to be irreparable and ephemeral, even as they become increasingly ubiquitous. Repair practices constitute resistance to their prescribed horizons and the dictate of use, loss, disposal and replacement inherent in their logic and design.

\section{Middens, unexploded ordinance, radioactive waste: myths of purity and control} Sarah May (UCL)

Ethics of radioactive waste management require this generation to control that waste in perpetuity without risk or responsibility for future generations. Other dangerous residues from previous generations continue to resurface, often reconceived as heritage. Here I explore this divergence.

\section{Thu 20th Sept 09:00-10:30}

Exhuming infectious pasts. Researching the history of a false "Ebola" epidemic in the Cameroon-Congo borderland

Guillaume Lachenal (Université Paris Diderot)

Archival research (and more generally the historiographic operation) is always a risky confrontation to the latent, even toxic, potentials of archives - and of other traces of the past. How do historians of epidemics - whether they literally exhume bodies or not negotiate this risk?

\section{Agrochemical traces in Bangladeshi landscapes and bodies}

\section{Camelia Dewan}

This paper explores the latent potentialities of agrochemicals in Bangladesh - introduced through development projects. It examines how emic concepts of 'shakti' [life force, strength] and 'bhejal' [impure, adulterated] food to illustrate the unpredictability of agrochemical traces. 
Panel and paper abstracts: Env14

Brave New Worlds: emergent vitalities and survival in the Anthropocene Bernard Perley (University of Wisconsin-Milwaukee)

Five hundred years of colonization in the New World have eradicated many North American Native American communities and left others in extreme states of ruin. Today, the surviving Native American communities are reconfiguring colonial salvage materials into emergent cosmologies of survival.

14:15-15:45

Seeds of an uncertain future: dreaming of survival with plant genetic resources Tracey Heatherington (University of Wisconsin Milwaukee)

In the face of environmental uncertainties, plant genetic resources animate alternative visions of the future. From the Svalbard Global Seed Vault to the dandelion dreams of Thomas Heatherwick's seed cathedral, the latent possibilities of seed are woven through Anthropocene imaginaries.

Traces of the future: art, alter-engineering, and alternative geophysical relations Nicholas Shapiro (University of Toronto)

This paper asks, what if the role of the anthropologist of toxic traces is not to document the protracted tragedy of toxicant harm or the farce of traditional techniques of detoxification but to highlight and accentuate the traces of radically different futures, latent in the everyday.

\section{Env14 Whose green? Imagining socio-ecological transitions}

Convenors: Laura Rival (University of Oxford); Nina Moeller (University of Manchester) Queen Elizabeth House (QEH) SR1: Tue 18th Sept, 13:30-15:00, 15:30-17:00

This panel explores the heterogeneous socio-ecological effects of the diverse understandings of 'sustainability' underpinning different transition initiatives, and critically asks: Whose green? Who benefits and who suffers from particular framings and associated actions?

$13: 30-15: 00$

Dominating discourses, rebel rhetorics: amplified and silenced framings of urban nature

Julian Dobson (University of Sheffield)

This paper discusses findings from Improving Wellbeing through Urban Nature, a threeyear project in Sheffield, UK. It shows how policies to promote wellbeing of humans and 'nature' are muted through decision-making rhetorics that box environmental imaginaries within neoliberal governance models. 
Panel and paper abstracts: Env14

Grounds for resistance in Wales: green lifestyle migration and the problem with transition

Elaine Forde (Swansea University)

Wales' One Planet Development policy enables green lifestyle migration. The extant population's ways of life and land use are criticised by a dominant environmental ideology that makes resistance difficult. This interplay of policy, morality and settlement invites parallels with settler colonialism.

Humans in the landscape - is low-impact community living an effective response to socio-ecological crises?

Julyan Levy

Low-impact developments(Fairlie 2009) offer alternatives to food / energy production and housing. These alternatives have the potential to provide solutions to environmental sustainability and economic hardship. I am interested in the challenges low-impact living poses for sustainability discourses

\section{Green economy as future orientation}

Daniel Knight (University of St Andrews)

This paper explores the green economy as a sustainable alternative to austerity in Greece and as an 'orientation' to the future caught between speculation and disillusion.

\section{5:30-17:00}

\section{Green transition friction in the Ecuadorian Amazon}

Nina Moeller (University of Manchester)

The Regional Amazonian University IKIAM has been conceived as a catalyst for Ecuador's economic transition towards sustainability. I explore this site of friction with attention to the way in which pathways to alternative sustainabilities are opened up and foreclosed in the Amazon and beyond.

\section{Fragile cultures: interrogating visions of 'greening' in synthetic biology} Sally Atkinson (University of Exeter); Susan Molyneux-Hodgson (University of Exeter) We explore the assemblage of narratives of environmental responsibility and sustainability in synthetic biology. Drawing on Strathern's notion of 'fragile futures' we interrogate the partiality of existing anthropocentric and market-driven narratives of 'green' production.

The "soon to be extinct" fishers of the Finnish archipelago and the struggle over resources

Kirsi Sonck-Rautio (University of Turku)

Small-scale fisheries in the Finnish archipelago are struggling with growing tension between authorities, environmentalist, climate change, growing seal population and alien species. Through anthropology, can we find 'green' that would benefit all the stakeholders, and promote sustainability? 
Panel and paper abstracts: Env15

Climate change adaptation strategies and ecological innovations in rural Tanzania: an ethnographic perspective from Chololo 'ecovillage'

Margherita Lala (Lancaster University)

An ethnographic perspective on climate change adaptation strategies in an 'ecovillage' in Sub-Saharan Africa will be presented, engaging with global discourses on development, power relations and the different moralities underpinning socio-ecological transitions.

\section{Env15 Coastal encounters: temporality, memory and morality}

Convenors: Nadine Beckmann (University of Roehampton); Ana Santos (Roehampton

University)

Queen Elizabeth House (QEH) SR2: Wed 19th Sept, 16:15-17:45

This panel probes the parallels and distinctions between those living in coastal regions, and explores the ways in which these influence the political, moral realms, and the shifts in collective and personal memories.

$16: 15-17: 45$

\section{The Bay of Bengal delta and inter Asia connections}

Debojyotu Das (Bristol University)

Life in the delta is like the edge of a knife. A transdisciplinary approach, which highlights the socio-economic, political, cultural and ecological aspects of interaction is essential to understanding the multiple facets of delta and coastal regions in South Asia.

\section{Surfers and fishermen : heritage, work and sport in Ericeira}

Vera Azevedo (CRIA. NOVA / FCSH - Universidade Nova de Lisboa)

This presentation considers the impact of sea patrimonialization in Ericeira and explores how official discourses about Portuguese maritime heritage are related to the (re) definition of surfing and fishing pratices in the village.

Experienced and imagined belonging: waterscape related cultural knowledge by and with the Baltic Sea

Jaana Kouri (University of Turku)

I approach the human-nature relationship in the past experiences of water revealed in the oral tradition of the Baltic Finns to the present experiences of the villagers in my case study. I examine imagination as a theoretical and analytical framework for tacit and experience based knowledge.

\section{The enduring legacy of violence: coastal encounters in northern Mozambique}

Ana Santos (Roehampton University)

This paper will explore the ways in which different communities living by the coast in

Cabo Delgado try to create, position and represent themselves within contemporary

Mozambican history. 
Panel and paper abstracts: Inf01

\section{Inf01 Homo faber revisited}

Convenors: Penny Harvey (University of Manchester); Petra Tjitske Kalshoven (University of Manchester)

Examination Schools Room 15: Tue 18th Sept, 13:30-15:00, 15:30-17:00

In the pursuit of an anthropological understanding of human imagination, ingenuity, and hubris engaged in purposefully shaping the natural, we welcome papers that explore, collaboratively, large-scale engineering projects aimed at returning landscapes to the wild.

\section{3:30-15:00}

\section{Enlisting concrete for nuclear 'clean up'}

Penny Harvey (University of Manchester)

The paper explores the ways in which 'concrete' is enlisted in the 'clean up' processes intrinsic to nuclear decommissioning. Building on the history of a synthetic material that has long been deployed to re-fashion nature, the paper discusses the on-going engineering of material potential.

\section{Irreversible returns}

\section{Cristián Simonetti (Pontificia Universidad Católica de Chile)}

Scientific discourses often speak of the need to revert climate change. Yet reversibility resulting simultaneously from a process of abstraction and containment of climate, as well as a solidification of change - contrasts with what it is to feel immersed in a living world in constant becoming.

\section{Thinking with slurry in the Anthropocene}

Claire Waterton (Lancaster University)

I look at the seemingly modest making of things - in clay, in concrete, in steel and in fibre-glass - that have had played a role in the containment, concentration and distribution of nutrients in the earth of the Anthropocene. I consider the prospects, efforts and politics of their re-ordering.

\section{Ruins of the future nature: an ethnography of environmental remediation in Newtown Creek, New York City \\ Liviu Chelcea (University of Bucharest)}

The scope, depths and pace of the efforts to remove and stop further pollution invites us to see polluted landscapes not only as ruins of past nature, but also, following Akhil Gupta, as ruins of the future nature. Remediation includes short term, long term and open-ended future interventions. 
Post-nuclear engineering: patterns of aligning and fissuring in technological, natural, and social future-making

Petra Tjitske Kalshoven (University of Manchester)

Sellafield has long sparked the imagination as a place of human engagement with fissile materials. As these must now be stifled in decommissioning, alignments and fissures pattern the company's ambitious project of engineering that seeks to integrate technological, natural, and social futures.

\section{Restoring the landscape of future's past}

Anna Kuprian (The University of Aberdeen); Arnar Árnason (University of Aberdeen) Based on fieldwork with ecologists, foresters, conservationists, volunteers, and members of the public, this paper explores human imaginations, scientific expertise, and practices on the ground involved in the deliberate re-makings of Icelandic environments, centered on the plant the Alaska lupin.

\section{Aquatic multispecies infrastructures and the making of entangled futures}

Davide Marino (University of Manchester)

Focusing on river biomonitoring practices, carried out by a team of biologists in Talamanca, Costa Rica, this paper discusses how engineered multispecies infrastructures - such as rivers and hydroelectric dams - come to matter across species lines in the making of entangled environmental futures.

\section{Inf02 Logistics, time and environment}

Convenors: Scott Lash (Oxford University); Sophie Haines (University of Oxford)

Discussant: Biao Xiang (Oxford University)

Examination Schools Room 9: Wed 19th Sept, 09:00-10:30, 14:15-15:45

This panel examines the changing geopolitics of time, environmental imagination, and materialities in a logistics-culture predicated on managing flows of material and immaterial things through operations, platforms and infrastructures.

09:00-10:30

\section{The time of operations}

\section{Brett Neilson (Western Sydney University)}

Operations produce political orders of circulation, expand capital's frontiers, and establish rhythms of contemporary life. The paper draws on research conducted in the Greek port of Piraeus - conceded to Chinese state enterprise - to ask how logistical operations cross relations of space and time. 
Panel and paper abstracts: Inf03

Infrastructure politics and substantive economy in China: the cultural bases Scott Lash (Oxford University)

China's critical left proffers a public sector and infrastructure-driven Polanyian substantive economy. Here 'ontological' substance unpacks into cultures of lineage, analogism and religion. This is explored in the logistics of infrastructure-based development of rural eco-tourism.

Fast flow, fluid security: logistics and time on Colombia's Magdalena river Austin Zeiderman (London School of Economics)

This paper examines the plan to remake Colombia's Magdalena River as a logistics corridor. It focuses on how the smooth and uninterrupted flow of vessels and cargo along the river is secured, paying special attention to temporalities of speed and slowness.

\section{4:15-15:45}

The logistical city and its temporal borders of extraction. The supply of construction materials in the new smart city of Kolkata, India

Chiara Arnavas (London School Of Economics)

This paper shows how logistics is a key analytical strategy to probe the worldly practices of resource extraction shaping the construction of Smart City projects in India.

Emergent environments: time and transformation in a watershed management project

Sophie Haines (University of Oxford)

This paper examines how environmental imaginations are contested in the infrastructural devices and practices that mediate resource use, conservation and tourism in a community-based watershed management project in rural Belize.

The mass balance act: the spatial and temporal logistics of global supply chains Martin Skrydstrup (Copenhagen Business School); Esther Turnhout (Wageningen University)

This paper investigates the changing geopolitics of spatialities and temporalities in the logics of global supply chains through a technical debate about the global trade of sustainable palm oil.

\section{Inf03 Water futures: making a living in times of environmental uncertainty} Convenors: Tom Boyd (University of Manchester); Noah Walker-Crawford (University of Manchester)

Discussant: Veronica Strang (Durham University)

Examination Schools Room 14: Wed 19th Sept, 09:00-10:30, 14:15-15:45, 16:15-17:45

Water shapes life. It mediates our understanding of an increasingly unstable environment in the context of climate change. This panel explores how people's engagements 
with water shape imaginations of water futures and their respective speculative life possibilities.

09:00-10:30

\section{Changing water, changing pastoralism in the Andes}

Karina Yager (Stony Brook University)

Climate change and associated water changes present unprecedented challenges in the Andes, while global change presents new opportunities that herders must consider as they redefine their identity, livelihoods and cultural landscapes in the Anthropocene.

Pipelines, wells and satellites: where does the imagination of the "manageability" of climate change come from?

Marketa Zandlova (Faculty of Humanities, Charles University in Prague)

The paper, based on the ethnography of drought in Czechia, explores the interplay between the actors' assumptions about water scarcity/abundance, their notions of infrastructure as material form facilitating water supply, and their imaginations of the "manageability" of environmental change.

Surfing without the ocean?: the effect of artificial wave pools on surfing practice, environmental intimacy, and conceptual production

David Whyte (University College London)

This paper explores the difference between the relationships cultivated while surfing oceanic waves versus while surfing in wave-pools, an emerging technology which radically transform the surfing landscape. It will discuss the effect of these on surfer environmentalism and environmental intimacy.

\section{Waterwork and progeneration in the Sine-Saloum Delta, Senegal}

Sandro Simon (University of Cologne)

This paper traces how the dwellers of the Sine-Saloum Delta navigate through their volatile lifeworld by focusing on clam digging, a highly tactile practice that requires constant (re)attunement as one strives to anticipates and follow the tides and to move on and with/in moving water and soil.

14:15-15:45

Water vulnerability: the water-energy nexus and disaster vulnerability in the United States Virgin Islands

Cori Bender (University of South Florida)

Hurricanes in the Caribbean region are a force capable of altering lives in profound ways that influence how water is understood, in times of both scarcity and extreme inundation. 
Panel and paper abstracts: Inf03

A living shaped by water: reading the political economy of flood narratives on Majuli island (Assam), India

Kh. Neil Young (Delhi School of Economics, University of Delhi)

Majuli Island is a waterscape. The paper explores the various flood narratives on Majuli and argues that such narratives are shaped by certain political economy. Such narratives of flood in turn construct people's imagination of their possible future that can arise from uncertain waterscapes.

\section{Mythologizing water futures in contemporary Albania}

Natasa Gregoric Bon (Research Centre SASA, Slovenia)

Departing from the notion of water as a 'total social fact', this paper questions how shortand long-term environmental water-connected changes in contemporary Albania are related to the ways in which people understand environmental futures.

\section{Water futures in the Peruvian Andes}

\section{Noah Walker-Crawford (University of Manchester)}

In the Peruvian Andes, glacial retreat raises worries about flood risk in the short term and water scarcity in the long term. Glaciers and mountain lakes are sites of negotiation between urban authorities and rural communities over how these future threats should be valued and addressed.

\section{6:15-17:45}

Present absences, future connections: claims for connectivity on a large river island in Northeast India

Tom Boyd (University of Manchester)

This paper explores ethical reflections concerning prospective large infrastructure projects on a large river island in Northeast India, elucidating the attached hopes and fears bundled up within these imagined water futures for those living beside the river.

On aqueducts and anxiety: reading L.A.'s water future through infrastructure stories Sayd Randle (University of Southern California)

This paper explores the expectations for and meanings of L.A.'s water future articulated through artistic representations of the city's water network. I show how infrastructural imagery is used to index anxieties about crises of water scarcity-to-come.

\section{Melting waters in the Mackenzie Delta, Canada}

Franz Krause (University of Cologne)

This presentation describes the water- and ice-related means of transport in the Delta, and expands on some of the uncertainties for its inhabitants that a changing climate has introduced into this pattern. 
Inf04 Towards computing anthropology: imagination, cooperation, and future infrastructures of trust

Convenors: Roxana Moroşanu Firth (University of Cambridge); Razvan Nicolescu (Imperial College London)

Discussant: Kathleen Richardson (Centre for Computing and Social Responsibility, De Montfort University)

All Souls Old Library: Thu 20th Sept, 09:00-10:30, 14:15-15:45

This panel aims to advance the emerging field of computing anthropology by addressing the way recent technological innovations and related economies transform social relations, understandings of 'the material' and imagination, and how these challenge the anthropological scrutiny and practice.

09:00-10:30

Computational imaginaries and substantive realities: doing anthropology and blockchain projects in hybrid grounds

Ines Faria (University of Lisbon)

This paper explores liminalities crossed in ethnographic research about blockchain technology. It includes reflections on the methodological mixture of digital and live terrains, but also on the issues researched projects met while managing implementation in digital-material hybrid grounds.

Giving shape to the unknown: science and gut feeling in technological innovation Roxana Moroşanu Firth (University of Cambridge)

This paper looks at development processes of three innovative technologies: ultrasound for tactile feedback, low-cost microcomputer, and inclusive indoor navigation technologies.

\section{Computing technologies in the manufacturing company: an anthropological perspective \\ Marta Songin-Mokrzan (University of Lodz)}

The goal of the paper is to elaborate on the way computing technologies, automation systems and processes reconstruct the working environment and influence social relations in a contemporary production plant.

\section{What could an anthropologist of computing do: notes toward an anthropology of computer scientists \\ Vlad Schüler-Costa (University of Manchester)}

This paper is a short exposition on some methodological shortcomings and opportunities I faced while conducting 12 months of fieldwork within a computer science laboratory in the UK. 
Panel and paper abstracts: Inf05

\section{4:15-15:45}

Contested notions of trust in the emerging digital economy

Razvan Nicolescu (Imperial College London)

The paper discusses the fundamental misalignment between the new notions of trust proposed by the emerging digital technologies and the traditional forms of social trust people know and recognize.

'Think of it this way': an ethnography of technological design

Sandra Faustino Coelho (ISEG-UL (Lisbon, Portugal))

This paper addresses the technological design of blockchain technologies and the co-relations between people and technology in the creation of meaning. It draws on a collaborative ethnography with the Economic Space Agency and reflects on the particularities of ethnographic fieldwork.

How do we rate each other? A study of Uber's rider-driver rating perceptions in India Shriram Venkatraman (Indraprastha Institute of Information Technology, Delhi (IIIT-D)); Nalin Gupta (IIIT Delhi)

This paper, based on the study of the two-sided rating system used by Uber, will show how anthropology and computational methods can be combined to better understand the perceptions of the riders and the drivers who rate each other after every trip.

Taxi drivers' choice faced with ride-sharing: conflicts between socio-technical systems Linzhou Xing (The University of Hong Kong)

The paper addresses why Chinese taxi drivers choose not to switch to the supposedly desired ride-sharing business. It argues for a socio-technical system approach to see the conflict between the existing taxi system where taxi drivers form a community and the totally new system of sharing economy.

\section{Inf05 The sociality of taxes: state-citizen imaginaries}

Convenors: Robin Smith (Leiden University); Nicolette Makovicky (University of Oxford)

Discussant: Lotta Björklund Larsen (Linköping University)

Examination Schools Room 14: Thu 20th Sept, 09:00-10:30

We invite researchers to consider the ways in which state efforts to instill fiscal discipline through the collection of taxes shape how the state is imagined, materialized, and experienced by citizens in everyday life. 
'Going legit': taxation, trust and attention in rural Nigeria

Olly Owen (Oxford University)

Benue State's reintroduction of tax in a largely agrarian region after 30 years requires the state to re-negotiate terms of entry with limited credibility or coercive leverage. This exposes a public conversation about trust, legitimacy and how publics find it advantageous to engage with government.

The eager taxpayer and the evasive collector: contradictions of fiscal expansion in peri-urban Bolivia

Miranda Sheild Johansson (University College London)

This paper discusses the barriers to fiscal expansion in Bolivia. It demonstrates how a significant hurdle lies not with the unwilling taxpayers, but rather with a complex set of barriers that are produced by the local government and economy.

\section{Reciprocity reconsidered: taxation creates relations and expectations}

Lotta Björklund Larsen (Linköping University)

Why do people pay tax? And why do they avoid doing so? A fiscal anthropological approach to taxation means thinking about taxes as making social relations. Tax collection in practice thus has an impact on how taxpayers view their relationship with the state and ultimately with other citizens.

\section{Producing the state through tax evasion? Economic disobedience, emerging tax} regimes, and state effects in a Catalonian cooperative

Vinzenz Baumer Escobar (Utrecht University)

Drawing on ethnographic fieldwork with a Catalonian Cooperative that developed an alternative tax regime in crisis-ridden Spain, this paper will examine how formalized tax-evasion strategies can, somewhat paradoxically, result in state effects or the sensation of reproducing the state.

\section{Account for yourself}

Dora-Olivia Vicol (Queen Mary University of London)

Drawing on fieldwork with self-employed migrants, this paper theorises taxation as an intersection of agency and coercive structure, where the ability to fashion oneself morally, as a contributing subject, is informed by the ability to navigate an increasingly digitised bureaucracy.

\section{Inf06 The times of infrastructure}

Convenors: Luke Heslop (London School of Economics); Elisa Tamburo (SOAS, University of London)

Discussants: Laura Bear (London School of Economics and Political Science), Edward Simpson (SOAS) 
Panel and paper abstracts: Inf06

Examination Schools Room 14: Tue 18th Sept, 13:30-15:00, 15:30-17:00, Thu 20th Sept 14:15-15:45

This panel turns its attention to the intersection of infrastructure and time by examining how temporal registers of infrastructure affect people's past, presents and futures and their possibilities to move, stay or settle.

\section{Tue 18th Sept, 13:30-15:00}

Suspended futures: planning, horizons, and the politics of urban relocation in Taiwan Elisa Tamburo (SOAS, University of London)

This paper investigates the politics and the temporal contradictions emerging from the large-scale reconstruction project of military villages in urban Taiwan. It looks at the rationale of the project as well as the effects of different temporal horizons of planning on the life of the residents.

Lethargic present, uncertain future: the water conundrum in north Cyprus Ezgi Ozdemir (Central European University)

This paper investigates how a network of water pipelines reflects the political engagements that the communities they supply have with states, local governance systems, and with people's senses of time and belonging.

Emerging Cochin: from the remnants of unrealized promises, the building of new investible urban futures

Ikuno Naka (University of Oxford)

The paper examines the 'spectacular urbanism' fueling the urban development of an emerging South Indian city, Cochin. More specifically, it focuses on the everyday hustlings of local real estate builders and investors as they construct/imagine new urban futures in the face of unfulfilled promises

Latent matters: spectacular urban planning and its afterlives in post-revolution Tunis Rosa Sansone (University of Manchester)

This paper examines the intertwinement of affects and latent materialities, exploring moral, temporal, and political dispositions emerging through engagements with a morphing urban landscape, in a post-revolutionary context. 
Speculations on Infrastructure: the longue duree of financialisation on the Indian Railways

Laura Bear (London School of Economics and Political Science)

This paper takes the long view on contemporary global processes of financial accumulation from the Indian railways. It traces the connections between the railway guarantee of the 1840s and current investment strategies shaped by the World Bank. Overall it argues for an analysis of speculation as a technology of imagination that sets lose contradictory conflicts in time --particularly in relation to fixed capital. And crucially for a critical engagement with the term infrastructure which was first given currency by World Bank initiatives to turn circulatory systems into an asset class.

Collapsed futures or the normality of permanent crisis? Tracing the oil price drop in the port of Lobito

Jon Schubert (Brunel University London)

How to people live with infrastructures if these fail to materialise the promised future of economic growth, development and modernity? I look at the effects of the oil price drop on the transport infrastructures of the southern Angolan port of Lobito to question the notions of ruination and crisis.

\section{Fashioning infrastructure, trending crisis in Ghana}

Pauline Destree (University College London)

This paper looks at the temporal transformation of an electricity crisis in Accra, Ghana into a "trend", exploring the postcolonial "chronopolitics" of infrastructure through the remaking of a fashionable present.

Dream homes at the home front: designing futures in a suburb / off-duty warscape Sonia Zafer-Smith (University College London)

This paper observes how an Israeli architect mediates between military and civilian futures, when building bomb shelters in homes. It considers the different expectations of modernity and future intersecting, as shelters solidify the infrastructure of war and Occupation within Israeli homes.

Thu 20th Sept 14:15-15:45

Envisioning- scaling-infrastructuring - the case of Durban's port infrastructure Souad Zeineddine (A.r.t.e.s graduate School)

This paper seeks to broaden the understanding of infrastructures as highly political socio-technical entities. Infrastructures are thought of as the materialization and enactment of multiple intertwined practices like envisioning, scaling and infrastructuring which have an effect on time and space. 
Panel and paper abstracts: Lang01

Hub interrupted: confining infrastructure in 21 st century Colombo

Alessandra Radicati (London School of Economics \& Political Science)

This paper provides an ethnographic exploration of urban life in Colombo to theorize confinement, rather than unrestricted mobility, as one of the primary effects of infrastructure construction.

\section{Metro buses and public spaces}

Aysha Khawaja

This paper directs its attention toward the intersection of infrastructure and embodied experiences of women in the public sphere by exploring how the Metro Bus system allows them, albeit limited, access to inhabit the outside world in the form of commuting.

Cycling dreams in Mexico: activist politics for inclusive mobility infrastructures Raul Gerardo Acosta Garcia (Universität Konstanz)

Guadalajara and Mexico City have been shaped by power practices with visible markers of inequalities. Recently, cycling activists have achieved changes in mobility infrastructures by navigating chronotopes defined by bureaucratic and neoliberal principles, while focusing on their own aspirations.

\section{Lang01 Semiosis as orchestration}

Convenors: David Parkin (Oxford University); Theresia Hofer (University of Bristol); Alex Pillen (DR)

Discussant: Adam Kendon (University College London)

Magdalen Lecture Room A: Fri 21st Sept, 09:00-10:30, 11:00-12:30, 16:00-17:30

How are the sensory modalities of sound, touch, sight, smell and taste co-ordinated in interactive communication? How do interlocutors sense a drive towards harmonious collaboration, and how much does verbal language heal or repair communication when modalities clash? Original papers are invited.

\section{9:00-10:30}

Unspeakable taste: communicating through the sensory modalities of tea in China David Parkin (Oxford University); Kunbing Xiao (SouthWest University for Nationalities) Descriptions of tea taste often diverge. Chinese tea circles (chaye quan) address this elusiveness over time through sight, touch, smell and voice, with each sense alternately marking phases of the communication event. How much is this orchestrated by commerce, aesthetics or rivalry? 
Panel and paper abstracts: Lang01

Reflexivity, experiment and ambiguity in the semiotic orchestra of ritualized everyday life

Chloe Nahum-Claudel (London School of Economics)

Enawenê-nawê everyday life is analysed as a series of intercalated patterns of directional movement, tempo, touch, vision, voice and sound. The play of visibility and invisibility, silence and speech, noise and melody, touching and distanced bodies, achieves a social and cosmic orchestration.

\section{The phono-aesthetics of qing in Chinese medicine}

Elisabeth Hsu (University of Oxford)

In Chinese lexicography sounds and meaning tend to be intricately related, as they appear to be in some Chinese materia medica texts. The sound of the word qing, 1st tone, can mean light, transparent, bluegreen, depending on the graph with which it is written.

Peyo: song, sense and sign in Araweté vocal art

Guilherme Heurich (UCL)

This presentation will ethnographically pursue the description of different semiotic dimensions of the peyo ceremony amongst the Araweté, an amazonian society.

11:00-12:30

"Natural sign" in gestural languaging and in Tibetan sign language in Lhasa, Tibet Autonomous Region

Theresia Hofer (University of Bristol)

This paper explores and analyses the use of gestures in the context of so-called "natural sign" and Tibetan Sign Language in Lhasa.

\section{Thoughts as space: visual representations of deaf-centric thought-maps} Kelly Fagan Robinson (UCL)

'VV' is a performance praxis in which deaf people externally map thoughts in space, constructing specific instants, people, landscapes, emotions \& musings-made-flesh in order to consider or help others understand their thinking. This praxis reframes listening as seeing, in art \& in welfare support.

Silent playgrounds. Non-verbal communication among children moving and playing in a multicultural setting

Giulia Cavicchioli (University College London)

How do children mediate aspects of social life in a multicultural context where verbal language cannot become ultimate source of explanation? How are communicative resources at their disposal (such as gestures, eye gaze) to create, sustain, and shape the settings in which the children move and play? 
Panel and paper abstracts: Lang02

Language and the body in Datooga children's concepts of kinship Alice Mitchell (University of Bristol); Fiona Jordan (University of Bristol)

This paper explores how Datooga-speaking children of Tanzania articulate kinship concepts through verbal and embodied action. To what extent is the body a resource for communicating kinship concepts, and what might this tell us about how children conceptualise kinship relations?

\section{6:00-17:30}

The power of sonic 'things': the power of sonic 'things': multi-species communication in the Batek's forest

Alice Rudge (UCL)

This paper considers the ethical and aesthetic discourses surrounding how sensory modalities are used among the Batek, a forest dwelling, hunting and gathering group of Peninsular Malaysia. How do these come to orchestrate human relationships with the non-humans of the forest?

Interruption and enumeration: rhythm, gesture and tone in Northern Kurdish Alex Pillen (DR)

This paper questions the orchestration of verbal style across speech genres in Northern Kurdish: from challenges to a turn-taking system in conversation, to narrative flight and enumeration in rhetorical speech.

Thinking through the Cello. Prelude to the 3 Suite for Unaccompanied Cello of J. S. Bach

Tim Ingold (University of Aberdeen)

\section{Lang02 Imagining language: ethnographic approaches}

Convenors: Guilherme Heurich (UCL); Jan David Hauck (University of California, Los Angeles)

Discussants: Alessandro Duranti (University of California, Los Angeles); Sinfree Makoni (Pennsylvania State University)

Examination Schools Room 6: Tue 18th Sept, 13:30-15:00, 15:30-17:00

What is language in the human imagination? How do different intellectual traditions make sense of and compare between linguistic forms? In this panel, we are interested in empirically exploring the ontological variation of language, multiplying the possibilities of what language(s) could be. 
Panel and paper abstracts: Lang02

13:30-15:00

Ontologies and linguistic relativity: the symbolic construction of reality in poetry, music, and the social imagination

Sean O'Neill (University of Oklahoma)

This paper critically reexamines current claims about the diversity of ontological orientations among human societies, while resisting work work on linguistic relativitythe social construction of such lived-realities by means of the symbolism of everyday language: in particular poetry and music.

"Spoken language is a prison": phenomenology of speech and ways of speaking in North-West Greenland

Stephen Pax Leonard (University of Durham)

An Inugguit informant of mine said 'spoken language is a prison', oqauheq parnaerussiviuho: a Wittgensteinian description meaning verbalising limits thought. This paper explores an alternative ontology of language through the lens of the phenomenology of speech and Hymesian 'ways of speaking'.

“Eating Jesus everyday!”: re-assessing Watchman Nee's writings in light of fieldwork with his followers in Taiwan

Gareth Breen (LSE)

Much has been written on the writings of the famous Chinese Christian preacher Watchman Nee (Ni Tuosheng 1903-1972). However all of these assessments of Nee's oeuvre assume a referential approach to language. In contrast, his modern-day followers focus upon the "edibility" of his writings.

Language as an interactional achievement: mixed codes and metalinguistic awareness in Aché children's play

Jan David Hauck (University of California, Los Angeles)

This paper discusses how language and linguistic difference emerge in interaction. Analyzing everyday playful interactions of Aché children it examines the twin processes of constituting language as an object of consciousness and distinguishing between languages as separate entities.

$15: 30-17: 00$

Inter-indigenous difference and the changing role of language in the Peruvian Altiplano

Sandhya Narayanan (University of Michigan)

This paper will look at the different ways that linguistic difference has become an ideologized sign of inter-indigenous social difference between Quechua and Aymara speakers in the Peruvian Altiplano, influencing speaker identities and perceptions of the boundaries between languages and speakers. 
Panel and paper abstracts: Lang03

\section{Lang03 Language, justice and belonging}

Convenors: Kinga Kozminska (Birkbeck, University of London); Leonie Schulte (University of Oxford); Alessandro Duranti (UCLA); Nancy Hawker (University of Oxford); Rosemary Hall (University of Oxford)

Magdalen Lecture Room A: Wed 19th Sept, 09:00-10:30, 14:15-15:45, 16:15-17:45

Imaginations of 'justice' and 'language' affect speakers' senses of belonging. These are experienced, expressed and enacted verbally in legal, political and social arenas, which the panel will analyse discursively and ethno-linguistically. Normative methods and researchers' ethics will be discussed.

\section{9:00-10:30}

Teaching Germanness: migrant identity and linguistic integration in Berlin, Germany

Leonie Schulte (University of Oxford)

This paper explores the ways in which migrants and refugees experience Germany's language and civic integration program, while negotiating forms new and emergent forms of belonging and identity, which challenge and reimagine imposed and stereotyped notions of the 'integrate able migrant'.

The prosecution of Public Order (and related) offences in England and Wales John R. Campbell (School of Oriental \& African Studies)

This paper explores how the police and the CPS prosecute individuals for speech acts in London using The Public Order Act (1986). In this paper language, space and the law intersect in such a way as to criminalize wide swathes of public behavior.

\section{Communication and creativity in plurilingual institutional contexts in the Central} Andes

Antonia Schneider (LMU Munich and others)

Translation processes in plurilingual institutional contexts and spaces of interaction include not only denotational meanings, but index ideological, ambivalent and creative aspects of understandng and communication going beyond power relations and established dichotomies.

Utopian workers: language, migration and the neoliberal politics of solidarity and justice

Alfonso Del Percio (University College London)

This paper provides an ethnographic account of the tensions, doubts and controversies around the 'neoliberalization of solidarity' and documents social workers' investments in language and communication to pursue the utopian projects of justice that they associate with their professional practice. 
Panel and paper abstracts: Lang03

\section{4:15-15:45}

The persistent dissonance of Arabic in Israel: the linguistic performance of ideological positions on citizenship

Nancy Hawker (University of Oxford)

Palestinians inside Israel are judged for their supposed political 'quiescence' to subordinate citizenship. Analysis (avoiding normative nationalist traps) of codeswitched Arabic public discourse explores how this dissonant medium bears on civic conceptualisations. Research choices are questionned.

\section{Thou shalt not be silent: daring to speak about sexual abuse in religious Jewish} communities

Michal Kravel-Tovi (Tel Aviv University)

This paper will explore the language through which observant Jews, survivors of sexual abuse, advocate their claims for both justice and belonging. It will draw from transcripts of public testimonies of abuse, and will illuminate the discursive sensibilities that sustain this daring form of speech.

The struggle for representation: imaginations of language and justice within the Polish-speaking community in the UK.

Kinga Kozminska (Birkbeck, University of London); Hua Zhu (Birkbeck, University of London)

The paper explores the intersection between linguistic diversity and imaginations of justice within British society looking at Polish-speaking community's language policy efforts. We analyse migrants' senses of belonging in relation to economic inequality,political participation,cultural domination.

'I'm allowed to make fun of my own people': (il)legitimate dialect parody in Bermuda Rosemary Hall (University of Oxford)

This paper examines the racialized dialect performances of a group of white men in Bermuda, exploring the implications of this type of data for sociolinguistic theories of authenticity, and discussing methodological concerns in research contexts involving highly empowered participants.

16:15-17:45

The need to belong: monolingual 'integration' and multilingual realities Kamran Khan

I investigate belonging from a psychological perspective within an ethnography. I will use an ethnographic study to demonstrate how the need to belong and how people find ways of belonging through language in interacting with others is at odds with political discourse.

General discussion and summing up

Alessandro Duranti (UCLA) 
Panel and paper abstracts: Med01

Med01 When psychotherapy goes awry: theorising the unexpected in therapeutic encounters

Convenor: Nicholas Long (London School of Economics and Political Science)

Magdalen Daubeny: Fri 21st Sept, 09:00-10:30, 11:00-12:30

This panel explores how both therapists and anthropologists can and do make sense of unexpected or unwelcome developments in the consulting room, and what these perspectives might contribute to cross-disciplinary debates about whether, how and why people can change.

\section{9:00-10:30}

The psychoanalytic training analysis in ethnographic perspective Douglas Hollan (UCLA)

This paper analyzes psychoanalytic trainees' doubts and uncertainties about the thoroughness of their own training analyzes and how this effects therapeutic outcomes for themselves and for their own analysands, paying particular attention to institutional constraints and contradictions.

'Ten years of therapy in one day': unruliness, prediction and surprise in psychedelic psychotherapy

Tehseen Noorani (Durham University)

Resurgent psychedelics-assisted psychotherapy is subject to contemporary scientific imperatives. Yet psychedelics are unruly, producing unpredictable experiences. By combining surprise and prediction, the skillful configuration of psychedelic therapy is able to shape wider spiritual practices.

Erickson in the postcolony: hypnotherapists as figures of ambivalence in Indonesia's mental revolution

Nicholas Long (London School of Economics and Political Science)

When Ericksonian hypnotherapy is practiced in a developmentalist postcolonial context (Indonesia), it loses its capacity to accommodate certain unexpected forms of speech. 'The unexpected' can then render patients ambivalent towards hypnotherapy and therapists pessimistic about national development.

In (the) practice: translating, appropriating and 'doing' psychotherapy in Uganda Julia Vorhoelter (Goettingen University)

This paper focuses on a small group of Ugandan psychotherapists and their efforts and challenges to establish psychological psychotherapy as a practice and academic discipline in Uganda. 
How fragmentariness of contemporary non-conventional psychotherapies attempts to replace the longer and culturally historicized analysis

Denise Lombardi (GSRL / Université de Lorraine)

The objective of the paper is to focus on the role of neo-shamanic practices as a nonsomatic therapy. We observed that inherently lengthy institutional psychotherapies are being replaced by a multitude of fragmented practices that may fulfill the duration of the conventional therapies.

Beyond the therapeutic encounter: exploring metaphors of care and sociality in counseling practice in Sri Lanka

Nadia Augustyniak (The Graduate Center, CUNY)

This paper focuses on the nature and significance of the therapeutic relationship in psychological counseling in Sri Lanka with the broader aim of examining the social and political dimensions of this relatively recent and now increasingly common practice.

Fallacies of care: failures of empathy in the therapeutic alliance in U.S. forensic psychotherapy

Kristina Pinto (Suffolk University); Sarah Pinto (Tufts University)

In U.S. forensic psychotherapy, failures of empathy can be guides to therapeutic efficacy, and, in reverse, empathetic success may signal therapeutic failure, a situation we refer to as a "fallacy of care" as we ask what new ethical goals take empathy's place in the forensic therapeutic alliance.

Med02 Embodied ecologies: materiality, environments, and health Convenor: Andrea Ford (University of Chicago)

Discussant: Theresia Hofer (University of Bristol)

Magdalen Old Law Library: Wed 19th Sept, 16:15-17:45

The small-scale materiality of human bodies - genes, microbes, chemicals, hormones - is increasingly understood as both responsive to broader environmental contexts and a crucial determinant of health and well-being. How are bodies imagined ecologically among anthropologists and those we study?

$16: 15-17: 45$

Bodies and boundaries: radiation 'protection' in post-disaster Japan Jennifer Clarke (Robert Gordon University)

Emerging from art-anthropological fieldwork in post-disaster, post-nuclear Japan, this paper will consider the porosity of bodies and boundaries, and other socio-materialentanglements, through forms of radiation protection, and in light of feminist theories. 
Panel and paper abstracts: $\quad$ Med03

\section{Toxic stress and the reproductive body}

Andrea Ford (University of Chicago)

The idea of "toxic stress" pushes anthropologists to reimagine materiality. Activists, scientists, and childbearing people in California understand experiences, thoughts, and feelings to be intertwined with the body's physical makeup via genes and hormones, which are passed on in reproduction.

\section{The stem cell niche - biological control in post-genomic science}

Karen Jent (University of Cambridge)

The recent turn to post-genomic science examines health and disease by exploring how environments expand into bodies. Taking its cues from work with stem cell researchers, this paper suggests that in the process the microenvironment itself has been turned into a potent tool of biological control.

\section{Transgenerational embodiment of material-symbolic practices. Anthropogenic environments and epigenetic inheritance}

Eugenia Ramirez-Goicoechea (Universidad Nacional de Educación a Distancia, UNED) Environmental materialsymbolic practices may be embodied as biological responsiveness through epigenetic processes which may impinge on future health over the generations. The epigenetic turn goes well beyond biomolecularising "culture" and fosters a new opportunity for anthropological enquiry.

\section{Med03 Food as medicine: biosocialities of eating in health and illness} Convenors: Anna Lavis (University of Birmingham); Heather Howard (Michigan State University); Narelle Warren (Monash University); Karin Eli (University of Oxford) Magdalen Oscar Wilde Room: Fri 21st Sept, 09:00-10:30, 11:00-12:30, 16:00-17:30

This panel examines food as medicine at the convergence of material, imagined and biosocial aspects of healing. It explores medicalized transformations of commensality, experiential liminalities of feeding spaces and technologies, and productions of agency and sovereignty in healing through food.

\section{9:00-10:30}

\section{Food as love, food as medicine: the shadow habitus revealed}

Pauline Herbst (University of Auckland)

Children diagnosed with MCADD develop a sense of self within the constraints of habitus, daily behaviour radiating around food practices and preventative medical intervention shaped by the genetic diagnosis. This experiential, sensory knowledge is learned by the body in the first few years of life. 
Recipes for soup: Parkinson's disease, care, and a good life

Narelle Warren (Monash University)

Care in the context of Parkinson's disease is grounded in and expressed through affective and relational practices. As neurodegeneration progresses, everyday care practices become increasingly intimate - and these intimacies are reflected through the preparation and sharing of food.

\section{Caring for the cancer patient through healthy eating}

Anna Maria Frost-Jensen (University of Copenhagen)

Malnutrition is common among cancer patients, but often not a focus of the doctor. Caregivers and cancer patients seek to gain agency by turning to food as a form of medicine when facing cancer. This article explores the challenges faced in, the midst of, contradicting strategies and information.

Food as a node: constructing agency for "demented bodies"

Noa Vana (Tel Aviv University); Haim Hazan (Tel Aviv University)

We focus on food as a node in the study of caring for people with advanced stages of dementia living at home. We contend that families construct an agency for the "demented bodies," through food-related caring practices; one which is differentiated from their non-existing subjectivity

11:00-12:30

\section{Medicinal food, social food, and the 'eating cure': scenes from an eating disorders} ward

Karin Eli (University of Oxford); Liron Cohen

In this presentation, we explore food as medicine in eating disorders care, examining tensions between refeeding as a technical process and eating as a commensal process. These tensions highlight the ontological liminality of food, as the means to both (social) recovery and (physiological) survival.

"My bariatric staples": resocializing relationships with food after metabolic surgery Heather Howard (Michigan State University); Linda Hunt (Michigan State University); Anna Martinez-Hume (Michigan State University)

This paper examines the transformation of food in the clinical management of obesity and diabetes through metabolic surgery, and concomitant shifts in selfhood, identity, intimacies, and commensality as the surgery's power extends beyond the individual upon whose body it has intervened.

\section{The health seeking behaviours of people with food allergies}

Jelika Gumbo (Witwatesrand)

Food can cause different health conditions such as food allergies. Living with food allergies has physical, economic, social and cultural challenges. 
Panel and paper abstracts: Med04

Man, medicine and foods: the healing power of foods among the indigenous people in Bangladesh

Muhammad Ala Uddin (University of Chittagong)

This paper examines food as medicine at the biosocial aspects of healing. It explores the medicinal power of foods among the indigenous people of Chittagong Hill Tracts (CHT) in Bangladesh.

\section{6:00-17:30}

Embodied medi(c)ations: (not) swallowing anti-psychotics

Anna Lavis (University of Birmingham)

This paper explores embodied encounters with anti-psychotic medications. It traces the ways in which the act of swallowing draws food and medicine into visceral entanglements that disrupt psychiatric imaginings of illness, treatment and recovery, and transform food into medicine.

Learning to feed the body: food, diet, and the body in LCHAD deficiency Malgorzata Rajtar (Polish Academy of Sciences)

Drawing from ongoing ethnographic research in Finland and Poland, this paper attends to living experiences of patients with LCHADD and their caregivers at the intersections of food regimes, the body, and technologies.

First Vita Plus: the biosocialities and efficacies of a Filipino food supplement Anita Hardon (Amsterdam Institute for Social Science Research, University of Amsterdam) This analysis follows the informing of First Vita Plus, a Filipino food supplement that was designed by a Filipino community-based doctor to contain five "power" herbs. It points to the fluidity and bio-sociality of the products, that are sold through multi-level marketing as cure-alls.

\section{Healthy eating and obesity management: biopedagogies of food}

Lavinia Bertini (University of Sussex)

Using ethnographic data, I illustrate how the promotion of "healthy eating" in weightloss groups utilises biopodegogies of food as "enabling practices" that reproduce normative ideas of biocitizenship and consumer choice through nutritional knowledge.

Med04 Reimagining urban health: infrastructures, economies and human-animal relations in the Global South

Convenors: Jamie Lorimer (University of Oxford); Michelle Pentecost (Kings College

London); Thomas Cousins (University of Oxford)

Magdalen Daubeny: Tue 18th Sept, 13:30-15:00, 15:30-17:00

How do animals, cities, and health shape each other in urban contexts of the global South? This panel brings together ethnographies of animal life, urban human livelihoods, 
and the governance of health in order to examine how trans-species interactions shape livelihoods and health.

13:30-15:00

More-than-human encounters: an urban political ecology

Maan Barua (University of Cambridge); Sushrut Jadhav (University College London); Anindya Sinha (National Institute of Advanced Studies)

This paper focuses on more-than-human encounters and their implications for articulating the urban in the Global South. Drawing upon etho-geographical research, the paper front-stages the ways in which they have bearings upon everyday life, the ecologies of urban health and governance.

Ethics, violence and disgust: the practice of Qurbani in Mumbai Shaheed Tayob (Stellenbosch University)

An ethnography of the Muslim festival of sacrifice in Mumbai as a moment of worship, labor, commerce and play: I argue that the association of animal slaughter with disgust and cruelty entails an ethical judgement where an act of violence is imbued with an affect of horror.

Urban entanglements and multispecies relations: the case of bioengineered mosquitos in Medellín

Rosie Sims (Graduate Institute of International and Development Studies)

In the context of a global health technology involving bioengineered mosquitos, this paper considers how unforeseen events shed light on the ways in which multispecies relations are entangled within the complex fabric of the city of Medellín, and how local and global dynamics of governance emerge.

Infection, compensation, containment and justice: biosecurity and value in the 2017 avian flu outbreak in Cape Town, South Africa

Thomas Cousins (University of Oxford); Michelle Pentecost (Kings College London)

We give an account of the course of, and state response to, the 2017 avian influenza outbreak in Cape Town, South Africa, considering how ideas of enforcement, containment, compensation, and value are mediated across forms of life and death.

$15: 30-17: 00$

The rat trap: contestation over rodent control in Cape Town

Nicoli Nattrass (UCT)

This paper discusses rival conceptions and approaches to rodent control in Cape Town. 
Panel and paper abstracts: Med05

The political life of rats in Cape Town, South Africa: reflections from a scoping study Pieter du Plessis (University of Cape Town)

This paper stems from a scoping study that was conducted in Cape Town, South Africa on how rats are managed in different parts of the city, how rats are perceived and what effects rats have on human health.

The whistling of rats, street pesticides, and childhood poisoning in Cape Town, South Africa

Susan Levine (University of Cape Town); Alison Swartz (University of Cape Town)

Caring for children in precarious urban contexts requires rats be 'exterminated.'This paper explores the complex human-animal interface, with ethnographic data drawn from the city if Cape Town where schools of thought around animal cruelty clash.

\section{Med05 Understanding health workers at the interface of community and} development

Convenors: Juli Huang (LSE); Jeevan Sharma (University of Edinburgh); Sumeet Jain (University of Edinburgh); Ian Harper (University of Edinburgh)

Magdalen Oscar Wilde Room: Thu 20th Sept, 09:00-10:30, 14:15-15:45

This panel explores the roles of Community Health Workers (CHWs) in the context of social development. As the link between communities and programmes, theoretical and ethnographic papers will showcase how they translate and adapt in differing sociopolitical, religious and gendered spaces.

\section{9:00-10:30}

On the brink of danger: a case of vaccination teams performing in precarious situations in Pakistan

Inayat Ali (University of Vienna)

This paper explicates the precarious situations of vaccination teams in Pakistan, who are performing their roles, despite the dangers of being killed.

Relations of care, relations of market: incentives and informal payments among Accredited Social Heath Workers in Delhi

Emilija Zabiliute (University of Edinburgh)

Based on an ethnographic fieldwork, this paper examines care work and monetary transactions among Accredited Social Health Workers (ASHAs) in urban India. It shows how ASHAs' monetary incentives and informal payments by their neighbours are intrinsic to their neighbourly relations of care. 
Panel and paper abstracts: Med05

Healing 'heart-minds': agency, creativity, and brokerage among frontline psychosocial workers in post-earthquake Nepal

Liana Chase (SOAS, University of London)

This paper explores how frontline psychosocial workers in rural Nepal strategically broker between global and local illness categories to facilitate access to care. Findings highlight a need for greater attention to the role and contributions of frontline workers within global mental health.

The role of community health workers in enabling mental health 'recovery' through use of a visual tool

Sumeet Jain (University of Edinburgh)

Community health workers (CHWs) played a central role in implementing a visual mental health recovery tool in northern India. This paper analyses the role of CHWs in enabling social recovery.

14:15-15:45

Transforming "bad patients" into "good patients": community health workers' role in governing Roma communities in Romania

Charlotte Kühlbrandt (King's College London)

This paper engages with the ways in which "patienthood" is physically and discursively enacted by community health workers in Roma communities in Romania.

ASHA workers and the blurred margins of the State: reflections on health practices among Kondh tribal women in Odisha

Bibekananda Nayak (Babasaheb Bhimrao Ambedkar University, Lucknow)

This paper shows as to how ASHA workers among Kondh community in Odisha 'blur' the oft-presumed boundaries of the State-sponsored modern healthcare system and indigenous health practices.

\section{Contradictory demands of participation and bureaucratization in Pakistan's HIV} sector

Ayaz Qureshi (University of Edinburgh)

This paper explores the tension between the contradictory demands of 'participation' and 'bureaucratization' in Pakistan's HIV sector. The ethnography shows that regardless of their relevance to local populations, projects that cannot produce measurable impact lose support from donors.

Community Health Workers and the micro-politics of indigence in South Kivu, Eastern DR Congo Jean-Benoit Falisse (University of Edinburgh)

This paper looks at the way Community Health Workers operationalize the 'indigent' label in Eastern DR Congo (which officially entitles to rights), and how this affects their actions and positioning in their own communities. 
Panel and paper abstracts: Med06

Med06 Hermeneutical injustice, clinical imagination and patient discontent in mental healthcare

Convenors: Edward Harcourt (University of Oxford); Neil Armstrong (Magdalen College, Oxford)

Magdalen Daubeny: Thu 20th Sept, 09:00-10:30

This panel combines philosophical work on hermeneutical injustice and the imagination with empirically informed anthropological work on mental healthcare and patient health experiences to investigate mental healthcare patients' claims to be misunderstood by clinicians.

\section{9:00-10:30}

Lost in translation? Clinical knowledge, epistemic injustice and mental health patients

Neil Armstrong (Magdalen College, Oxford)

This paper uses the notion of hermeneutical injustice to understand the relationship between clinical knowledge and patient narratives.

Re-imagining therapeutic relationships: mutual-help among 'Service Evader' activists in times of crisis

Keira Pratt-Boyden (University of Kent)

This paper explores therapeutic relationships in an intentional mental health activist community influenced by anti-capitalism. Examining how 'Service Evaders' incorporate practices of care into their daily lives, this paper reveals how mental illness can be a site of social re-generation.

\section{Epistemic injustice, children and mental illness}

Edward Harcourt (University of Oxford); Kate Martin (UCL)

The paper argues that the experiences of health services both of children and of the mentally ill challenge some formulations of the notion of epistemic injustice, and proposes an alternative formulation.

Mistaking the map for the territory: biomedical ontology and hermeneutical injustice Alistair Wardrope (University of Sheffield/Sheffield University Hospitals NHSFT)

I argue that hermeneutical marginalisation of non-medicalised perspectives on mental health arises from unjustified reification of medical models of mental illness that are only intended to serve certain limited purposes and are not exclusive of alternative perspectives on the same phenomena. 


\section{Conflict with patients in hospital psychiatry, and addressing this with ReCreate Psychiatry \\ Khaldoon Ahmed (Camden and Islington NHS Foundation Trust)}

I respond to the mismatch between clinical language and patient experience drawing on my work as an inpatient consultant psychiatrist, and ethnographic research in psychosis. I present the findings of the ReCreate psychiatry project that seeks to address these imbalances through dialogue.

\section{Med07 Temporalities in the postgenomic era}

Convenors: Bastien Llamas (University of Adelaide); Michael Davies (Robinson Institute, University of Adelaide); Megan Warin (University of Adelaide)

Magdalen Oscar Wilde Room: Tue 18th Sept, 13:30-15:00, 15:30-17:00

Postgenomic theories challenge and transform our temporal understandings of disease and health, personhood, the environment, and reproduction. This panel examines temporality as it is embodied, constructed and experienced across differing postgenomic sites, opening up new imaginations of time.

\section{$13: 30-15: 00$}

\section{Times are changing: a paleogenomics and epigenomics perspective} Bastien Llamas (University of Adelaide)

Recent technological advances have revolutionised the study of DNA, allowing the analysis of ancient DNA and elusive epigenetic marks. These atypical molecular data provide new ways of measuring evolutionary times, and ultimately reveal that molecular time is all but relative.

\section{A postgenomic plasticity: genealogy, histories, politics}

Maurizio Meloni (Deakin University)

I argue here that postgenomic plasticity is neither a modernistic form of instrumental control of the body nor a postmodernist celebration of potentialities. It is instead closer to alter-modernistic views that disrupt clear boundaries between openness and determination, individual and community.

\section{Fertility preservation and the elasticity of time}

Michael Davies (Robinson Institute, University of Adelaide)

Technological innovations in reproductive biology have altered patterns of human senescence, the planning of reproductive careers, and reproductive identity. Documenting these innovations, the promises, and the outcomes may assist in developing a critical awareness for evaluating current and future technologies. 
Panel and paper abstracts: Med08

The precarious temporality of cure: 'hot-housing' stem cell transplants for children with thalassaemia in India

Sangeeta Chattoo (University of York)

This paper explores the precarious nature of risk and temporality of cure promised by stem cell transplants for children with thalassaemia, using ethnographic material from a study being carried out in India. Whilst state subsidy bridges inequities in care, it creates further dilemmas for parents.

\section{5:30-17:00}

Creating space and time in the postgenomic age: studying epigenetics researchers' narratives discussing the interactions between genes, the epigenome and environment

Clemence Pinel (King's College London)

I discuss narratives constructed by researchers around the notions of environment and epigenetics. The environment is defined as modifiable lifestyle factors, the epigenome as a malleable space that can be 'worked' on, while individuals are framed as responsible agents that can change their health.

Temporal ontologies, epigenetics and historical trauma in Indigenous Australian lives

Megan Warin (University of Adelaide)

This paper examines time as 'situated knowledge' in Australian Indigenous cosmologies and epigenetics. In a postcolonial context, the enfolding of time and trauma across generations has implications for current states of health and disease, and political strategies to redress such violence.

The biosocial spatio-temporalities of epigenetics: from labs to politics Luca Chiapperino (University of Lausanne); Francesco Panese (University of Lausanne) In this paper, we describe: first, the process through which animal evidence gets translated into several understandings of the 'biosociality of trauma' in humans; second, how the spatio-temporalities of "epigenetic trauma" are scaled-up as distinct political possibilities of biosocial intervention.

\section{Med08 Movement for mental health}

Convenors: Eline Kieft (Coventry University); Elisabeth Hsu (University of Oxford); Paola Esposito (University of Oxford)

Magdalen Lecture Room A: Thu 20th Sept, 09:00-10:30, 14:15-15:45

This panel combines medical and sensory anthropological approaches to explore innovative treatment avenues for mental and other chronic conditions. The panel aims to bring together movement practitioners, anthropologists and the neuroscientists. Contributions can be multi-modal. 
Move dance feel: exploring dance and wellbeing with women recovering from cancer Emily Jenkins (Freelance - inc. Trinity Laban Conservatoire of Music and Dance) This study explores the benefits of dance for women recovering from cancer and considers how such benefits relate to individual wellbeing. The study details what it is in the dance practice that is effective in this context, and contributes new knowledge to be used in both dance and health sectors.

Recommitting the people within the impaired Self: regenerative medicine as transfiguration of immunological and psychological socialities

Márcio Vilar (University of Sussex)

I explore relations between immunostimulating therapies to treat autoimmunity and of the 'parts therapy' to treat psychological wounds. My aim is to identify and understand movements (performative, institutional, and psycho-organic) for one's journey of selfregeneration through these therapies.

'Mentally and physically improvised': subjective health and wellbeing in tango Jonathan Skinner (University of Roehampton)

This paper is a presentation of results from a mixed-methods study of elderly Argentine tango dancers in London, specifically investigating how they use the improvised dance form in terms of addressing their mental and physical health.

Preterm birth and the arts: towards an expressive arts-based support programme for navigating parental distress

Gemma Collard-Stokes (University of Derby)

This research paper reveals the ongoing activity of the Birth and the Arts project, an investigation that aims to assess a necessity and function for a programme of expressive arts-based intervention within antenatal support systems for parents at risk of preterm birth.

14:15-15:45

\section{Movement therapy, basic neurology explained!}

Gert-Jan de Haas (NAR-Lab)

While many movement/dance therapies exist and find their way within specific cultural surroundings, fundamentally, these therapies draw upon the functional neurology of movement as a gateway to moving, feeling and thinking, and attempt to maintain or restore normal relations among these functions. 
Panel and paper abstracts: Mor01

Somatic awareness for (medical) anthropologists: staying healthy and well when we research illness and disease

Eline Kieft (Coventry University)

Presenting a Somatics Toolkit for Ethnographers, in this session I focus on those aspects that actively draw on our bodies' resources for mental and emotional support during our challenging work as researchers in (medical) anthropology.

\section{Mor01 Objects of mistrust. The relationship between material environment,} culture, and beliefs

Convenor: Radu Umbres (Faculty of Political Sciences, SNSPA)

Examination Schools Room 9: Fri 21st Sept, 16:00-17:30

This panel calls for papers looking at things as created in and constitutive of social relationships based on mistrust.

\section{6:00-17:30}

Wooden figures, tiger teeth and a bundle of sticks: 'objects of mistrust' from the Naga collection at the Pitt Rivers Museum, Oxford

Vibha Joshi (Tuebingen University/University of Oxford)

The paper investigates certain artefacts in the Pitt Rivers Museum collected from the Naga peoples of northeast India during colonial time which can be seen to embody 'social relationships based on mistrust'.

The manifest "good room" of secretive households in a Romanian village Radu Umbres (Faculty of Political Sciences, SNSPA)

Based on ethnography in a Romanian village, this paper analyses the dual epistemic nature of households. I propose a mechanism explaining both the material culture of opacity and secrecy in everyday life and their conspicuously overt "good room" in the rituals of death.

Cemetry sorcery in the Maghreb: a story of one newspaper article Anna Korovkina (Saint-Petersburg State University)

The author analyses the phenomenon of magic practices in the Maghreb on the basis of a leading article of an everyday Algerian newspaper dedicated to a case of, well-known in Maghreb, cemetery sorcery and the material of her personal field research.

Mor02 The moral language of economic imagination Convenors: Patrice Ladwig (Max Planck Institute for the Study of Religious and Ethnic Diversity); Patrick McKearney (University of Cambridge); Rachel Smith (Cambridge); Anna-Riikka Kauppinen (University of Cambridge) 
Chair: Laura Bear (London School of Economics)

Queen Elizabeth House (QEH) SR1: Wed 19th Sept, 09:00-10:30, 14:15-15:45, 16:15$17: 45$

This panel explores how and why people may turn to a language of morality to imagine ways the economy and their position in it seem fraught with ought. It examines comparatively how talk of ethics may relate to other registers for imagining norms at play in (dis)ordering people's economic lives.

09:00-10:30

Panel introduction. Moralizing languages and economic imaginaries: witchcraft, ritual and prosperity religions

Patrice Ladwig (Max Planck Institute for the Study of Religious and Ethnic Diversity); Anna-Riikka Kauppinen (University of Cambridge)

This introduction gives two illustrations of moral language as a window to imaginaries about economic success, failure and inequality in two ethnographic contexts characterised by the rise of 'prosperity religions'.

Responsible parasites? Moral registers in the private rental market in Britain Stephanie Grohmann (University of Oxford)

This paper explores the private rental market in Britain as characterized by increasingly acrimonious conflicts between an ethics of individual responsibilisation through property investment, and moralising calls for an end to 'parasitic' rent seeking and a universal 'right to a home'.

The moral language of work and (re)distribution: discourses of laziness and hard work in Jeppestown, South Africa

Elizaveta Fouksman (University of Oxford)

This paper analyzes the moral language of laziness, hard work, autonomy and dependence of the long-term unemployed poor in South Africa. In linking jobs to fairness, hope and citizenship, my informants insist on a work-based moral economy of contemporary capitalism, despite its inaccessibility.

\section{'Moral hazard' and ethics of work in economics}

Alice Pearson (University of Cambridge)

This paper explores how and why language of 'moral hazard' is deployed in undergraduate economics education, to examine certain tensions this illuminates between ethical and other registers in the discipline. 
Panel and paper abstracts: $\quad$ Mor04

\section{4:15-15:45}

\section{Moral grammars of the solidarity economy}

Richard Pfeilstetter (University of Seville)

This paper explores the moral language of doing business in the social welfare economy as experienced through my involvement with policies, practitioners and research within a European Commission funded project studying "successful social enterprises".

"From each according to their means to each according to their...how does it go again?": the faltering moral imagination of economic activists in a neoliberal world Timothy Stacey (University of Ottawa)

Indigenous worlds, Christendom, communism - all alternatives to the neoliberal present in the contemporary West seem to recede into the past. Imagined alternatives are a precious resource. This paper explores emergent imagined alternatives amongst economic activists in Vancouver, Canada.

"Ya harga ya sharga": migration anxieties and moral accusations in a Tunisian border town

Valentina Zagaria (London School of Economics and Political Science (LSE))

This paper will explore how migration and pursuing a dignified life are experienced and valuated, and what the anxieties and blame games they give rise to might reveal about people's understandings of their economic and moral lives.

\section{6:15-17:45}

\section{Suspicion and moral reflection among South African musicians}

Tuulikki Pietilä (University of Helsinki)

The presentation discusses South African musicians' prevalent suspicion that they have been taken advantage of by the music industry insiders. It provides an example of baffling moral reflection and studies the kind of moral language and understanding concerning exploitation that ensues from it.

\section{"Exchanging" time in the Helsinki Timebank}

Matti Erasaari (University of Helsinki)

This paper looks into the moral assumptions underlying the terminological choices surrounding timebanking in Helsinki, Finland. In particular, I focus on the idea of "exchanging" time and the way it conflicts with the tax authority's idea of time credits as "work performances".

\section{Mor04 Rules, ethics, and the everyday}

Convenors: Morgan Clarke (University of Oxford); Fernanda Pirie (University of Oxford) Magdalen Daubeny: Fri 21st Sept, 16:00-17:30

Laws, rules, and categories are all around us, but so are individualistic practices, 
Panel and paper abstracts: Mor05

strategies, and techniques. In this panel, participants are invited to explore the nature and use of rules, their attractions and limitations, and their relationship to other social practices and resources.

$16: 00-17: 30$

Back to the rules, and forth: negotiation and the forces of procedural legalism Andrea Nicolas

The paper argues that 'negotiating law' and 'following the rules' are not opposite poles of a spectrum of rule-abiding or -rejecting. Based on the example of the ethnic group of the Oromo of Ethiopia, the 'channelling forces' of procedural rule-conformity will be examined.

\section{Moral rules and ethical proverbs in medieval Tibet}

Fernanda Pirie (University of Oxford)

This presentation uses historical sources from medieval Tibet to ask about the resources that people draw upon to make ethical decisions, and why they might prefer examples, narratives, and metaphors to legalistic rules.

'Four "I love you's" each day': numbers and mnemonics in US marriage counselling Siobhan Magee (University of Edinburgh)

This paper draws on ethnographic research on marriage counselling in Virginia to discuss why rules are frequently centred on numbering and mnemonics.

Legalistic gaze on the state: the alliance for deportation beyond nation-state borders and across boundaries in Europe

Ioana Vrabiescu (University of Amsterdam)

The paper focuses on the work of civil society organizations and legal practitioners who are auxiliary to the deportation apparatus in France. Through daily routine these agents abide and create rules and generate trust in the judicial system thus revealing a debatable legalistic gaze on the state.

\section{Mor05 Valences of sociality: unpacking sociality through values}

Convenor: Kenneth Sillander (University of Helsinki)

Chair: Signe Howell (University of Oslo)

Discussant: Harry Walker (London School of Economics and Political Science)

Queen Elizabeth House (QEH) SR1: Thu 20th Sept, 09:00-10:30, 14:15-15:45

This panel explores linkages between sociality and value with the aim of opening up the sociality concept. Principal foci are the varying values attributed to sociality in different ethnographic contexts, and how values inform, shape and are generated through the practice. 
Panel and paper abstracts: $\mathrm{Mor} 05$

\section{9:00-10:30}

Sociality as ethics and politics

Kenneth Sillander (University of Helsinki)

This paper asserts that sociality is fundamentally ethical and political, invested with values and interests. It explores how visiting, sharing and other forms of sociality among the Bentian of Indonesian Borneo work as means of moral cultivation and strategic utilization of relationships.

\section{Fractal sociality among the Makassar of Indonesia}

Thomas Gibson (University or Rochester)

Villagers in Ara, Indonesia, are simultaneously members of ranked houses, of the Islamic umma, and of the nation state. Each institution generates a distinct mode of sociality and regime of value that interacts with the others to produce complex fractal forms of subjectivity.

\section{Shifting patterns of sociality and changing valuations of nature in a disturbed environment \\ Anu Lounela (University of Helsinki) \\ This paper explores how changing patterns of sociality and values reflect changing patterns of production and appropriation of nature in the context of environmental change. It argues that value production is indivisible from the production of social relations and the material means of livelihoods.}

'Pasin' and everyday acts of recognition: a necessary demonstration and accumulation of value in and around the Goroka Marketplace

Olivia Barnett-Naghshineh (University of Auckland)

This paper explores the local concept of pasin in Goroka alongside Honneth's notion of recognition in order to argue that maintaining sociality is critical in Goroka in spite of and resulting from the increasing focus on cash and commodities in people's social, material and emotional lives.

\section{4:15-15:45}

\section{Sociality as professional ethics}

Monica Heintz (University of Paris Nanterre)

This paper asserts that while sociality is not disinterested, by being an integral part of many collaborative projects, it acquires crucial work and professional value. I will illustrate this through case studies coming from the independent theatre and cinema milieu in France. 
Panel and paper abstracts: Pol01

Fashioning a mind of one's own in the valued company of deities

Sally Anderson (Aarhus University)

In forming minds of their own, the company children keep is important. Teaching religion in Danish public school is marked by efforts to engage deities as cultural ancestors but not as real interlocutors. The paper explores the sociality such simultaneous absence/presence, real/unreal gives on to.

\section{Luangan ritual sociality and the limits of shamanic efficacy}

Isabell Herrmans (University of Helsinki)

This paper explores the different modes of Luangan ritual sociality and how they are informed and qualified by moral values. It shows how a "conditional ontology" of notknowing and the unpredictability of real-life events motivate the extension of sociality and the diversification of its forms.

\section{The values of a murder: how values shape sociality's forms in a Philippine highland} village

Jon Henrik Ziegler Remme (University of Oslo)

This paper discusses the dynamic character of sociality in Ifugao, the Philippines, and demonstrates the ways in which values gave shape to sociality's dynamics after the murder of an innocent foreign visitor to a village in Ifugao, the Philippines.

\section{Pol01 From managed change to utopian disjuncture: socio-environmental} transitions in a fluctuating world

Convenors: Agustin Diz (London School of Economics); Andrea Enrico Pia (London School of Economics)

Examination Schools Room 7: Thu 20th Sept, 09:00-10:30

Transitions suggest managed change in the face of disruption, but they also create opportunities for alternative futures. This panel explores how social collectives engage with the imaginaries and practices of transition in a context of changing capitalist relations to nature and labour.

09:00-10:30

Changing forms of land governance in Costa Rica: unintended results of socioenvironmental transitions

Clate Korsant

I examine what the discourse on socio-environmental transitions in Costa Rica's Osa region suggests regarding recent growth in tourism interests for farmers (campesinos), conservationism as a new form of land governance, and previous instances of resource extraction linked to global markets. 
Panel and paper abstracts: Pol02

Corporate sustainability and the narrative of smooth transitions

Matthew Archer (Copenhagen Business School)

Corporate sustainability uses the language of "smooth transitions" to preclude critique while reinforcing the corporation's position at the center of neoliberal sustainable development. This paper explores the implications of - and alternatives to-the dominance of this transition narrative.

Imagining transition: social and political construction of local-food movement in postcolonial Hong Kong

Hao-Tzu Ho (Durham University)

Europe-based transition initiatives has been adapted and adopted in Hong Kong's postcolonial situation. Local-food movement emerged amid contestations over locality, seeking alternative life forms and calling for adjustments in cultural and politicaleconomic norms underlying current food systems.

\section{Energy transitions and political revolutions in the Ecuadorian Andes and Amazon} Chris Hebdon (Yale University)

This paper examines the ways that state-led energy transition in Ecuador has hinged on the assumed convertibility of fossil fuels habits into electrical ones, and how this process has been contested, halted, and rerouted, particularly from the Ecuadorian Amazon.

\section{Pol02 Imagining and creating walls, utopias, and co-fragile formations} Convenors: Teruko Mitsuhara (University of California, Los Angeles); Matthew McCoy (Anthropology)

All Souls Wharton Room: Wed 19th Sept, 09:00-10:30, 14:15-15:45, 16:15-17:45

This panel examines the ways in which societies, communities, and individuals come to form fragile barriers and estrangements between themselves and others. We ask, in what ways do people imagine, contest, and normalize the creation and maintenance of divisions?

\section{9:00-10:30}

\section{"Getting out the rat race": migration to utopia}

Teruko Mitsuhara (University of California, Los Angeles)

This paper focuses on a utopia project comprised of international and Indian religious migrants to rural India. It explores how the commune has become a 21 st century critique of today's "societies of control" as people attempt to disentangle from capitalism and create their own world. 
Panel and paper abstracts: $\mathrm{Pol02}$

Imagining and creating of walls: ostracism, banishment and the reconstitution of witch communities in northern Ghana

Matthew Gmalifo Mabefam (University of Melbourne)

This paper examines the different forms of walls that are created in Ghana by categorising communities into 'witch', 'feeder' (communities where most accused witches come from) and 'normal'. It will address the implications of belonging to any of the walled communities.

\section{"Youse people and us:" ways of life within the peace walls of Belfast}

Matthew McCoy (Anthropology)

Based on ethnographic fieldwork with Protestants and Catholics who live on opposite sides of a series of peace walls in east Belfast, this paper examines how these walls have shaped the possibilities for cultivating a good life amidst the ongoing legacy of conflict, poverty, and segregation.

Imagination, collectivity, and the state: an ethnography of Kel Tamasheq in Bamako Giulia Gonzales (University of Turin)

Through an ethnography of rumours, knowledge claims, and daily practices among Malian Kel Tamasheq in Bamako, this paper enquires into the formation of heterogeneous positions in relation to this collectivity's own imagination, the state, and the current political crisis.

14:15-15:45

Ethnographing the Mexican-American bordeland: the liminal space of Ciudad Juárez-El Paso

Hugo Gaggiotti (University of the West of England); Diana Marre (Autonomous University

of Barcelona); Francisco Lara (National Institute of Anthropology and History Mexico); Ana Vera (INAORB)

The "muro" (wall) and the "puente" (bridge) are equally embedded in the cultural practices of Americans and Mexicans of Ciudad Juárez and El Paso. The paper discusses the liminality of the borderland and it's construction as a social space in-between the static and the mobile (Kearney, 1998).

\section{A park for whom?}

Courtney Cecale (University of California, Los Angeles (UCLA))

This paper ethnographically explores the impacts of the establishment of Huascaran National Park; including forced evictions, the creation of legally porous boundaries for shared use, and the subsequent collisions arising from changing climate conditions. 
Panel and paper abstracts: Pol03

The country and the city: locating the peasant persona at the infra-national border in discourse about language

Félix Danos (Université Paris-Descartes)

Drawing on fieldwork conducted in rural Central France (Allier), I will look at discourses about linguistic practices qualified as "patois" in contrast to French, and the effects on the regimentation and hierarchization of people, of their social-semiotic association with spatiotemporal ensembles.

Borders without fences and confinement without walls: the use and experiences of electronic bracelets for migration control

Carolina Boe (Université Paris V)

The paper will map some of the larger, complex network of transnational private and public actors who advocate for or against the use of electronic monitoring of migrants and analyze the experience of border control in the most intimate spheres, in homes and on bodies.

\section{$16: 15-17: 45$}

Re-imagining origins and the bypassing of exclusion (Sahel / Sahara)

Clare Oxby

Based on interviews in C Niger and S Algeria, this piece looks at the local caste-like social system of exclusion by descent, and how people of nomadic Tuareg heritage re-imagine their origins after times of insecurity, to facilitate integration in a new location.

Bringing down the illegality wall? The social life of the new 'neighbor ID card' for undocumented migrants in Barcelona, Spain

Barak Kalir (University of Amsterdam)

The paper explores the municipality of Barcelona's recent utopic initiative to issue a 'neighbor ID card' to undocumented migrants. While potentially countering central state efforts at the socio-legal exclusion of certain migrants, the initiative produces tension between "neighbors" and key actors.

\section{Pol03 On anthropological frontiers: divisions and intersections between} environment, personhood and sociality Convenors: Julia Sauma (University of Bergen); Antonia Walford (University College London/University of Copenhagen); Lewis Daly (University College London)

All Souls Wharton Room: Thu 20th Sept, 09:00-10:30, 14:15-15:45

Reflecting on its potential for rethinking anthropology, this panel considers the work that the idea of "frontier" does to conjure divisions - between places and people - and intersections, such as those between matter and sociality, human and nonhuman, the conceptual, empirical and political. 
Panel and paper abstracts: $\mathrm{Pol03}$

09:00-10:30

From exoplanets to endoplanets. How astrobiologists reorient metaphysics Istvan Praet (University of Roehampton)

Based on anthropological research with astrobiologists, this paper shows how astronomical conceptions of 'distance' are being redefined and illustrates that the interplanetary medium is losing its privileged status as the boundary of boundaries.

Science of the European frontier: Serbian astrophysics navigating "in-betweenness" Mirjana Uzelac (University of Alberta)

The paper explores how the notions of living on the frontier of Europe and being "inbetween" the East and the West influence the work of astrophysicists in Serbia.

From frontiers to borders. Land and ethnic identity in post-colonial Northeast India Mahendran Chokkalingam (Central European University)

This paper explores how colonial law of Inner Line Permit(ILP) in uncharted north east frontier agency(NEFA) has strengthen the ethnic identity of indigenous communities in the current state of Arunachal Pradesh, India..

Fruits of peace? The (un)making of a banana plantation in a frontier town in Muslim Mindanao

Steven Schoofs (Ghent University)

This paper deploys the frontier concept to study the intersection between place-making, identity formation, and agrarian change in conflict-affected Muslim Mindanao, Southern Philippines.

14:15-15:45

Entangled stories: emergence of personhood in dementia care during AnimalAssisted Therapy (AAT)

Cristina Douglas (University of Aberdeen)

My paper explores what kind of subjects/persons/selves emerge in the entanglement of political, public health, bio-medical, social, institutional, interpersonal and interspecies relations in the liminal space between life and death during Animal-Assisted Therapy in institutionalized dementia care.

Naamiwan's wiikaanag: awakening ceremonial relationships in the post-colonial museum

Maureen Matthews (The Manitoba Museum); Roger Roulette (Aboriginal Languages of $M B)$

Attempts at decolonisation and reconciliation have radically altered the theory and practice of museum ethnography, making museums a new frontier in decolonized relationships. This paper looks at the impact of privileging a relational Anishinaabe centered approach to the person/objects in museums. 
Panel and paper abstracts: Pol04

\section{Frontiers of reason in Latin America}

Victor Cova (University of Aarhus)

In this paper I present a portrait of a town at the Amazonian frontier of Ecuadorian settler colonialism, Macas. I do this by going back and forth across the borders and divisions (class, gender, race, sexuality, temporality) that constitute it, and that constitute it as a frontier town.

\section{Pol04 Cosmopolitics of land: engagement and negotiation in the lived world} Convenors: Susana Viegas (Institute of Social Sciences, University of Lisbon); Elizabeth Ewart (University of Oxford); Alejandro Reig (University Of Oxford)

All Souls Old Library: Wed 19th Sept, 09:00-10:30, 14:15-15:45, 16:15-17:45

This panel seeks to explore the relationship between land/the lived experience of land and cosmopolitical agency. We invite ethnographically based contributions that foster productive comparative dialogues on land as a cosmopolitic axis of sociality.

\section{9:00-10:30}

\section{Cosmopolitics in an "egalitarian" society}

Dan Rosengren

The indigenous Matsigenka, of the Peruvian Amazon, and representatives of the modernist Peruvian society live in ontologically distinct worlds and they frequently fail to understand each other. When Matsigenka people act (cosmo)politically it is understood by their adversaries in distinct terms.

'God gave us this land': cosmopolitics and Christianity in indigenous Amazonia Elliott Oakley (University of Edinburgh)

In this paper I ask how Waiwai experiences of Christianity relate to regional political and economic transformations in Guyana. I argue that cosmopolitical connections with land exceed the colonial and post-colonial contexts in which they are embedded.

The delineation of indigenous peoples' traditional territory and cosmopolitics of land in Taiwan

Shu-Yuan Yang (Academia Sinica)

This paper attempts to explore how indigenous peoples in Taiwan negotiate claims to land and autonomy within the nation-state by analyzing the Bunun's movement to reclaim their traditional territory through embodied engagement with ancestral entities. 
Panel and paper abstracts: Pol04

Replanting trees on earth landscaped by property. The predicament of humans trying to survive ecocide in Central Brazil

Marcela Coelho de Souza (University of Brasilia)

How kisêdjê persons reflect on and and struggle to respond to ecocide - caused by cattle and soybean production - through collective projects of replanting, in a larger scale, fruit trees they had always lived with in terms of more person-to-person relationships?

14:15-15:45

Maraguápaji: the superimposition of conflicting spatial projects in the Abacaxis River Valley in the Central Amazon

Gabriel Soares

This paper seeks to describe the spatial project of the Maraguápaji in the Abacaxis river valley and how it interacts with other superimposed projects being developed in the same region by different agents.

Dancing with the enemy: people and land in Lake Niassa region, Mozambique Elisio Jossias (Eduardo Mondlane University)

This communication is based on ethnographic research undertaken in the Lake Niassa region, in northern Mozambique, where the question of land tenure, territory and territoriality is experienced in a context dominated by the state interventionist matrix.

Of reindeer shoulder blades and tears of the earth: adaptability, animist relationality and responses to climate change among Siberian Eveny

Olga Ulturgasheva (University of Manchester)

The paper examines intensification of ecological fragility and rapidity of environmental change in the Arctic. The discussion focuses on human capacity to predict ecological disasters while pointing at potential limitations of available models for forecasting, risk mitigation and relief efforts.

Spirits, curses, and "that thing that killed the grass": allusions to the occult by local herders concerned about a new refugee settlement in Turkana, North-west Kenya Cory Rodgers (University of Oxford)

As UNHCR implements a new refugee settlement in Turkana, references to more-thanhuman agents in the complaints of local herders - who had previously used the land as wet season pasture - convey complex political ecological concerns and resist bureaucratic rationalisation of land negotiations. 
Panel and paper abstracts: Pol05

\section{$16: 15-17: 45$}

\section{About coexistence: on the constitution of djeoromitxi's places}

Nicole Soares-Pinto (Federal University of Espírito Santo)

The purpose is to consider djeoromitxi indigenous ways of living and inhabiting the land through movements tied to founding and re-founding villages, involve intrahuman and transespecific relations with spirit beings. In this investigation, kinship, leadership and territory themes are all intricade.

\section{Pol05 For an anthropology of political ideas}

Convenors: Anastasia Piliavsky (University of Cambridge); Judith Scheele (Zentrum Moderner Orient)

Examination Schools Room 6: Fri 21st Sept, 09:00-10:30, 11:00-12:30, 16:00-17:30

This panel asks how political anthropology can regain a distinctive intellectual identity by giving analytical priority to the ideas that underpin vernacular political action and thought.

\section{9:00-10:30}

Corruption and good governance: the political consequences of vernacular imaginations in contemporary Thailand

Claudio Sopranzetti (Oxford University)

This paper explores Thai local imaginaries of corruption and good governance. In so doing it reveals both the imaginative power of vernacular languages and how an ethnographic theory of political concepts can contribute in getting political analysis out of present impasses.

\section{Towards a political anthropology of conscience}

Tobias Kelly (University of Edinburgh)

This paper examines what an anthropology of conscience might offer political anthropology. It focuses on the lives of British pacifists during the Second World War, and asks what forms of relationships and persons claims of conscience help to produce.

\section{A "genuine" anthropology: political anthropology in the UK IACs}

Rine Vieth (McGill University)

With statistics not currently kept on faith-based cases, and minimal Home Office guidance, how do UK Immigration and Asylum Tribunals wrestle with the idea of faith and conversion? What does it mean to have "genuine" belief? 
Full hearts, empty stomachs: the politics of pity in Amazonian Peru

Harry Walker (London School of Economics and Political Science)

The elicitation of 'pity' among Amazonian Urarina is a deeply embodied as well as eminently political process. It grounds an everyday politics of redistribution that owes little to notions of fairness or equality.

11:00-12:30

\section{Rethinking political representation}

Taras Fedirko (University of Cambridge)

My paper explores political hermeneutics of Ukrainian parliamentary reporters in order to argue for a renewed, comparative attention to issues of political representation.

\section{For an anthropology of political relations}

Anastasia Piliavsky (University of Cambridge)

Political anthropology was born out of the realization that something important can be learned about politics if we focus on the moral logic of social relations. How can a refocus on relational logic help us understand people's political lives, whatever role 'the state' may now play in them?

\section{Living with/against Others: 'inequality' as a resource in Gypsy-Gadge relations} Ana Chiritoiu (Central European University)

Through an ethnography of moral engagement and disengagement in the relations between Gypsies and Gadge, the paper argues that, rather than disrupt sociality, 'inequality' and antagonism are in fact constitutive of it, as they delineate commonality from otherness, and thereby enable moral behavior.

\section{Towards an anthropology of state avoidance}

Judith Scheele (Zentrum Moderner Orient)

This paper revisits concepts that used to be at the heart of political anthropology but that have since been discarded (such as 'stateless societies' and 'segmentation'), in the light of recent ethnographic material from Algeria, Mali and Chad.

16:00-17:30

Laws of the jungle: ethics, politics and ecology in the Sundarbans Delta of West

\section{Bengal, India}

Megnaa Mehtta (London School of Economics)

A moral code referred to by fishermen in the Sundarbans as jongoler niyam, literally

'laws of the jungle,'is relegated by regional stakeholders to a depoliticized sphere of religion and ritual. Instead, I argue, if understood holistically, they are a form of alternative vernacular forest governance. 
Panel and paper abstracts: Pol06

Ethnography, kratography and the study of projects of governance

David Sneath (Cambridge University)

Few political anthropologists now take their object of study to be an 'ethnos' or culture. In the light of post-Weberian theories of power it is the political order that emerges as the most convenient unit for anthropological comparison, a project we might term 'kratography' rather than 'ethnography'

\section{Pol06 Diagrams of revolution: an experiment with social and material} morphologies Convenor: Martin Holbraad (University College, London)

Examination Schools East School: Fri 21st Sept, 09:00-10:30, 11:00-12:30, 16:00-17:30

This panel proposes a thought-experiment: what if such projects of social transformation as revolutions were to be conceived and analyzed by analogy to diagrams? What might we understand about the dynamics of such social transformations if we attend to their diagrammatic qualities?

\section{9:00-10:30}

\section{Traps as diagrams and diagrams as traps?}

Hermione Spriggs

This project aims to further Alfred Gell's assertion that traps be considered as functional artworks and vice versa, and builds on this foundation for an even bolder approach to diagramming the relationship between art and anthropology.

\section{Metallurgy of the subject}

Dean Kenning

Reflecting on the art project Metallurgy of the Subject, the paper will address how diagramming can operate as an exploratory method of thinking revolutionary politics, specifically how abstraction and allegorical figuration can help us to imagine subject positions beyond the sovereign individual.

\section{Qaddhafi as diagrammatic exception: a graphic analysis of the end of the Jamahiriya} Igor Cherstich (UCL)

By examining the role of diagrams in Qaddhafi's revolutionary thought we discover his state of exception: a leader who actions his diagrams without being subjected to them. In so doing, we realise that the non-diagrammatic nature of the anti-Qaddhafi revolution was a reaction against this dynamic. 
Panel and paper abstracts: Pol06

Moving diagrams: the choreography of lives and houses in Cuba, and how to see it Martin Holbraad (University College, London)

How do diagrams move? And what can they move by doing so? Based on filmic as well as textual ethnography of people's relationships with their homes in late revolutionary Cuba, this paper addresses the motility of diagrams by comparing it with the motions of social transformation.

11:00-12:30

\section{Diagrammatic coffee readings: mapping Syrian revolutionary futures}

Charlotte Loris-rodionoff (UCL)

How can diagrams of coffee readings help us understand how Syrians perceive their revolution's outcomes? This paper explores « openings of coffee» that bring together ruptures and disruptions presenting revolution's future transformations and figuring its reinvention.

(Meta)modelling the future: diagrammatics for creating common worlds Toby Austin Locke (Goldsmiths College)

This paper examines the diagrammatic qualities of experiments with alternative social models through an ethnography of the construction of a social centre in a disused building. Using collectively produced visual materials, it examines how diagrammatic fields function in the creation of futures.

\section{Shabih-khani - to represent and present the real}

Narges Ansari (UCL)

How can we envisage a diagram which relies on its viewer for conveying a set of meanings? Looking at the rituals of shabih-khani this presentation draws on alternative understandings of reality as a departure point to problematise certain assumptions about the idea of reality and its depiction.

\section{Lines, circles and blocks}

David Burrows (UCL)

The paper explores three kinds of political action in the UK - the line, the circle and the block (or the picket line, anti-capitalist encirclement of the powerful and the Occupy movement) - to discuss how different groups make diagrammatic interventions to manifest protest and revolution. 
Panel and paper abstracts: Pol08

\section{6:00-17:30}

The revolutionary practice of art theory: pedagogical diagrams for art and social change since the 1960's

John Cussans (University of Oxford)

In this paper I discuss the pedagogy of diagrams within contemporary art as a consequence of the transformation of the field since the 1960's and the recent

Educational Turn in the arts. I ask what parallels might be drawn between these changes and the Ontological Turn within anthropology.

Pol08 The humanitarian imagination: socialities and materialities of voluntarism Convenors: Tess Altman (University College London); Katerina Rozakou (University of Amsterdam)

Discussants: Mary Mostafanezhad (University of Hawaii at Manoa), Roger Norum Examination Schools Room 15: Wed 19th Sept, 09:00-10:30, 14:15-15:45, 16:15-17:45

Volunteers imagine and engage with "others" through activities that involve relational processes and acts of self-making. The papers in this session will explore the role of the humanitarian imagination in animating and informing socialities and materialities of voluntarism.

\section{9:00-10:30}

'Helping refugees': Norwegian volunteers in Greece and humanitarian imaginations of solidarity, hospitality and dugnad

Synnøve Bendixsen (University of Bergen)

Drawing on fieldwork with people volunteering for "A drop in the ocean", a humanitarian non-profit organization working with refugees in Greece, I will discuss the humanitarian imaginations that inform the motivation of people to volunteer and what happens in the encounters with refugees.

Taking the host hostage: grassroots NGOs' hospitality practices and humanitarian violence against Syrian refugees in Jordan

Ann-Christin Wagner (University of Edinburgh)

In Jordan, grassroots NGOs reframe aid delivery to Syrian refugees as customary "visits" and handing over goods as "presents". Meant to attenuate power inequalities between aid providers and recipients, humanitarian house visits reify them in spectacular ways and push refugees to perform "suffering" 
Panel and paper abstracts: Pol08

Making the stranger familiar through the "domestic arts": gendered voluntarism for people seeking asylum in Australia

Tess Altman (University College London)

This paper explores gendered voluntarism in humanitarian aid. Using examples from a predominantly female volunteer group supporting people seeking asylum in Melbourne, it considers the potential of "domestic arts" as a form of "imaginative politics" against the Australian state's deterrence policy.

Development and the desire to connect in citizen aid [co-authors: Meike Fechter and Anke Schwittay]

Anne-Meike Fechter (University of Sussex)

Efforts in international aid have been understood as, at least partly, driven by the 'desire to help. We argue that this has left a potentially key motivation out of sight: the search for a 'personal connection'. These intertwined strands help explain people's engagement in assisting others.

$14: 15-15: 45$

Self-making through humanitarianism: good citizens vs. good persons?

Eda Sevinin (Central European University)

This paper focuses on the self-making aspect of Islamically-oriented humanitarian practices that enable humanitarian workers to constitute themselves both as good persons and as good citizens as embodying the state's "benevolence" towards Syrians within a certain imaginary of the state.

\section{Moral connections? Roma religious humanitarianism(s) and shared imaginaries of the self \\ Raluca Roman (University of St Andrews)}

Looking at the humanitarian work conducted by Western Roma Pentecostals among Roma communities in Eastern Europe, this paper analyses the ways in which both 'givers' and 'receivers' continuously re-shift their understandings of moral duty, 'sameness' and 'otherness' in relation to one another.

\section{Contingent images and shifting imaginaries of staff and student volunteering in} Higher Education

Joanna Puckering (Durham University)

Shifting images and imaginaries of volunteering illustrate how themes of power, inequality and self-interest, emerging from my doctoral research into volunteering within UK Higher Education, resonate with the concepts of 'philanthropic particularism' and the 'humanitarian imagination'. 
Panel and paper abstracts: Pol09

Rescuing strangers: humanitarian imaginations among the volunteers in Southeast China

Jiazhi Fengjiang (LSE)

This paper explores how humanitarian imaginations generate grassroots networks and are materialised in various forms in Southeast China where there is a tremendous growth in self-organised rescue and relief volunteerism, predominantly organised and run by middle-aged male volunteers.

\section{6:15-17:45}

Solidarity humanitarianism and the refugee crisis: independent volunteers and alternative visions of society in Greece

Katerina Rozakou (University of Amsterdam)

This paper draws upon the presence of independent local and international volunteers during the refugee crisis in Greece to focus on socialities of voluntarism. These socialities are loci for alternative visions of society informed both by local idioms and the antiglobalization movements.

\section{Administering solidarity: voluntary welfare in post-debt crisis Greece}

Russell Henshaw (University of Oxford)

What practices are made possible by the imaginative spaces of solidarity? What happens when ideals are translated into action? This paper examines the moral subjects elicited by voluntary welfare in terms of the everyday demands of administering it.

\section{Humanitarianism and mutual aid in the food co-operative imaginary}

Celia Plender (University of Exeter)

Building on two years of ethnographic fieldwork with grassroots, retail food co-ops in London, this paper argues that they attempt to reconfigure the relationship between volunteers and aid recipients due to the joint ideals of humanitarianism and mutual aid

Selling charity: volunteers, value, and values in a thrift store Katelyn Lyons (College of the Holy Cross); Ann Marie Leshkowich (College of the Holy Cross)

This paper analyzes how neoliberal consumerist logics shape the humanitarian imagination of volunteers in a thrift store. Volunteers' evaluative practices enact a symbolic violence that obscures the thrift store's implication in the hierarchies that the non-profit organization seeks to combat.

\section{Pol09 Revolutions and activism in retrospect: the material and immaterial} production of legacies and meanings

Convenors: Charis Boutieri (King's College London); Alice Wilson (University of Sussex)

Chair: Sian Lazar (University of Cambridge)

Discussant: Frances Pine (University of London) 
Panel and paper abstracts: Pol10

Examination Schools Room 7: Tue 18th Sept, 15:30-17:00

The panel explores how in the years following intense activism or revolution, those affected use diverse social and material forms to shape new meanings and legacies for their experiences.

Reproducing revolutionary values after military defeat: mundane socialisng in Dhufar, southern Oman

Alice Wilson (University of Sussex)

Mundane socialising may help restore social worlds threatened by violence (Das 2006, Kelly 2008). In Dhufar, Oman, however, everyday sociality helps defeated former revolutionaries to reproduce a social world forged through insurgency, namely revolutionary values of social egalitarianism.

On revolution and resolution: agonistic appraisals of democracy within intimate social relations in Tunisia

Charis Boutieri (King's College London)

Narratives of the "revolutionary event" among young Tunisian activists reveal the importance of assessing the post-revolutionary moment within the realm of intimate social relations. Shifts in sociality that probe gender, age, and material boundaries can be at once liberating and devastating

Loss in the Gezi protests' aftermath: performing Biz in the Europalia/Turkey festival Sinibaldo De Rosa (University of Exeter)

The paper considers the contemporary dance piece 'Biz' (2014) as a dramaturgy of loss emerged in the Gezi protests' aftermath. Its touring to the Belgium-based EuropaliaTurkey festival will be analysed to highlight the contradictions and shortcuts in the creative reworking of the protests' failure.

'Nothing will ever be the same again': experience, meaning and personal change in the aftermaths of the 'Arab spring'

Francesco Vacchiano (ICS-UL, Lisbon)

This paper explores the personal, long-term transformations induced by the experience of political engagement among young activists of Morocco, Tunisia and the Egyptian diaspora.

Pol10 Dalits and other stigmatized groups: imagining changed lives and livelihoods

Convenors: Krishna Adhikari (University of Oxford); David Gellner (University of Oxford) Discussant: Clarinda Still (University of Oxford)

All Souls Hovenden Room: Wed 19th Sept, 09:00-10:30, 14:15-15:45, 16:15-17:45 
Panel and paper abstracts: Pol10

Highly stigmatized groups usually have ways of imagining alternatives. How alternatives are imagined varies by generation and over time; and the language in which they are couched also varies. The panel seeks to explore the extent of this variation crossculturally.

\section{9:00-10:30}

We are Dalit, but we are also Pakistani: the Dalit movement in Pakistan Mustafa Khan (SOAS)

Dalit assertion, infrastructural interventions, religious minorities, borderlands.

Futures together: Buraku and South Asian Dalit solidarities

Joseph Hankins (UCSD)

This paper examines the futures that Japanese Buraku and South Asian Dalit are building together.

\section{Imagining an alternative modernity: Islamic reformism in rural India and liberal} models of change

Fernande Pool (Erasmus Universiteit Rotterdam)

Western imperialist and Indian majoritarian politics inspire aspirations for ethical reform among marginalised Bengali Muslims. I reflect on how these aspirations manifest in the idiom and practice of Islamic reformism and the consequences of this imagined alternative for liberal models of change.

\section{4:15-15:45}

The limits of imagination: psychological essentialism and caste-based discrimination in Nepal Ivan Deschenaux (London School of Economics)

In Nepal, the future is often imagined as 'casteless', yet caste-based discrimination persists. This paper suggests that psychological essentialism, a bias which is well-known in cognitive science but often overlooked in anthropology, can help explain this situation.

Mainzan system and conversion from Dalit to non-Dalit caste: a case study of intercaste married couple of Madhesh

Tilak Biswakarma (Ratna Rajya Laxmi Campus. Tribhuwan Univeraity.)

Sociology defines caste as unchangeable status which bestow by birth.becoming Dalit to non-Dalit is almost impossible in Hindu caste system but this paper delves into how power elite can change from Dalit to non-Dalit caste with the case study of inter-caste married couples of Madhesi community. 
Panel and paper abstracts: Pol1 1

\section{Which way forward for Dalit liberation in Nepal?}

Krishna Adhikari (Oxford); David Gellner (University of Oxford)

Nepali Dalits are divided by caste, language, and geography; they lack any single outstanding leader. There are four basic options available for imagining a future different from the present and past and, as will be illustrated ethnographically, all four have their adherents.

16:15-17:45

India's de-notified tribes: the stigma, systemic oppression, and attempts at transformation

Malvika Gupta (University of Oxford)

Pardhis, a denotified tribal group live in the slums of Bhopal as ragpickers and engage with Freire's pedagogy of the oppressed, through an organisation called Muskaan. The potential of education as transformation against the government policy of assimilation in the name of integration is examined.

Patronage or brokerage? Civil society and the new idiom of subaltern mobilization among the Valmikis in Delhi

Aditya Mohanty (University of Aberdeen)

This paper shows as to how 'political society' in postcolonial cities of the Global South moves beyond the rubric of patronage politics (Piliavsky 2014) and operates as a 'rhizome' (Deleuze and Guattari 1998) of brokerage in shaping the contours of subaltern aspirations.

The dream of a legal utopia: aspirational horizons of socio-political change and the 1989 scheduled caste/scheduled tribe prevention of atrocities act in India Sandhya Fuchs (London School of Economics)

The paper proposes that for Dalit victims of violence in Rajasthan, India legal social protection measures, like the 1989 Scheduled Caste/Scheduled Tribe Prevention of Atrocities Act can come to represent idealised, fixed and potentially accessible horizons of hope in moments of social breakdown.

\section{Pol11 Conviviality and religious coexistence: theoretical and comparative} persectives

Convenors: Ruy Blanes (University of Gothenburg/Spanish National Research Council); José Mapril (Universidade Nova de Lisboa and Center for Research in Anthropology (CRIA)); Ambra Formenti (FCSH/NOVA)

Discussant: Ramon Sarró (University of Oxford)

Examination Schools Room 7: Fri 21st Sept, 09:00-10:30, 11:00-12:30, 16:00-17:30

The objective of this panel is to address the relation between conviviality and religious coexistence in the contemporary moment. 
Panel and paper abstracts: Pol11

09:00-10:30

Interfaith initiatives in London: social action, advocacy, and the post-secular urban future

Jan Bock (Cumberland Lodge)

Interfaith initiatives in London address a wide range of social and community issues, seeking to establish religious actors as crucial agents for the production of post-secular pluralist coexistence. The paper explores interfaith activities and their contribution to shaping the shared urban future.

"Love covers everything": religious coexistence among Guinean migrant families in Greater Lisbon

Ambra Formenti (FCSH/NOVA)

The Guinean population living in Greater Lisbon is marked by a high degree of religious plurality, even within the same families. This paper will present an ethnographic portrayal of Guinean transnational families, focusing on the practicalities of religious coexistence in this context.

Hosay Trinidad. Practices of conviviality in a transnational Caribbean ritual Eric Heuser (Freie Universitaet Berlin)

The paper discusses how the yearly Hosay festivities function as a transnational representation of religious belonging and how the local practice of 'liming' provides affective tools for conviviality that enables Trinidadians to relate to the wider superdiverse Trinbagonian society.

\section{1:00-12:30}

\section{Milk kinship between Muslims and Christians in Cyprus}

Stephanie Jacobs (Flinders University)

Interviews of elderly Greek and Turkish Cypriots who grew up in the former mixed villages of Cyprus reveal that cross-religious milk-kinship existed through the widespread practice of wet-nursing. Such relationships were common prior to nationalism and conflict which saw the division of the island.

Religious diversities, cohabitation, and urban regeneration: an ethnography of the moorish square project in Lisbon

José Mapril (Universidade Nova de Lisboa and Center for Research in Anthropology (CRIA))

Based on an ongoing ethnography about the construction of a new square in downtown Lisbon, named the Moorish square (in which a previously established mosque will be relocated), the objective of this paper is to address the relation between religious diversities and urban economies and regeneration. 
Panel and paper abstracts: Pol12

\begin{abstract}
"Good behavior": the everyday ethics of living together in a North Indian village Meredith McLaughlin (Yale University)

This paper examines the ethics of religious pluralism among Hindu and Muslim residents in a village in Rajasthan, India. It offers the local concept of "good behavior" as a way of understanding both personal conduct and inter-community relations amid the divisive politics of Hindu nationalism.
\end{abstract}

$16: 00-17: 30$

Getting along in the Umma: spaces of rupture and continuity among barelvi and deobandi Muslims in Portugal

Pedro Pestana Soares (FCSH - UNL)

We look at how Portuguese Muslims from a South Asian background create spaces of conviviality that temporarily suspend traditional antagonisms between divergent doctrinal sensibilities. These ephemeral continuities stress how conviviality can also be relevant to the domain of intra-faith diversity.

Religious super-diversity and conviviality on the field: Islam, gender, and girls' football in an urban neighbourhood in the Netherlands

Kathrine (C.E.) van den Bogert (Utrecht University)

In this paper, I discuss my ethnographic research about Muslim girls who play urban street football. I argue that the study of religious diversity in urban spaces should include and combine both religious and non-religious or secular practices of conviviality, like street football.

\title{
The priest's pyramid: interweaving Catholicism and Aztec religion in highland Mexico \\ Catherine Whittaker (University of Edinburgh)
}

The case of a Mexican Catholic priest seemingly promoting Aztec religious revitalisation cannot be adequately described in terms of religious "hybridity" or "folk Catholicism". This paper introduces the concept of "interweaving" to capture conviviality in plurireligious contexts of coloniality.

Pol12 The good in 'bad Buddhism: beyond ancient wisdom for contemporary woes Convenors: Melyn McKay (University of Oxford); Hannah Gould (The University of Melbourne)

All Souls Old Library: Fri 21st Sept, 09:00-10:30, 11:00-12:30, 16:00-17:30

This panel asks how historical imaginings of Buddhism intersect with contemporary ethnographic experience. We invite scholars working in all regions to consider how their engagement with Buddhism's consumerism, violence, or politics creates opportunities for re-thinking the anthropology of religion. 
Panel and paper abstracts: Pol12

\section{9:00-10:30}

"The moral good and the immoral intruder" - an anthropological analysis of the cosmological orientation among Buddhist monks and lay followers in Myanmar Mikael Gravers (Aarhus University)

Monks in Myanmar have a long tradition of social engagement, as well as upholding Buddhism's doctrine of non-violence as during the 2007 demonstrations. Why are they now connected to anti-muslim riots and the recent Muslim exodus?

Cultivating certainty: risk mitigation as a moral undertaking in modern Myanmar Melyn McKay (University of Oxford)

Theories of risk posit logics by which we may understand how societies evaluate and attempt to overcome the discomforting conditions of uncertainty. Logics informing Burmese Buddhist nationalisms draw attention to relationality and necessitate articulation with anthropologies of ethics and affect.

Bodu Bala Sena's critique of Muslims and Islam in Sri Lanka

Mahinda Deegalle (Bath Spa University)

Notwithstanding international condemnation of Bodu Bala Sena as an extremist movement, this paper evaluates its critique of Muslims and Islam in Sri Lanka by concentrating on selected cases on the basis of primary materials in the Sinhala language, which are not often used in most investigations.

Real and fake Khuba: saintly entrepreneurialism and political aspirations of Theravadin saints in mainland Southeast Asia.

Alexander Horstmann (Tallinn University)

My paper is concerned with gossip as a central instrument to control the moral integrity of the Khuba as a fundraiser for monumental works as well as a Buddhist ascetic. It examines the rise and fall of authenticity and the emergence of a discourse on fake Khuba.

\section{1:00-12:30}

Kuyō as commerce and care: the affective labours of the disposal of Buddhist altars (butsudan) in contemporary Japan

Hannah Gould (The University of Melbourne)

Drawing on fieldwork with butsudan workers, I detail the affective labours performed in the disposal of altars. In commercializing the Buddhist rite of kuyō, this industry, maligned for profiteering and materialism, cares for "dead" objects and people's complicated emotional attachments to them. 


\section{Paying for pilgrimage: Buddhist consumerism in modern China}

Junfu Wong (School of Oriental and African Studies (University of London))

By studying the economic network of modern monasteries, this paper contends that consumerism is a fundamental feature in understanding Buddhism. It presents that the charging system of high entrance fee virtually generated a consumerist challenge to pilgrimage activities.

\section{The contribution of the ethnographic context of Hong Kong to a re-thinking of Buddhism}

Mariske Westendorp (Radboud University Nijmegen)

My paper relates the political context of Hong Kong to how 'modern Buddhism' is lived in the city. I explore what an ethnographic exploration of Hong Kong Buddhism in the years leading up to the Umbrella Movement can contribute to an anthropological understanding of the religion.

\section{Experimental Buddhisms}

John Nelson (University of San Francisco)

This paper proposes a system for integrating Buddhisms within the rubric of practice. It emphasizes the creative, doctrine-flexible, and stubbornly-pragmatic ways in which local priests and practitioners try to use their temple resources for is considered to be the greater good.

$16: 00-17: 30$

\section{Moving beyond good and bad: reflections on the study of Buddhism and violence} Iselin Frydenlund (MF Norwegian School of Theology)

Systematic violence against religious minorities in Buddhist majority states in recent years raises crucial questions about Buddhism and violence. What has the Anthropology of Buddhism to offer to our understanding of 'Buddhist violence'?

\section{Buddhism as distinctively 'good' in transitional Myanmar (Burma)}

\section{Bénédicte Brac de la Perrière}

In this contribution, I would like to reconsider the ensuing formation of a new Buddhist ultra-nationalist movement (Mabatha) led by monks, claiming a domination on the defence of religion in Burma and obliterating any more temperate position as not truly Buddhist.

\section{Time01 Imagination, migration \& (im)mobility}

Convenors: Ross Wignall (Oxford Brookes University); Thomas Chambers (Oxford Brookes University)

Examination Schools Room 7: Wed 19th Sept, 09:00-10:30, 14:15-15:45, 16:15-17:45

The panel brings together contributors focusing on imagination, migration \& (im) 
Panel and paper abstracts: Time01

mobility. We consider how vernacular understandings of mobility and immobility are conceived and experienced within the temporal and material contexts of migration.

\section{9:00-10:30}

'Town is for the young': (im)mobility, agency and interdependency amongst older people in urban Uganda

Katie McQuaid (University of Leeds)

This ethnographic paper explores lived experiences of becoming and being old to capture the agency, social navigation and interdependencies embedded in older people's experiences of being 'stuck' in a sub-Saharan African city.

Culture of migration and redefinition of gender roles: recent trends in rural Bangladesh

Main Uddin (Tallinn University)

This paper is an ethnographic details of the culture of migration and the rearrangement of gender boundary in a patriarchal Muslim society in rural Bangladesh. The study explores the continuity and changes in the discourse and practices of traditional gender roles in the village.

A staggered journey: migration imaginaries and spatio-temporal suspension of young Chinese temporary migrants in the UK

Candice Hiu-Yan Yu (University of Edinburgh)

This paper examines the dialogical interactions between migration imaginaries and suspension in mobilities in the context of temporary migration. Suspension shifts migrants' life focus from the present moments to the imagined future, transforming waiting times into precariousness and opportunities.

Becoming urbanites? Imagination, mobility and self-transformation of migrant workers in contemporary China

Jialing Luo (Sichuan University)

This paper explores the imagination, aspirations and self-transformation of the ruralurban migrant workers in contemporary China. It examines the socio-political milieu in which peasants' (im)mobility is constructed and experienced, and the dilemma of becoming urbanites. 
The meanings of women's mobilities: gender ideals and female mobility in West Africa

Gunvor Jonsson (University of Oxford)

Malian women's mobilities are associated with numerous meanings and partly constrained by Islamic, patriarchal and Mande ideals. Discourses on women's mobilities and the 'strangerhood' of women reflect notions of "ideal femininity" but also, alternative femininities and changing gender ideologies.

\section{Continuity in mind: imagination and migration in India and the Gulf}

Thomas Chambers (Oxford Brookes University)

In the context of migration between Uttar Pradesh, other areas of India and the Gulf, this article explores the role of the imagination in shaping subjective experiences of male Muslim migrants from a woodworking industry in the North Indian city of Saharanpur.

Islam, sport and development: three ways of imagining youth (im)mobility at the Young Men's Christian Association (YMCA) in the Gambia

Ross Wignall (Oxford Brookes University)

This paper uses awkward encounters with young men participating in a Sport-forDevelopment programme at the Young Men's Christian Association (YMCA) in The Gambia, West Africa to explore discourses of mobility, immobility and imagined global relationships

Lessons from stillness. Social im/mobilities and imagined futures among Eritrean refugees in Ethiopia

Aurora Massa (University of Trento)

By analyzing the everyday life of the Eritrean refugees in Ethiopia, I show how stillness urges people to embody a practical knowledge to adapt to contingencies, giving shape to an agency that can be conceptualized as a "waiting for the chance".

$16: 15-17: 45$

Immobility, mobility, imaginations: sub-Saharan migrants' journeys in Libya Marthe Achtnich (University of Oxford)

Focusing on the lived experiences of sub-Saharan migrants moving to and through Libya, this paper argues that attending to the complex dynamics between mobility and immobility on unauthorised journeys is vital to understanding forces connecting people's mobility experiences and imaginations. 
Panel and paper abstracts: Time02

An indigenous local mobility: rethinking and reimagining daily practices through the experience of migration

Beatriz Ribeiro (University of Brasília)

This presentation intends to reflect on the rethinking of identity by indigenous women through the experience of mobility, in the north of Brazil,. From the countryside to the metropolis, they face different issues that rearrange practices and the imagination built upon the migration process.

Imaginations and mobilities of self and wellbeing: asylum seekers in Norway reaching beyond social marginalization and enclavement

Anne Sigfrid Grønseth (Inland Norway University of Applied Sciences, Lillehammer)

With reference to asylum seekers' experiences, as these are accessed by an approach of

"being there", I suggest how asylum seekers transform and embed a variety and mobilities of identity, belonging and wellbeing.

Imagined lives "over there". The trajectory of progress as envisioned in Guinea-Bissau and the Gambia

Magdalena Brzezinska (The University of Gdansk)

Young people in Guinea-Bissau and the Gambia commonly construct their "life projects" in Europe as Western ideologies map out a trajectory in the collective imagination: from the "backward" village to the "modern" city and ultimately to the "real" site of progress the West.

\section{Time02 Resource temporalities: anticipations, retentions and afterlives} Convenors: Kärg Kama (University of Birmingham); Gisa Weszkalnys (London School of Economics)

Examination Schools South School: Wed 19th Sept, 09:00-10:30, 14:15-15:45, 16:15$17: 45$

This panel asks new questions about the multiple temporalities of resource-making raised by current research in anthropology and cognate disciplines. Papers will explore the variety of imaginative practices involved, drawing on a range of methods and analytical approaches.

09:00-10:30

\section{Resource temporalities}

Gisa Weszkalnys (London School of Economics); Kärg Kama (University of Birmingham) 
Shale gas development and owned hydrocarbon futures: the temporal power of volatile infrastructures, unruly materialities and conspiracies

Anna Szolucha (Polish Academy of Sciences)

I explore how a particular configuration of power based on the appearance of a predetermined hydrocarbon future was created out of a heterogeneous set of circumstances surrounding shale gas development. The analysis points also to multiple temporalities that unsettled the narratives of control.

The price of becoming a mineral: coltan, money and plural temporalities in Sierra Leone

Lorenzo D’Angelo (University of Milano-Bicocca)

This paper examines the temporal process of coltan-making, an high-value mineral extracted in Sierra Leone at the artisanal level. It shows how the process of coltan- and price-making is based on the possibility of managing the multiple temporalities of coltan mining.

$14: 15-15: 45$

(Im)permanent development: the affects of value and oil speculation in Kenya Doris Okenwa (London School of Economics and Political Science)

This paper considers how resource-making in Kenya is articulated around the concept of permanence. Through various strategies deployed to materialise oil, what emerges is in fact a struggle over value. That is, the idea that some resources have the potential to create more wealth than others.

Fast capitalism \& slow resistance: an ethnography of dual temporalities in extraction \& resistance

Amber Murrey-Ndewa (University of Oxford)

Taking the varied speeds of action(s) within the 25-year lifespan of the Chad-Cameroon Oil Pipeline as the point of departure, this discussion centers on the assorted ways in which speed informs perceptions of and potential resistances to extraction at the scale of the grassroots.

Securing the volume: Nepal's water for the people's investment?

Matthäus Rest (Max Planck Institute for the Science of Human History); Austin Lord (Cornell University)

Despite extreme seasonality of water and a chronic shortage of electricity, Nepal's rivers function as foundation of an imagined "hydropower nation" whose citizens will become wealthy from their shares in export-oriented dams. China and India are simultaneously trying to secure those rivers' volumes. 
Panel and paper abstracts: Time03

\section{6:15-17:45}

Matters of conspiracy: oil prospects, geological knowledge, and temporality in Turkey

Zeynep Oguz (The Graduate Center, CUNY)

Tracing the material and symbolic life of abandoned oil wells, geological knowledge, and state practices, this paper examines the political futures and pasts about national sovereignty that conspiracy theories around oil discovery and abundance generate in Turkey today.

'The gold is gone': techniques, generativity and present-ism in the afterlife of a gold rush

Rosalie Allain (University College London)

This paper explores temporal dynamics that have arisen in the aftermath of a gold rush in eastern Cameroon. Divergent temporalities are enacted within and between techniques of resource-making that attempt to fold the past and future into the present whilst articulating imaginings of generativity.

\section{Making the individual in a Papua New Guinea oil economy}

Emma Gilberthorpe (University of East Anglia)

I identify the social costs of extraction in Papua New Guinea's Kutubu Oil Project through an examination of how the capitalist discourse accompanying the transformation of nature into a resource for development diminishes egalitarian principles whilst creating instability and fragmentation.

\section{Time03 Chronotopic materialities}

Convenors: Safet HadziMuhamedovic (University of Bristol); Magdalena Buchczyk (University of Bristol)

Discussant: Tom Selwyn (SOAS University of London)

Magdalen Old Law Library: Fri 21st Sept, 09:00-10:30, 11:00-12:30, 16:00-17:30

How do objects - their placements, textures, routes and traces - come to encapsulate the bonding of time and space? And, to what ends? What claims do they make and what novel directions do they indicate? What is the breadth of such objects' sensorial potency?

09:00-10:30

\section{Translocal chronotopes - material culture and the configuring of time and space in} the Niger Delta

Julia Binter (University of Oxford)

This paper looks at the ways in which people and things configure time and space within shifting political and economic contexts. It takes the heritage practices of people in the Niger Delta, Nigeria, and their long history of transatlantic relations as a case study. 
Panel and paper abstracts: $\mathrm{Time} 03$

Recreating the last garefowl: the chronotopic materialities of species extinction and recreation

Arnar Árnason (University of Aberdeen); Gro Ween (University of Oslo)

This paper discusses the extinction and recreation of the garefowl as a case of chronotopic materialities. In juxtaposing stories of the last garefowl and the prospect of the recreation of the species, the paper asks how materialities bind actors across space and time.

Class, social mobility, and biography: materiality and temporality in a Kenyan city Ruth Prince (University of Oslo)

This paper explores how certain objects, spaces and materialities can suddenly and unpredictably fold time, exposing ruptures in personal biographies and horizons of expectation, and the loss of social mobility. The ethnographic material is drawn from urban Kenya

Socio-natural chronotopes: rhythmicality, sensoriality and emotionality of allotment gardens

Petr Gibas (Institute of Sociology, Czech Academy of Sciences)

The paper dissects the temporality of allotment gardens and explores how their materiality becomes imbued with time through a continuous practice of gardening. To account for the complexity of the garden chronotope, the paper combines rhythm analysis with a Deleuzian concept of territorialisation.

11:00-12:30

The border as ruin. Memory, defeat and nostalgia

Garikoitz Gomez Alfaro (University of Brighton)

The paper explores how temporality is experienced in a Spanish border town haunted by the ghost of Walter Benjamin, a landscape that triggers nostalgic memories and a certain sense of "being stuck in time". It discusses temporality as mediated and by the materiality of a ruined landscape.

Holy Sepulchre: affect-inducing objects in the making of sacred borders Georgios Tsourous (University of Kent)

The study traces the use of Christian devotional objects in Jerusalem's Church of the Holy Sepulchre and focuses particularly on their capacity to authoritatively mark space and time in and around the tomb of Jesus (known as Edicule). 
Panel and paper abstracts: Time04

The multiple temporalities of pilgrimage: space and time interaction in the movement of pilgrims

Evgenia Mesaritou (University of Toronto, University of Cyprus)

The paper explores the ways in which space and time interact in the movement of Greek Cypriot pilgrims to a shrine that constitutes 'matter out of time' (Hamman 2008) as well as place, looking at the different temporalities experienced by pilgrims and traced by sites.

From earth to paper: property claims and the materiality of loss in post-war Kosovo Agathe Mora (Graduate Insitute of International and Development Studies)

In the context of post-war Kosovo, this paper looks at Kosovo Serbian claimants' narratives of loss, and at how loss shifts chronotopic material encapsulations from earth to paper through the judicialisation of property claims.

\section{6:00-17:30}

Chronotopic debris: saints, archives and the invention of absence Safet HadziMuhamedovic (University of Bristol)

This paper is an anthropological postscript to the work of the ICTY. Drawing on longterm fieldwork in Bosnia, I trace in the Tribunal's archives the strange afterlives of two syncretic Bosnian saints, George and Elijah, their feasts and the religiously plural landscapes they encapsulated.

Time04 Insuring inbetween governing and being governed, for crisis of today and catastrophic future

Convenors: Irmelin Joelson (University of Oxford); Marissa Smith (San Jose State

University)

Examination Schools East School: Thu 20th Sept, 09:00-10:30, 14:15-15:45

As new forms of insurance backed by international financial institutions and development organisations are implemented throughout the world, we ask how the roles and practices of different organisations and communities, acting as international, national, and local are reinforced or redefined.

\section{9:00-10:30}

Gambling livelihoods on the steppe: livestock insurance and the financialization of risk in Mongolia

Daniel Murphy (University of Cincinnati)

This paper considers the case of index-based livestock insurance (IBLI) in Mongolia and its failure to materialize as an effective form of pastoral risk management. In order to understand this failure, the paper explores how insurance is utilized and understood by herders. 
Panel and paper abstracts: Time05

Managing the risk of relations: insurance as governance to ensure production Marissa Smith (San Jose State University)

Mongolian insurances (daatgal) include shamanic and Buddhist practices as well as those of privatized state agencies. Intensified by development actors' reforms figuring climate change and loss as universal risk, daatgal remains concerned with the use of state-power to ensure continued production.

Replacing mom is expensive: speculating on women in Indian life insurance Sohini Kar (London School of Economics)

In India, there is a growing market of life insurance targeting women, pointing to the undervalued work of "wives and mothers." This paper examines how emergent policies life insurance for women reconceptualises the value of women's domestic and reproductive labour in an era of financialization.

14:15-15:45

Valences of insurability: between life and property

Abdul-Karim Mustapha

This paper looks at the idea of multiplicity implied in insurability, with a comment on Ian Baucom's analysis of the origins of insurance in transatlantic slave trade, focusing on recent work on neoliberalism and life, and on the dual mutations of life becoming property and property becoming life.

Imagining wealth to attract wealth: popular insurance schemes in Dar es Salaam Irmelin Joelson (University of Oxford)

This paper conceptualise the broad scope of repertoires manoeuvring economic governance through anticipation as "popular insurance", by exploring hedging strategies at play in Dar es Salaam, a city where the access to finance is highly constrained, savings are scarce; yet investment are made.

\section{Time05 Temporalities of work, money, and fantasy}

Convenors: Patrick Alexander (Oxford Brookes University); John Loewenthal (Oxford Brookes University)

Magdalen Summer Common Room: Fri 21st Sept, 09:00-10:30, 11:00-12:30, 16:0017:30

This panel explores the ongoing existential dynamics of what kind of a life one can or cannot lead, as manifest through the domains of work, money, and fantasy. Papers will illustrate how different modes of temporality unite these fields as a constellation - from routines to daydreams to life plans. 
Panel and paper abstracts: Time05

\section{9:00-10:30}

The cost of labour precarity and attempts at everyday survival for working holidaymakers doing seasonal agricultural labour in rural Australia Esther Anderson (University of Southern Queensland)

This microcosmic study of place, belonging, and temporariness examines working holidaymakers doing seasonal agricultural labour in rural Australia, and the economic vulnerability that is encoded into their everyday lives via this precarious work. Working holidaymakers' enact various strategies for survival, which reveal overlapping and discordant realities, with consequences ranging from the mundane to sinister.

"I need to do a few more postdocs" or how to become a scientist from the perspective of Indian postgraduates in Germany

Antonie Fuhse (Georg-August-University Göttingen)

The Indian postgraduates in my study navigate constructions of the academic life course as well as Indian ideas of the perfect timing of events in life. I argue that "temporal agency" (Flaherty 2011) is an important means in that process of navigation.

Working and reworking the future: narratives of work at the end of schooling Patrick Alexander (Oxford Brookes University)

This paper draws on ethnographic research carried out in New York City and London to explore how young people make sense of 'work' as an organising concept for understanding the future.

Temporalities of work, crisis and resistance in an Italian recovered enterprise Giovanni Orlando (University of Turin)

This paper aims to gain a perspective on the breakdown of the Fordist social contract by examining the temporalities of work, its absence - unemployment - and its renewed presence as a more politicized, yet also more precarious, human activity among members of an Italian "recovered enterprise".

\section{1:00-12:30}

Running to nowhere? Velocities and outcomes of graduate aspirations in New York and Los Angeles

John Loewenthal (Oxford Brookes University)

Drawing on an ethnography of graduates from an elite university in New York City many of whom move to Los Angeles - this paper traces the dialectical transformation of aspirations and transitions. Faced with unexpected outcomes, graduates revise their fantasies and question the velocity of life. 
Panel and paper abstracts: Time05

Dealing with bullas (commotions/windfalls): mining temporalities and local economic strategies in Southeastern Venezuela

Natalia Garcia-Bonet (University of Kent)

In this paper, I explore Pemon peoples' involvement in informal gold mining in light of the current economic crisis in Venezuela. I argue that the rhythms and temporalities of mining are compatible with other Pemon productive activities, and are consistent with local ways of dealing with abundance.

"You never know what's coming 'round the corner": optimism and fantasy in the lives of "compers" or the serial entrants of promotional competitions

Cynthia Sear (University of Melbourne)

Compers are the serial entrants of promotional competitions. Based on ethnography amongst compers in Australia, I explore how the practice of entering, winning and fantasizing about winning can create and sustain an optimistic world-view despite challenging personal and financial circumstances.

Work and life in the Harris Tweed industry: personal narratives, everyday labour, and visions of 'lives worth leading'

Joana Nascimento (University of Manchester)

Protected by an Act of Parliament, Harris Tweed can only be handwoven at home in the Outer Hebrides. Considering fluctuations in the industry, this paper explores how workers' biographies and everyday work experiences can illuminate diverse visions of a 'good life' in contexts of labour uncertainty.

$16: 00-17: 30$

Transnational imaginaries - the case of Afghanistan women's national football team Narges Ghandchi (Aarhus university)

This study examines the transnational activities and aspirations of female Afghan football players: some living in Afghanistan, some being migrants in other countries. The study discusses transnational imaginaries of the future, career possibilities, and love for the nation.

Imagining the future: subjectivity, schooling and neoliberalism in contemporary Portugal

Maria João Fernandes (Faculdade de Ciências Sociais e Humanas, Universidade Nova de Lisboa)

This paper looks at the complex interplay between educational systems, neoliberal politics and the students strategies in imagining a future through their schooling experience in neoliberal urban Portugal. 
Panel and paper abstracts: Time06

The backward housewife: historical time and women's labour in Jordan

Susan MacDougall (Keble College)

In Jordan, women's increased engagement in public life is considered a hallmark of progress. This paper explores how this equation of women working with progress has created, and problematised, a temporality of the home that is considered separate from that of the world outside the home.

\section{Time06 Aftermaths of disaster: individual/collective futures and the brutal logics of the past \\ Convenors: Mitchell W. Sedgwick (London School of Economics); Susanna Hoffman (International Commission on Risk and Disaster) \\ Examination Schools Room 6: Wed 19th Sept, 09:00-10:30, 14:15-15:45, 16:15-17:45 \\ This panel addresses the contestations of former and presently-lived experience among disaster victims. It also engages with the institutional structuring, by governments, NGOs, etc., of those persons, i.e., the disjunctions between 'expert knowledge' and disasters' real experts.}

\section{9:00-10:30}

A chronicle of emotions, effects, and their import after a disaster and the three vectors of pain of displacement

Susanna Hoffman (International Commission on Risk and Disaster)

Chronicled in this paper is the cascade of emotions that survivors of disaster undergo.

Further brought up are the nuances of pain of past, home, and place that the dispossessed suffer when the fabric of life unravels.

Who is the expert here? Professional responders and fishing village women rehearse for disasters

\section{Zuzana Hrdlickova}

What do professional responders and ordinary village folk really prepare for in disaster preparedness exercise? Looking at exercise practices of NDRF and women's group in a fishing village in South India, this paper looks at various forms of experience, expertise and their entanglements.

Saving money, healing the wounds of war, and heading towards a future together: experience of healing and reconciliation in post-genocide Rwanda Yuko Otake

Exploring healing experience in post-genocide Rwanda, the research observed a mutualsaving group and reported that local healing experience was oriented toward a future, which took place as members recovered and integrated different social times through materialistic, bodily, linguistic activities. 
Panel and paper abstracts: Time06

A pretence of recovery: distortions of time, ritual reproduction, and the vicissitudes of 'normalcy' during and after crisis

Mitchell W Sedgwick (London School of Economics)

Even if practically-meaningless in the face of trauma, this paper reflects on the collective psychological efficacy, however tenuous, of patterned, ritualized activity: an outstretched hand reaching towards safety and the stability: that is, a pretence of recovery.

14:15-15:45

From Kataribe to Katari-tsugi: storytelling and cultural memory in post-disaster Japan

Flavia Fulco (University of Toyama)

This paper explores the connection between memory and storytelling after 3.11 disaster focusing on kataribe tours and other practices related to transmission of the memory of the disaster.

Re-Mapping Japan

Duccio Gasparri (Oxford Brookes University)

Locality construction, subalternity, and social change in post-disaster Japanese

Northeast: an ethnographic study in placemaking, narration, and human mobility.

Community empowerment or powerlessness: challenging the 'community-based' narrative of post-disaster recovery

Anna Vainio (University of Sheffield)

The paper explores the gap between theory and practice in community-based approaches to recovery. It's main argument is that there is a lack of 'power' in empowerment in the process that is designed to promote community agency and control over recovery.

Crisis heritage and heritage in crisis after Japan's 2011 tsunami

Andrew Littlejohn (Harvard University)

This paper explores continuity and rupture after Japan's 2011 tsunami, asking how disaster has reshaped local identities by prompting the re-evaluation and resurrection of traditional materials and practices and the incorporation of objects and landscapes produced by the tsunami into local heritage.

16:15-17:45

Aftermaths of disaster: organizational learning and collective memory in post-war Japan

Maja Vodopivec (Leiden University)

In order to explore the learning process in the aftermath of a disaster causing multidimensional social shifts, this study will deploy Fukushima case study research with multiple disciplinary perspectives and paradigms from memory studies, crisis management and industrial safety fields. 
Panel and paper abstracts: Time06

The disastrous equation of forced disaster consumerism - capitalism, communism, permanent crisis - a few vignettes from the Republic of Croatia

Sanja Špoljar Vržina (Institute of Social Sciences Ivo Pilar)

This paper is part of recording the slow micro-fanonesque awakenings that span well beyond the historical fact of Croatia's entering the EU (1st July 2013) and surviving the consequences of it's disastrous communist heritage into the state of opposing the forced disaster consumerism. 


\section{Laboratories programme}

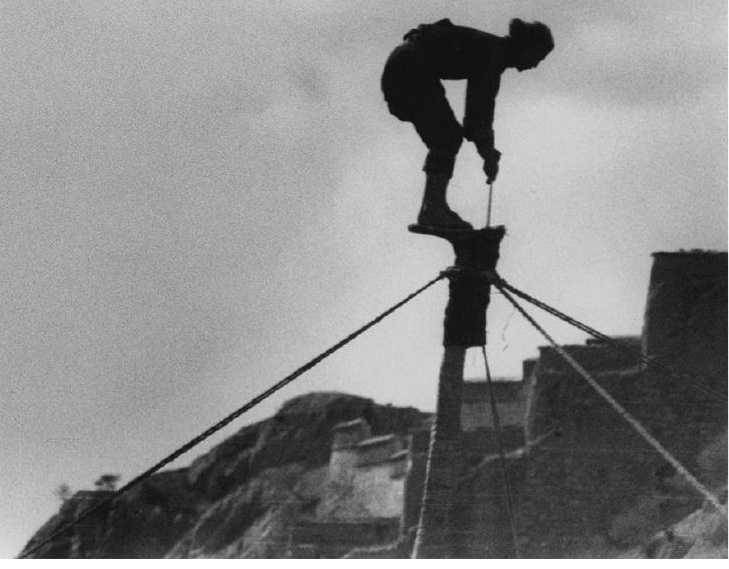

The ASA18 Laboratories programme provides spaces and opportunities for participants to explore the conference themes in sessions that differ from panels comprising 20-minute papers. With more flexible formats, Laboratories potentially open up ways of doing anthropology that generate fresh insights, understandings or approaches. They can set up situations for introducing, developing and testing ideas, for collaboratively identifying, examining, and taking action on issues.

To address pressing and difficult concerns, anthropologists are increasingly doing their work in experimental modes, whether with film, video, photography, drawing, exhibitions, sound productions, performance or with written words. Indeed, many aspects of contemporary life and death that anthropologists seek to analyse demand critical re-evaluation and innovation in method, interpretation and presentation.

ASA18 asks participants to consider a key question: if sociality, matter, and the imagination are reconsidered from multiple perspectives across the discipline, how might we renew and re-create anthropology? Alongside the conference panels, the Laboratories programme aims to engage with this question and to help stimulate wideranging debate around the conference sub-themes: language and imagination, creative 
bodies, environmental imaginations, transformation and time. How do social, material and imaginative dimensions of lived bodies and environments mesh, become separated or morph over time? How might anthropologists document and theorise these processes more effectively, and with sensitivity to the politics, ethics, affects and sensations entailed?

Laboratories are designed as interactive, reflexive sessions that prioritise exploration, rather than the discussion of already established research results. They can be used to tackle practical problems, to revaluate concepts and to find new theoretical directions. They can facilitate anthropological investigation of matters and entities ranging from the macro to the micro. Labs might turn attention to the generation and shaping of knowledge in practice, to the attunement of the senses, and to processes of sense-making. Whether concerned with possibilities and limitations in current anthropological method, theory, analysis, and styles of communication, Labs can provide space for addressing any aspect of our conference themes.

Lab convenors at ASA18 have devised sessions in experimental formats involving collaborative activities, using a range of media. The Labs will explore fermentation, narratives, movement, imaginative processes, drawing, photography, writing, design, sensory engagement with material objects, sound recording, performance, visual imaging, social media, display, art practice, the making of $3 \mathrm{D}$ forms, computational notebooks, filming, and editing.

Lab stream convenor

Elizabeth Hallam (University of Oxford)

\section{Lab01 Fomenting fermentation}

Convenors: Salla Sariola (University of Helsinki); Matthäus Rest (Max Planck Institute for the Science of Human History)

Private Dining Room, Wolfson College: Tue 18th Sept, 13:30-15:00, 15:30-17:00

Fermentation is a quintessential multi-species entanglement. Historically, it has been the most important food preservation technology but with industrialisation, fermentation entanglements are rapidly disappearing. In this laboratory we will try out fermentation and discuss its history and future. 
Lab02 Language, story and the visual imagination as anthropological communication

Convenor: Brenda Beck (University of Toronto)

Examination Schools Room 12: Tue 18th Sept, 15:30-17:00

The panel will discuss the merits/pitfalls of retelling culture-based story treasures using modern visual aids such as murals, video animation, graphic novels, and digital games. The Legend of Ponnivala Nadu will provide one example. Participants are encouraged to contribute additional case materials.

\section{Lab03 Caring in movement: anthropology as contemplation}

Convenors: Krzysztof Bierski (Durham University); Elizabeth Rahman (University of Oxford); Paolo Maccagno (University of Aberdeen)

Examination Schools East School: Wed 19th Sept, 14:15-15:45

Both anthropology and contemplative techniques encourage its practitioners to explore the world with all our being; they allow us to appreciate the transformative nature of experience and caringly participate in the world's becoming. In this lab, we explore anthropology as a contemplative practice.

Lab04 Envisioning ethnographies of the future: lab exercises for the imagination Convenor: Jessica Symons (University of Manchester)

Examination Schools South School: Thu 20th Sept, 14:15-15:45

This Visioning Lab will stimulate future scenarios to imagine ethnographic encounters within them. It builds on design futures, foresight, futurism, speculative fiction and anthropologies of the future to spontaneously produce speculative ethnographies of multiple futures in 90 minutes.

Lab05 Hard and disagreeable labour: a laboratory exploring drawing conventions Convenor: Ray Lucas (University of Manchester)

Pitt Rivers Museum Seminar Room: Tue 18th Sept, 13:30-15:00

This lab addresses one of the most enduring descriptive practices: drawing. The focus will be on drawing conventions used in architecture and design for the depiction of space and form. The lab will consist of a series of practical exercises and discussion of drawing as knowledge production. 
Lab06 Citizens of photography: the camera and the political imagination Convenors: Sokphea Young (University College London); Christopher Pinney (University College, London); Konstantinos Kalantzis (University College, London); Ileana Lucia Selejan (University College London); Naluwembe Binaisa (University College London); Vindhya Buthpitiya (UCL)

Examination Schools East School: Wed 19th Sept, 16:15-17:45

An experimental presentation of fieldwork by six members of an ERC-funded project exploring a hypothesis about the relationship between photographic self-representation and different societies' understanding of what is politically possible.

\section{Lab08 People-centred development: what is a meter?}

Convenors: Maria Salaru (Durham University); Simone Abram (Durham University); Hannah Knox (University College London)

58 Banbury Road, COMPAS visitors' room: Wed 19th Sept, 16:15-17:45

How can anthropology contribute to the conditions of everyday life? This lab will rethink the design of infrastructural objects, highlighting the conditions that they impose on the everyday, and repositioning the 'user' through people-centred design.

\section{Lab09 Messy realities: the secret life of technology}

Convenors: Gemma Hughes (University of Oxford); Caitlin Pilbeam (University of Oxford); Sara Shaw (University of Oxford)

Pitt Rivers Museum Main Gallery: Wed 19th Sept, 09:00-10:30, 14:15-15:45, 16:15$17: 45$

Join us in exploring the secret life of technologies in the Pitt Rivers Museum: from pendant alarms to amulets. We disrupt our ethnographic work with assisted living technologies to experiment with the juxtaposition of everyday objects with artefacts layered with complex cultural relevancies.

\section{Lab10 Listening and performing together: emotions, experience, and ethnopoetry} Convenor: Asif Majid (University of Manchester)

Pitt Rivers Museum Seminar Room: Wed 19th Sept, 14:15-15:45

This Lab combines performance and ethnopoetry, enabling attendees to experiment with these techniques and consider their ethnographic implications. Participants will leave the Lab having experienced two emotional complexities: embodying someone else's story and having someone else perform theirs. 
Lab11 From postcards to Instagram: image, text and social media Convenors: Stephen Hughes (SOAS); Emily Stevenson (SOAS) Examination Schools Room 12: Thu 20th Sept, 09:00-10:30

We compare historical postcards and Instagram as forms of sociality that creatively repurpose photographs to link people over time and space. By juxtaposing these media we explore multiple alliances and affordances of how images and their metadata are mobilised in the service of social networking.

\section{Lab12 Learning from art practices?}

Convenors: Alex Flynn (Durham University); Giulia Battaglia (EHESS/Paris 3) Examination Schools Room 14: Fri 21st Sept, 09:00-10:30, 11:00-12:30, 16:00-17:30

This lab seeks to reflect on potentials/limitations of existing projects in art and anthropology to challenge contemporary questions pertaining to both these practices. Is the encounter between art and anthropology a useful way to renew/recreate anthropology? If so, in what sense might this occur?

\section{Lab13 Imagination and materiality: exploring geometry through the making of} fabric bowls

Convenors: Ricardo Nemirovsky (MMU); Tam Dibley (Manchester Metropolitan

University)

Pitt Rivers Museum Lecture Theatre: Wed 19th Sept, 14:15-15:45

In this laboratory, we will explore relationships between imagining and materiality. Participants will create fabric bowls - 3D shapes created by joining flat pieces of fabric considering how the shapes develop, and how the physical act of making participates in how we imagine these changes.

\section{Lab15 The geometry of a single line}

Convenor: Jaime Refoyo

Pitt Rivers Museum Lecture Theatre: Thu 20th Sept, 09:00-10:30

This lab has the idea of experimenting the imprint of body movement on the floor surface and, at the same time, finding common geometries of the different body imprints of the participants. 


\section{Lab16 Data objects re-designed}

Convenor: Polly Macpherson (University of Plymouth)

Pitt Rivers Museum Seminar Room: Thu 20th Sept, 14:15-15:45

With the continual 'offer' of new 'must have' artefacts this workshop invites participants to creatively assess and evaluate their own objects before developing and re-creating imaginative new outcomes.

\section{Lab17 Crafting non-human characters: unorthodox vistas for ethnographic film} Convenors: Pedro Afonso Branco Ramos Pinto (University of Brasília); Guilherme Moura Fagundes (Universidade de Brasília)

Pitt Rivers Museum Lecture Theatre: Fri 21st Sept, 16:00-17:30

What approaches might ethnographic filmmakers employ when conventional cinematic strategies prove inadequate to represent non-human beings and things? The challenges of crafting non-human characters present visual anthropology with unorthodox avenues for stylistic and epistemological innovation. 


\section{List of participants: convenors, chairs, discussants and presenters}

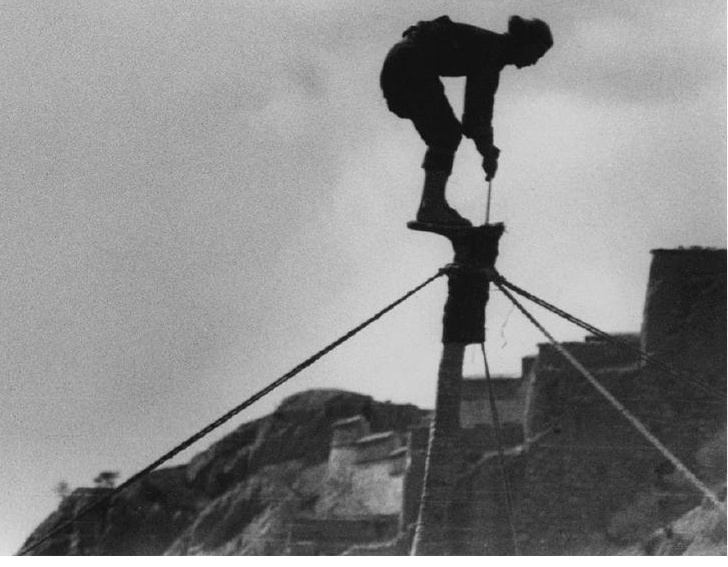

Abram, Simone -- Lab08

Abramson, Allen - Body09

Achtnich, Marthe -- Time01

Acosta Garcia, Raul Gerardo

-- Inf06

Adhikari, Krishna -- Pol10

Afonso Branco Ramos Pinto,

Pedro -- Lab17

Agbetu, Toyin -- Ant04

Ahmed, Khaldoon -- Med06

Ala Uddin, Muhammad

-- Med03

Alderman, Jonathan --

Body03

Alexander, Patrick -- Time05
Ali, Inayat -- Med05

Allain, Rosalie -- Time02

Allen, Nicholas -- Ant05

Almenara Niebla, Silvia --

Body08

Altinisik, Asli -- Env04

Altman, Tess -- Pol08

Anderson, Esther -- Ant02;

Time05

Anderson, Sally -- Mor05

Annist, Aet -- Env05

Ansari, Narges -- Pol06

Antovic, Mihailo -- Cre07
Anyadike-Danes, Chima

Michael -- Ant04

Apostu, Alina -- Cre08

Archer, Alex -- Cog02

Archer, Matthew -- Pol01

Armstrong, Neil -- Med06

Árnason, Arnar -- Inf01;

Time03

Arnavas, Chiara -- Inf02

Asselin, Jodie -- Env05

Atkinson, Sally -- Env14

Aubinet, Stephane -- Body05

Augustyniak, Nadia --

Med01 
List of participants: convenors, chairs, discussants and presenters

\begin{tabular}{|c|c|c|}
\hline Austin Locke, Toby -- Pol06 & Bird, Tess -- Body02 & Campbell, Ben -- Env04 \\
\hline Azevedo, Vera -- Env15 & Biswakarma, Tilak -- Pol10 & Campbell, John R. -- Lang03 \\
\hline Baehren, Lucy -- Cog05 & Björklund Larsen, Lotta & Campbell, Kirsten -- Env04 \\
\hline Bagchi, Tanima -- Body04 & -- Inf05 & Campeau-Bouthillier, \\
\hline Balasubramanian, & Blanchier, Raphaël -- & Cassandre -- Body02 \\
\hline Harshadha -- Ant04 & & Cardinale, Stefania -- Ant01 \\
\hline Balthazar, Ana Carolina & Blanes, Ruy -- Pol11 & Carroll, Timothy -- Body03 \\
\hline -- Cre08 & Bock, Jan -- Pol11 & Castillo, Rosa Cordillera A. \\
\hline Bamford, Joshua -- Cog05 & Boe, Carolina -- Pol02 & -- Body01 \\
\hline Bankole-Race, Eni -- Cre01 & Bombjaková, Daša -- Cog04 & Cavicchioli De Togni, Giulia \\
\hline Barnett-Naghshineh, Olivia & Borecký, Pavel -- Env09 & -- Lang01 \\
\hline -- Mor05 & Borioli, Aladin -- Env09 & Cecale, Courtney -- Pol02 \\
\hline Barton, Robert -- Cog01 & Born, Georgina -- Cre08 & Chambers, Thomas -- \\
\hline Barua, Maan -- Med04 & Botticello, Julie -- Ant04 & Time01 \\
\hline Battaglia, Giulia -- Lab12 & 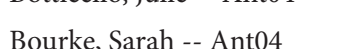 & Chanet, Corentin -- Cre07 \\
\hline $\begin{array}{l}\text { Baumer Escobar, Vinzenz } \\
\text {-- Inf05 }\end{array}$ & Boutieri, Charis -- Pol09 & $\begin{array}{l}\text { Chanta-Martin, Natasa -- } \\
\text { Body11 }\end{array}$ \\
\hline Bear, Laura -- Inf06; Mor02 & Bowie, Laura -- Env03 & Chase, Liana -- Med05 \\
\hline Beck, Brenda -- Exhib; & Boyd, Tom -- Inf03 & Chatterson, Nicole -- Env02 \\
\hline Lab02 & Boylston, Thomas -- Cre03 & Chattoo, Sangeeta -- Med07 \\
\hline Beckmann, Elizabeth -- & $\begin{array}{l}\text { Brac de la Perrière, } \\
\text { Bénédicte -- Pol12 }\end{array}$ & Chatzikidi, Katerina -- Cre09 \\
\hline Beckmann, Nadine -- Env15 & Bradford, Danielle -- Ant02 & $\begin{array}{l}\text { Chatzipanagiotidou, Evropi } \\
\text {-- Cre06 }\end{array}$ \\
\hline Ben Hamed, Mahé -- & Breen, Gareth -- Lang02 & Chelcea, Liviu -- Inf01 \\
\hline Body02 & $\begin{array}{l}\text { Brito-Henriques, Eduardo } \\
\text {-- Env05 }\end{array}$ & Chen, Meixuan -- Ant01 \\
\hline Bender, Cori -- Inf03 & & Chen, Yu Chun -- Cre03 \\
\hline Bendixsen, Synnøve -- Pol08 & Cog03 & Chen, Ze -- Cre05 \\
\hline Bertini, Lavinia -- Med03 & Brzezinska, Magdalena -- & Cherstich, Igor -- Pol06 \\
\hline Bevilacqua, Daniela -- & Time01 & Chiapperino, Luca -- Med07 \\
\hline & Buchczyk, Magdalena -- & Chiritoiu, Ana -- Pol05 \\
\hline Bierski, & & Chokkalingam, Mahendran \\
\hline Binaisa, Naluwembe -- & Buckler, Sarah -- Ant01 & -- Pol03 \\
\hline & Bullo, Stella -- Cre07 & Christen, Anna -- Cre05 \\
\hline Cre05 & Burrows, David -- Pol06 & Clarke, Jennifer -- Med02 \\
\hline Binter, Julia -- Time03 & Buthpitiya, Vindhya -- Lab06 & Clarke, Morgan -- Mor04 \\
\hline
\end{tabular}


List of participants: convenors, chairs, discussants and presenters

Coates, James -- Body01

Coelho de Souza, Marcela

-- Pol04

Coelho, Sandra Faustino

-- Inf04

Cohen, Liron -- Med03

Colchester, Chloe -- Cre08

Collard-Stokes, Gemma -Med08

Collison, Claire -- Body02

Cook, Emma -- Body01

Cook, Joanna -- Cog03

Cortesi, Luisa -- Env02

Cory-Pearce, Elizabeth --

Ant01

Coupaye, Ludovic -- Cog02

Cousins, Thomas -- Med04

Cova, Victor -- Pol03

Crawley, Michael -- Cre02

Crawley, Rosalind -- Cre03

Cussans, John -- Pol06

D’Angelo, Lorenzo -- Time02

Dai, Lianghao -- Cog03

Daly, Lewis -- Env07; Pol03

Danos, Félix -- Pol02

Das, Debojyotu -- Env15

Datiles, Marianne Jennifer

-- Ant03

Davies, Michael -- Med07

Davoll, James -- Env02

Dawney, Leila -- Env05

De Antoni, Andrea --

Body01

de Bourbon Parme, Shira

-- $\operatorname{Cog} 02$ de Haas, Gert-Jan -- Med08

De Rosa, Sinibaldo -- Pol09

De Souza Santos, Andreza

Aruska -- Env08

Deegalle, Mahinda -- Pol12

Del Percio, Alfonso --

Lang03

Demeulenaere, Elise --

Env11

Dennehy, Sally -- Ant04

Deschenaux, Ivan -- Pol10

DeSilvey, Caitlin -- Env13

Destree, Pauline -- Inf06

Dewan, Camelia -- Env13

Dibley, Tam -- Lab13

Dieckmann, Samantha --

Cre09

Dippel, Anne -- Cre03

Diz, Agustin -- Pol01

Dobson, Julian -- Env14

Doering, Adam -- Env02

Doherty, Jacob -- Env10

Donnan, Hastings -- Cre09

Dorsett, Chris -- Cre08

Douglas, Cristina -- Pol03

Douglas, Megan Jane --

Ant02

Driessen, Miriam -- Env08

Driscoll, Helen -- Cre03

Droma, Nyema -- Exhib

du Plessis, Pieter -- Med04

Dubos, Anne -- Body11

Dubowitz, Dan -- Env06

Dugnoille, Julien -- Body07
Duica-Amaya, Liliana --

$\operatorname{Cog} 07$

Dunn, Nick -- Env06

Duranti, Alessandro --

Cre05; Lang02; Lang03

Duru, Asli -- Cre02

Dzenovska, Dace -- Env08

Ebbensgaard, Casper Laing

-- Env03

Edensor, Tim -- Cre01

El Khachab, Chihab -- Cre04

Eli, Karin -- Med03

Elliot, Alice -- Ant04

Erasaari, Matti -- Mor02

Ernst, Lisa -- Ant03

Esposito, Paola -- Med08

Eubelen, David -- Cre07

Evans, Gillian -- Body02;

Env03

Evers, Clifton -- Env02

Evrard, Olivier -- Env02

Ewart, Elizabeth -- Pol04

Fagan Robinson, Kelly --

Body03; Lang01

Fagerlid, Cicilie -- Ant01

Falisse, Jean-Benoît --

Med05

Faria, Ines -- Inf04

Fechter, Anne-Meike --

Pol08

Feder-Nadoff, Michele -Env06

Fedirko, Taras -- Pol05

Fejdiova, Elena -- Cog04

Fengjiang, Jiazhi -- Pol08 
List of participants: convenors, chairs, discussants and presenters

Ferdous, Raihana -- Env04

Fernandes, Maria João --

Time05

Ferrari-Nunes, Rodrigo --

Cog07; Cre06

Finnegan, Morna -- Cog04

Fisher, Josh -- Env02

Flynn, Alex -- Lab12

Ford, Andrea -- Med02

Forde, Elaine -- Env14

Formenti, Ambra -- Pol11

Förster, Till -- Body01

Fouksman, Elizaveta --

Mor02

Frost-Jensen, Anna Maria

-- Med03

Frydenlund, Iselin -- Pol12

Fuchs, Sandhya -- Pol10

Fuhse, Antonie -- Time05

Fulco, Flavia -- Time06

Gaggiotti, Hugo -- Pol02

Gallagher, Shaun -- Cog02

Garcia-Bonet, Natalia --

Time05

Garey, Amy -- Cog07

Gasparri, Duccio -- Time06

Geissler, Paul Wenzel --

Env13

Gellner, David -- Pol10

Ghandchi, Narges -- Time05

Ghose, Alysa -- Body05

Gibas, Petr -- Time03

Gibson, Lydia -- Env07

Gibson, Thomas -- Mor05
Gilberthorpe, Emma --

Time02

Giraldo Herrera, César

Enrique -- $\operatorname{Cog} 07$

Gisbert Alemany, Ester --

Env06

Godfrey-Isaacs, Laura --

Body10

Goldsworthy, Chris -- Cog02

Gomez Alfaro, Garikoitz

-- Time03

Gonzales, Giulia -- Pol02

Gore, Georgiana -- Body11

Gori, Yanina -- Cre08

Gould, Hannah -- Pol12

Govaerts, Brecht -- Cre08

Gravers, Mikael -- Pol12

Greenhalgh, Cathy -- Cre01

Gregoric Bon, Natasa --

Inf03

Griffith, Veronique --

Body08

Grohmann, Stephanie --

Mor02

Grønseth, Anne Sigfrid --

Time01

Grulke, Sonja -- Cre03

Gumbo, Jelika -- Med03

Gupta, Malvika -- Pol10

Gupta, Nalin -- Inf04

Guy, NK -- Cre01

HadziMuhamedovic, Safet

-- Time03

Haines, Sophie -- Inf02

Hakim, Lina -- Cre03

Haldane, Hillary -- Ant02
Hall, Rosemary -- Lang03

Hankins, Joseph -- Pol10

Harcourt, Edward -- Med06

Hardon, Anita -- Med03

Harper, Ian -- Med05

Harrison, Chloe -- Ant04

Harvey, Penny -- Env13;

Inf01

Hashemi, Amin -- Cre09

Hauck, Jan David -- Lang02

Hauser, Beatrix -- Body02

Hawker, Nancy -- Lang03

Hazan, Haim -- Med03

Heatherington, Tracey --

Env13

Hebdon, Chris -- Pol01

Heinrich, Michael -- Ant03

Heintz, Monica -- Mor05

Henshaw, Russell -- Pol08

Herbst, Pauline -- Med03

Herrmans, Isabell -- Mor05

Heslop, Luke -- Inf06

Heurich, Guilherme --

Lang01; Lang02

Heuser, Eric -- Pol11

Ho, Hao-Tzu -- Pol01

Hodgson, Thomas -- Cre04

Hofer, Theresia -- Lang01;

Med02

Hoffman, Susanna -- Time06

Holbraad, Martin -- Pol06

Hollan, Douglas -- Med01

Horstmann, Alexander --

Pol12 
List of participants: convenors, chairs, discussants and presenters

Houseman, Michael --

Body11

Howard, Heather -- Med03

Hrdlickova, Zuzana --

Time06

Hsu, Elisabeth -- Lang01;

Med08

Huang, Juli -- Med05

Hughes, Gemma -- Lab09

Hughes, Stephen -- Lab11

Hunt, Linda -- Med03

Ingold, Tim -- Cog07; Env06

Inverardi-Ferri, Carlo --

Env10

Irvine, Richard -- Env08

Jacobs, Stephanie -- Pol11

Jadhav, Sushrut -- Med04

Jain, Sumeet -- Med05

Jenkins, Emily -- Med08

Jenkins, Timothy -- Cre04

Jent, Karen -- Med02

Jeong, Jong-Min -- Body01

Joelson, Irmelin -- Time04

Johannsen, Niels N. --

Cog02

Jones McVey, Rosie -- Cre05

Jonsson, Gunvor -- Time01

Jordan, Joe -- Lang01

Josephides, Lisette -- Cre04

Joshi, Ameesha -- Film

Joshi, Vibha -- Mor01

Jossias, Elisio -- Pol04

Kaivanara, Marzieh --

Body03
Kalantzis, Konstantinos

-- Lab06

Kalir, Barak -- Pol02

Kalshoven, Petra Tjitske

-- Inf01

Kama, Kärg -- Time02

Kanno, Keiko -- Ant03

Kapitany, Rohan -- Cog05

Kar, Sohini -- Time04

Kauppinen, Anna-Riikka

-- Mor02

Kavedzija, Iza -- Cre04

Kaytaz, Esra -- Body02

Kelly, Tobias -- Pol05

Kelly, William -- Body09

Kendall, Blake -- Env09

Kendon, Adam -- Lang01

Kenning, Dean -- Pol06

Khan, Kamran -- Lang03

Khan, Mustafa -- Pol10

Khawaja, Aysha -- Inf06

Khoury, Krystel -- Body11

Kieft, Eline -- Med08

Kipgen, Ngamjahao -- Env07

Kirby, Peter -- Env10

Knight, Chris -- Cog04

Knight, Daniel -- Env08;

Env14

Knox, Hannah -- Lab08

Kolbe, Kristina -- Cre08

Koot, Stasja -- Env07

Korovkina, Anna -- Mor01

Korsant, Clate -- Pol01

Kouri, Jaana -- Env15

Kozminska, Kinga -- Lang03
Krause, Franz -- Inf03

Kravel-Tovi, Michal -Lang03

Kuberska, Karolina -Body10

Kubes, Tanja -- Ant02

Kühlbrandt, Charlotte -Med05

Kuprian, Anna -- Inf01

Lachenal, Guillaume --

Env13

Ladwig, Patrice -- Mor02

Lala, Margherita -- Env14

Lara, Francisco -- Pol02

Lash, Scott -- Inf02

Laviolette, Patrick -- Body09

Lavis, Anna -- Med03

Lee, Siew-Peng -- Ant01

Leonard, Stephen Pax --

Lang02

Leshkowich, Ann Marie

-- Pol08

Levine, Susan -- Med04

Levy, Julyan -- Env14

Lieberman, Oren -- Env06

Linders, Elke -- Ant04

Lindsay, Heidi -- Cre03

Littlejohn, Andrew --

Time06

Llamas, Bastien -- Med07

Loaiza, Juan M. -- Cre08

Loewenthal, John -- Time05

Lombardi, Denise -- Med01

Long, Nicholas -- Med01 
List of participants: convenors, chairs, discussants and presenters

Lora-Wainwright, Anna -Env02; Env10

Lord, Austin -- Time02

Lorimer, Jamie -- Env11;

Med04

Loris-rodionoff, Charlotte

-- Pol06

Lou, Loretta Ieng Tak --

Env02

Lounela, Anu -- Mor05

Lucas, Ray -- Env06; Lab05

Lucia Selejan, Ileana -Lab06

Luo, Jialing -- Time01

Lyons, Katelyn -- Pol08

M K, Senthil Babu -- Cre05

Mabefam, Matthew Gmalifo

-- Pol02

Maccagno, Paolo -- Lab03

MacClancy, Jeremy -- Env08

Macdonald, Alison -- Ant04

MacDougall, Susan --

Time05

Macpherson, Polly -- Lab16

Mæland, Siri -- Body11

Magee, Siobhan -- Mor04

Magowan, Fiona -- Cre09

Mair, Jonathan -- Cog03

Majczak, Ewa -- Body08

Majid, Asif -- Lab10

Makoni, Sinfree - Lang02

Makovicky, Nicolette -Inf05

Malafouris, Lambros -Cog02

Malcolm, Roslyn -- Cog02
Malcomson, Hettie -- Cre09

Manley, Gabriela -- Cre05

Mapril, José -- Pol11

Marino, Davide -- Inf01

Marquina Vega, Orietta

-- Env05

Marre, Diana -- Pol02

Martin, Jess -- Env07

Martin, Kate -- Med06

Martinez-Hume, Anna --

Med03

Martinez, Dolores -- Cre04

Massa, Aurora -- Time01

Matta, Mara -- Body04

Matthews, Maureen -- Pol03

May, Sarah -- Env13

Maynard, Elizabeth --

Body02

Mazuz, Keren -- Cre08

Mazzella, Marie -- Body11

Mc Loughlin, Eimear --

Body07

McCoy, Matthew -- Pol02

McHugh, Nessa -- Ant01

McKay, Melyn -- Pol12

McKearney, Patrick -Mor02

McLaughlin, Meredith --

Pol11

Mcluckie, Connie -- Ant01

McManus, John -- Body09

McQuaid, Katie -- Time01

Medaas, Christian -- Env13

Meheux, Katie -- Ant05

Mehtta, Megnaa -- Pol05
Meloni, Maurizio -- Med07

Mesaritou, Evgenia --

Time03

Messeder, Gabrielle -- Cre09

Meulemans, Germain --

Env11

Mills, David -- Ant04

Mitchell, Alice -- Lang01

Mitsuhara, Teruko -- Pol02

Moeller, Nina -- Env14

Mohanty, Aditya -- Pol10

Molyneux-Hodgson, Susan

-- Env14

Mookherjee, Nayanika --

$\operatorname{Cog} 01$

Mora, Agathe -- Time03

Moroşanu Firth, Roxana

-- Inf04

Morphy, Frances -- Cog01

Morphy, Howard -- Cog01

Mostafanezhad, Mary --

Env02; Pol08

Mottin, Monica -- Body04

Moura Fagundes, Guilherme -- Lab17

Mukherji, Mayanka -- Env08

Münster, Daniel -- Env11

Murawski, Michał -- Env03

Murphy, Daniel -- Time04

Murphy, Fiona -- Cre06

Murrey-Ndewa, Amber --

Time02

Mustapha, Abdul-Karim

-- Time04

Nagle, Alice -- Body05 
List of participants: convenors, chairs, discussants and presenters

Nahum-Claudel, Chloe --

Lang01

Naidu, Prash -- Body01

Nair, Janaki -- Cre08

Naka, Ikuno -- Inf06

Narayanan, Sandhya --

Lang02

Nascimento, Joana --

Time05

Nattrass, Nicoli -- Med04

Navaro-Yashin, Yael --

Env05

Nayak, Bibekananda --

Med05

Neilson, Brett -- Inf02

Nelson, John -- Pol12

Nemirovsky, Ricardo --

Env06; Lab13

Neveu Kringelbach, Hélène

-- Body11

Newson, Martha -- Cog05

Nicolas, Andrea -- Mor04

Nicolescu, Razvan -- Inf04

Nielsen, Lotte -- Cre08

Nijhawan, Sahil -- Env07

Noorani, Tehseen -- Med01

Norum, Roger -- Env02;

Pol08

O'Hare, Patrick -- Env13

O’Neill, Sean -- Lang02

Oakley, Elliott -- Pol04

Oanca, Alexandra -- Cre02

Obadia, Julienne -- Env01

Oberlack, Ulrike -- Cre01

Oguz, Zeynep -- Time02
Oinas, Elina -- Env11

Okenwa, Doris -- Time02

Oppitz, Gabriela -- Body01

Orlando, Giovanni --

Time05

Otake, Yuko -- Time06

Overmann, Karenleigh --

Cre07

Owen, Olly -- Inf05

Oxby, Clare -- Pol02

Ozdemir, Ezgican -- Inf06

Paiva, Daniel -- Env05

Panese, Francesco -- Med07

Parkhurst, Aaron -- Body03

Parkin, David -- Lang01

Parreiras Silva, Carolina

-- Ant03

Paulovich, Natallia --

Body02

Pearson, Alice -- Mor02

Pellegrino, Manuela -- Cre07

Pels, Peter -- Ant06

Pentecost, Michelle --

Med04

Perley, Bernard -- Env13

Pestana Soares, Pedro --

Pol11

Peter, Anu Mary -- Cre05

Pfeilstetter, Richard --

Mor02

Pia, Andrea Enrico -- Pol01

Pickles, Anthony -- Cre03

Pierini, Emily -- Body05

Pietilä, Tuulikki -- Mor02

Pilbeam, Caitlin -- Lab09
Piliavsky, Anastasia -- Pol05

Pillen, Alex -- Lang01

Pina-Cabral, Joao -- Cog02

Pine, Frances -- Pol09

Pinel, Clemence -- Med07

Pinney, Christopher -- Lab06

Pinto, Kristina -- Med01

Pinto, Sarah -- Med01

Pirdehghan, Maryam --

Body08

Pirie, Fernanda -- Mor04

Plaan, Joonas -- Env05

Plender, Celia -- Pol08

Pool, Fernande -- Pol10

Poulsgaard, Kåre -- Cog02

Power, Camilla -- Cog04

Praet, Istvan -- Pol03

Prates, Maria Paula --

Body 10

Pratt-Boyden, Keira --

Med06

Prince, Ruth -- Time03

Procter, Caitlin -- Ant03

Puckering, Joanna -- Pol08

Qureshi, Ayaz -- Med05

Radicati, Alessandra -- Inf06

Rahman, Elizabeth -- Cog03;

Lab03

Rajtar, Malgorzata -- Med03

Ramirez-Goicoechea,

Eugenia -- Med02

Rana, Jasmijn -- Body09

Randle, Sayd -- Inf03

Ransom, Tailer -- Cog02

Raudon, Sally -- Env01 
List of participants: convenors, chairs, discussants and presenters

Ravi Kasthuri, Raghavi --

Cre05

Ray, Charlotte -- Env04

Refoyo, Jaime -- Env06;

Lab15

Regitano, Aline -- Body10

Reig, Alejandro -- Pol04

Reinhardt, Thomas -- Cre01

Remme, Jon Henrik Ziegler

-- Mor05

Rest, Matthäus -- Lab01;

Time02

Ribeiro, Beatriz -- Time01

Richardson, Kathleen -

Inf04

Rival, Laura -- Env14

Rivers, Jessica -- Body09

Rix-Lièvre, Geraldine --

Body11

Roast, Asa -- Env03

Robertson, Craig -- Cre09

Robinson, Jude -- Ant06

Rodgers, Cory -- Pol04

Rojas, Pablo -- Cre08

Roman, Raluca -- Pol08

Rosengren, Dan -- Pol04

Roulette, Roger -- Pol03

Rozakou, Katerina -- Pol08

Rudge, Alice -- Lang01

Rush, Kayla -- Cre06

Salaru, Maria -- Film; Lab08

Salazar, Juan Francisco

-- Film

Samanani, Farhan -- Cre05

Sanches, Nicole -- Ant04
Sandelson, Jessica -- Body08

Sansone, Rosa -- Inf06

Santos, Ana -- Env15

Sariola, Salla -- Env11;

Lab01

Sarkissian, Anna -- Film

Sarró, Ramon -- Pol11

Sauma, Julia -- Pol03

Schaeverbeke, Robin --

Env06

Scheele, Judith -- Pol05

Schleiter, Markus -- Body04

Schneider, Antonia --

Lang03

Schoofs, Steven -- Pol03

Schubert, Jon -- Inf06

Schüler-Costa, Vlad -- Inf04

Schulte, Leonie -- Lang03

Schulz, Yvan -- Env10

Schut, Aischa -- Body10

Scott, Julie -- Ant01

Scotti, Francesca -- Ant03

Sear, Cynthia -- Time05

Sedgwick, Mitchell W --

Time06

Selwyn, Tom -- Time03

Sevinin, Eda -- Pol08

Shah, Sunil -- Exhib

Shahab, Sofya -- Env05

Shankland, David -- Ant05

Shapiro, Nicholas -- Env13

Sharma, Jeevan -- Med05

Shaw, Alison -- Body02

Shaw, Sara -- Lab09
Sheild Johansson, Miranda

-- Inf05

Sidnell, Jack -- Body02

Sillander, Kenneth -- Mor05

Simon, Sandro -- Inf03

Simonetti, Cristián -- Inf01

Simpkins, Robert -- Cre04

Simpson, Bob -- Ant06

Simpson, Edward -- Inf06

Sims, Rosie -- Med04

Sindelar, Melanie Janet --

Cre06

Singleton, Mark -- Body02

Sinha, Anindya -- Med04

Skinner, Jonathan -- Med08

Skrydstrup, Martin -- Inf02

Sleeboom-Faulkner,

Margaret -- Ant06

Smith, Constance -- Env03

Smith, Marissa -- Time04

Smith, Rachel -- Mor02

Smith, Robin -- Inf05

Sneath, David -- Env01;

Pol05

Soares-Pinto, Nicole -- Pol04

Soares, Gabriel -- Pol04

Sonck-Rautio, Kirsi -- Env14

Songin-Mokrzan, Marta

-- Inf04

Sopranzetti, Claudio -- Pol05

Spector, Branwen -- Ant03

Špoljar Vržina, Sanja --

Body05; Time06

Spriggs, Hermione -- Pol06

Stacey, Timothy -- Mor02 
List of participants: convenors, chairs, discussants and presenters

Stacul, Jaro -- Env08
Steffen, Megan -- Ant02
Stelmaszyk, Mally -- Body05
Stevenson, Edward --
Body03
Stevenson, Emily -- Lab11
Still, Clarinda -- Pol10
Stirton, Elishka -- Cre01
Strang, Veronica -- Cog01;
Inf03

Suhr, Christian -- Body05

Sutton, Theodora -- Body03

Svasek, Maruska -- Cre04

Swancutt, Katherine --

Cre04

Swartz, Alison -- Med04

Symons, Jessica -- Lab04

Szolucha, Anna -- Time02

Tamburo, Elisa -- Inf06

Tarr, Bronwyn -- Cog05

Taylor, Melina -- Ant02

Tayob, Shaheed -- Med04

Thiers, Robin -- Env11

Tinius, Jonas -- Cre08

Tonnaer, Anke -- Env01

Tsioulakis, Ioannis -- Cre06

Tsourous, Georgios --

Time03

Turk, Elizabeth -- Env01

Turnbull, Jonathon -- Env09

Turner, Britta -- Env04

Turner, Tamara -- Body05

Turnhout, Esther -- Inf02

Uddin, Main -- Time01

Ulturgasheva, Olga -- Pol04
Umbres, Radu -- Mor01

Underhill, Helen -- Cre06

Uzelac, Mirjana -- Pol03

Vacchiano, Francesco --

Pol09

Vainio, Anna -- Time06

Vallverdu, Jordi -- Cre07

van Dam, Arvid -- Env05

van den Bogert, Kathrine

(C.E.) -- Ant04; Pol11

van Mulukom, Valerie --

Cog05

Vana, Noa -- Med03

Vander Meer, Elizabeth -Body07

Vander Meer, Elizabeth --

Body07

Vardaki, Elia -- Cog01

Venkatraman, Shriram -Inf04

Vera, Ana -- Pol02

Verbockhaven, Johanne

-- Env06

Vicol, Dora-Olivia -- Inf05

Viegas, Susana -- Pol04

Vieth, Rine -- Pol05

Vilar, Márcio -- Med08

Villegas Silva, Argelia --

Body11

Vodopivec, Maja -- Time06

Vorhoelter, Julia -- Med01

Vrabiescu, Ioana -- Mor04

Wagner, Ann-Christin --

Pol08

Walford, Antonia -- Pol03
Walker-Crawford, Noah --

Cog01; Inf03

Walker, Harry -- Mor05;

Pol05

Walton, Shireen -- Body09

Ward, Christopher --

Body07

Wardrope, Alistair -- Med06

Warin, Megan -- Med07

Warren, Narelle -- Med03

Waterton, Claire -- Inf01

Watkins, Rachel -- Body05

Webb, Martin -- Env02

Webber, Matthew -- Cre06

Wedel, Julia -- Env08

Ween, Gro -- Time03

Westendorp, Mariske --

Pol12

Weszkalnys, Gisa -- Time02

White, Daniel -- Body01

White, Thomas -- Env01

Whitehouse, Harvey --

Cog05

Whittaker, Catherine --

Pol11

Whyte, David -- Inf03

Wiebe, Sarah -- Env02

Wies, Jennifer -- Ant02

Wignall, Ross -- Time01

Williams, Lucy -- Cre01

Wilson, Alice -- Pol09

Wissing, Kirsty -- Env02

Wolfová, Alžběta -- Cog02

Wong, Heung-wah -- Cre04

Wong, Junfu -- Pol12 
List of participants: convenors, chairs, discussants and presenters

Woodcraft, Saffron -- Env03

Woolner, Christina -- Cre05

Worrell, Helen -- Exhib

Wu , Ka-ming -- Env10

Wu, Wanting -- Body11

Xiang, Biao -- Inf02

Xiao, Kunbing -- Lang01

Xing, Linzhou -- Inf04

Yadav, Smita -- Ant03

Yager, Karina -- Inf03

Yaneva-Toraman, Inna -Cre03

Yang, Shu-Yuan -- Pol04

Yau, Hoi Yan -- Cre04

Yazdani, Jvan -- Env08

Young, Kh. Neil -- Inf03

Young, Sokphea -- Lab06

Yu, Candice Hiu-Yan --

Time01

Yuill, Cassandra -- Body10

Zabiliute, Emilija -- Med05

Zafer-Smith, Sonia -- Inf06

Zagaria, Valentina -- Mor02

Zandlova, Marketa -- Inf03

Zeiderman, Austin -- Inf02

Zeineddine, Souad -- Inf06

Zhu, Hua -- Lang03 


\section{Essential reading in anthropology from berghahn}

NEW SERIES: ROMANI STUDIES

Volume 1

ROMA ACTIVISM

Reimagining Power and Knowledge

Edited by Sam Beck and Ana Ivasiuc

250 pages - ISBN 978-1-78533-948-6 Hardback

NEW TITLES IN MATERIAL MEDIATIONS: PEOPLE AND

THINGS IN A WORLD OF MOVEMENT

Volume 8

ETHNOGRAPHIES OF MOVEMENT, SOCIALITY AND

SPACE

Place-Making in the New Northern Ireland

Edited by Milena Komarova and Maruška Svašek

310 pages - ISBN 978-1-78533-937-0 Hardback

Volume 9

\section{SENSE AND ESSENCE}

Heritage and the Cultural Production of the Real

Edited by Birgit Meyer and Mattijs van de Port

350 pages • ISBN 978-1-78533-939-4 Hardback • 978-1-78533-940-0 Paperback

\section{NEW TITLES IN EASA SERIES}

Volume 35

BEING HERE

Placemaking in a World of Movement

Annika Lems

252 pages • ISBN 978-1-78533-849-6 Hardback

Volume 34

EXPERIMENTAL COLLABORATIONS

Ethnography through Fieldwork Devices

Edited by Adolfo Estalella and Tomás Sánchez Criado

236 pages • ISBN 978-1-78533-853-3 Hardback

RECENTLY PUBLISHED

\section{MOMENTOUS MOBILITIES}

Anthropological Musings on the Meanings of Travel

Noel B. Salazar

208 pages • ISBN 978-1-78533-935-6 Hardback

\section{HIERARCHY AND VALUE}

Comparative Perspectives on Mo:al Order

Edited by Jason Hickel and Naomi Hiaynes

160 pages • ISBN 978-1-78533-996-7 Hardback • 978-1-78533-997-4

Paperback

\section{WORLDWIDE MOBILIZATIONS}

Class Struggles and Urban Commoning

Edited by Don Kalb and Massimiliano Mollona

256 pages - ISBN 978-1-78533-906-6 Hardback

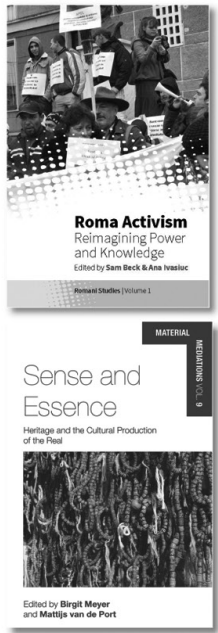

MIRRORS OF PASSING

Unlocking the Mysteries of Death, Materiality and Time

Edited by Sophie Seebach and Rane Willerslev

326 pages • ISBN 978-1-78533-908-0 Hardback • 978-1-78533-894-6 Paperback

\section{PILGRIMAGE AND POLITICAL ECONOMY}

Translating the Sacred

Edited by Simon Coleman and John Eade

206 pages ISBN 978-1-78533-942-4 Hardback

\section{AN AUSTRALIAN INDIGENOUS DIASPORA}

Warlpiri Matriarchs and the Refashioning of Tradition

Paul Burke

248 pages - ISBN 978-1-78533-388-0 Hardback

NEW IN PAPERBACK!

\section{LIVING BEFORE DYING}

Imagining and Remembering Home

Janette Davies

172 pages • ISBN 978-1-78533-130-7 Paperback

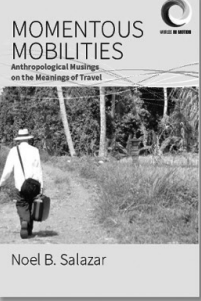

\section{MAKING UBUMWE}

Power, State and Camps in Rwanda's Unity-Building Project

Andrea Purdekova

306 pages - ISBN 978-1-78533-072-0 Paperback.

\section{CREATING A NEW PUBLIC UNIVERSITY AND} REVIVING DEMOCRACY

Action Research in Higher Education

Morten Levin and Davydd J. Greenwood

230 pages • ISBN 978-1-78533-839-7 Paperback

\section{HUMOUR, COMEDY AND LAUGHTER}

Obscenities, Paradoxes, Insights and the Renewal of Life

Edited by Lidia Dina Sciama

220 pages • ISBN 978-1-78533-070-6 Paperback

\section{PAUL BURYE}
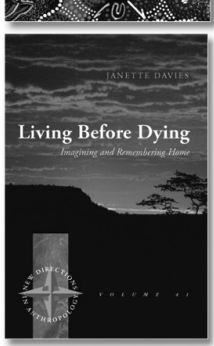

\section{COSMOS, GODS AND MADMEN}

Frameworks in the Anthropologies of Medicine Edited by Roland Littlewood and Rebecca Lynch 220 pages • ISBN 978-1-78533-062-1 Paperback

\section{WORLD HERITAGE ON THE GROUND}

Ethnographic Perspectives

Edited by Christoph Brumann and David Berliner

336 pages • ISBN 978-1-78533-061-4 Paperback 


\section{berghahn journals}

NEW IN 2018 !

MIGRATION AND SOCIETY

Editors: Mette Louise Berg and

Elena Fiddian-Qasmiyeh

Addresses both dynamics and drivers of migration;

processes of settlement and integration; and

transnational practices and diaspora formation.

JOURNAL OF LEGAL ANTHROPOLOGY

Editor: Narmala Halstead

Committed to anthropological understandings of socio-legal and cultural encounters.
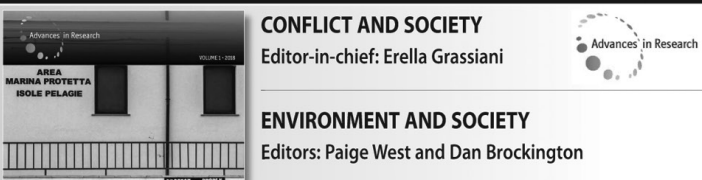

ENVIRONMENT AND SOCIETY

Editors: Paige West and Dan Brockington

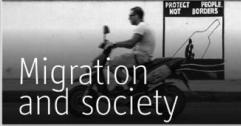

\section{MUSEUM WORLDS}

Editors: Sandra Dudley and Conal McCarthy

\section{RELIGION AND SOCIETY}

Editors: Ruy Llera Blanes, Simon Coleman, and Sondra L. Hausner
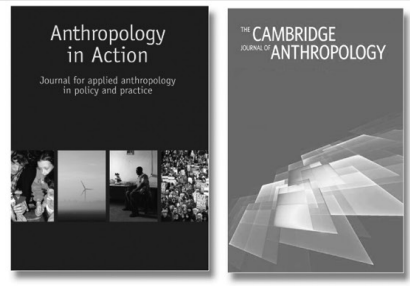

\section{ANTHROPOLOGICAL JOURNAL OF EUROPEAN CULTURES}

Editors: Ullrich Kockel and Elisabeth Timm

\section{NOW OPEN ACCESS!}

\section{ANTHROPOLOGY IN ACTION}

Journal for Applied Anthropology in Policy and Practice Editor: Christine McCourt

\section{ANTHROPOLOGY OF THE MIDDLE EAST}

Editor-in-chief: Soheila Shahshahani

\section{BOYHOOD STUDIES}

An Interdisciplinary Journal

Editor: Diederik F. Janssen

\section{THE CAMBRIDGE JOURNAL OF ANTHROPOLOGY}

Editors: Andrew Sanchez

\section{FOCAAL}

Journal of Global and Historical Anthropology

Managing and Lead Editor: Luisa Steur

\section{GIRLHOOD STUDIES}

An Interdisciplinary Journal

Editor-in-chief: Claudia Mitchell
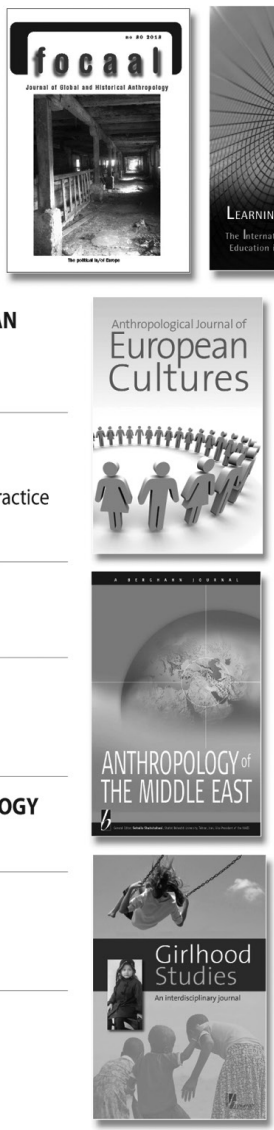
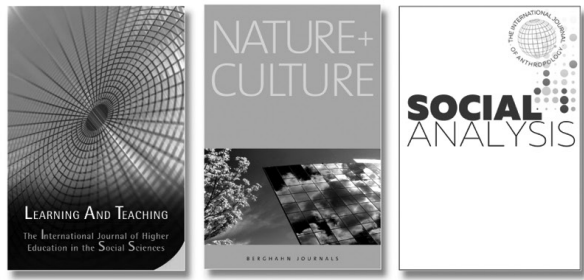

\section{JOURNEYS}

The International Journal of Travel and Travel Writing Editors: Maria Pia Di Bella and Brian Yothers

\section{LEARNING AND TEACHING}

The International Journal of Higher Education in the Social Sciences

Editors: Penny Welch and Susan Wright

\section{NATURE AND CULTURE}

Editors: Sing C. Chew and Matthias Gross

\section{REGIONS AND COHESION}

Regiones y Cohesión / Régions et Cohésion

Editors: Harlan Koff and Carmen Maganda

\section{SIBIRICA}

Interdisciplinary Journal of Siberian Studies Editor: Matthew Romaniello

\section{SOCIAL ANALYSIS}

The International Journal of Anthropology Editor: Martin Holbraad

\section{TRANSFERS}

Interdisciplinary Journal of Mobility Studies Editor: Dagmar Schäfer 


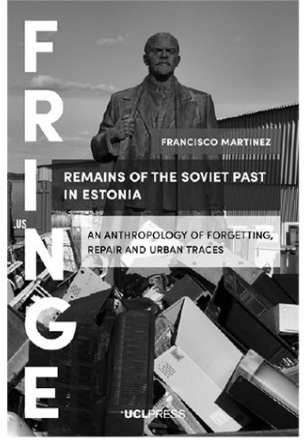

Remains of the Soviet Past in Estonia: An Anthropology of Forgetting, Repair and Urban Traces

Francisco Martinez

282 pp | July 2018

PB: 9781787353541 | £22.99

Download free PDF from ucl.ac.uk/ucl-press

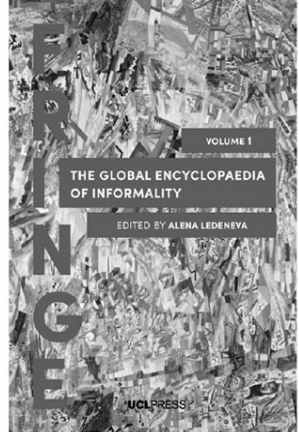

The Global

Encyclopaedia of

Informality, v1

Edited by Alena Ledeneva

464 pp | January 2018

PB: 9781911307891 | £30.00

Download free PDF

from ucl.ac.uk/ucl-press

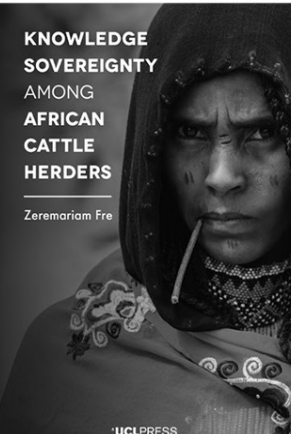

Knowledge Sovereignty Among African Cattle Herders

Zeremariam Fre

214 pp | July 2018

PB: $9781787353121 \mid £ 17.99$

Download free PDF

from ucl.ac.uk/ucl-press

\section{Open Access Anthropology Books from ${ }^{\star}$ UCLPRESS}

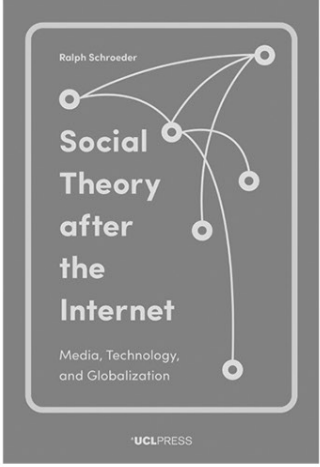

Social Theory after the Internet Ralph Schroeder

208 pp | January 2018 PB: 9781787351233 | £15.00 Download free PDF from ucl.ac.uk/ucl-press

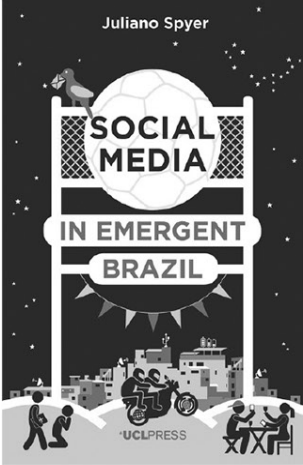

Social Media in Emergent Brazil Juliano Spyer

258 pp | October 2017 978-1-78735-166-0 | £15.00 Download free PDF from ucl.ac.uk/ucl-press

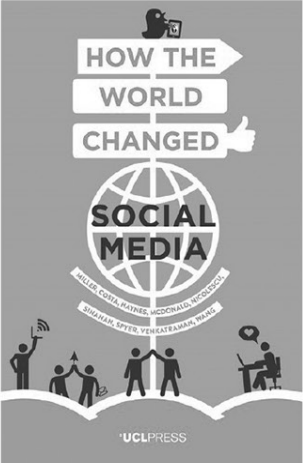

How the World Changed

Social Media

Daniel Miller et al

286 pp | February 2016 978-1-910634-48-6 | £15.00

Download free PDF from ucl.ac.uk/ucl-press

\section{Download free from ucl.ac.uk/ucl-press}


Notes 


\section{Panel grid}

\section{Location}

Examination Schools South School

Examination Schools East School

Examination Schools Room 6

Examination Schools Room 7

Examination Schools Room 8

Examination Schools Room 9

Examination Schools Room 10

Examination Schools Room 11

Examination Schools Room 12

Examination Schools Room 14

Examination Schools Room 15

All Souls Hovenden Room

All Souls Old Library

All Souls Wharton Room

Magdalen Daubeny

Magdalen Lecture Room A

Magdalen Old Law Library

Magdalen Oscar Wilde Room

Magdalen Summer Common Room

Queen Elizabeth House (QEH) SR1

Queen Elizabeth House (QEH) SR2

Pitt Rivers Museum Lecture Theatre

Pitt Rivers Museum Seminar Room

Pitt Rivers Museum Main Gallery

58 Banbury Road, COMPAS visitors' room

Private Dining Room, Wolfson College
Tuesday 18 September

\begin{tabular}{|l|l|l|l|l|}
\hline 13:30-15:00 & 15:30-17:00 & 09:00-10:30 & 14:15-15:45 & 16:15-17:45 \\
\hline & & Time02 & Time02 & Time02 \\
\hline Lang02 & Lang02 & Time06 & Time06 & Time06 \\
\hline & Pol09 & Time01 & Time01 & Time01 \\
\hline Cre08 & Cre08 & Cre04 & Cre04 & Cre04 \\
\hline Cre03 & Cre03 & Inf02 & Inf02 & Cre07 \\
\hline Cog03 & Cog03 & Cog05 & Cog05 & Cog07 \\
\hline Ant01 & Ant01 & Ant04 & Ant04 & Env13 \\
\hline & Lab02 & Env04 & & \\
\hline Inf06 & Inf06 & Inf03 & Inf03 & Inf03 \\
\hline Inf01 & Inf01 & Pol08 & Pol08 & Pol08 \\
\hline & & Pol10 & Pol10 & Pol10 \\
\hline & & Pol04 & Pol04 & Pol04 \\
\hline Med04 & Med04 & Pol02 & Pol02 & Pol02 \\
\hline & & Lang03 & Lang03 & Lang03 \\
\hline Body09 & Body04 & Body10 & Body10 & Med02 \\
\hline Med07 & Med07 & Body11 & Body11 & Body11 \\
\hline Body08 & Body08 & Body01 & Body01 & Body01 \\
\hline Env14 & Env14 & Mor02 & Mor02 & Mor02 \\
\hline Env01 & Env01 & Env05 & Env05 & Env15 \\
\hline Films & & & Lab13 & Films \\
\hline Lab05 & & Lab01 & Lab10 & Lab06 \\
\hline & & & & \\
\hline Lab01 & & & & \\
\hline
\end{tabular}

Thursday 20 September

Location

Examination Schools South School

Examination Schools East School

Examination Schools Room 6

Examination Schools Room 7

Examination Schools Room 8

Examination Schools Room 9

Examination Schools Room 10

Examination Schools Room 11

Examination Schools Room 12

Examination Schools Room 14

Examination Schools Room 15

All Souls Hovenden Room

All Souls Old Library

All Souls Wharton Room

Magdalen Daubeny

Magdalen Lecture Room A

Magdalen Old Law Library

Magdalen Oscar Wilde Room

Magdalen Summer Common Room

Queen Elizabeth House (QEH) SR1

Queen Elizabeth House (QEH) SR2

Pitt Rivers Museum Lecture Theatre

Pitt Rivers Museum Seminar Room

\begin{tabular}{|l|l|l|l|l|}
\multicolumn{3}{c}{ Thursday 2 September } & \multicolumn{3}{c}{ Friday 21 September } \\
\hline 09:00-10:30 & 14:15-15:45 & 09:00-10:30 & 11:00-12:30 & $16: 00-17: 30$ \\
\hline Ant06 & Lab04 & Ant03 & & Ant05 \\
\hline Time04 & Time04 & Pol06 & Pol06 & Pol06 \\
\hline Ant02 & Ant02 & Pol05 & Pol05 & Pol05 \\
\hline Po101 & Env11 & Pol11 & Pol11 & Pol11 \\
\hline Cre06 & Cre06 & Cre09 & Cre09 & Cre02 \\
\hline Cre05 & Cre05 & Cre01 & Cre01 & Mor01 \\
\hline Cog01 & Cog04 & Cog02 & Cog02 & Cog02 \\
\hline Env13 & Env13 & Env07 & Env07 & \\
\hline Lab11 & & & & \\
\hline Inf05 & Inf06 & Lab12 & Lab12 & Lab12 \\
\hline Env03 & Env03 & Env09 & Env10 & Env10 \\
\hline & & & & \\
\hline Inf04 & Inf04 & Pol12 & Pol12 & Pol12 \\
\hline Pol03 & Pol03 & & & \\
\hline Med06 & Body07 & Med01 & Med01 & Mor04 \\
\hline Med08 & Med08 & Lang01 & Lang01 & Lang01 \\
\hline Body03 & Body03 & Time03 & Time03 & Time03 \\
\hline Med05 & Med05 & Med03 & Med03 & Med03 \\
\hline Body05 & Body05 & Time05 & Time05 & Time05 \\
\hline Mor05 & Mor05 & Env06 & Env06 & \\
\hline Env02 & Env02 & Env02 & Env08 & Env08 \\
\hline Lab15 & Film & & & Lab17 \\
\hline & Lab16 & & & \\
\hline
\end{tabular}




\section{Conference timetable}

\section{Every day}

Uganda Stories exhibition

(Pitt Rivers Museum, Special Exhibition Gallery)

Performing Tibetan Identities exhibition

(Court and Clore Balcony, Pitt Rivers Museum)

Diversifying Portraiture in Anthropology exhibition

(Exam Schools)

The Legend of Ponnivala Nadu exhibition

(Exam Schools)

\section{Tuesday 18 September}

11:30-18:00 Registration desk open (Exam Schools)

13:30-15:00 Film screening: With this Ring

(Pitt Rivers Museum, Lecture Theatre)

13:30-15:00 Panel session 1

15:00-15:30 Refreshments (Exam Schools, North School and marquee)

15:30-17:00 Panel session 2

17:00-17:15 Break

17:15-18:30 Welcome and ASA's Firth Lecture (opening

keynote) (Exam Schools, South School)

19:00-21:00 Welcome reception (Pitt Rivers Museum)

\section{Wednesday 19 September}

08:00-16:15 Registration desk open (Exam Schools)

09:00-10:30 Panel session 3

10:30-11:00 Refreshments (Exam Schools, North School and marquee)

10:55-11:15 Walking to the Oxford University Natural History Museum

(if going to Semi-plenary 2)

11:15-12:45 Semi-plenary 1 - Environmental imaginations

(Exam Schools, South School)

11:15-12:45 Semi-plenary 2 - Transformation and time

(Oxford University Natural History Museum, Lecture Theatre)

12:45-14:15 Lunch (Exam Schools, North School and marquee)

12:45-14:15 Heads of Departments (HODs) meeting

(Exam Schools, Room 13)

13:00-14:15 APPLY network meeting (Exam Schools, Room 12)

13:00-14:15 \#MeTooAnthro: Supporting students in the field

(Exam Schools, East School)

14:15-15:45 Panel session 4

15:45-16:15 Refreshments (Exam Schools, North Schools and marquee)

16:15-17:45 Film screening: The Block/Blocul

(Pitt Rivers Museum Lecture Theatre)

16:15-17:45 Panel session 5

18:00-19:30 Roundtable: Anthropology and the imagination

(Exam Schools, South School)

\section{Thursday 20 September}

08:00-16:15 Registration desk open (Exam Schools)

09:00-10:30 Panel session 6

10:30-11:00 Refreshments (Exam Schools, North School and marquee)

10:55-11:15 Walking to the Oxford University Natural History Museum

(if going to Semi-plenary 3)

11:15-12:45 Semi-plenary 3 - Creative bodies

(Oxford University Natural History Museum, Lecture theatre)

11:15-12:45 Semi-plenary 4 - Language and imagination

(Exam Schools, South School)

12:45-14:15 Lunch (Exam Schools, North School and marquee)

13:00-14:15 ASA’s Annual General Meeting

(Exam Schools, South School)

14:15-15:45 Film screening: Nightfall on Gaia

(Pitt Rivers Museum, Lecture Theatre)

14:15-15:45 Panel session 7

15:45-16:15 Refreshments

(Exam Schools, North School and marquee)

16:15-17:45 Roundtable: Interdisciplinarity

(Exam Schools, South School)

19:00-21:00 Conference dinner

(Dining Hall of Keble College, Parks Road)

21:00-23:00 Conference dance (The Bar, Keble College)

\section{Friday 21 September}

08:00-16:15 Registration desk open (Exam Schools)

09:00-10:30 Debate: Morality and evolution, part 1

(Exam Schools, South School)

09:00-10:30 Panel session 8

10:30-11:00 Refreshments

(Exam Schools, North School and marquee)

11:00-12:30 Debate: Morality and evolution, part 2

(Exam Schools, South School)

11:00-12:30 Panel session 9

12:30-14:00 Lunch

(Exam Schools, North School and marquee)

14:00-15:30 Closing keynote

(Exam Schools, South School)

15:30-16:00 Refreshments

(Exam Schools, North School and marquee)

16:00-17:30 Panel session 10 